\title{
CATÁLOGO-GUÍA DE FENÓMENOS METEOROLÓGICOS ADVERSOS QUE AFECTAN A LA ISLA DE GRAN CANARIA
}

\author{
Nota técnica 25 de AEMET
}

\author{
DAVID SUÁREZ MOLINA ${ }^{1}$ \\ JOSÉ ANTONIO FERNÁNDEZ MONISTROL ${ }^{2}$ \\ AMADEO ENRIQUE URIEL GONZÁLEZ ${ }^{3}$
}

\footnotetext{
${ }^{1}$ Técnico Superior de meteorología. (AEMET, Delegación Territorial en Canarias)

${ }^{2}$ Director de Producción e Infraestructuras. (AEMET, Servicios centrales)

${ }^{3}$ Jefe del Departamento de Coordinación de Delegaciones Territoriales. (AEMET, Servicios centrales)
} 
Aviso Legal: los contenidos de esta publicación podrán ser reutilizados, citando la fuente y la fecha, en su caso, de la última actualización

\section{Edita:}

(C) Ministerio para la Transición Ecológica

Agencia Estatal de Meteorología

Madrid, 2018

Publicación incluida en el programa editorial del suprimido Ministerio de Agricultura y Pesca, Alimentación y Medio Ambiente y editada por el Ministerio para la Transición Ecológica (de acuerdo con la reestructuración ministerial establecida por Real Decreto 355/2018, de 6 de junio).

Catálogo de Publicaciones de la Administración General del Estado:

https://cpage.mpr.gob.es

NIPO: 014-18-005-8

https://doi.org/10.31978/014-18-005-8

Agencia Estatal de Meteorología (AEMET)

$\mathrm{C} /$ Leonardo Prieto Castro, 8

28040 Madrid

http://www.aemet.es/

@Aemet_Esp

https://www.facebook.com/AgenciaEstataldeMeteorologia 
ÍNDICE

1 Introducción y objeto del estudio ........................................................................... 5

2 Características geográficas y climáticas del archipiélago.............................................. 6

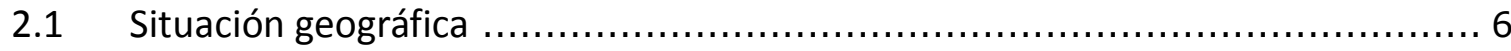

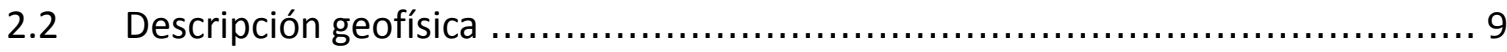

2.2.1 Principales zonas afectadas e impactos habituales...................................... 12

2.3 El aspecto humano: distribución de la población, turismo, infraestructuras, etc., como primera aproximación a la vulnerabilidad del territorio.............................. 15

3 Fenómenos meteorológicos adversos que afectan a Gran Canaria .............................. 15

3.1 Plan Meteoalerta. Zonas de aviso. Fenómenos. Umbrales. ........................... 16

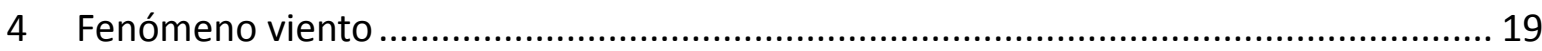

4.1 Descripción del viento como fenómeno adverso. ...................................... 19

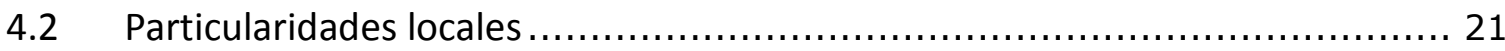

4.3 Patrones atmosféricos relacionados con episodios de viento fuerte …............ 22

4.4 Episodios de viento extremo, análisis histórico. Principales zonas afectadas e

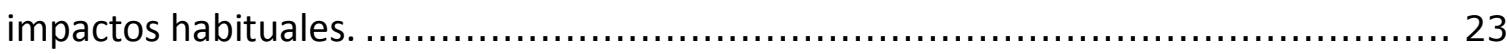

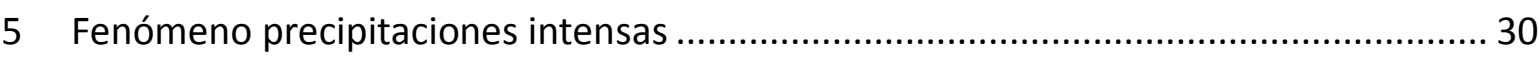

5.1 Descripción de la precipitación como fenómeno adverso. ............................. 30

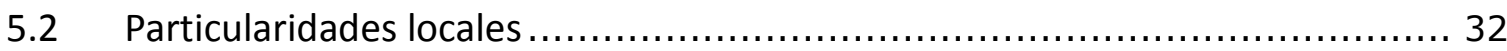

5.3 Patrones atmosféricos relacionados con episodios de precipitaciones intensas . 38

5.3.1 Patrones sinópticos favorables a precipitaciones intensas ............................ 38

5.4 Episodios de precipitaciones intensas, análisis histórico. Principales zonas

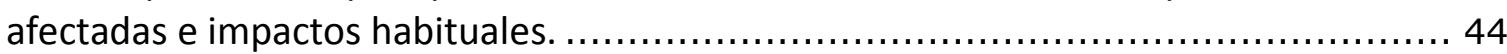

5.4.1 Situaciones de precipitaciones extremas ....................................................... 47

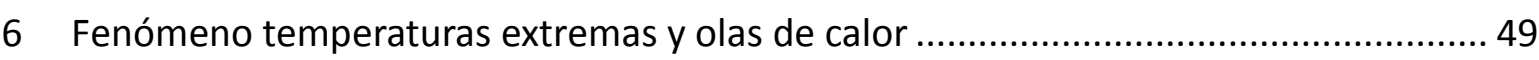

6.1 Descripción de las altas temperaturas y las olas de calor como fenómenos

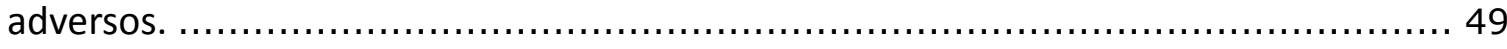

6.2 Episodios de temperaturas altas y olas de calor, análisis histórico. Principales

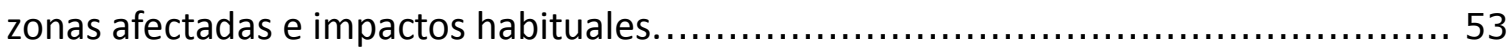

6.3 Patrones atmosféricos relacionados con episodios de temperaturas altas y

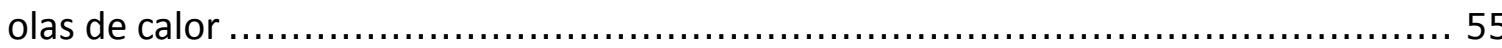


7 Fenómeno intrusiones de polvo sahariano

7.1 Descripción de las intrusiones de polvo sahariano como fenómeno adverso......57

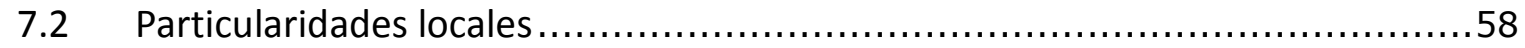

7.3 Patrones atmosféricos relacionados con episodios de intrusiones de polvo sahariano

7.4 Episodios de intrusiones de polvo sahariano, análisis histórico. Principales zonas

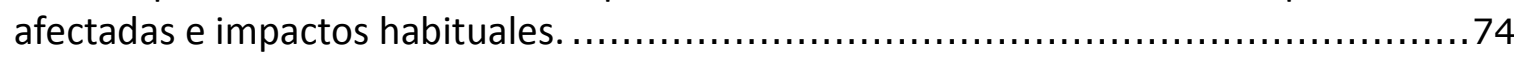

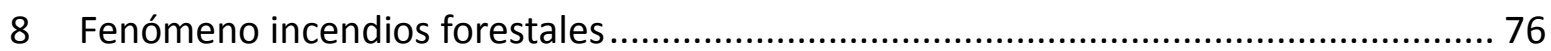

8.1 Descripción de las condiciones favorables a la ocurrencia de

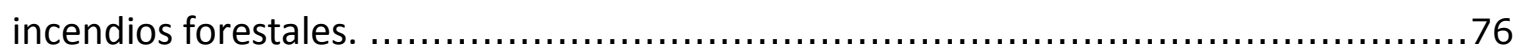

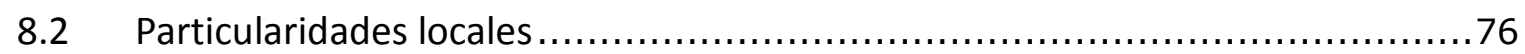

8.3 Episodios de condiciones favorables a los incendios forestales y patrón atmosférico típico. . . . .

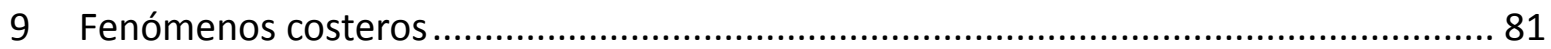

9.1 Descripción de los fenómenos costeros como adversos ........................... 81

9.2 Particularidades locales de los fenómenos costeros ............................ 81

9.3 Patrones atmosféricos relacionados con los fenómenos costeros .................90

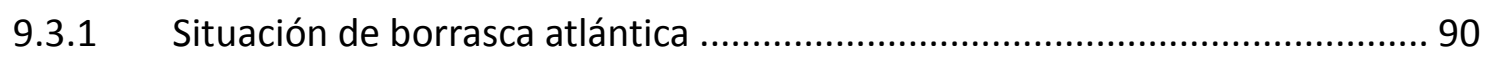

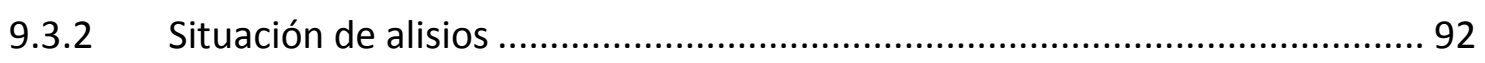

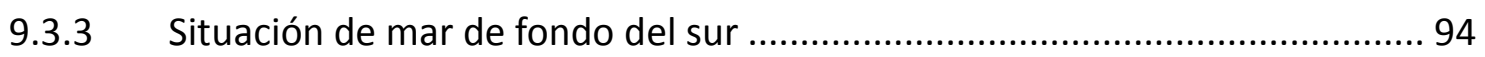

9.4 Episodios de fenómenos costeros, análisis histórico. Principales zonas afectadas

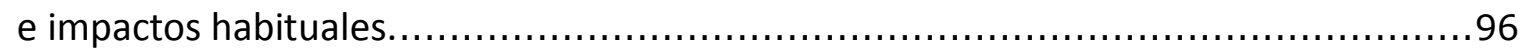

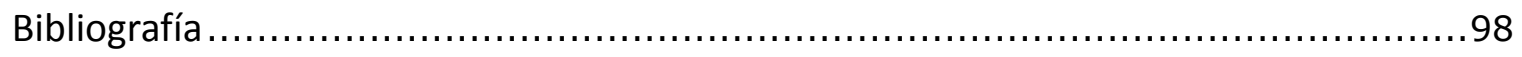




\section{INTRODUCCIÓN Y OBJETO DEL ESTUDIO}

El objeto del presente documento es describir los fenómenos meteorológicos adversos que afectan a la isla de Gran Canaria, identificar los patrones de circulación atmosférica asociados o potencialmente generadores y detallar sus características climáticas en cuanto a extremos registrados, periodos de retorno, etc..., teniendo en cuenta la orografía y otros factores.

Un paso posterior será identificar los posibles impactos para cada uno de los fenómenos y de sus especies. Se expondrán de forma general los impactos asociados a cada fenómeno.

En un tercer paso se debería analizar de forma crítica la actual zonificación para la emisión de avisos de FMA y determinar las posibles modificaciones que mejor garanticen la homogeneidad geográfica, siempre teniendo en cuenta que una zonificación óptima para un fenómeno puede no resultarlo para otro y que, finalmente, sólo pueda haber una zonificación para el conjunto de fenómenos.

En cuanto al uso de la palabra riesgo se seguirá lo establecido por la OMM en su Estrategia para la reducción de desastres. Así se usarán las siguientes definiciones:

Riesgo es la probabilidad y magnitud de un daño a personas o sus bienes debido a su exposición y vulnerabilidad frente a una amenaza o peligro.

\section{Riesgo de impacto $(x, t)=$}

amenaza o peligro $(x, t) \cup$ vulnerabilidad $(x, t) \cup$ exposición $(x, t)$

Los riesgos meteorológicos y los daños que causan deben considerarse como variables, evolucionando en función de la exposición (nuevas construcciones o viviendas en determinados lugares y aumento en la frecuencia debido a cambio climático). Por esta razón el presente documento hay que considerarlo como evolutivo; algunas partes se mantendrán fijas y otras se irán modificando según ocurran nuevos episodios.

Adicionalmente, en cuanto a riesgos, se deberán considerar dos aspectos:

- La creciente vulnerabilidad y exposición debido al crecimiento demográfico y al aumento de infraestructuras asociadas a la industria turística.

- $\quad$ El posible efecto asociado al cambio climático en cuanto al aumento en la frecuencia e intensidad de algunos FMA. 
Los avances científicos y tecnológicos permiten una mayor calidad en las predicciones gracias a una mejor simulación de los fenómenos atmosféricos basada en una mayor resolución temporal y espacial de los modelos numéricos y en la incorporación de más observaciones desde satélites o de la teledetección terrestre. No obstante, la información que se genera y difunde durante los episodios de fenómenos extremos, los avisos o alertas, no se explota al máximo por cierta dificultad a la hora de incorporarlos a la toma de decisiones. Esto es así pues están orientados a informar sobre el tiempo que va a hacer; una nueva aproximación que se está promoviendo por la Organización Meteorológica Mundial es orientar la información hacia qué consecuencias va a generar el tiempo atmosférico. No cabe duda, que esta nueva metodología requiere de la máxima colaboración de los servicios meteorológicos con otras autoridades, como las responsables de los servicios de emergencia y protección civil.

Existe ya una variada literatura dedicada a los fenómenos meteorológicos adversos más frecuentes o de mayor relevancia por su impacto sobre las islas Canarias (se citan algunos en el apartado de bibliografía). Todos coinciden en señalar a las precipitaciones intensas, vientos fuertes, olas de calor, intrusiones de polvo sahariano o calimas, temporales marítimos, sequías y situaciones que favorecen los incendios forestales, como los más relevantes. En el presente estudio se seguirá en gran parte aproximaciones anteriores pero actualizadas en cuanto a nuevos datos y dándole una orientación para que los resultados obtenidos sirvan de base para posteriores fases, al principio mencionadas.

\section{CARACTERÍSTICAS GEOGRÁFICAS Y CLIMÁTICAS DEL ARCHIPIÉLAGO}

\subsection{Situación geográfica}

Las islas Canarias están situadas en el océano Atlántico entre las latitudes, $29^{\circ} 24^{\prime} 40^{\prime \prime} \mathrm{N}$ de la punta Mosegos (Alegranza) y $27^{\circ} 38^{\prime} 16^{\prime \prime} \mathrm{N}$ de la punta de los Saltos (en El Hierro); y las longitudes, $13^{\circ} 19^{\prime} 54^{\prime \prime} \mathrm{O}$ de La Baja (en el Roque del Este) y $18^{\circ} 09^{\prime} 38^{\prime \prime} \mathrm{O}$ del Roque del Guincho (en El Hierro).

Distan 97 kilómetros de Marruecos y el Sahara occidental y unos 1400 kilómetros de la península Ibérica.

Se encuentran en el huso horario del meridiano $15^{\circ}$. Canarias es un archipiélago de origen volcánico con siete islas mayores (Tenerife, La Palma, La Gomera, El Hierro, Gran Canaria, Lanzarote y Fuerteventura) y seis menores (Alegranza, La Graciosa, Montaña Clara, Lobos, Roque del Este y Roque del Oeste).

Su superficie es de $7447 \mathrm{~km}^{2}$ y sus costas tienen una longitud total de 1583 kilómetros. 
Gran Canaria tiene una superficie de $1560,1 \mathrm{~km}^{2}$ y una altitud máxima de 1956 metros (Pico de las Nieves), siendo la tercera en extensión y altitud. Se encuentra a $28^{\circ}$ latitud Norte y $15^{\circ} 35^{\prime}$ longitud Oeste. En ocasiones se le denomina "continente en miniatura" por la diversidad de su clima, su geografía, su flora y su fauna.

Posee magníficos monumentos naturales como el Roque Nublo (1813 metros) y el Roque Bentayga.

El 29 de junio de 2005, parte de la isla de Gran Canaria y la zona marítima adyacente fue declarada por la UNESCO como reserva de la biosfera. La superficie protegida por esta declaración representa un $46 \%$ del territorio insular, además de 100458 ha de zona marina.

En junio de 2017 la población de Canarias era de 2164344 personas, en constante aumento, con una densidad de población de 291 habitantes por $\mathrm{km}^{2}$ (puesto 14 nacional) frente a la densidad media nacional de 92 habitantes por $\mathrm{km}^{2}$.

En esa misma fecha, la población de Gran Canaria era de 843158 habitantes, siendo la segunda más poblada de Canarias y la de mayor densidad de población. La capital de la isla, Las Palmas de Gran Canaria, es la ciudad más poblada de Canarias con 383343 habitantes, también es capital de la provincia oriental (Las Palmas) y de la comunidad autónoma de Canarias, conjuntamente con Santa Cruz de Tenerife.

Los núcleos poblacionales colindantes a la capital conforman un área metropolitana de unos de 680000 habitantes, primera de Canarias y novena de España. La ciudad cuenta con uno de los puertos más importantes de España y de Europa, el Puerto de la Luz.

La isla es uno de los destinos turísticos más importantes de España, con unos 3,3 millones de turistas en el 2011. En 2012 en el núcleo turístico de Maspalomas se celebró por primera vez en España el Día Mundial del Turismo.

El carnaval de Las Palmas de Gran Canaria, declarado Fiesta de Interés Turístico de Canarias, es uno de los eventos más importantes de la isla y goza de una importante proyección nacional e internacional.

Por su situación geográfica, las islas Canarias es la comunidad más austral de España y la isla de Gran Canaria está situada en el centro-sur de la misma.

La comunidad autónoma comprende dos provincias: Las Palmas, que engloba las islas de Gran Canaria, Fuerteventura y Lanzarote; y Santa Cruz de Tenerife, con las islas de Tenerife, La Gomera, El Hierro y La Palma. Además, cada isla mayor está considerada como una unidad administrativa que está gobernada por un cabildo insular. La capital de la comunidad autónoma está compartida entre las ciudades de Santa Cruz de Tenerife y Las Palmas de Gran Canaria. 
Esta situación geográfica (latitud y estar bañada por la corriente fría de Canarias y por la corriente de retorno de la corriente cálida del Golfo) favorece un clima caracterizado por las temperaturas suaves, predominio de la estabilidad atmosférica, escasas precipitaciones, elevada humedad relativa, vientos flojos o moderados con predominio de los alisios y un elevado número de horas de sol, lo que convierten a las islas Canarias en un destino turístico elegido por los turistas de zonas sometidas a climas más rigurosos.

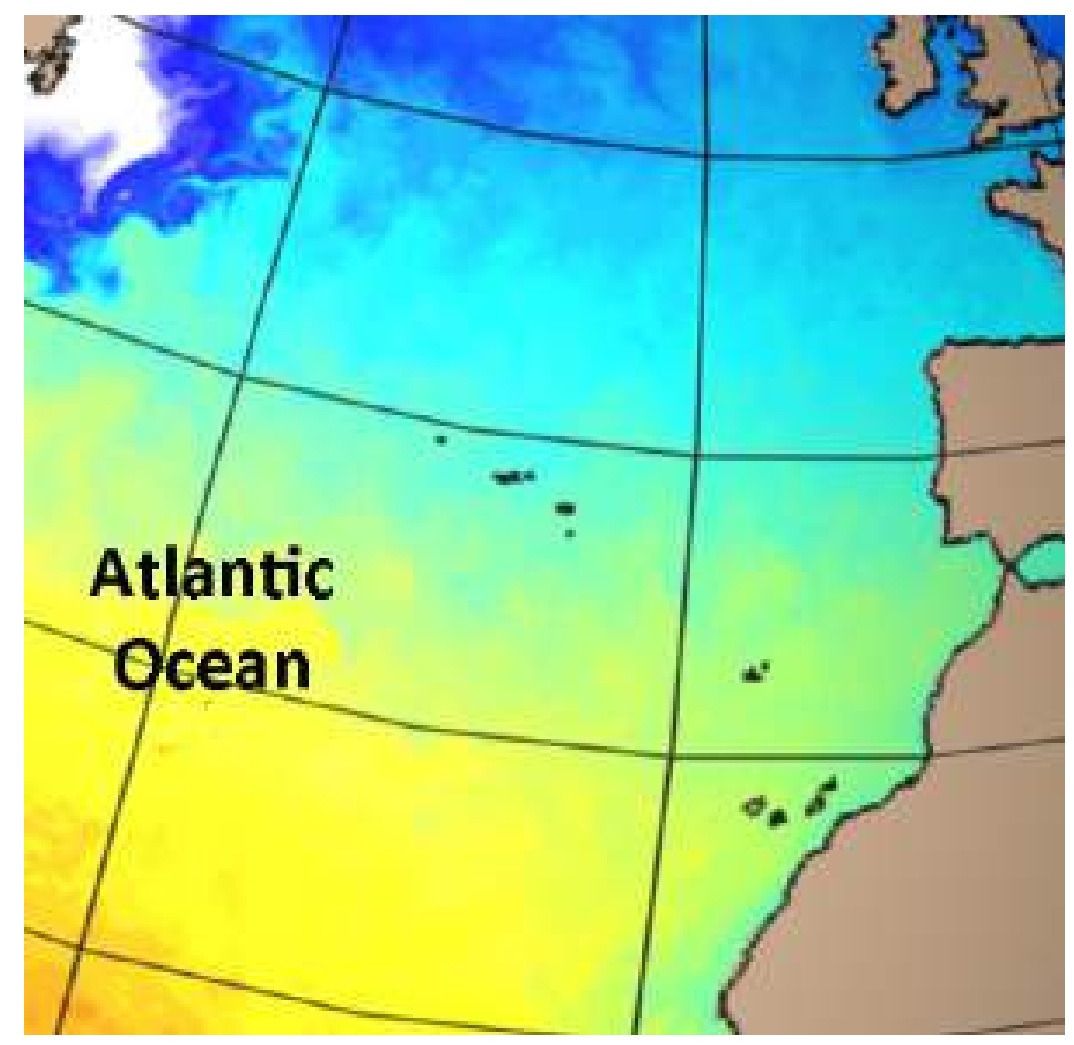

Figura 1: Temperaturas superficial del mar en el océano Atlántico. (fuente [NRL])

Obsérvese, en la figura anterior, el claro contraste de temperatura del agua del mar entre el océano abierto al oeste del archipiélago, más cálida, y la temperatura en el seno de la corriente fría de Canarias, al este. Este hecho tiene una clara influencia en la intensidad de la precipitación. En situaciones de lluvia en que el aire junto al océano lleva un largo recorrido sobre las aguas más cálidas del oeste, las intensidades observadas son mayores que cuando el recorrido se hace sobre las aguas más frías. Esta diferencia se debe a que el contenido de vapor de agua aumenta con la temperatura del aire y éste se va calentando al sobrevolar aguas cálidas al mismo tiempo que va incorporando más contenido de agua en forma de vapor. La imagen procede de la página web del U.S. Naval Research Laboratory [NRL].

Por otro lado, la proximidad al continente africano y al desierto del Sáhara facilita los aportes de aire caliente y aerosol mineral transportado por el viento. 


\subsection{Descripción geofísica}

Se trata de un territorio complejo debido a su carácter insular. Es un archipiélago volcánico muy reciente (30 millones de años), con grandes edificios volcánicos y una disposición de las islas que refleja la red de fallas presentes en la corteza oceánica.

Presentan un vulcanismo todavía activo, de poca intensidad. Las sucesivas coladas volcánicas y la posterior erosión dieron lugar a la formación del relieve y a que actualmente el territorio sea muy montañoso, con una altitud media de 415 metros y elevados gradientes altitudinales en algunos casos, ya que se puede pasar del nivel del mar a los 3718 metros en el caso del Teide. En la tabla adjunta se muestran los valores de las máximas altitudes de cada isla.

\begin{tabular}{||l|l|}
\hline \multicolumn{1}{|c|}{ Pico } & \multicolumn{1}{c|}{ Altitud e isla } \\
\hline \hline Teide & 3718 metros (Tenerife) \\
\hline \hline Roque de los Muchachos & 2426 metros (La Palma) \\
\hline \hline Pico de las Nieves & 1956 metros (Gran Canaria) \\
\hline \hline Pico de Malpaso & 1500 metros (El Hierro) \\
\hline \hline Garajonay & 1487 metros (La Gomera) \\
\hline \hline Pico de la Zarza & 812 metros (Fuerteventura) \\
\hline \hline Peñas del Chache & 670 metros (Lanzarote) \\
\hline \hline
\end{tabular}

Tabla 1: altitud máxima por islas. (Elaboración propia)

La orografía marcará una clara influencia a la hora de considerar como se distribuye el régimen de vientos, precipitaciones, fenómenos de estancamiento a barlovento, etc.

Como consecuencia de la complejidad orográfica, otra característica muy importante de las islas son los barrancos, generalmente con recorrido corto y perfil rectilíneo, dando lugar a cuencas pequeñas y de rápida respuesta a las precipitaciones.

A lo anterior se une el hecho del carácter impermeable del suelo rocoso, con escasa vegetación que favorece la escorrentía y posterior arrastre de materiales sólidos sueltos.

A pesar del carácter montañoso de la mayor parte de las islas también existen importantes Ilanuras. En Lanzarote y Fuerteventura son característicos sus "glacis".

En Gran Canaria se distinguen dos zonas geomorfológicas:

1) Neocanaria, situada al nordeste de la isla, de formación más reciente, donde aparecen algunos terrenos sedimentarios y de formación submarina. En esta zona 
hay terrazas y algunos conos volcánicos como la montaña de Arucas y el Pico y caldera de Bandama, así como otras calderas de erosión como Tenteniguada, Temisas y Tirajana. También se extienden algunos llanos. Aquí se ubican los barrancos de Telde, Guayadeque y Tirajana. En su extremo noreste se encuentra una pequeña península llamada La Isleta, unida al resto de la isla por el istmo de Guanarteme, con las playas de Las Canteras y Las Alcaravaneras a sus márgenes.

2) Tamarán, en el suroeste, es la parte más antigua de la isla, hecho que puede constatarse por la cantidad de barrancos que la surcan. A esta zona pertenece también el centro de la isla, donde se localizan las altitudes máximas. Destaca por otro lado el macizo de Tamadaba, con sus acantilados. El risco Faneque, a pocos metros de la costa, tiene una altitud de 1096 metros sobre el nivel del mar. En esta zona se ubican los barrancos de la Aldea, Agaete, Arguineguín y Fataga, entre otros. Cabe destacar también la reserva natural especial de las dunas de Maspalomas, una de las zonas turísticas más importantes de Canarias, junto con la anexa playa del Inglés.

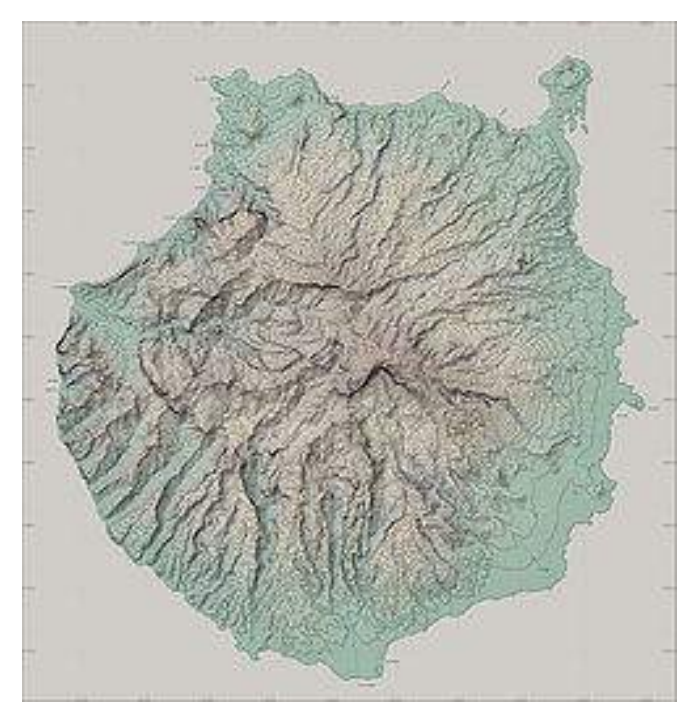

Figura 2: Topografía de Gran Canaria.

Gran Canaria posee treinta y tres entornos sujetos a diferentes fórmulas de preservación según recoge la Red Canaria de Espacios Naturales Protegidos, entre los que destacan el parque rural del Nublo, la selva de Doramas, el barranco de Azuaje, Tamadaba, Pino Santo, Inagua, etc.

Los roques son formaciones volcánicas de tipo rocoso que se erigen en el paisaje: destacan el Roque Nublo, con 1813 m de altitud (símbolo de la isla), el Cura (también conocido como 
El Fraile), La Rana, Bentayga, el Roque de Gando, y el Peñón Bermejo. Algunas playas de la isla son Maspalomas, playa del Inglés, playa de Las Canteras, Puerto Rico, La Laja, San Agustín, etc.

Gran Canaria presenta una gran diversidad climática, debida tanto al gradiente altitudinal como al efecto de los vientos alisios, que originan acusadas diferencias paisajísticas entre barlovento y sotavento, por tal motivo, se la denomina "el continente en miniatura".

La capital insular, Las Palmas de Gran Canaria, es considerada la ciudad con el mejor clima del mundo según un estudio de la Universidad de Siracusa (Nueva York). Por su parte, Mogán, al sur de la isla, es el lugar de la Unión Europea con más días despejados. El clima grancanario hace que la diversidad ecológica sea notable: la isla cuenta con más de cien endemismos vegetales, así como con otros quinientos compartidos con el resto de las islas Canarias.

Cabe destacar que en la zona de la cumbre, las temperaturas pueden llegar a alcanzar valores muy bajos, pudiendo darse precipitaciones en forma de nieve en las zonas altas.

En la siguiente tabla podemos ver los valores climatológicos normales de la estación meteorológica del aeropuerto de Gran Canaria.

\begin{tabular}{|c|c|c|c|c|c|c|c|c|c|c|c|c|}
\hline \multicolumn{13}{|c|}{$\begin{array}{l}\text { Periodo: } 1981-2010 \text { - Altitud (m): } 32 \\
\text { Latitud: } 27^{\circ} 55^{\prime} 4^{\prime \prime} \mathrm{N} \text { - Longitud: } 15^{\circ} 23^{\prime} 43^{\prime \prime} \mathrm{O}-\end{array}$} \\
\hline Mes & $\mathbf{T}$ & TM & $\mathrm{Tm}$ & $\mathbf{R}$ & H & DR & DN & DT & DF & DH & DD & 1 \\
\hline Enero & 17,9 & 20,8 & 15,0 & 25 & 65 & 3,1 & 0,0 & 0,4 & 0,0 & 0,0 & 4,1 & 184 \\
\hline Febrero & 18,2 & 21,2 & 15,0 & 24 & 66 & 3,0 & 0,0 & 0,4 & 0,1 & 0,0 & 4,4 & 191 \\
\hline Marzo & 19,0 & 22,3 & 15,7 & 12 & 64 & 2,3 & 0,0 & 0,3 & 0,1 & 0,0 & 5,5 & 229 \\
\hline Abril & 19,4 & 22,6 & 16,2 & 6 & 64 & 1,3 & 0,0 & 0,1 & 0,0 & 0,0 & 3,1 & 228 \\
\hline Mayo & 20,4 & 23,6 & 17,3 & 1 & 65 & 0,3 & 0,0 & 0,0 & 0,0 & 0,0 & 5,0 & 272 \\
\hline Junio & 22,2 & 25,3 & 19,2 & 0 & 66 & 0,1 & 0,0 & 0,0 & 0,0 & 0,0 & 7,4 & 284 \\
\hline Julio & 23,8 & 26,9 & 20,8 & 0 & 65 & 0,0 & 0,0 & 0,0 & 0,0 & 0,0 & 11,6 & 308 \\
\hline Agosto & 24,6 & 27,5 & 21,6 & 0 & 66 & 0,1 & 0,0 & 0,1 & 0,0 & 0,0 & 11,6 & 300 \\
\hline Septiembre & e 24,3 & 27,2 & 21,4 & 9 & 68 & 1,1 & 0,0 & 0,3 & 0,0 & 0,0 & 6,7 & 242 \\
\hline Octubre & 23,1 & 26,2 & 20,1 & 16 & 69 & 2,3 & 0,0 & 0,3 & 0,0 & 0,0 & 4,1 & 220 \\
\hline Noviembre & 21,2 & 24,2 & 18,1 & 22 & 67 & 3,9 & 0,0 & 0,3 & 0,0 & 0,0 & 3,6 & 185 \\
\hline Diciembre & 19,2 & 22,2 & 16,2 & 31 & 68 & 4,5 & 0,0 & 0,5 & 0,0 & 0,0 & 3,9 & 179 \\
\hline Año & 21,1 & 24,2 & 18,0 & 151 & 66 & 22,1 & 0,0 & 2,7 & 0,3 & 0,0 & 70,9 & - \\
\hline \multicolumn{13}{|c|}{ Leyenda } \\
\hline $\mathbf{T}$ & \multicolumn{12}{|c|}{ Temperatura media mensual/anual $\left({ }^{\circ} \mathrm{C}\right)$} \\
\hline TM & \multicolumn{12}{|c|}{ Media mensual/anual de las temperaturas máximas diarias $\left({ }^{\circ} \mathrm{C}\right)$} \\
\hline $\mathrm{Tm}$ & \multicolumn{12}{|c|}{ Media mensual/anual de las temperaturas mínimas diarias $\left({ }^{\circ} \mathrm{C}\right)$} \\
\hline $\mathbf{R}$ & \multicolumn{12}{|c|}{ Precipitación mensual/anual media (mm) } \\
\hline $\mathbf{H}$ & \multicolumn{12}{|c|}{ Humedad relativa media (\%) } \\
\hline DR & \multicolumn{12}{|c|}{ Número medio mensual/anual de días de precipitación superior o igual a $1 \mathrm{~mm}$} \\
\hline
\end{tabular}




\begin{tabular}{|c|c|c|c|c|c|c|c|c|c|c|c|}
\hline Mes & $\mathbf{T}$ & TM & $\mathrm{Tm}$ & $\mathbf{R}$ & $\mathbf{H}$ & DR & DN & DF & DH & DD & $\mathbf{I}$ \\
\hline DN & \multicolumn{11}{|c|}{ Número medio mensual/anual de días de nieve } \\
\hline DT & \multicolumn{11}{|c|}{ Número medio mensual/anual de días de tormenta } \\
\hline DF & \multicolumn{11}{|c|}{ Número medio mensual/anual de días de niebla } \\
\hline DH & \multicolumn{11}{|c|}{ Número medio mensual/anual de días de helada } \\
\hline DD & \multicolumn{11}{|c|}{ Número medio mensual/anual de días despejados } \\
\hline $\mathbf{I}$ & \multicolumn{11}{|c|}{ Número medio mensual/anual de horas de sol } \\
\hline
\end{tabular}

Tabla 2: Valores climáticos normales del aeropuerto de Gran Canaria. (Fuente: [AEMET,2])

Información climatológica más detallada se puede consultar por ejemplo en el Atlas climático de los archipiélagos de Canarias, Madeira y Azores. [AEMET ,1]

Los valores extremos medidos en la citada estación para algunos parámetros son los siguientes:

Intervalos de validez por variables:

Precipitación: 1951-2017 Temperatura: 1951-2017 Viento: 1961-2017

\begin{tabular}{lc}
\hline \multicolumn{1}{c}{ Variable } & Anual \\
\hline \hline Prec. máx. en un día $\left(\mathrm{l} / \mathrm{m}^{2}\right)$ & 85,0 (28 sep 1987) \\
\hline \hline Prec. mensual más alta $\left(\mathrm{l} / \mathrm{m}^{2}\right)$ & 233,7 (nov 1954) \\
\hline \hline Racha máx. viento: velocidad y dirección $(\mathrm{km} / \mathrm{h})$ Vel 113, Dir $190(28$ nov 2005 19:38) \\
\hline \hline Tem. máx. absoluta $\left({ }^{\circ} \mathrm{C}\right)$ & 44,2 (13 jul 1952) \\
\hline \hline Tem. mín. absoluta $\left({ }^{\circ} \mathrm{C}\right)$ & 6,5 (27 mar 1954) \\
\hline
\end{tabular}

(Valores extremos absolutos son el máximo o el mínimo absolutos de los datos de la serie de la variable climatológica del observatorio respectivo considerados desde el año 1920. Son calculados por mes o por año para un conjunto de observatorios previamente seleccionados)

Tabla 3: Valores climáticos extremos del aeropuerto de Gran Canaria. (Fuente [AEMET,2])

\subsubsection{Principales zonas afectadas e impactos habituales}

Debido al impacto que ocasionan los fenómenos meteorológicos adversos sobre la población, es interesante hacer un análisis del número de víctimas mortales por riesgos naturales en las islas Canarias. 


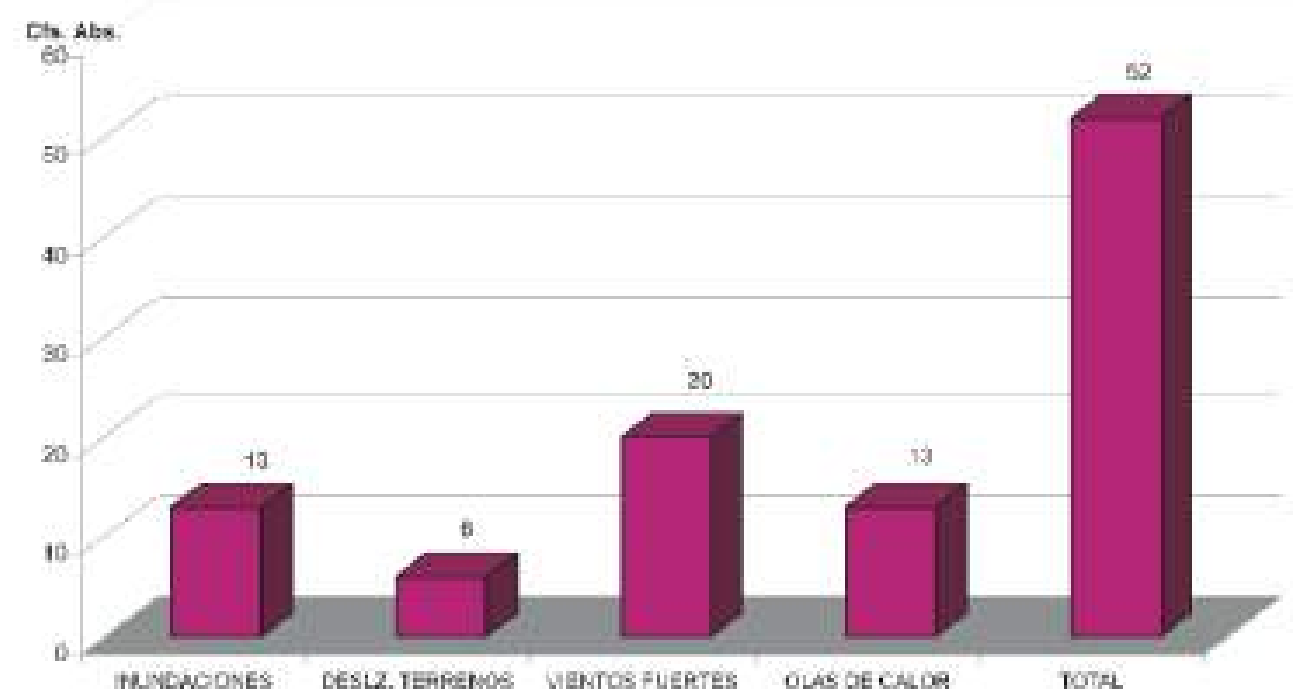

Figura 3: № de víctimas mortales por riesgos naturales en las islas Canarias periodo 1995-2005 (Fuente: Ministerio del Interior)

Las estadísticas elaboradas anualmente por la Dirección General de Protección Civil y Emergencias proporcionan los datos sobre ocurrencia de desastres de origen climático. En el periodo (1995-2005) se produjeron 13 víctimas mortales por inundaciones a las que hay que añadir otras 6 por deslizamientos de terreno, que representan casi el $40 \%$ del total de víctimas, cifra muy similar al del total de España.

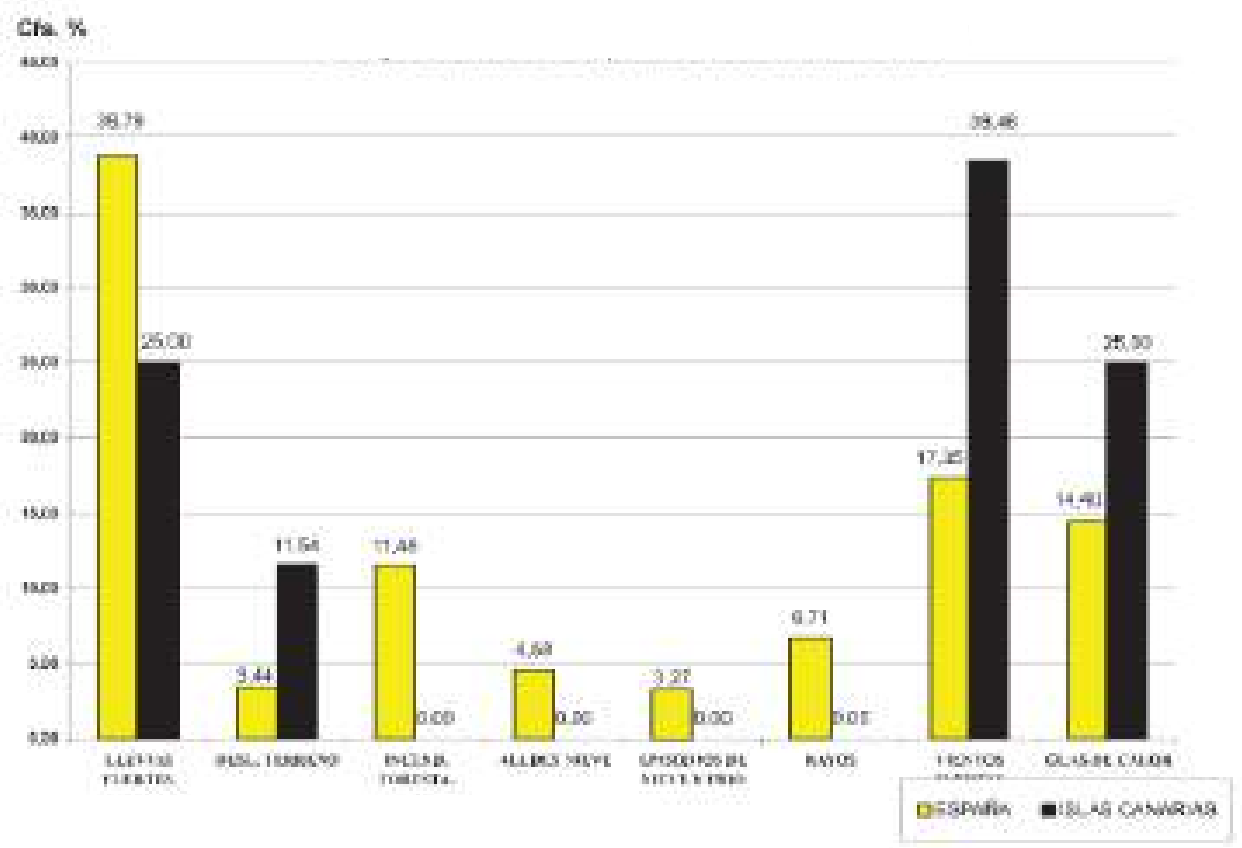

Figura 4: Fallecidos por riesgos naturales periodo 1995-2005.Comparación en \% entre España e islas Canarias (Fuente: Ministerio del Interior) 


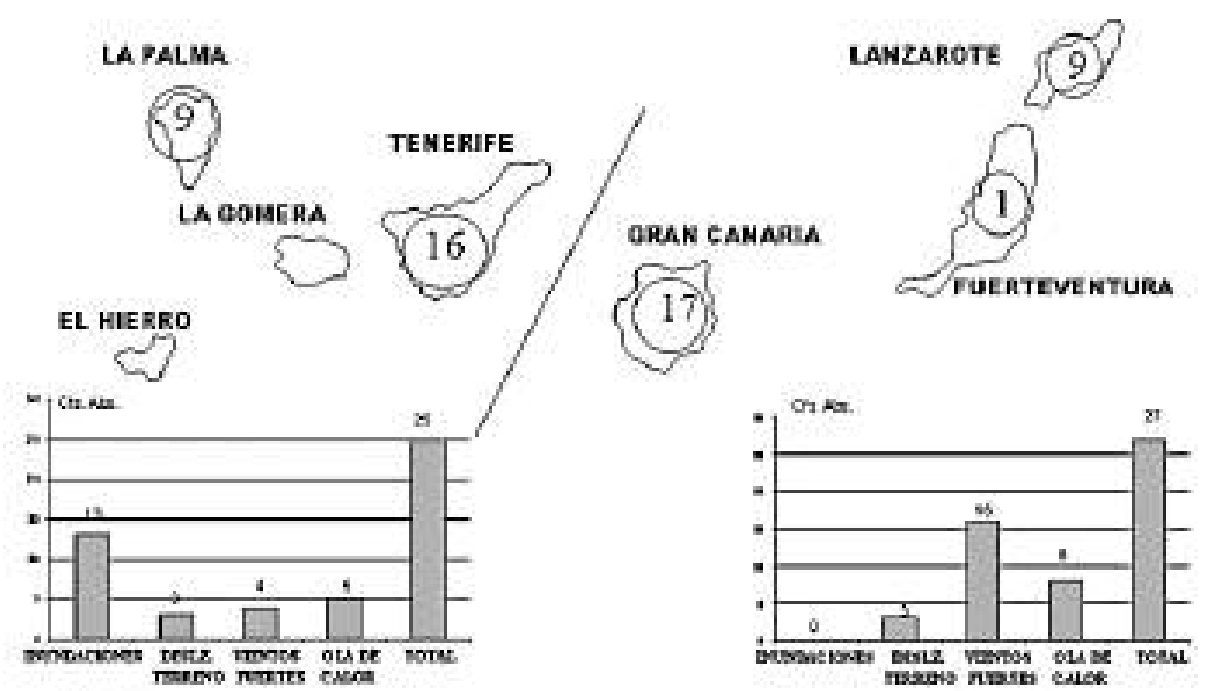

Figura 5: № de Fallecidos por riesgos naturales islas Canarias periodo 1995-2005. (Fuente: Ministerio del Interior)

En la isla de Gran Canaria, únicamente hay 3 víctimas por deslizamientos del terreno y ninguna vinculada directamente a las precipitaciones. La cifra de víctimas por inundación es significativamente inferior a la de la isla de Tenerife, 13.

De estas tres víctimas mortales por deslizamientos de terreno, dos se produjeron el día 03 de marzo de 1996 en los municipios de Mogán y Gáldar, respectivamente. El tercero se registró, de nuevo, en este último municipio el 12 de diciembre de 2002, durante un episodio de lluvias intensas.

En cuanto a daños materiales por inundaciones, según datos del Consorcio de Compensación de Seguros, en el temporal de noviembre de 2005 las pérdidas fueron de 400 millones.

En el periodo entre 2005-2014 se han producido 22 víctimas mortales a causa de desastres naturales. En 2012 se registraron dos víctimas mortales como consecuencia de las altas temperaturas, en 2013 las víctimas mortales fueron consecuencia de deslizamientos de terreno, 2, y por temporal marítimo, 4. Por último en 2014 murieron 8 personas a causa de temporal marítimo, 1 por inundaciones y 1 por vientos fuertes.

\begin{tabular}{|c|c|c|c|c|c|c|c|c|c|c|}
\hline Añ̂́ & 2005 & 2006 & 2007 & 2008 & 2009 & 2010 & 2011 & 2012 & 2013 & 2014 \\
\hline & 0 & 0 & 0 & 0 & 2 & 1 & 1 & 2 & 6 & 10 \\
\hline
\end{tabular}

Tabla 4: № de víctimas mortales. (Fuente: www.gobiernodecanarias.org) 


\subsection{El aspecto humano: distribución de la población, turismo, infraestructuras, etc., como primera aproximación a la vulnerabilidad del territorio}

Si bien el clima constituye uno de los principales atractivos turísticos, las islas están sometidas a la ocurrencia de adversidades meteorológicas, al tiempo que su vulnerabilidad aumenta año tras año.

Por tomar una referencia, en el trabajo de P. Dorta [DORTA, 2007] podemos leer que entre 1999 y 2005 los fenómenos meteorológicos adversos causaron unas pérdidas económicas de más de 300 millones de euros y alrededor de 30 víctimas mortales en la Comunidad.

Si bien hay autores que indican, que al menos en el caso de las precipitaciones intensas no es constatable un aumento en el número e intensidad de los episodios, si parece constatable que la sociedad canaria es cada vez más vulnerable por los siguientes hechos:

- Un aumento constante de la población, con tendencia a concentrarse en el área de la capital y de los principales núcleos turísticos.

- Algunos núcleos de población están enclavados en pendientes acusadas, fondos de valle o desembocaduras de barrancos.

- Existen poblaciones dispersas que obliga a una amplia red de transportes e infraestructuras de todo tipo.

Las precipitaciones son muy poco frecuentes y muy localizadas, lo que las hace más destructivas puesto que ni las infraestructuras, ni la población, están preparadas para afrontarlas. La concentración espacial y temporal de la lluvia en Canarias supone, por tanto, una amenaza severa, lo que unido a la alta vulnerabilidad crea situaciones de riesgo extremo.

\section{FENÓMENOS METEOROLÓGICOS ADVERSOS QUE AFECTAN A GRAN CANARIA}

A pesar de contar con un clima privilegiado, los fenómenos meteorológicos adversos tienen graves consecuencias en Canarias.

Habitualmente se considera que los fenómenos que suponen más riesgo son:

- Vientos fuertes

- Precipitaciones intensas, y las inundaciones a las que dan lugar

- Olas de calor

- Incendios forestales

- Invasiones de polvo sahariano 
- Temporales marítimos (afectación a la costa).

- Otros fenómenos asociados a determinadas situaciones meteorológicas: invasiones de langostas y gusanos de tierra

Como ya se adelantó, el enfoque de este documento es elaborar una climatología dinámica; es decir, identificar un catálogo de situaciones y patrones (descritas de forma sinóptica y/o mesoescalar) que dan lugar a este tipo de episodios.

Disponer de un análisis climático previo que dirija a las principales situaciones es fundamental. Por esta razón se comenzará localizando los episodios en el tiempo a través de los registros extremos disponibles. Por otro lado no solo se considerará los registros máximos locales, sino que se pretende delimitar la afección geográfica (partes de la isla, orientaciones, altitudes, etc..).

\subsection{Plan Meteoalerta. Zonas de aviso. Fenómenos. Umbrales.}

Tal y como se establece en el Estatuto de la Agencia Estatal de Meteorología (AEMET) una de sus funciones primordiales es la elaboración, el suministro y la difusión de las informaciones meteorológicas y predicciones de interés general para los ciudadanos en todo el ámbito nacional, y la emisión de avisos y predicciones de fenómenos meteorológicos que puedan afectar a la seguridad de las personas y a los bienes materiales.

Se considera fenómeno meteorológico adverso a todo evento atmosférico capaz de producir, directa o indirectamente, daños a las personas o daños materiales de consideración. En sentido menos restringido, también puede considerarse como tal cualquier fenómeno susceptible de alterar la actividad humana de forma significativa en un ámbito espacial determinado. En consecuencia pueden resultar adversas, por sí mismas, aquellas situaciones en las que algunas variables meteorológicas alcanzan valores extremos. También pueden ser potencialmente adversas aquellas situaciones susceptibles de favorecer el desencadenamiento de otras adversidades, aunque éstas no tengan, intrínsecamente, carácter meteorológico.

La evolución de las técnicas meteorológicas permite generar información sobre la ocurrencia de este tipo de fenómenos con una resolución espacial y temporal mucho mayor que la de hace unos años y también cuantificar con mayor precisión y fiabilidad la intensidad de los fenómenos en cuestión, si bien para algunos fenómenos, todavía se está lejos de disponer de unas predicciones plenamente satisfactorias. 
De acuerdo con todo ello el Instituto Nacional de Meteorología (INM), precursor de AEMET, ha venido desarrollando, desde la década de los 80 , diversos planes operativos tendentes a facilitar la mejor información posible sobre la predicción y vigilancia de este tipo de fenómenos. A los primitivos planes PREVIMET siguió, desde mediados de los 90, el denominado Plan Nacional de Predicción y Vigilancia de Fenómenos Adversos (PNPVFA). Con la intención de mejorar este plan y para satisfacer de modo armónico los requerimientos del proyecto europeo EMMA Meteoalarm, se lanzó en junio de 2006 este nuevo plan, denominado Plan Nacional de Predicción y Vigilancia de Fenómenos Meteorológicos Adversos: Meteoalerta. Su revisión periódica, basada en la experiencia acumulada, permitirá adaptarse a las necesidades y requerimientos del público en general y de Protección Civil, converger en mayor medida con nuestros vecinos europeos en el proyecto EMMA-Meteoalarm, y recoger los cambios organizativos de AEMET. El objeto del plan es facilitar a todos los ciudadanos y a las instituciones públicas, muy singularmente a las autoridades de Protección Civil, la mejor y más actualizada información posible sobre los fenómenos atmosféricos adversos que se prevean, con un adelanto de hasta 60 horas, así como mantener una información puntual de la evolución de los mismos, una vez que se ha iniciado su desarrollo. Esta información, recogida en los boletines de aviso, se distribuye a diversos organismos e instituciones del Estado, entre ellos las autoridades responsables de Protección Civil, así como a los distintos medios informativos. También se difunde al público en general a través de la página Web de AEMET.

Meteoalerta establece los fenómenos que se consideran como adversos, así como las cantidades o intensidades de sus variables meteorológicas asociadas no solamente inusuales desde el punto de vista climatológico, sino también lo suficientemente adversas como para que puedan afectar seriamente a la población, al no estar preparada para las mismas.

Con tal fin y para discriminar en la medida de lo posible la mayor peligrosidad del fenómeno y su posible adversidad se establecen, para cada uno de ellos, tres umbrales específicos, lo que da origen a cuatro niveles definidos por colores, el primero de los cuales, identificado con el color verde, implica la no existencia de aviso por debajo de su valor; los tres niveles siguientes, con los que se corresponden los umbrales citados, identificados por los colores amarillo, naranja y rojo respectivamente, son ya niveles de aviso.

Los umbrales tienen carácter zonal. Siempre que sea posible se detallarán las zonas provinciales específicamente afectadas, de acuerdo con la zonificación previamente establecida por AEMET.

En ocasiones la coincidencia de determinadas variables atmosféricas, su intensidad, la duración en el tiempo o su ocurrencia en épocas de marcada importancia social pueden justificar la realización de "avisos especiales" que sin interferir en absoluto con la 
operatividad normal del Plan Meteoalerta, harán una llamada a la población para que se preste una atención muy especial a la evolución meteorológica.

Darán lugar a la emisión de boletines de "Fenómenos Meteorológicos Adversos", si se espera el alcance o la superación de los umbrales establecidos, las situaciones relacionadas con los siguientes fenómenos

- Lluvias (acumulaciones en $\mathrm{mm} / 1$ hora o periodo inferior $\mathrm{y} / \mathrm{o} \mathrm{mm} / 12$ horas)

- Nevadas (acumulación de nieve en el suelo en 24 horas (cm/24 horas))

- Vientos (rachas máximas de viento $(\mathrm{km} / \mathrm{hora})$ )

- Tormentas (ocurrencia y grado de intensidad)

- Temperaturas máximas (grados Celsius)

- Temperaturas mínimas (grados Celsius)

- Fenómenos costeros:

○ viento en zonas costeras (escala Beaufort)

- altura del oleaje (combinación de la mar de viento (escala Douglas) y la mar de fondo (metros)).

- Polvo en suspensión (visibilidad en metros)

- Aludes (nivel de riesgo y nivel de salida)

- Galernas en el área Cantábrica y norte de Galicia (ocurrencia e intensidad)

- Rissagues o risagas (Illes Balears) (oscilaciones nivel agua del mar en metros)

- Nieblas

- Deshielos

- Olas de calor

- Olas de frío

- Tormenta tropical

Con el fin de ofrecer la información más adecuada posible y en armonía con los criterios europeos comunes, se contemplan cuatro niveles básicos, a partir del posible alcance de determinados umbrales de adversidad. Estos umbrales se han establecido con criterios climatológicos cercanos al concepto de "poco o muy poco frecuente" y de adversidad, en función de la amenaza que puedan suponer para la población. 
Las denominaciones y significados de los niveles son los siguientes:

NIVEL VERDE: No existe ningún riesgo meteorológico.

NIVEL AMARILLO: No existe riesgo meteorológico para la población en general aunque sí para alguna actividad concreta (fenómenos meteorológicos habituales pero potencialmente peligrosos) o localización de alta vulnerabilidad, como una gran conurbación.

NIVEL NARANJA: Existe un riesgo meteorológico importante (fenómenos meteorológicos no habituales y con cierto grado de peligro para las actividades usuales).

NIVEL ROJO: El riesgo meteorológico es extremo (fenómenos meteorológicos no habituales, de intensidad excepcional y con un nivel de riesgo para la población muy alto).

A continuación, en la siguiente tabla se facilitan las variables cuyos umbrales se han especificado para cada zona provincial.

2.5. COMUNIDAD AUTONOMA DE CANARIAS

\begin{tabular}{|c|c|c|c|c|c|c|c|c|c|c|c|c|c|c|c|c|c|c|c|}
\hline & metupn & & Emen & tous nia & $\operatorname{mon}$ & omen & 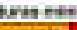 & $\tan$ & & ohrton & & Hexpen & & & powern & & & beves en & \\
\hline 0000 & 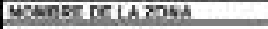 & 250MWNA & $n=12$ & $\operatorname{man} 5$ & & minto & encin & ine & infes & nangal & $\log$ & Axarse & & $m^{2} n$ & amaris. & & anter & recuila & \\
\hline $\cos 2$ & 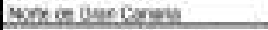 & Lestron & 4 & 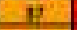 & 24 & 4 & 4 & $e$ & $n$ & $\infty$ & 41 & As & is & it & n & 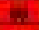 & 2 & 1 & $\mathrm{a}$ \\
\hline Esaja & 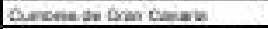 & Laskme & is & atz & $=$ & 1 & 4 & $=$ & to & $\infty$ & At & to & 12 & tu & st & 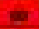 & $z$ & 4 & a \\
\hline $\cos 2 x$ & 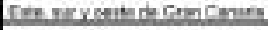 & $\ln 2 x \operatorname{man}$ & lit & $\pi$ & 2 & -1 & -1 & $\geq$ & n. & m. & 41 & 10. & 12 & is & 3. & E & 2 & 1 & 峿 \\
\hline $\sin 201$ & Leneatin & torman. & 로 & w & e & 4 & 4 & \pm & na & m & 4 & As & 12 & in & n. & $\mathbf{p}$ & 3 & 1 & IE \\
\hline Esabot & Fundumea & Lastemen & 量 & at & 눈 & -1 & + & $=$ & No & ㅂ.ᅳ. & $a$ & 此 & $1 \pm$ & 14 & In & $=$ & 2 & $t$ & 르 \\
\hline 105308 & Prtho sila Pirs. & SbGrede Trests & it & I7. & s. & -1 & 4 & $=$ & $n$ & $n$ & et & 120 & 14 & t3. & x. & an & 2. & I. & in \\
\hline tonses & Eecolne freta & suscosts 3yeth & 4 & II. & $=$ & 4 & 4 & 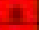 & $n$ & 里 & ef. & $m$ & 1E & in & x & w & $x$ & \pm & $\mathbf{z}$ \\
\hline East & 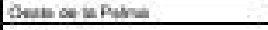 & 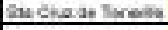 & 蛅 & at. & $=$ & -1 & + & $=$ & no & $\infty$ & 6 & 100 & in & t4 & 30. & $=$ & $=$ & \pm & a \\
\hline $13+21$ & Lacorra & Spocrade Trents & 24 & 17. & $=$ & -1 & + & 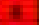 & 70 & $\infty$ & a. & 130 & it: & 19 & x & a & $\pi$ & 1. & at \\
\hline $\operatorname{sen} 2$ & fines & 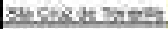 & it & $p$ & $=$ & 4 & 4 & $=$ & $n$ & 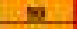 & eu & $m$ & in & in & a & e & 3 & 1 & \\
\hline Ecosit & when in inele & En Crous Terete & w & 11 & $=$ & 1 & 4 & 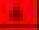 & 电 & $=$ & 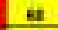 & $m$ & is & th & $n$ & \# & 2 & 4 & 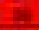 \\
\hline $\operatorname{sen} 2$ & 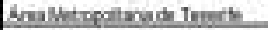 & 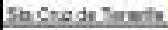 & $\mathrm{x}$ & I7 & $=$ & -1 & -4 & E & $x$ & $\infty$ & $\boldsymbol{u}$ & $m$ & th: & 13 & $x$ & x & 2 & i & a \\
\hline 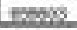 & 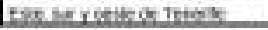 & 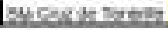 & $\mu$ & 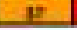 & $=$ & 4 & 4 & $1 \mathrm{z}$ & $m$ & $m$ & 토 & $m$ & it & in. & 료 & 要 & $x$ & \pm & \\
\hline
\end{tabular}

Tabla 5: Umbrales de aviso por zona Comunidad Autónoma de Canarias.Plan meteoalerta. (Fuente:AEMET)

\section{FENÓMENO VIENTO}

\subsection{Descripción del viento como fenómeno adverso}

El viento supone un riesgo de primera magnitud que ha generado graves daños en el archipiélago. Su frecuencia, como amenaza, es muy irregular y las rachas máximas se acercan a las registradas en el Cantábrico o la costa catalana, en especial después del paso por las islas de la tormenta tropical Delta en noviembre de 2005 [DORTA, 2007].

Debido a la situación atmosférica típica que afecta a Canarias, y de la influencia del anticiclón de las Azores sobre el flujo en niveles bajos, los vientos predominantes sobre el archipiélago son vientos del nordeste (la dirección del viento es la dirección de su procedencia) con intensidades medias de entre 20 a $35 \mathrm{~km} / \mathrm{h}$. 
Los alisios serán por tanto los vientos dominantes y estos soplan con una frecuencia superior al $50 \%$ en otoño, invierno y primavera y con una frecuencia superior al 90 o $95 \%$ en verano [FONT, 1956].

Para apoyar esta tesis, a continuación se muestran datos extraídos de la climatología del aeropuerto de Gran Canaria:

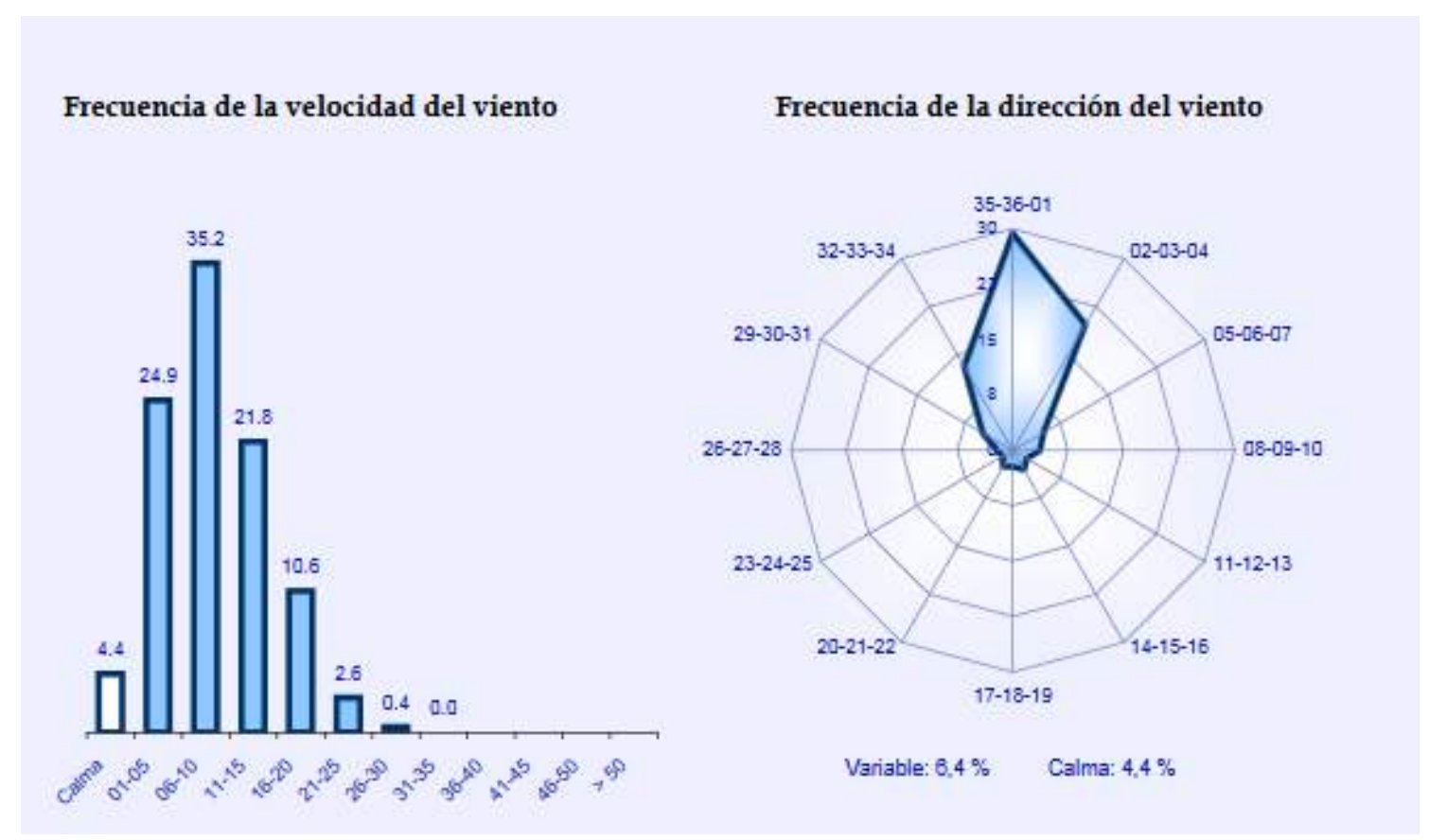

Figura 6: Frecuencia de la velocidad y dirección del viento en el aeropuerto de Gran Canaria (Enero). (Fuente: (Fuente: [AEMET,2])

Los datos que se muestran en la figura superior, comprenden el periodo desde 1998 a 2011 y se realizaron 20435 observaciones entre las 00 a 23 UTC para el mes de enero. Se observa que la dirección del viento predominante es de componente norte y la frecuencia de intensidad preponderante para los meses de enero es con un 35,2 \% entre 6 a 10 nudos (viento flojo). 

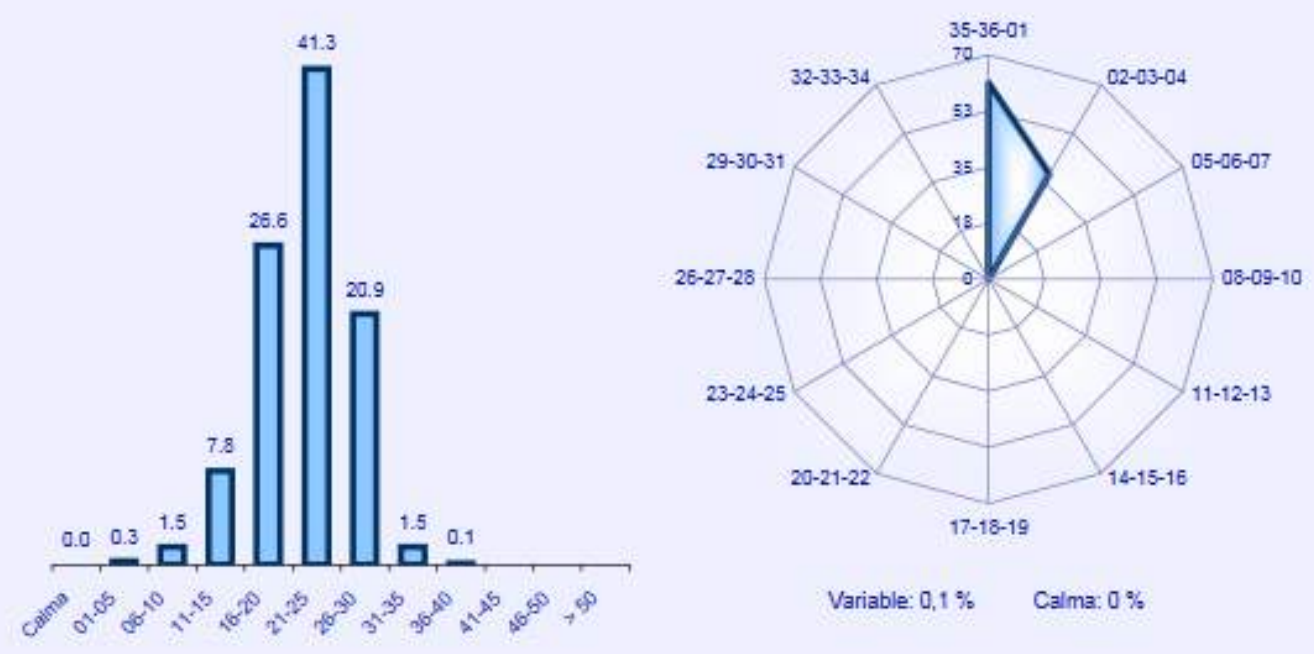

Figura 7: Frecuencia de la velocidad y dirección del viento en el aeropuerto de Gran Canaria (Julio). (Fuente: [AEMET,2])

Para el mes de julio, por el contrario se constata que aunque la dirección predominante sigue siendo de componente norte, dentro de esta componente predominan las direcciones norte y nordeste. Queda verificado que la intensidad en los meses de verano es superior, y con un 41,3\% esta es de entre 21 a 25 nudos (viento fuerte).

Existen variados escenarios atmosféricos que pueden generar episodios de vientos fuertes en Gran Canaria. En el siguiente apartado se verá los más relevantes, sin embargo podemos contextualizar en este punto algunas particularidades que produce la interacción del flujo con la orografía de la isla y los efectos que cabría esperar. De modo general puede afirmarse que el viento se intensifica con la altura por dos razones básicas:

- Disminución de la densidad del aire con la altura que contribuye a que aumente la fuerza de gradiente.

- Disminución de la fuerza de rozamiento.

\subsection{Particularidades locales}

Se puede esperar que el viento de forma general sea más intenso en las cumbres de Gran Canaria que en el litoral. Sin embargo hay que tener en cuenta las modificaciones originadas en el viento por una barrera orográfica. Una vez que el viento superficial encuentra en su recorrido un obstáculo tiene en general dos opciones, remontarlo o rodearlo, la trayectoria depende a grandes rasgos de las condiciones de estabilidad atmosférica. Es sabido que la configuración de la costa o de la topografía ocasiona un aumento en la velocidad del flujo, de manera que el relieve, como ocurre con la precipitación, juega un papel crucial en la peligrosidad de este elemento. 
Debido a lo expuesto en el párrafo anterior, bajo el régimen de alisios la vertiente de sotavento (vertiente sur), presenta vientos de menor intensidad e incluso de dirección variable (costas suroeste) que la vertiente de barlovento (vertiente norte).

Sin embargo hay que tener en cuenta, que en ocasiones la cumbre de Gran Canaria genera efectos aceleradores como es el caso de las ondas de montaña o los vientos catabáticos que, dependiendo de la dirección originaria, asolan las vertientes de sotavento.

Otra característica reseñable de la situación típica de alisos es que debido a la interacción de este con Gran Canaria, se produce un aceleramiento en los extremos noroeste y sureste de la isla.

Existen además otros factores locales como el que se origina en el viento por los valles y barrancos, donde el viento se canaliza y se produce una acumulación de aire que conduce a una aceleración de los vientos.

Este factor se refleja en zonas de salida de la red de profundos barrancos y valles que conforman la isla de Gran Canaria. La estación meteorológica de la red de AEMET (C619Y) situada en San Nicolás de Tolentino, puede servir como ejemplo de este tipo de efecto local, ya que es natural observar como la intensidad del viento registrada por dicha estación, es superior al viento medio en zonas cercanas.

Otra de las particularidades del viento, es que debido a la diferencia de temperaturas entre tierra y el océano se producen brisas costeras. Durante el día, el aire más frio y denso del océano se dirige hacia la superficie terrestre, en la cual el aire cálido y ligero tiene tendencia a subir. Durante la noche la situación es justamente la inversa de la descrita.

La brisa diurna (marina) suele ser de mayor intensidad a la brisa nocturna (de montaña), debido a que durante el día las diferencias de temperatura mar-tierra es más marcada.

Este efecto local de brisas se observa de forma habitual en la isla de Gran Canaria en el litoral sur-suroeste de la isla. Además en situaciones donde el gradiente barométrico sea escaso en superficie, este efecto se puede producir de forma generalizada en todo el litoral e incluso afectar a zonas de interior. Estas situaciones de brisas junto a una capa húmeda profunda (en torno a los primeros 1500 o 2000 metros de la troposfera) suelen generar nubosidad de evolución debido a la convección generada por el calentamiento de la masa de aire superficial unido a la humedad aportada por la brisa marina.

\subsection{Patrones atmosféricos relacionados con episodios de viento fuerte}

Por regla general los principales temporales de viento se producen con la llegada de borrascas atlánticas que dan lugar a fuertes vientos del cuarto cuadrante. Sin embargo son 
especialmente peligrosos los de dirección Sur puesto que la mayor parte de las infraestructuras no están preparadas para soportar vientos intensos no habituales del segundo o tercer cuadrante.

\subsection{Episodios de viento extremo, análisis histórico. Principales zonas afectadas e impactos habituales.}

Históricamente viene siempre a la mente el temporal de viento de 1999 con vientos del segundo cuadrante de hasta $90 \mathrm{~km} / \mathrm{h}$ y daños estimados en 156 millones de euros [CRIADO y DORTA 2003] y la tormenta tropical Delta en noviembre de 2005 que originó una víctima mortal y numerosas pérdidas materiales.

A la hora de estudiar episodios de viento extremo se puede recurrir también a la última relación de episodios de vientos fuertes en Canarias desde 2010, para los cuales AEMET ha hecho estudio de casos de Tempestad Ciclónica Atípica (TCA) por vientos extraordinarios a requerimiento del Consorcio de Compensación de Seguros, junto con el mapa con la racha máxima estimada en cada situación. Vamos a tomar en consideración aquellas rachas que hayan podido superar los $120 \mathrm{~km} / \mathrm{h}$.

En la mayoría de los casos se hizo una interpolación espacial de los datos de racha máxima de viento durante el episodio, sin embargo en algunos de los primeros solamente se dispone del valor puntual de los valores registrados en las estaciones.

\section{Episodio del 16 al 18 de febrero de 2010}

Este es un caso de vientos del oeste originados por una baja que fue descolgándose desde el oeste de la Península, hasta situarse al norte del archipiélago.

En Gran Canaria los máximos valores se registraron el día 17, llegando a alcanzar las rachas el valor de $123 \mathrm{~km} / \mathrm{h}$ en el centro de la isla.

Las figuras siguientes muestran:

- Valores registrados de rachas máximas $(\mathrm{km} / \mathrm{h})$ el 17 de febrero de 2010

- Situación en superficie a las 18 UTC el 17 de febrero de 2010 (incluye isotermas 850 hPa)

- Situación en 500 hPa a las 06 UTC el 17 de febrero de 2010 


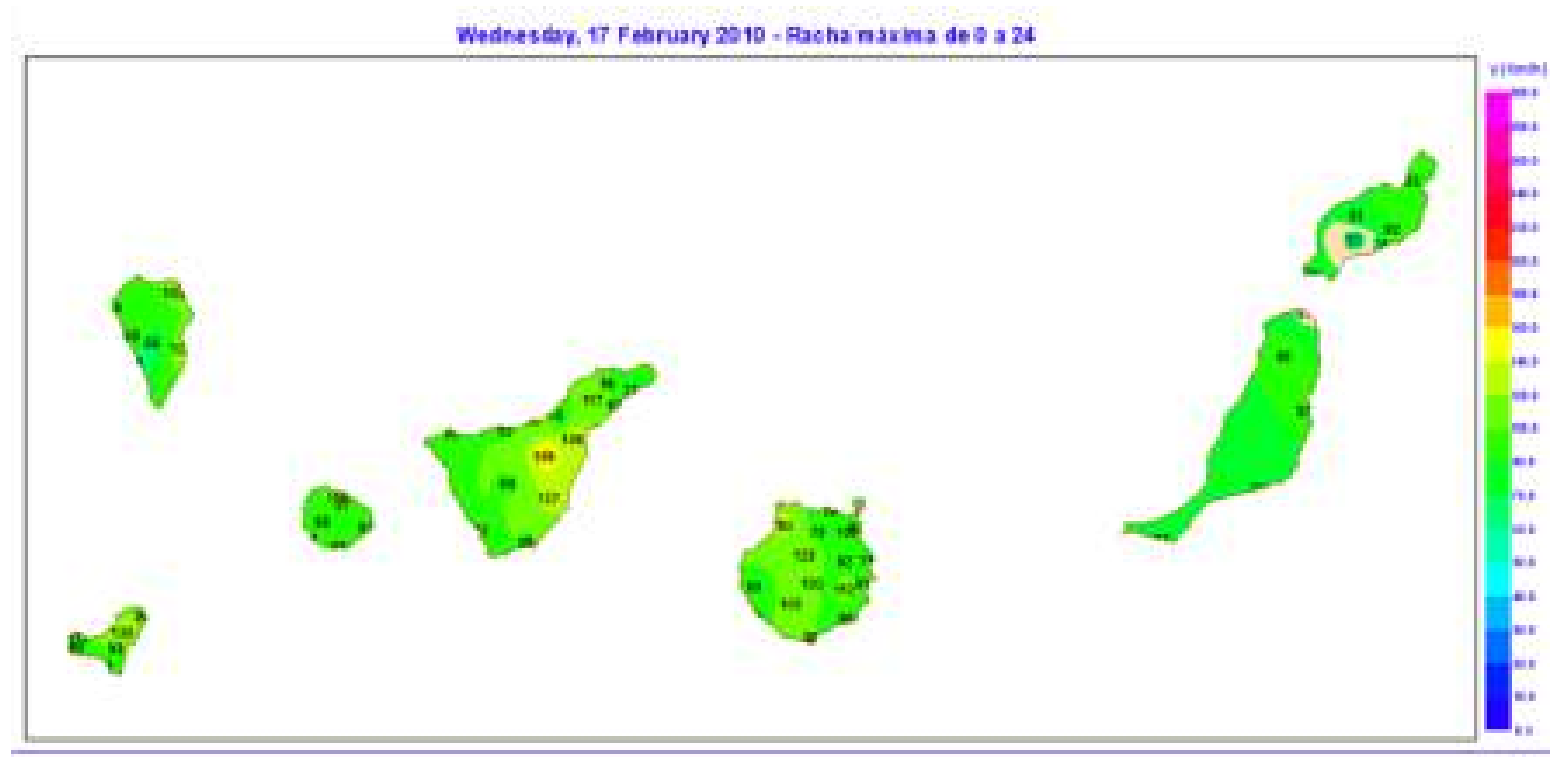

Figura 8: Racha máxima de 0 a 24 horas del 17 de febrero de 2010. (Fuente: AEMET)

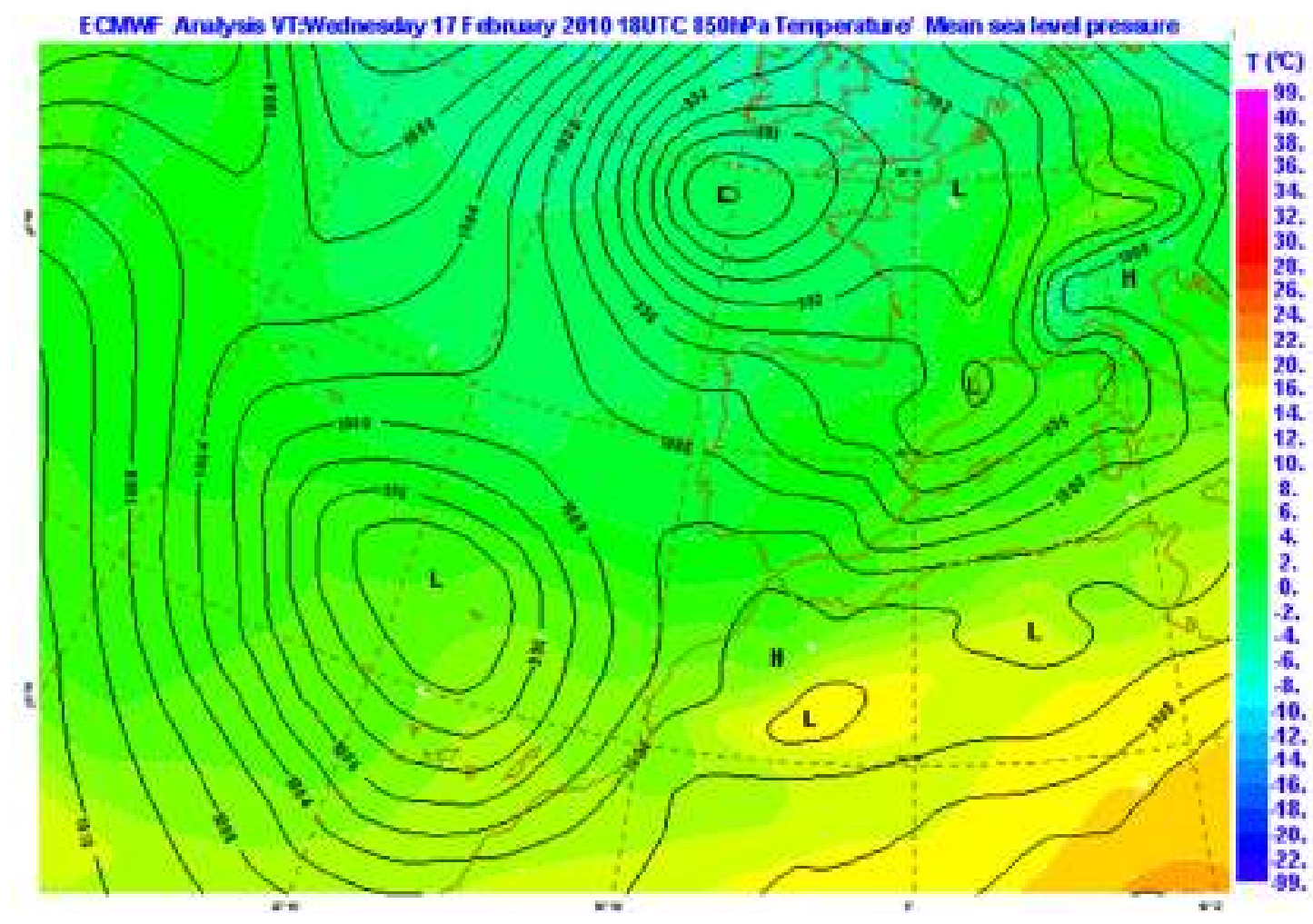

Figura 9: Análisis de superficie, 18 horas del 17 de febrero de 2010. (Fuente: AEMET) 


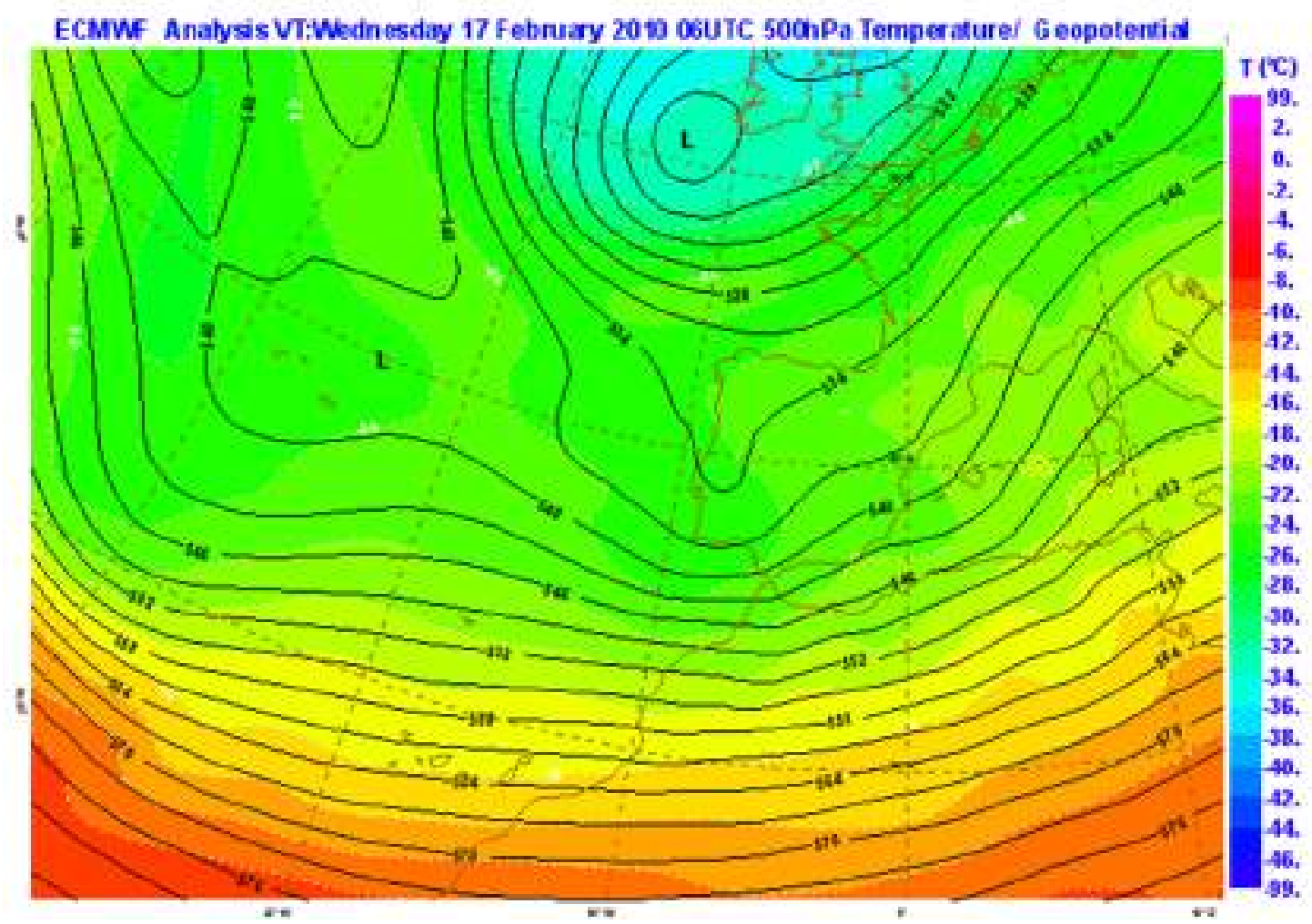

Figura 10: Análisis de 500 hPa, 18 horas del 17 de febrero de 2010. (Fuente: AEMET)

\section{Episodio del 27-28 de febrero de 2010}

Esta situación que afectó al archipiélago canario durante los días 27 y 28 de febrero de 2010 corresponde al ciclón extratropical "Xynthia".

El ciclón extratropical Xynthia fue un ciclón de latitudes medias que se originó en el océano Atlántico, entre los días 26 y 28 de febrero del año 2010. El viento asociado a la depresión alcanzó vientos fuerza 2 - 3 (mayores a $180 \mathrm{~km} / \mathrm{h}$ ) según la escala de Saffir-Simpson en varios puntos de España y Francia. A pesar de haber perdido toda característica tropical, el ciclón Xynthia experimentó un proceso de ciclogénesis explosiva a su paso por Madeira en su avance hacia el nordeste.

A continuación como es habitual, se muestra :

- Valores registrados de rachas máximas $(\mathrm{km} / \mathrm{h})$ el 27 de febrero de 2010

- Situación en superficie a las 12 UTC el 27 de febrero de 2010 (incluye isotermas 850 hPa)

- Situación en 500 hPa a las 12 UTC el 27 de febrero de 2010 


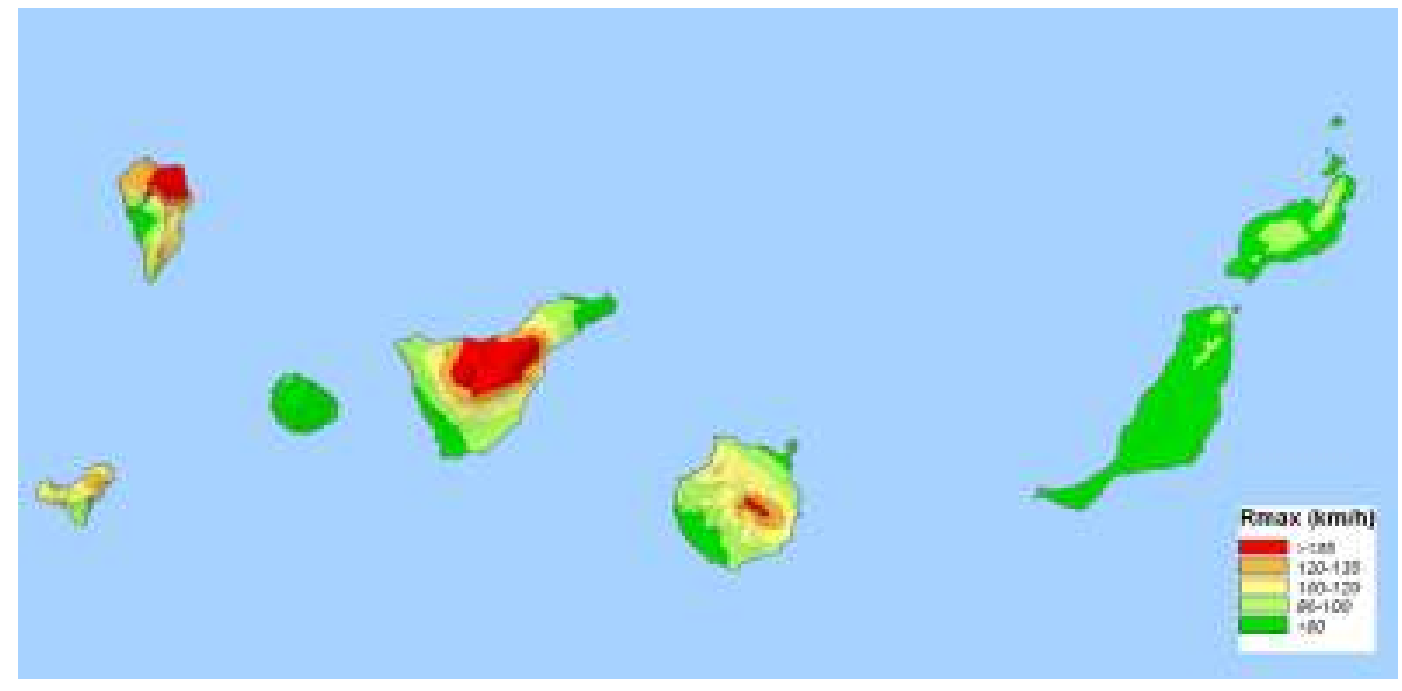

Figura 11: Racha máxima de 0 a 24 horas del 27 de febrero de 2010. (Fuente: AEMET)

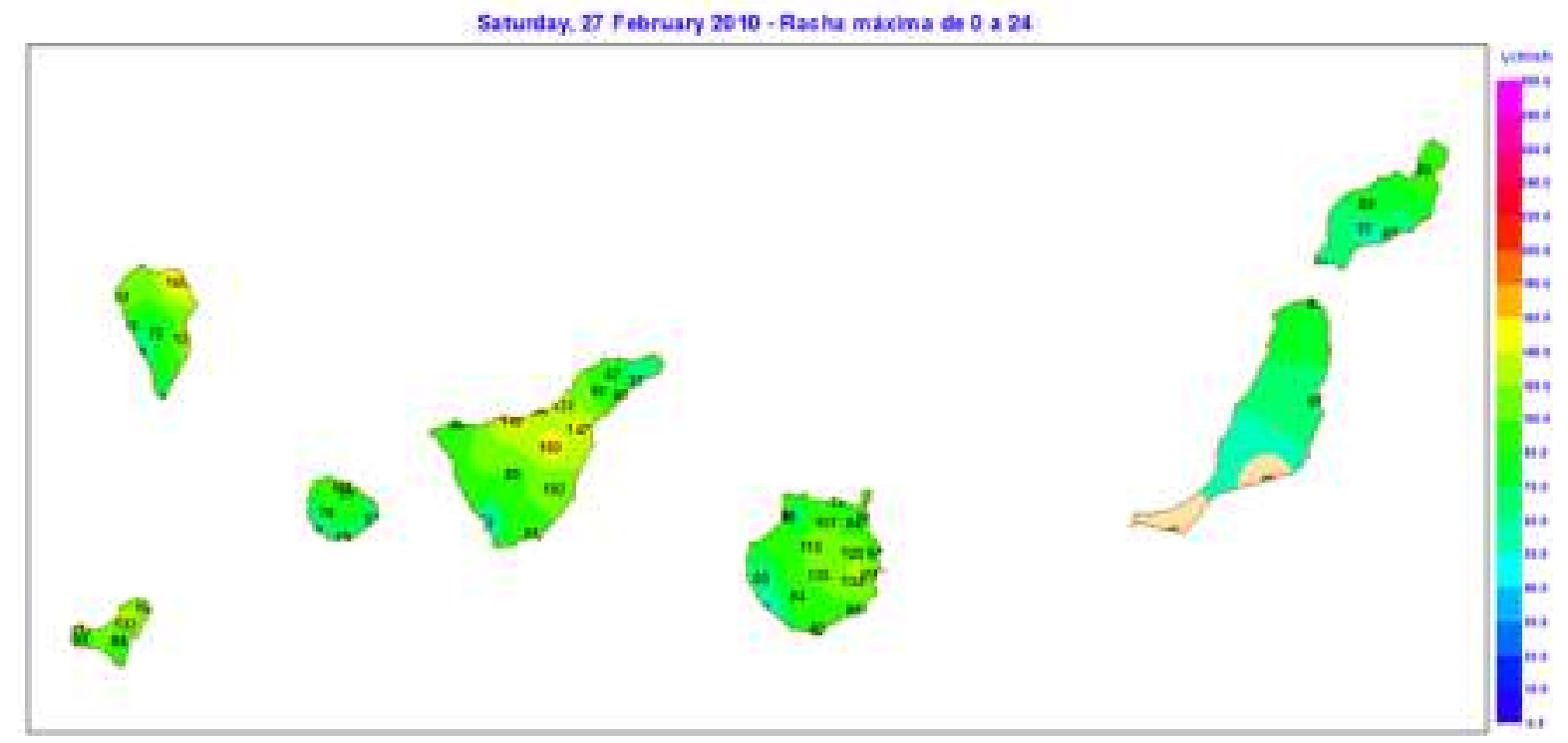

Figura 12: Racha máxima de 0 a 24 horas del 27 de febrero de 2010. (Fuente: AEMET) 


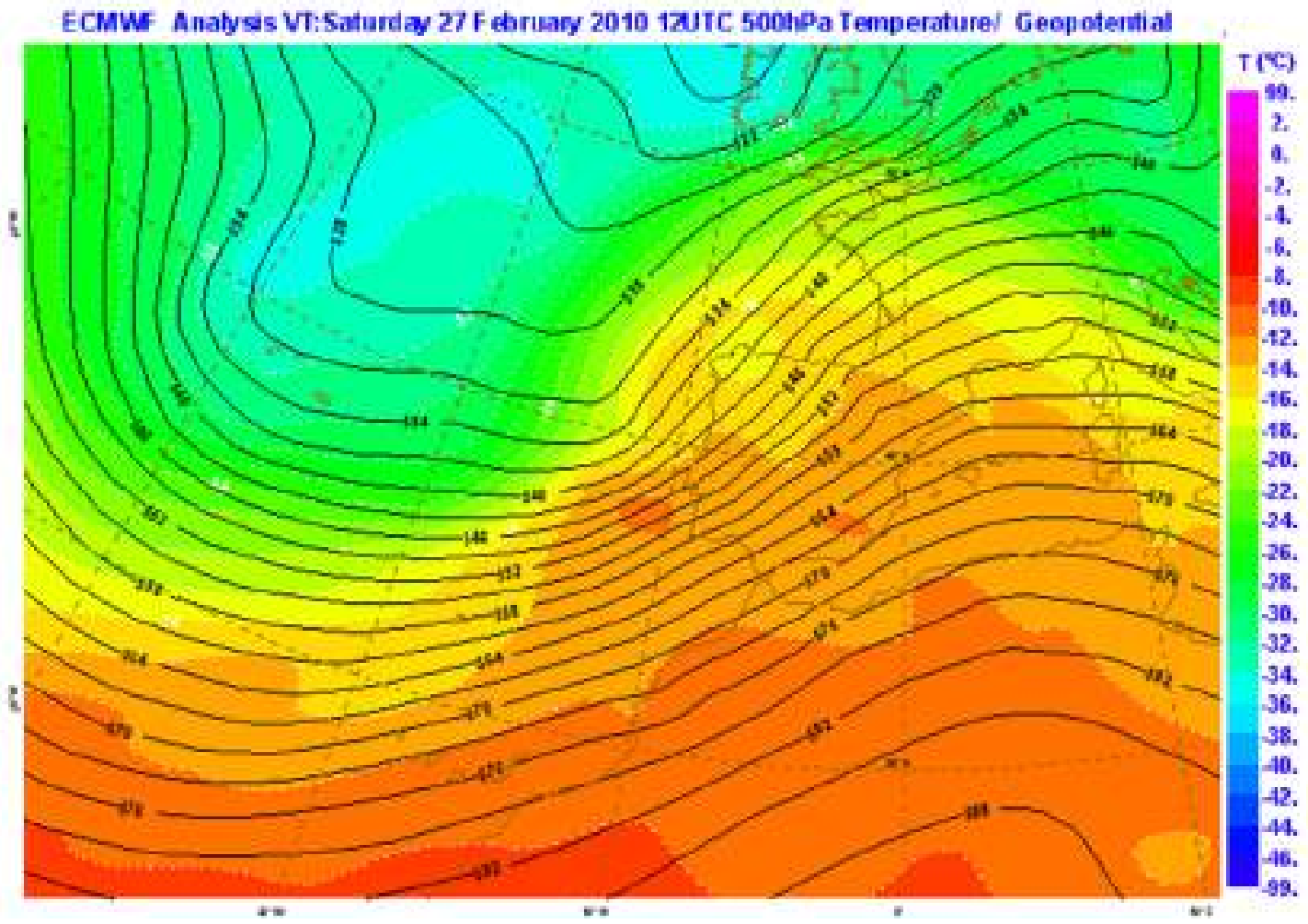

Figura 13: Análisis de 500 hPa, 12 horas del 27 de febrero de 2010. (Fuente: AEMET)

ECMNG Aralysis VESaturday 27 Fetruary $20101201 \mathrm{C}$ s501 Pa Tenperature/ Mean sea leved pressare

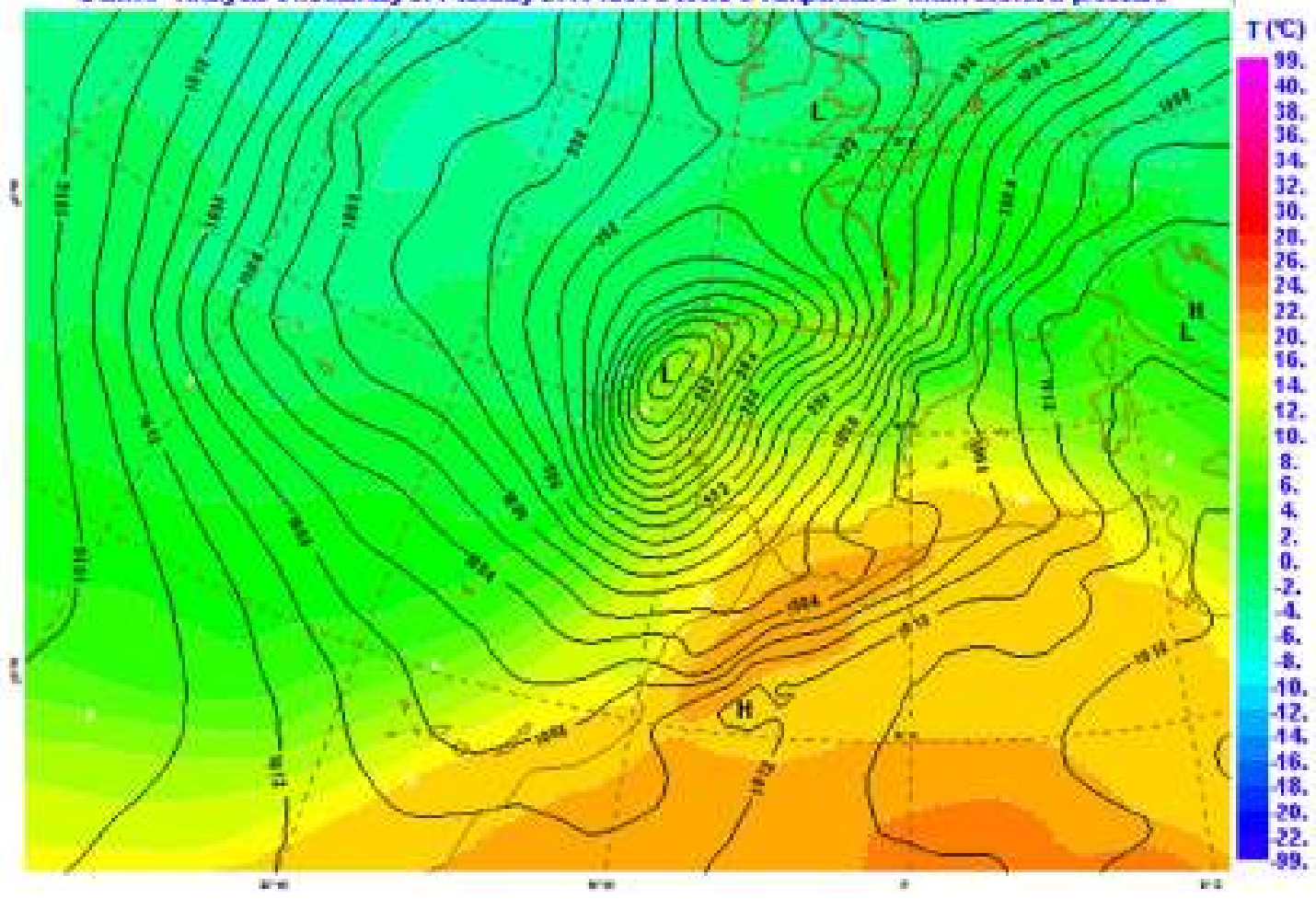

Figura 14: Análisis de superficie, 12 horas del 27 de febrero de 2010. (Fuente: AEMET) 
En Gran Canaria destacan los 130 km/h registrados en Agüimes y los $120 \mathrm{~km} / \mathrm{h}$ en Telde y en San Bartolomé de Tirajana.

Episodio del 9 al 14 de diciembre de 2013

En esta situación se sobrepasaron en Gran Canaria los 120 km/h el día 14, en la estación de San Bartolomé de Tirajana $121 \mathrm{~km} / \mathrm{h}$.

Se muestra a continuación la gráfica con los datos registrados para ese día en las islas:

Saturday, 14 Desember 2013 - Faehs maxisa 440 a 24

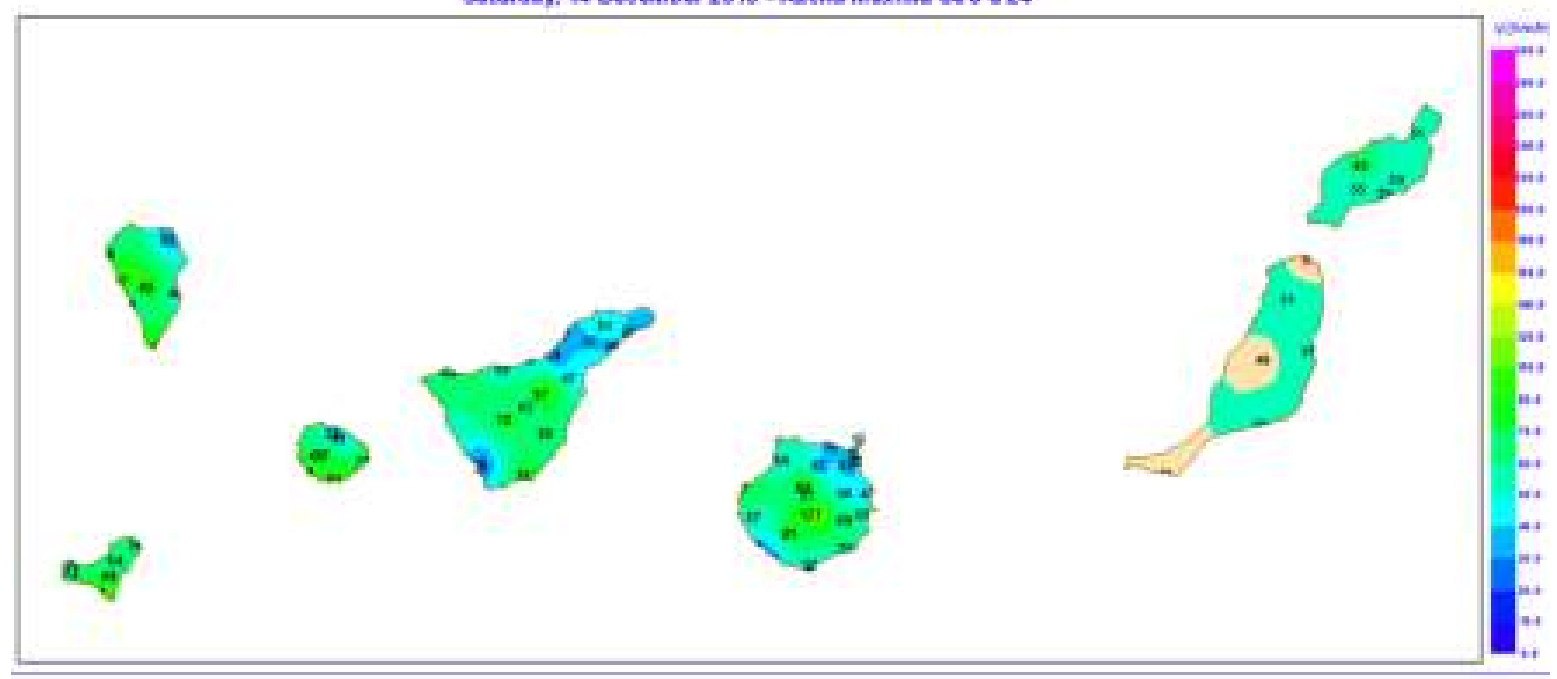

Figura 15: Racha máxima de 0 a 24 horas del 14 de diciembre de 2013. (Fuente: AEMET)

Episodio del 25 de febrero de 2015

Esta situación correspondió a un potente anticiclón de 1040 hPa situado entre Azores y Portugal, que generó viento del nordeste fuerte a muy fuerte sobre las islas.

En Gran Canaria la estación de San Bartolomé de Tirajana alcanzó los 123 km/h: 


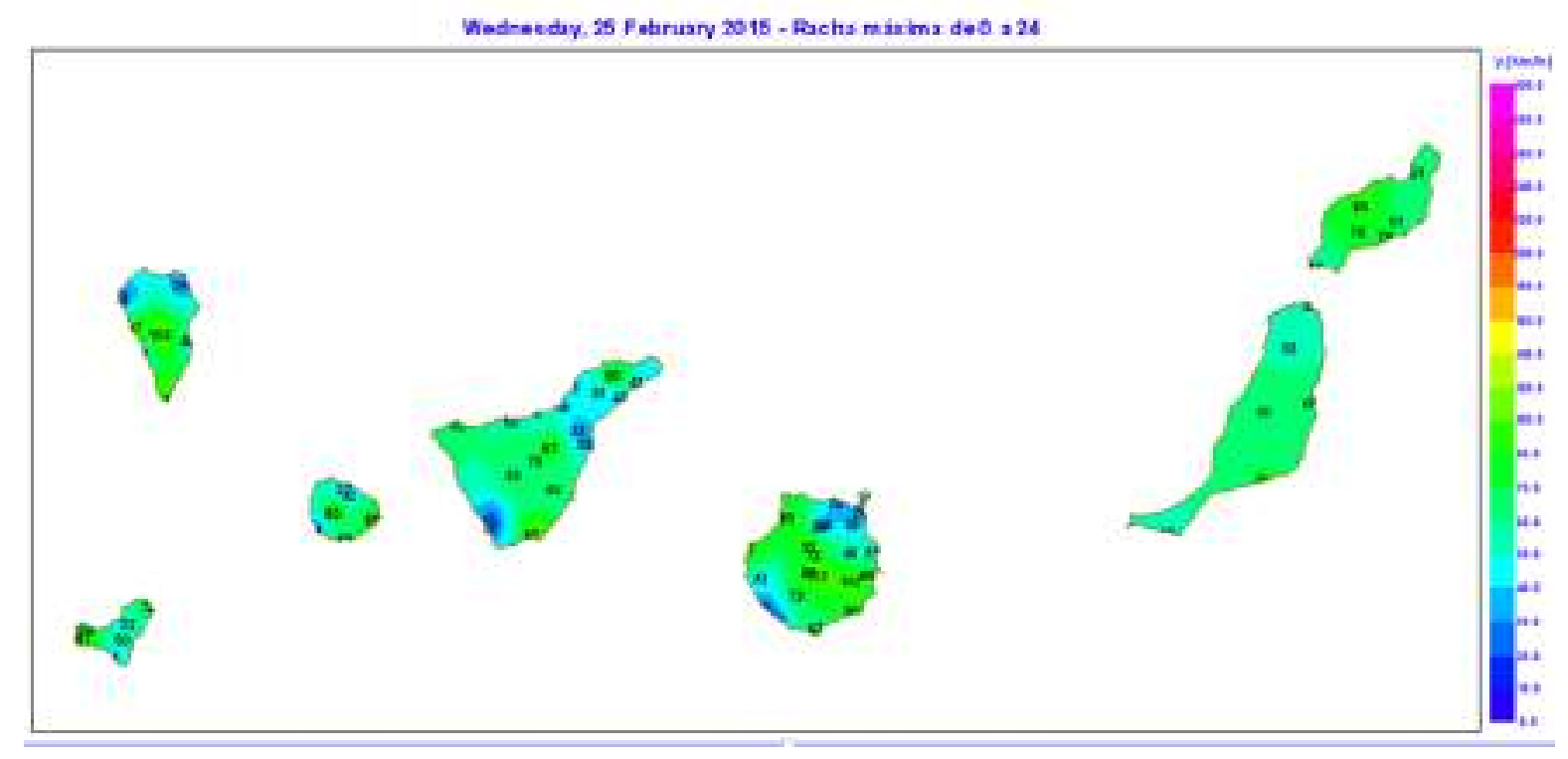

Figura 16: Racha máxima de 0 a 24 horas del 25 de febrero de 2015. (Fuente: AEMET)

\section{Episodio del 12 de febrero de 2017}

Este episodio estuvo caracterizado por la presencia de una baja en superficie de $996 \mathrm{hPa}$ centrada entre el nordeste de Madeira y el oeste de Portugal, que generó un flujo del Noroeste sobre las islas.

En Gran Canaria destacan las rachas máximas registradas en la Cruz de Tejeda 122 km/h y en Valleseco $119 \mathrm{~km} / \mathrm{h}$. 


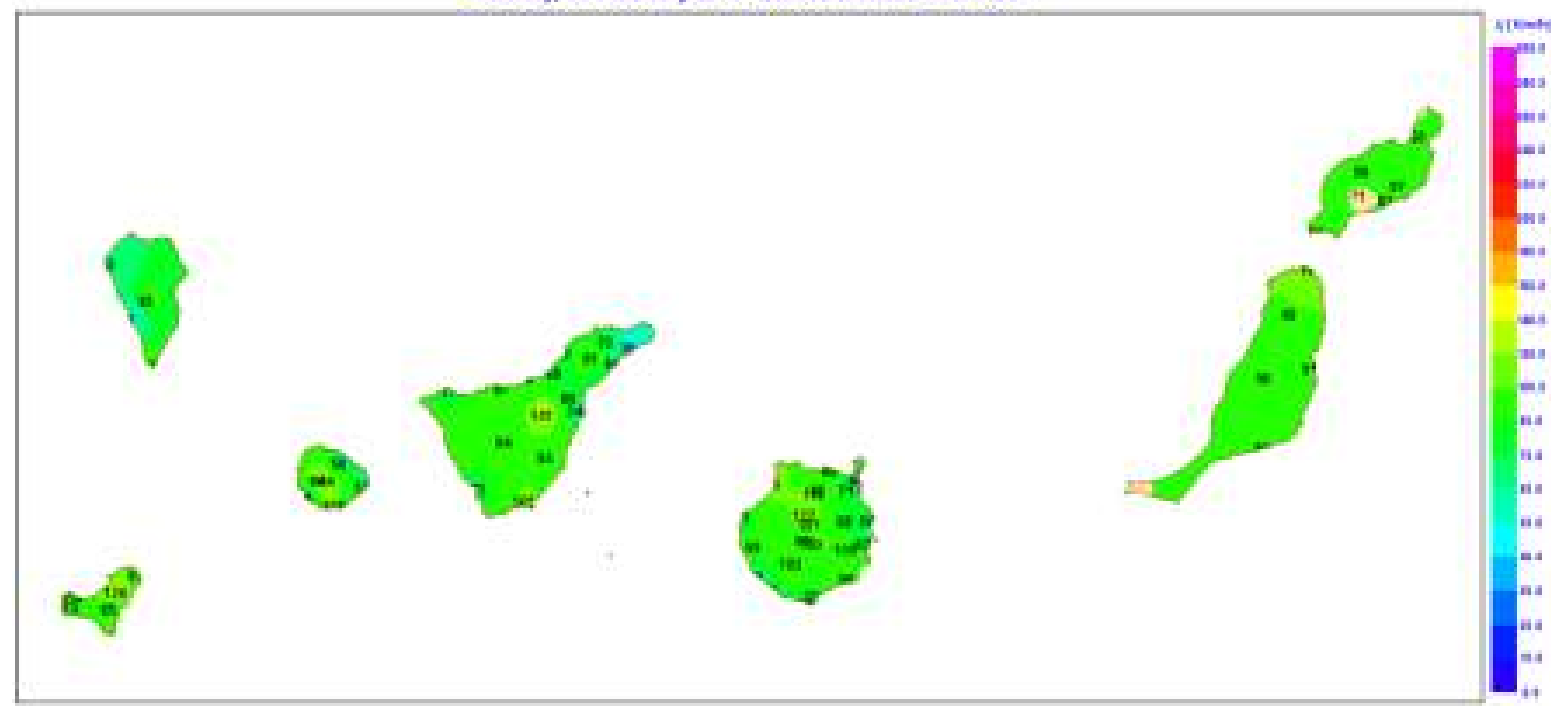

Figura 17: Racha máxima de 0 a 24 horas del 12 de febrero de 2017. (Fuente: AEMET)

\section{FENÓMENO PRECIPITACIONES INTENSAS}

En este apartado se hará una descripción de cómo las precipitaciones intensas suponen una de las principales amenazas a la isla de Gran Canaria.

Existen numerosos trabajos publicados sobre los rasgos de la precipitación en el archipiélago canario. Este estudio pondrá énfasis en caracterizar el tipo de situaciones que pueden generar precipitaciones significativas y los efectos que provocan estas en la isla de Gran Canaria.

\subsection{Descripción de la precipitación como fenómeno adverso}

Las precipitaciones en Canarias se producen de forma irregular y pueden tener un carácter torrencial. De hecho los valores máximos de intensidad diaria superan a gran parte del territorio peninsular y están cercanos a las de las regiones mediterráneas o del País Vasco. En 24 o 48 horas se pueden acumular valores varias veces las acumulaciones medias anuales. Las precipitaciones intensas y los posibles efectos posteriores de inundaciones y corrimientos de tierra constituyen el principal riesgo climático para Gran Canaria, junto con los vientos fuertes. Los desprendimientos de terreno, asociados a lluvias intensas de corta duración o a episodios de lluvias no tan intensas pero de mayor duración, se deben a que el terreno pierde consistencia al empaparse y aumenta el riesgo de su desplazamiento por efecto de su peso en zonas abruptas. El riesgo existe tanto inmediatamente tras la precipitación o en fechas posteriores. 
A este potencial carácter adverso de las precipitaciones contribuyen los siguientes factores:

* Un territorio montañoso, muy compartimentado, con algunos de los desniveles mayores del país. Su efecto es actuar de mecanismo de disparo para desencadenar la convección cuando existe inestabilidad térmica.

* Una orografía compleja conformada por pequeñas cuencas hidrográficas, de sólo algunas decenas de kilómetros cuadrados, lo que da lugar a la aparición de avenidas muy violentas.

* La concentración temporal y espacial de la precipitación asociada al carácter convectivo y a su localización en zonas concretas.

La fuerte escorrentía en suelos carentes de vegetación -sobre todo en las vertientes meridionales- unida al carácter impermeable del suelo, provoca avenidas que actúan sobre materiales fácilmente erosionables que son arrastrados por la lluvia. En última instancia, el consiguiente acarreo de abundante caudal sólido, incrementa la densidad y el poder destructivo del flujo. Además, en núcleos urbanos de fuerte pendiente, la falta de un drenaje adecuado ocasiona coeficientes de escorrentía elevados y tiempos de concentración de fuertes caudales muy cortos. Se originan así inundaciones relámpago [AYALA, 2002], fenómenos muy localizados espacial y temporalmente.

Un factor, que se considerará aparte como común a otros riesgos, es el de amplificación de daños por vulnerabilidad o exposición al riesgo. El efecto de este factor se está acelerando como consecuencia del desarrollo urbano e industrial.

Es evidente que los datos ofrecidos muestran la alta probabilidad de precipitaciones torrenciales en casi cualquier punto de las islas. Sin embargo, los periodos de retorno no son eficaces para evaluar la probabilidad de ocurrencia del fenómeno tal y como se ha demostrado, por ejemplo, para las lluvias del 31 de marzo de 2002 en Santa Cruz de Tenerife. Asimismo, los desniveles topográficos generalizados dejan poco espacio llano o de baja pendiente, por lo que una parte importante de la población vive en áreas muy expuestas a fuertes escorrentías. El rápido incremento poblacional hace que la vulnerabilidad vaya en aumento en los sectores más poblados de las islas, con umbrales de riesgo cada vez más bajos.

La principal causa de estas inundaciones es la impermeabilización de grandes superficies que han sido urbanizadas con el consecuente incremento de los coeficientes de escorrentía los graves quebrantos ocasionados a las empresas turísticas del sur de la isla, así como a las infraestructuras y edificaciones públicas con motivo de los temporales de enero de 2000 y noviembre de 2001. 


\subsection{Particularidades locales}

El archipiélago se encuentra en la zona de vientos alisios por lo que el clima es estable a lo largo del año. La advección de aire húmedo de los alisios en su recorrido marítimo al remontar las zonas norte de las islas, especialmente las más orográficas, da a estas áreas un régimen más húmedo que el que correspondería por latitud. Típicamente podemos distinguir tres capas atmosféricas, la cercana a la superficie que es relativamente húmeda y fresca, la inversión de subsidencia situada entre 700 y 1500 m y la capa de subsidencia por encima, con aire seco y cálido. Los episodios de lluvia únicamente ocurren cuando la capa de inversión se rompe debido a la presencia de borrascas atlánticas o por inestabilidad generada por vaguadas de niveles altos, sin traza en los campos de presión en superficie. Estas perturbaciones alcanzan a las islas cuando el anticiclón de las Azores se retira, lo que permite que las borrascas, frentes, vaguadas, etc... de la zona templada afecten a Canarias, produciendo un tiempo muy inestable, con lluvias intensas, vientos fuertes, temperaturas bajas y fuerte oleaje en alta mar y en las costas.

En las siguientes figuras se pueden apreciar distintas características relacionadas con la distribución geográfica y frecuencia de la precipitación.

Se aprecia que para la provincia de Las Palmas, como número medio anual, la precipitación supera los 10 mm, 3 días al año; supera los 20 mm, 1,1 días al año; y supera los 50 mm, 0,3 días al año. 


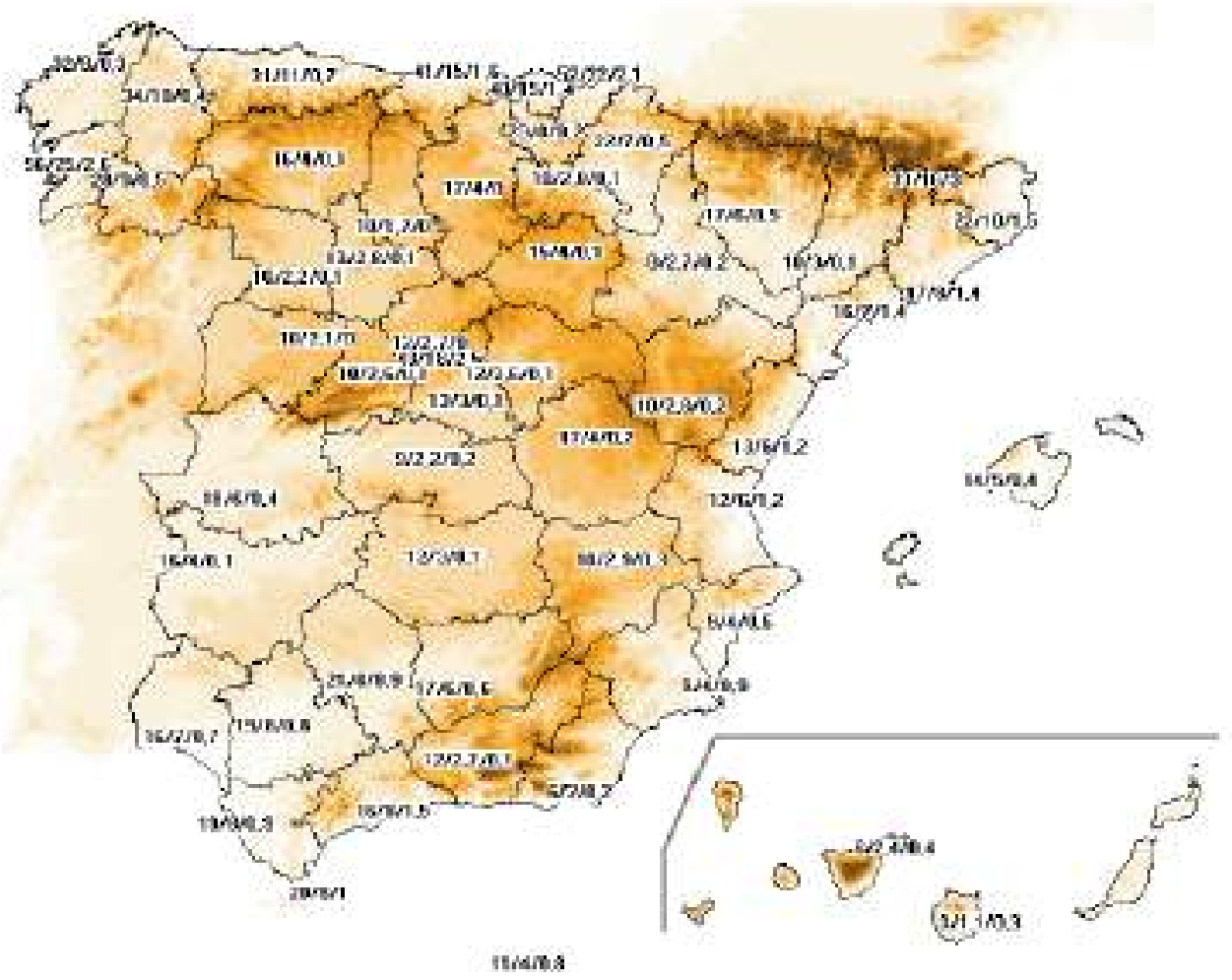

Figura 18: Número medio anual de días en los que la precipitación supera una serie de umbrales $(10,20,50)$. (Fuente:AEMET)

En la siguiente figura se muestra el número medio de días con precipitación superior o igual a 0,1 mm en el archipiélago de Canarias (1971-2000): 


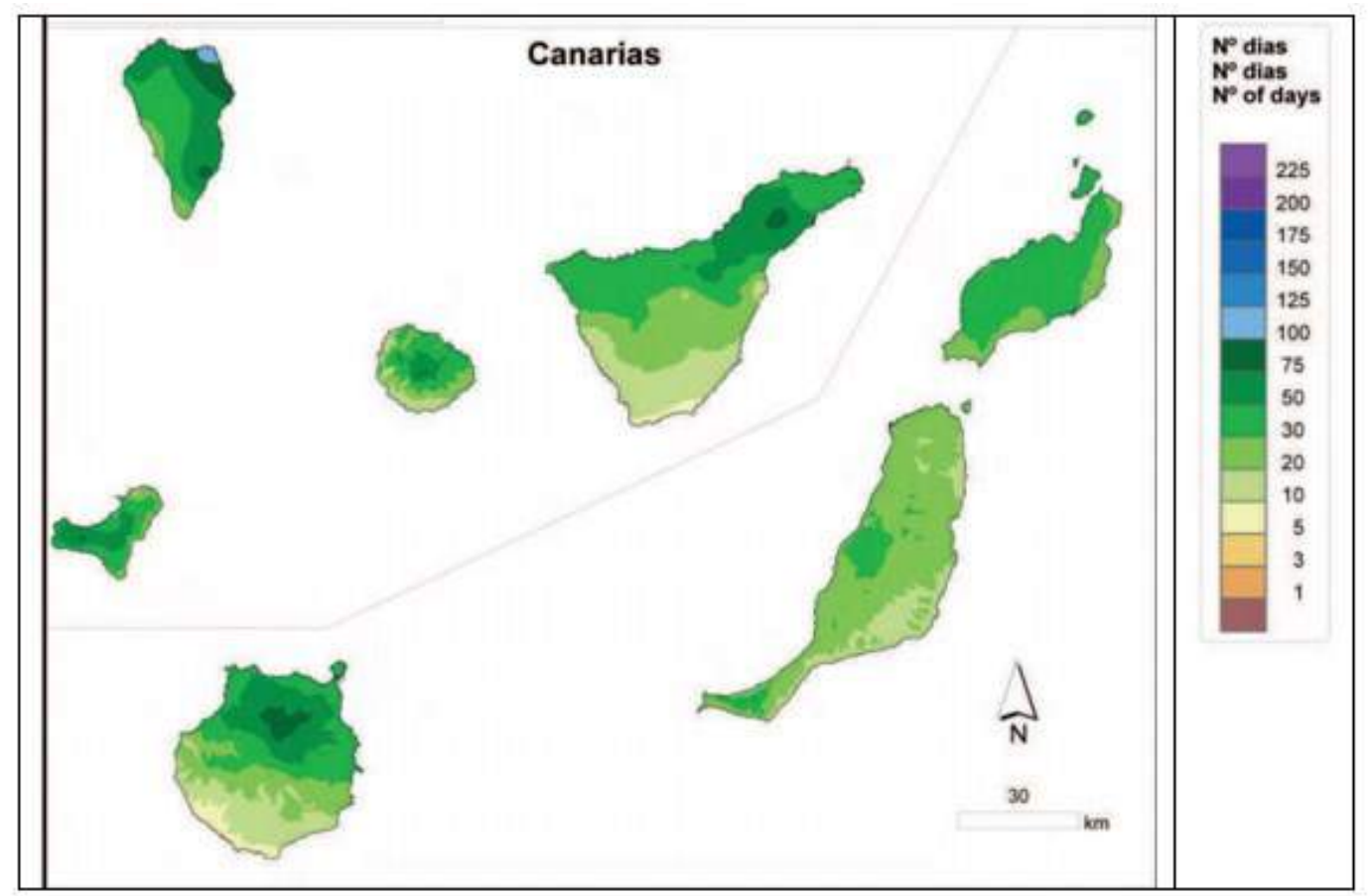

Figura 19: Número medio anual de días con precipitación igual o superior a 0,1.

(Fuente: [AEMET, 1])

La siguiente muestra la distribución espacial de las acumulaciones anuales de precipitación.

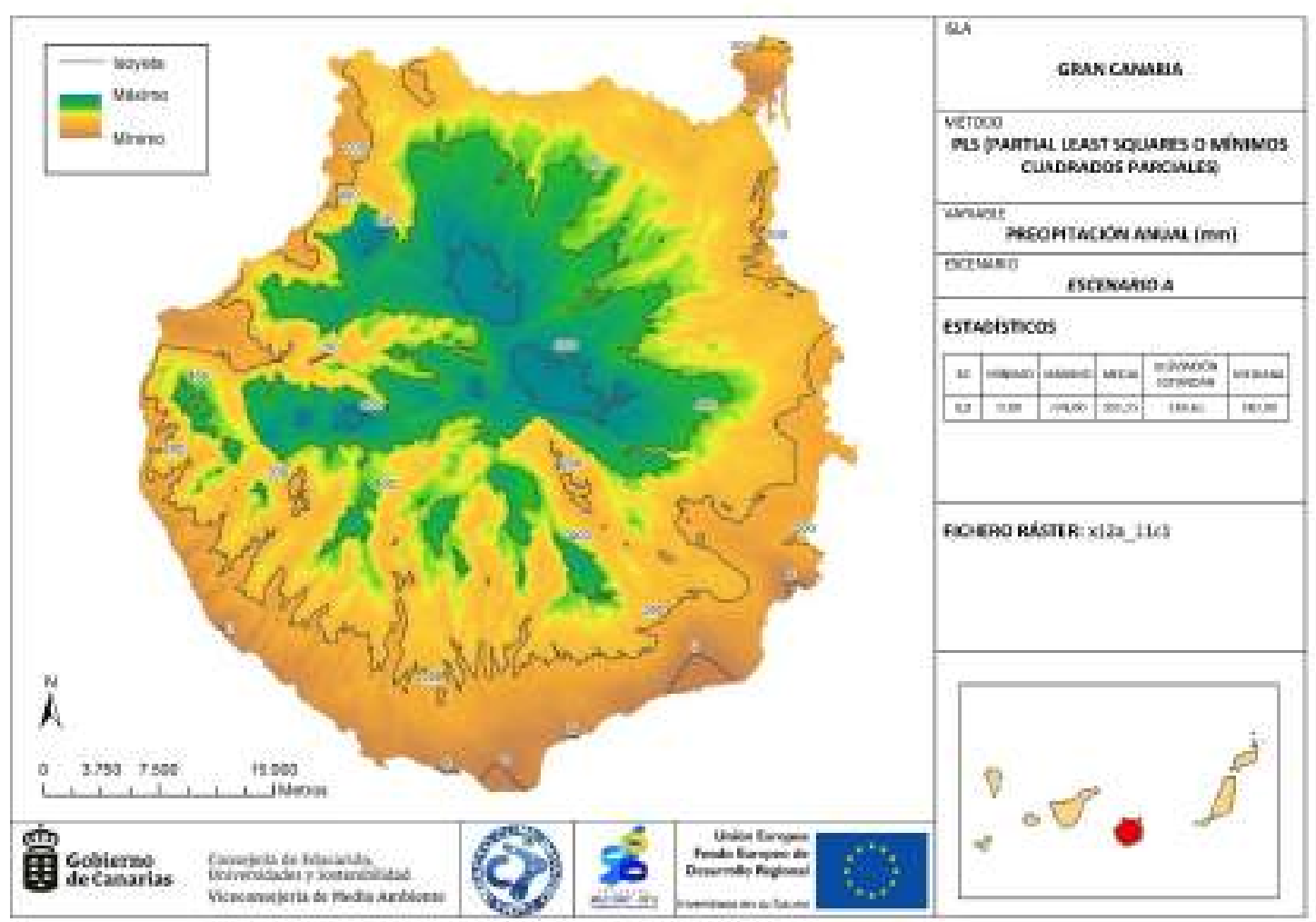

Figura 20: Precipitación anual. (Fuente: Gobierno de Canarias) 
Y la siguiente tabla los valores medios anuales más altos y más bajos de precipitación anual.

\begin{tabular}{|c|c|c|c|c|}
\hline \multicolumn{5}{|c|}{ 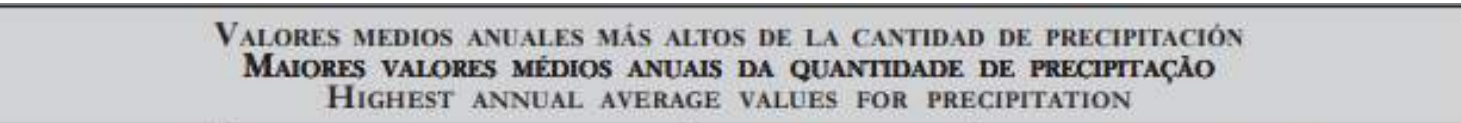 } \\
\hline \multirow[t]{2}{*}{$\begin{array}{l}\text { Archipiélago } \\
\text { Arquipélago } \\
\text { Archipelago }\end{array}$} & \multirow[t]{2}{*}{$\begin{array}{l}\text { Lugar } \\
\text { Local } \\
\text { Location }\end{array}$} & \multirow{2}{*}{\begin{tabular}{|c|}
$\begin{array}{c}\text { Media anual } \\
\text { Média anual } \\
\text { Annual average }\end{array}$ \\
$(\mathrm{mm})$
\end{tabular}} & \multicolumn{2}{|c|}{$\begin{array}{l}\text { Valor más alto } \\
\text { Maior valor } \\
\text { Highest value }\end{array}$} \\
\hline & & & $(\mathrm{mm})$ & Año/Ano/Year \\
\hline \multirow{5}{*}{ CANARIAS } & Vallehermoso-Igualero/La Gomera' & 634,0 & 1083,1 & 1987 \\
\hline & Tacoronte-Caridad/Tenerife ${ }^{2}$ & 632,2 & 989,8 & 1989 \\
\hline & $\begin{array}{l}\text { Moya-Lomo La Majadilla/ } \\
\text { Gran Canaria }\end{array}$ & 593,0 & 973,9 & 1979 \\
\hline & Garafia-Tricias/La Palma ${ }^{3}$ & 585,4 & 886,8 & 1987 \\
\hline & $\begin{array}{l}\text { San Mateo-Cueva Grande/ } \\
\text { Gran Canariat }\end{array}$ & 574,2 & 951,2 & 1984 \\
\hline \multicolumn{5}{|c|}{ 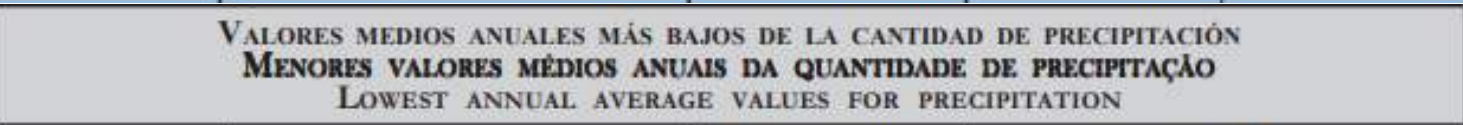 } \\
\hline \multirow{2}{*}{$\begin{array}{l}\text { Archipiélago } \\
\text { Arquipélago } \\
\text { Archipelago }\end{array}$} & \multirow[t]{2}{*}{$\begin{array}{l}\text { Lugar } \\
\text { Local } \\
\text { Location }\end{array}$} & $\begin{array}{c}\text { Media anual } \\
\text { Média anual } \\
\text { Annual average }\end{array}$ & \multicolumn{2}{|c|}{$\begin{array}{l}\text { Valor más bajo } \\
\text { Menor valor } \\
\text { Lowest value }\end{array}$} \\
\hline & & $(\mathbf{m m})$ & $(\mathrm{mm})$ & Año/Ano/Year \\
\hline \multirow{5}{*}{ CANARIAS } & Fuerteventura/Aeropuerto & 104,9 & 31,5 & 1983 \\
\hline & Lanzarote/Aeropuerto ${ }^{9}$ & 109,5 & 45,8 & 1992 \\
\hline & $\begin{array}{l}\text { Las Palmas de Gran Canaria/ } \\
\text { Las Canteras }\end{array}$ & 115,5 & 34,8 & 1998 \\
\hline & Gando/Gran Canaria 9 & 136,6 & 43,3 & 1975 \\
\hline & Haria-Orzola/Lanzarote ${ }^{4}$ & 159,4 & 61,1 & 1992 \\
\hline
\end{tabular}

Tabla 6: Valores medios anuales más altos y más bajos de precipitación en Canarias. (Fuente: [AEMET, 1])

Se observa que la complejidad orográfica y el nivel de exposición a los vientos más húmedos hacen que los totales pluviométricos sean muy variados. Los sectores de altitud media orientados al norte, rondan valores medios más altos en torno a $600 \mathrm{~mm}$ (ver figura 20 y tabla 6), mientras que las costas meridionales apenas llegan a los $100 \mathrm{~mm}$. La distribución espacial de lluvia en Gran Canaria está claramente vinculada con el relieve. Las precipitaciones máximas por encima de $500 \mathrm{~mm}$ al año con más de 65 días de lluvia se concentran en el lado norte. En contraste, en las zonas orientadas hacia el sur la precipitación anual se sitúa en torno a $200 \mathrm{~mm}$ anuales con unos 20 días de lluvia.

La irregularidad en el tiempo con grandes variaciones interanuales es, sin duda, la característica más sobresaliente de la lluvia. Esta sensibilidad a pequeñas variaciones en la circulación atmosférica ha quedado patente por la existencia de correlación significativa con el fenómeno de El Niño [GALLEGO et al 2001].

Las lluvias son más intensas en los meses de invierno (cuando la NAO está más marcada), le sigue el otoño y luego la primavera, siendo el verano la estación más seca del año. 


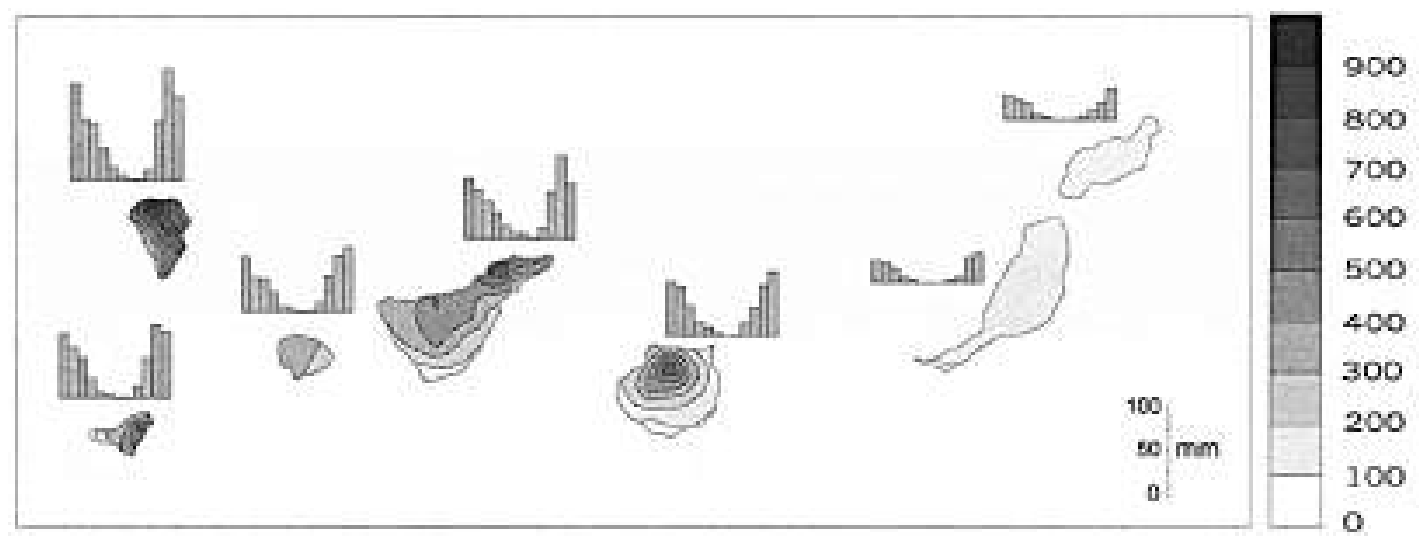

Figura 21: Precipitación anual y régimen de precipitación en mm/año. (Fuente: [GALLEGO et al 2001])

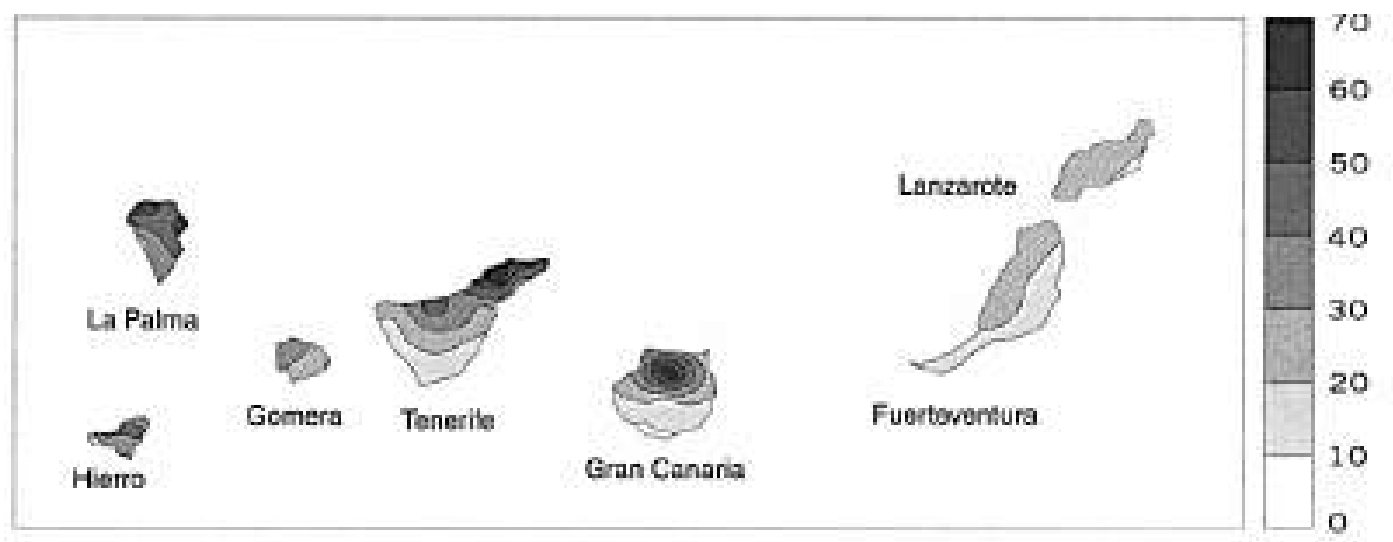

Figura 22: Número de días de precipitación anual. (Fuente: [GALLEGO et al 2001])

\section{Factores que influyen en las precipitaciones}

Las precipitaciones en el archipiélago canario están condicionadas por la yuxtaposición de dos factores regionales: La circulación atmosférica y las condiciones geográficas. La combinación de ambos permite comprender los contrastes existentes en su distribución.

Desde el punto de vista geográfico hay que tener en cuenta la cercanía al mayor desierto del planeta, el Sáhara y, por tanto, al más importante manantial de aire cálido y de aerosol mineral [GELADO et al 2003].

La localización de las islas en el límite meridional de la latitud templada posibilita que hasta ellas lleguen masas de aire de muy diversos orígenes y características, si bien las que causan las lluvias de cierta importancia siempre proceden de la zona templada.

Desde el punto de vista meteorológico, en la siguiente tabla tomada de [GARCíA et al. 2001] se analiza el reparto porcentual de la precipitación, en ocurrencia y acumulación, para distintas estaciones según el tipo de perturbación a la que se asocia (ASL - borrascas atlánticas en superficie, MSL - borrascas mediterráneas en superficie, UAL - depresiones 
aisladas en niveles altos, TRO - vaguadas de presión en niveles altos, DAL - depresiones en todos los niveles, y ND - no detectadas.

\begin{tabular}{|c|c|c|c|c|c|c|c|c|c|c|}
\hline \multirow{2}{*}{\multicolumn{2}{|c|}{ Disturbanot }} & \multicolumn{8}{|c|}{ Sarion } & \multirow[b]{2}{*}{ Average } \\
\hline & & LP. & TEI & $\mathrm{TE}$ & TE & $\mathrm{GCl}$ & $\mathrm{GC} 2$ & FU & LA & \\
\hline \multirow[t]{3}{*}{ ASL. } & pro. & 10.8 & 12.5 & 9.9 & 118 & 1.7 & 10.6 & 16.2 & 15.6 & 120 \\
\hline & $\mathrm{MP}$ & 10.8 & 10.0 & 113 & 5,2 & 4,3 & 6.2 & 5.4 & 3.1 & 3.2 \\
\hline & PTP & 22.2 & 158 & 16.7 & 160 & 14.8 & 148 & 19.6 & 16.5 & 17.0 \\
\hline \multirow[t]{3}{*}{ MSL } & mo & 3.3 & t. 7 & 4.1 & 42 & 4.3 & 4.3 & 32 & 5.1 & 4.0 \\
\hline & $M P$ & 3.5 & 6.6 & 5.1 & 23 & 2.2 & 3.6 & 2.3 & 1.6 & 3.4 \\
\hline & PTP & 22 & 30 & 3.1 & 24 & 3.8 & 35 & 16 & 2.8 & 28 \\
\hline \multirow[t]{3}{*}{ UAL } & no & 160 & 253 & 193 & 215 & 21.4 & 22.6 & 22.6 & 234 & 21.2 \\
\hline & $\mathrm{MP}$ & 3.2 & 9.t & 6.1 & 4.1 & 2.9 & 4.7 & 42 & 2.9 & 4.9 \\
\hline & PIP & 16.8 & 253 & 178 & 208 & 24.9 & 23.9 & 20.4 & 21.9 & 21.5 \\
\hline \multirow[t]{3}{*}{ TRO } & mo & 124 & 170 & 130 & 145 & 13.8 & 144 & 13.9 & 13.0 & $1+0$ \\
\hline & MP & 5.9 & 9.8 & 93 & 53 & 3.3 & 5.4 & 5.1 & 3.3 & 5.9 \\
\hline & PIP & 14.1 & 198 & $17 \%$ & 18.4 & 15.2 & 17.4 & 155 & 14.7 & 17.0 \\
\hline \multirow[t]{3}{*}{ DAL. } & PRo & 8.5 & 11.4 & 75 & 100 & 1.6 & 10.7 & 306 & 16.1 & 11.7 \\
\hline & $M P$ & 9.2 & 11.4 & 16.6 & 9.1 & 4.8 & 3,9 & 7.4 & 5.8 & 8.9 \\
\hline & PIP & 1500 & 15.4 & 175 & 220 & 16.4 & 18.9 & $3 \geq 8$ & 31.8 & 21.2 \\
\hline \multirow[t]{3}{*}{ ND } & mo & 48.0 & 320 & 46.3 & 37.9 & 41.2 & 37.4 & 23.5 & 27,8 & 37.0 \\
\hline & $M P$ & 3.3 & 5.4 & 40 & 2.3 & 1.3 & 26 & 21 & 1.3 & 28 \\
\hline & PTP & 29.8 & 20.7 & 27.4 & 20.5 & 21.0 & 21.5 & 10.9 & 12.4 & 20.7 \\
\hline
\end{tabular}

Figura 23: Porcentaje de ocurrencias de precipitaciones dependiendo del tipo de perturbación.

(Fuente: [GARCÍA et al. 2001])

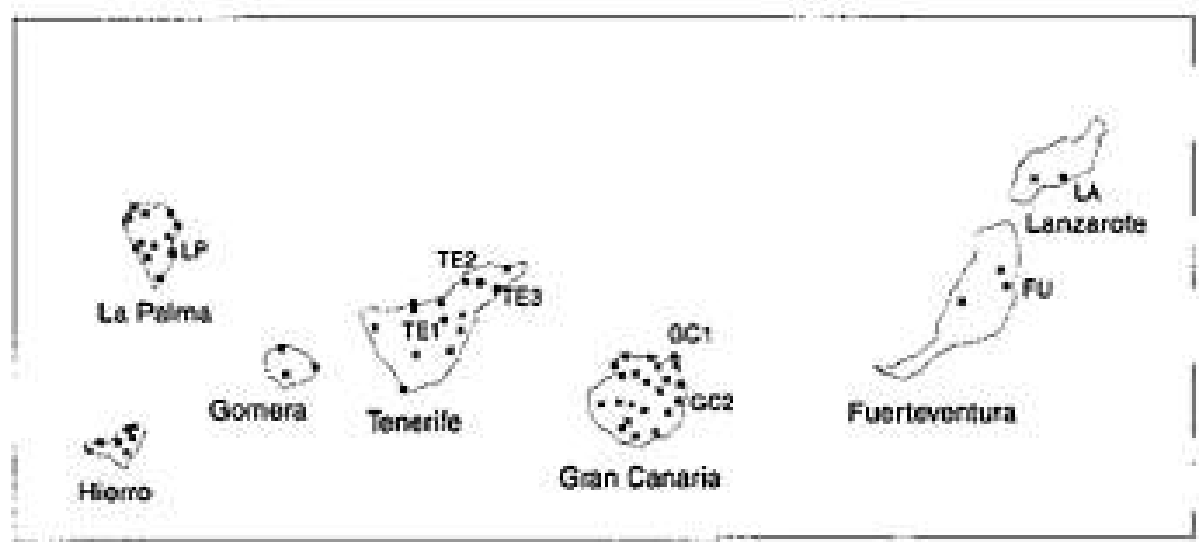

Figura 24: Localización de las estaciones usadas en el estudio.

(Fuente: [GARCÍA et al. 2001])

Para la isla de Gran Canaria el mayor porcentaje de ocurrencia de precipitación está asociado a UAL (Depresiones aisladas en niveles altos), sin tener en cuenta las ND (no detectadas).

Para un análisis en mayor profundidad y detalles los estudios se deben orientar a los últimos 70 años, para los que se dispone de más datos de observación y de reanálisis numéricos. 


\subsection{Patrones atmosféricos relacionados con episodios de precipitaciones intensas}

\subsubsection{Patrones sinópticos favorables a precipitaciones intensas}

El origen de estas situaciones de extrema adversidad hay que buscarlas en la acción de vaguadas de niveles altos y de depresiones aisladas en niveles altos, con marcada inestabilidad térmica que desemboca en convección profunda asociada a mecanismos locales de disparo. No se debe descartar la presencia de factores tropicales en alguno de los eventos, en la forma directa de una perturbación de origen tropical o en la interacción del frente polar con masas de aire tropicales marítimas de alto contenido de humedad que ocupa un gran espesor de la troposfera.

Al combinar la situación de escala sinóptica con los efectos mesoescalares (disparo por convergencia en la costa y por forzamiento orográfico), se observa que con frecuencia, la componente dominante en superficie es del Sur (SE o SW), tal como ocurrió, por ejemplo, con las precipitaciones extraordinarias de febrero de 1971, abril de 1977, febrero de 1989 o marzo de 2002

Existen otros factores menos estudiados pero que pueden tener influencia en la precipitación en las islas Canarias. Es interesante destacar la influencia de la NAO sobre la precipitación subtropical en el Atlántico Norte, aún no bien conocida en profundidad debido a que no se dispone de largas series climáticas. En el caso de Canarias [GARCíA et al. 2001] la variabilidad de la NAO parece ser un factor significativo en cuanto a la precipitación. Puesto que casi el 80 \% de la lluvia total se asocia a cinco perturbaciones tipo, la influencia de la NAO puede realizarse a través de las características de estos patrones.

Para ilustrar este apartado se analiza alguna situación representativa de precipitaciones intensas en Gran Canaria.

Para ello se hará referencia a la situación meteorológica que afectó a Canarias y en particular a Gran Canaria, en la que se recogieron más de $100 \mathrm{~mm}$ durante el día 23 de noviembre de 2014.

En la siguiente figura se muestra la presión a nivel del mar y en sombreado la temperatura en el nivel de $850 \mathrm{hPa}$. Ese día Canarias estaba bajo la influencia de una borrasca de $1010 \mathrm{hPa}$ centrada al nordeste de Lanzarote. Por otro lado, el Atlántico estaba dominado por un anticiclón de $1024 \mathrm{hPa}$ situado al sureste de Azores. Sobre las islas soplaba en general, viento de componente Sur, dirección sur sobre las de mayor relieve y dirección sureste en Lanzarote y Fuerteventura. 


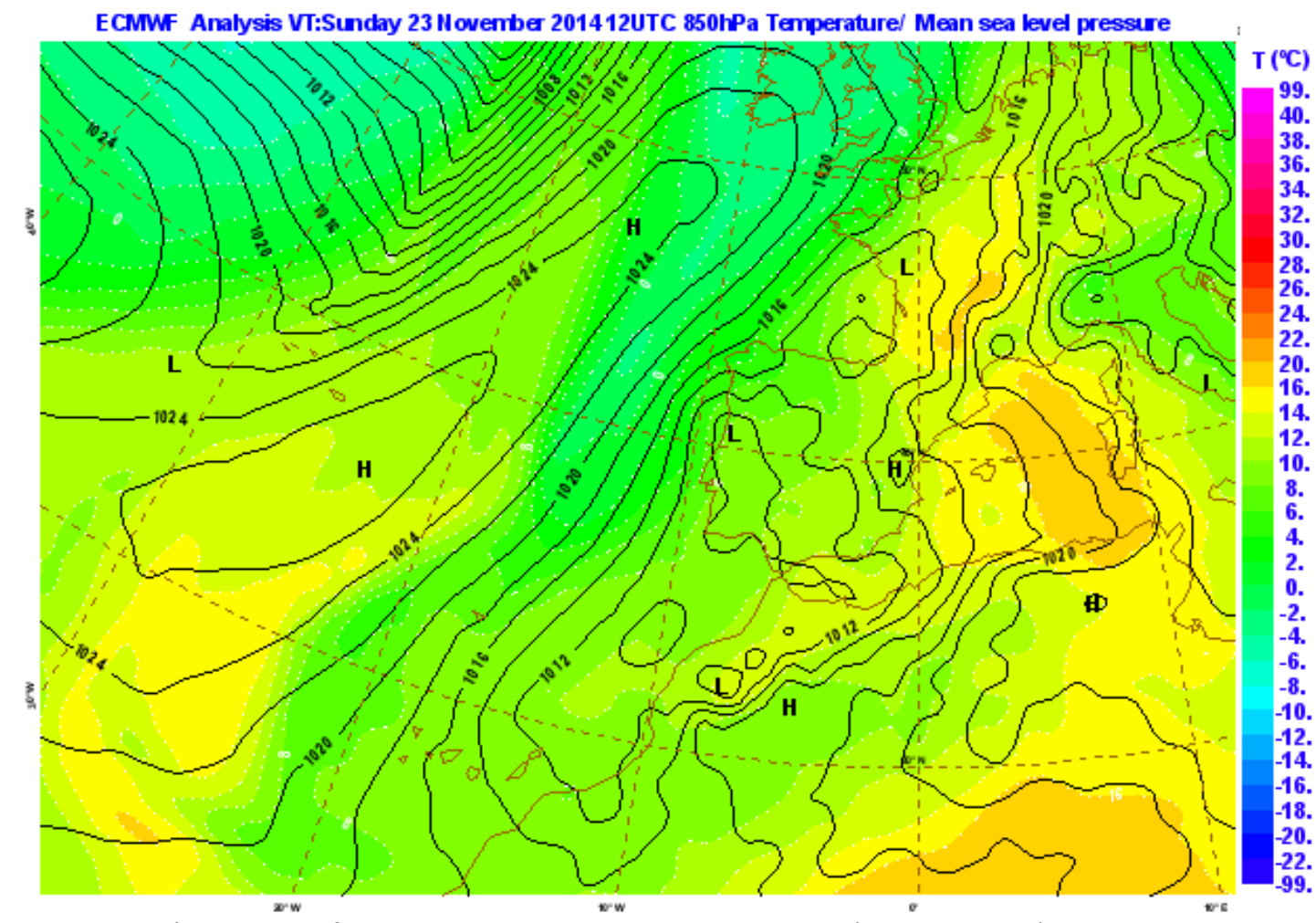

Figura 25: Análisis de superficie, 12 horas del 23 de noviembre de 2014. (Fuente: AEMET)

A continuación se muestra el mapa del nivel de $500 \mathrm{hPa}$. En él se representa temperatura sombreada y altura geopotencial. Al este de las islas más orientales se observa el núcleo frío de -22 a $-24{ }^{\circ} \mathrm{C}$. Además queda marcada la frontera entre la masa cálida subtropical al sur de las islas y la fría asociada al frente polar. En este nivel existía un máximo de viento del Oeste al sur del archipiélago. 


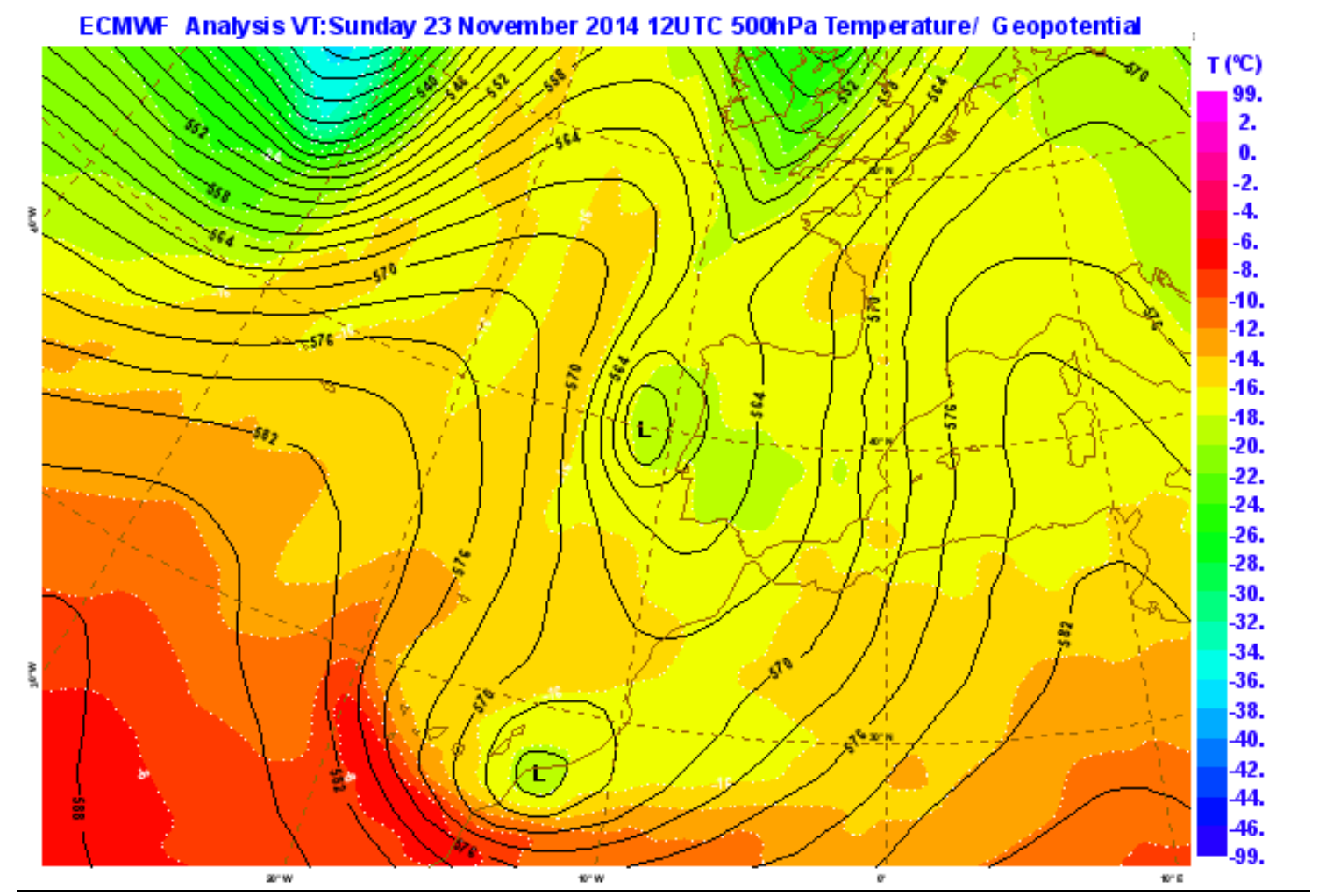

Figura 26: Análisis de 500 hPa, 12 horas del 23 de noviembre de 2014. (Fuente: AEMET)

La situación aquí descrita ocasionó precipitaciones notables en gran parte del archipiélago canario. Destacan los 220 mm recogidos en la estación de los Realejos (Tenerife).

Como se muestra en la siguiente figura, las precipitaciones en Gran Canaria también fueron abundantes. Destacan los 111,6 mm recogidos en la estación de Las Palmas de G.C. (Jardín Canario II) y los 103,6 en la estación de Cruz de Tejeda entre otros. 


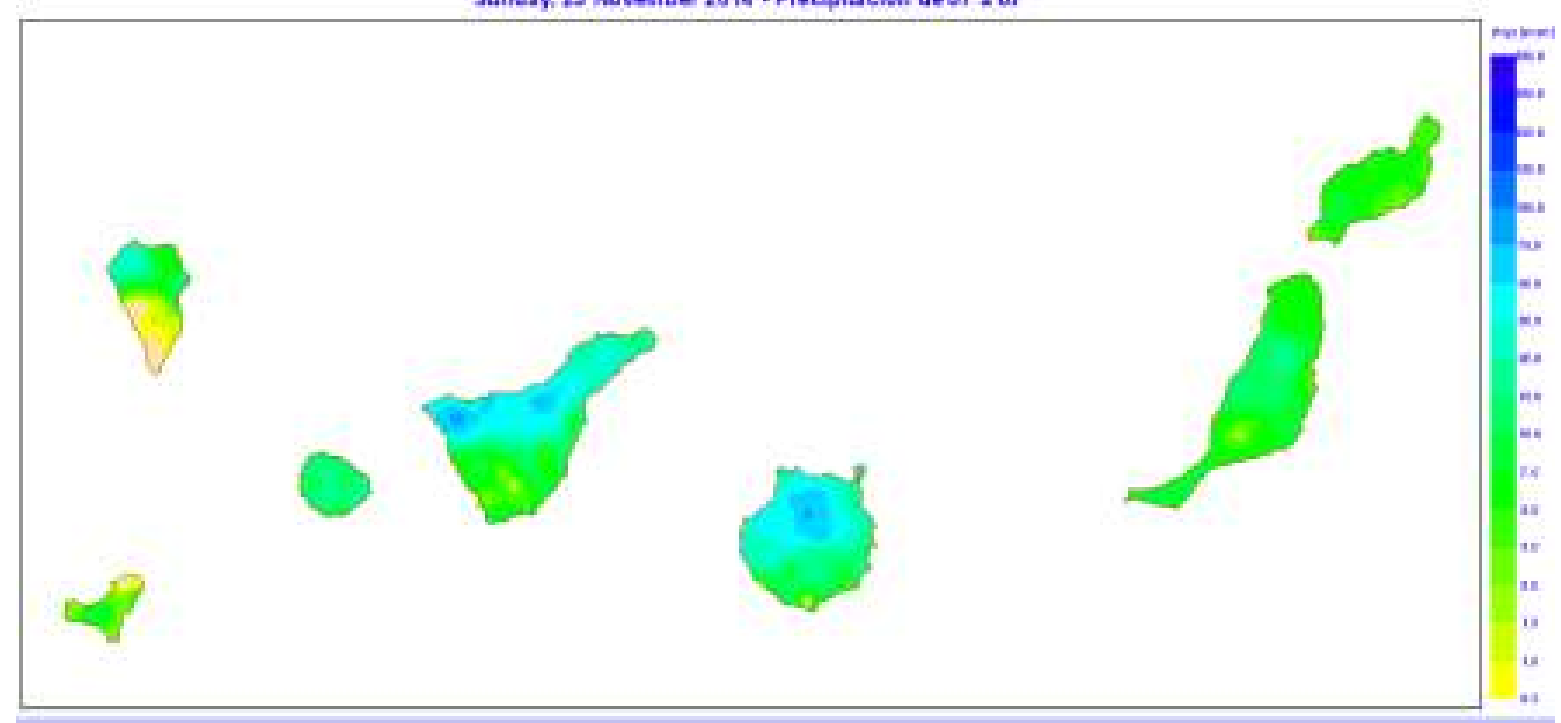

Figura 27: Precipitaciones acumuladas de 07 horas del día 23 de noviembre a 07 horas del 24 de noviembre de 2014. (Fuente: AEMET)

Como se ha ido comentando en este documento, en una gran mayoría las situaciones que pueden ocasionar precipitaciones intensas en Gran Canaria, están asociadas a depresiones aisladas en niveles altos o a situaciones asociadas a borrascas extratropicales. Sin embargo, por la localización subtropical del archipiélago no se pueden olvidar los escenarios con rasgos tropicales.

A continuación se expone, a modo de ejemplo de este tipo de patrones, la situación del 31 de enero al 3 de febrero de 2010, donde un ciclón híbrido (es un sistema de bajas presiones que comienza a tener ciertos elementos nubosos convectivos de cierta profundidad y simetría en su estructura y rodeando el mínimo depresionario en superficie. Con el tiempo conforman una anomalía cálida bien definida en capas bajas, por los procesos de liberación de calor latente. En ellos se comienza a ganar una simetría en el campo de nubosidad convectiva y en el campo de viento en capas bajas, pero mucho menor y de menor grado cuando se compara con los de tipo tropical. Se suelen formar a partir de ciclones subtropicales o de estructuras de latitudes medias que se han desplazado fuera del vórtice circumpolar).

En la figura siguiente se muestra la presión a nivel del mar y la temperatura en el nivel de $850 \mathrm{hPa}$. Queda reflejada la presencia de un anticiclón de bloqueo de $1024 \mathrm{hPa}$ situado al noroeste de la península ibérica. Además se observa centrado al oeste del archipiélago el ciclón híbrido de $1006 \mathrm{hPa}$. Este ciclón generaba vientos del Sur o Suroeste sobre las islas. 


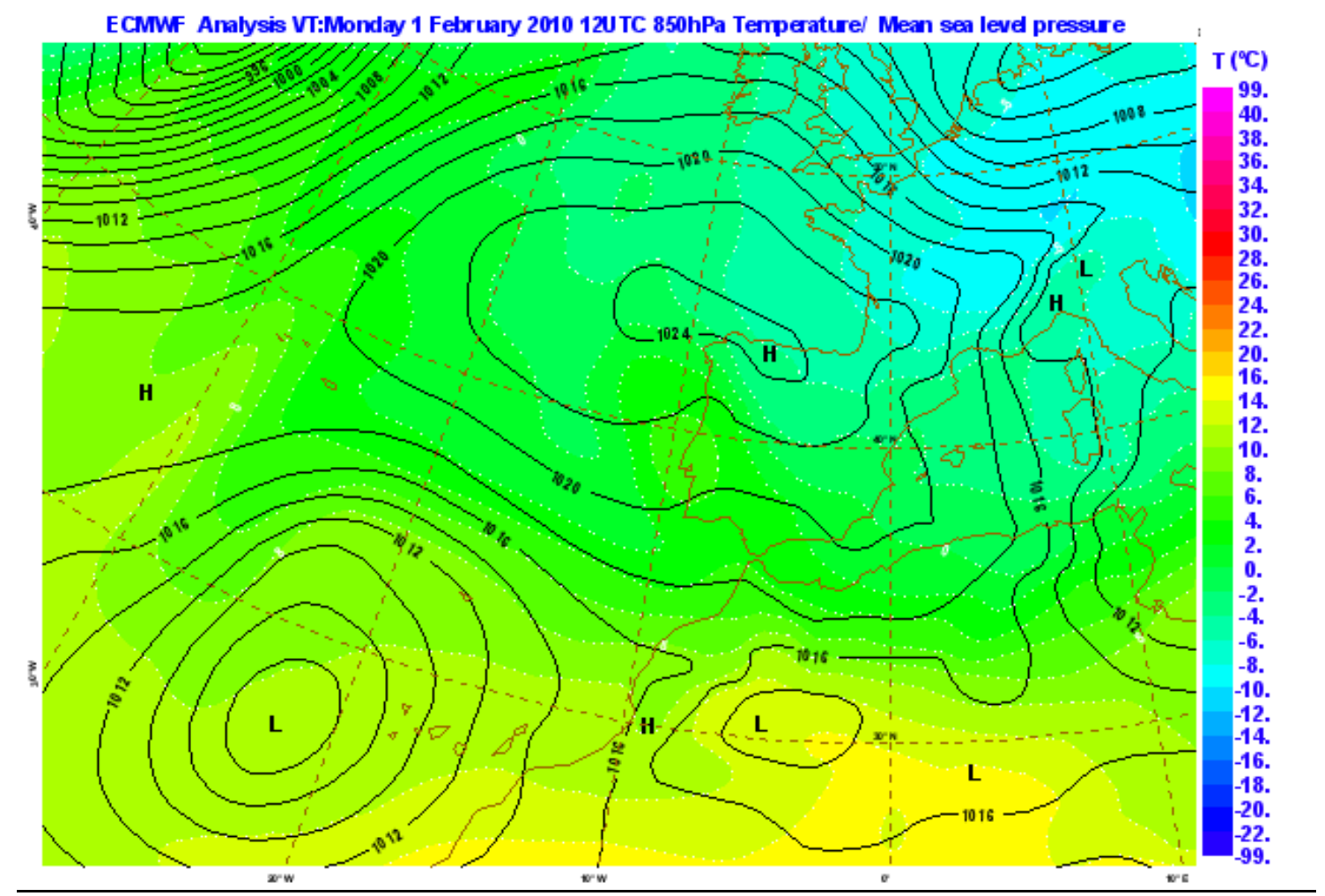

Figura 28: Análisis de superficie, 12 horas del 1 de febrero de 2010. (Fuente: AEMET)

En el siguiente mapa de $500 \mathrm{hPa}$, queda mostrado el núcleo cálido de la estructura centrado al oeste de las islas, típico de ciclones tropicales. A este nivel el flujo sobre Canarias era del Suroeste. 


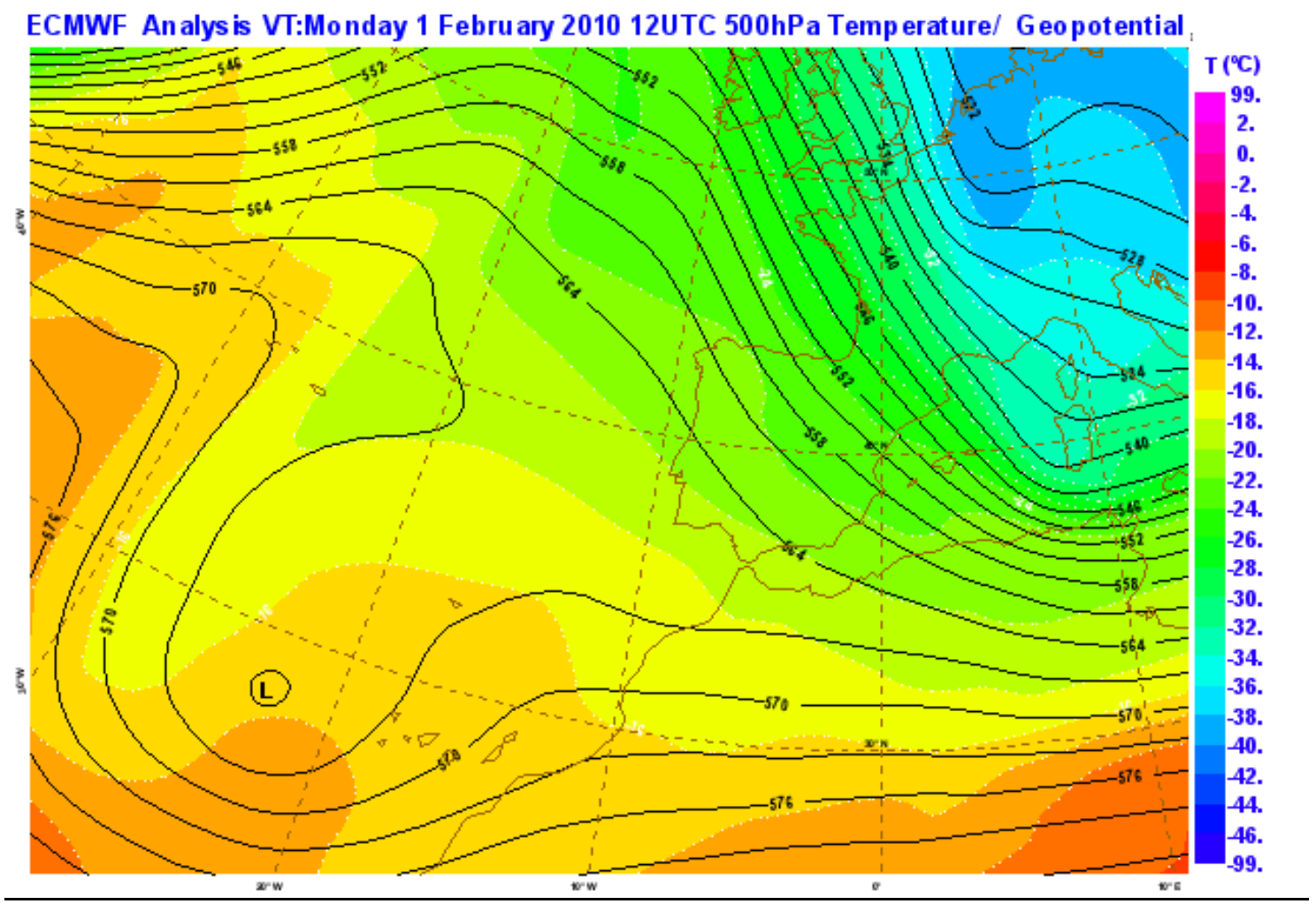

Figura 29: Análisis de $500 \mathrm{hPa}, 12$ horas del 1 de febrero de 2010. (Fuente: AEMET)

Las precipitaciones asociadas a este episodio fueron de carácter torrencial en gran parte de las islas y en particular para Gran Canaria. A continuación se muestran los registros de precipitación acumulada durante el día 1 de febrero de 2010:

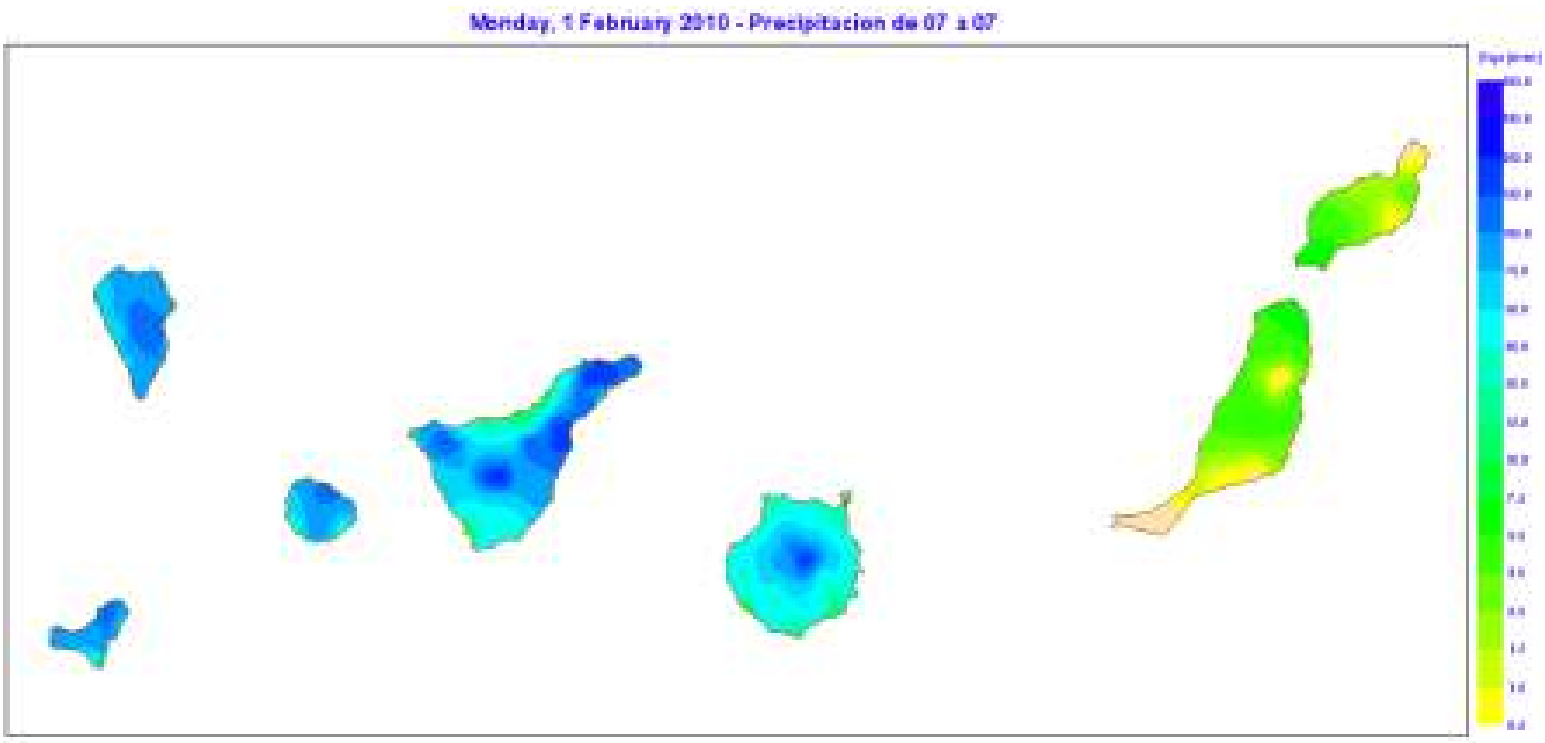

Figura 30: Precipitaciones acumuladas de 07 horas del día 1 de febrero a 07 horas del 2 de febrero de 2010. (Fuente: AEMET) 
Este día numerosas estaciones superaron los $200 \mathrm{~mm}$ de precipitación acumulada. Para Gran Canaria cabe destacar los $194 \mathrm{~mm}$ registrados en San Mateo, 174,6 mm en Valsequillo y los 165 mm en San Bartolomé de Tirajana Casco, entre otros.

Además de los acumulados en 24 horas, es reseñable que la intensidad máxima horaria de las precipitaciones en algunos puntos del suroeste de Gran Canaria fue en torno a 100 o $120 \mathrm{~mm} / \mathrm{h}$.

\section{0-02-01: Máxima intensidad de precipitación ( $\mathrm{mm} / \mathrm{h})$}

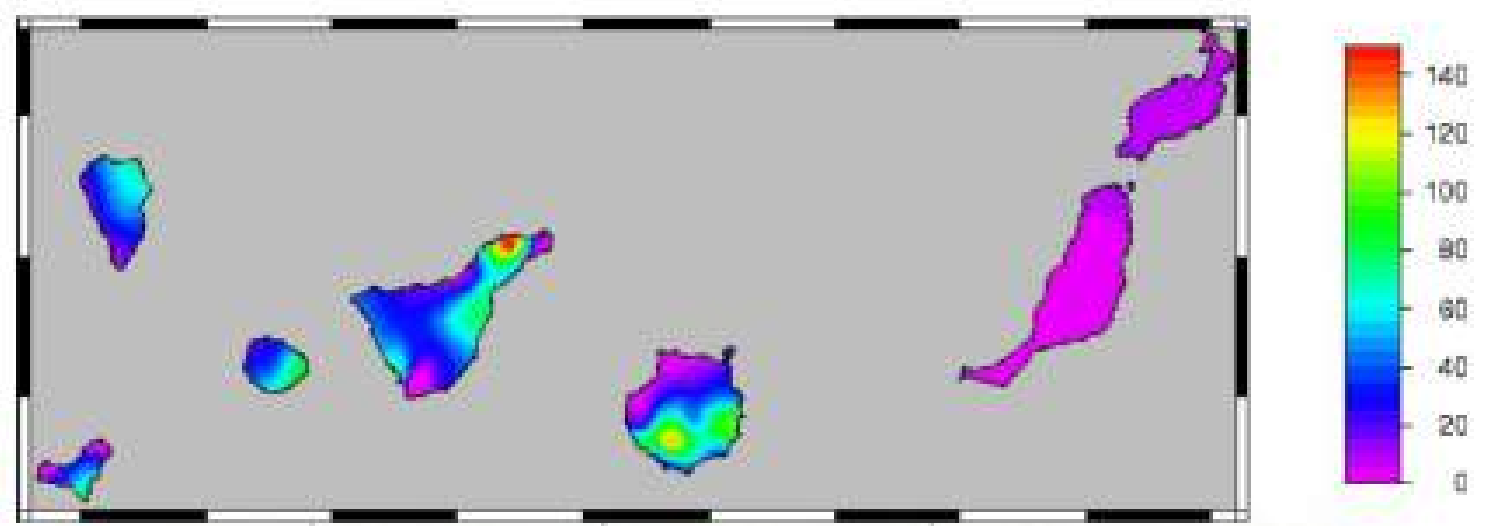

Figura 31: Máxima intensidad de precipitación $(\mathrm{mm} / \mathrm{h})$ durante el 1 de febrero de 2010.

(Fuente: [AGUADO et al 2010])

\subsection{Episodios de precipitaciones intensas, análisis histórico. Principales zonas} afectadas e impactos habituales.

A título introductorio se muestran a continuación diversas gráficas y tablas que dan una idea de la ocurrencia de extremos de precipitación en Canarias y en Gran Canaria en particular.
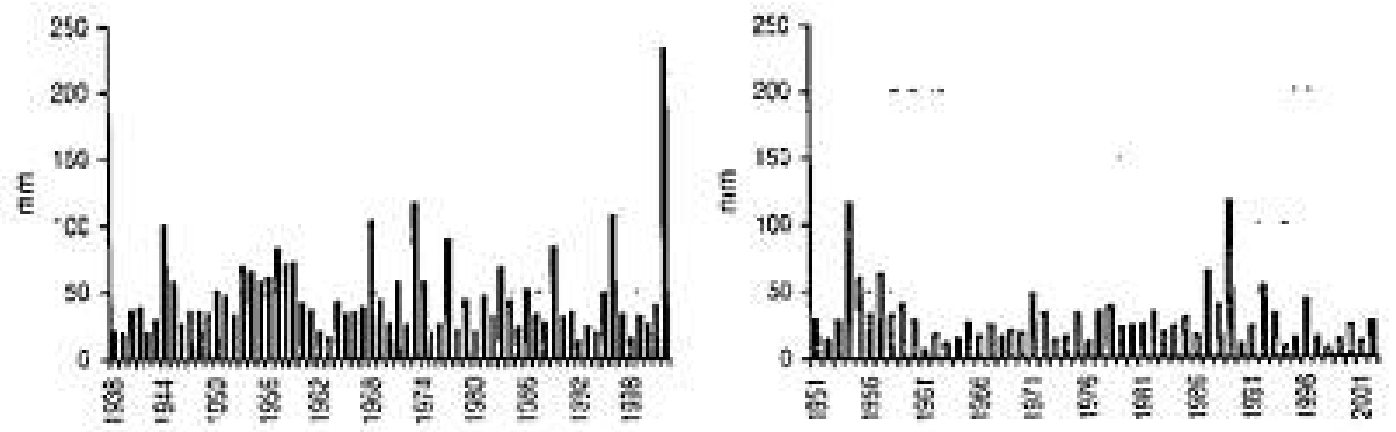

Figura 32: Precipitaciones diarias máximas $(\mathrm{mm})$ anuales en Santa Cruz de Tenerife (1938-2002) y Las Palmas de Gran Canaria (1951-2002).

(Fuente: extinto INM, actualmente AEMET) 


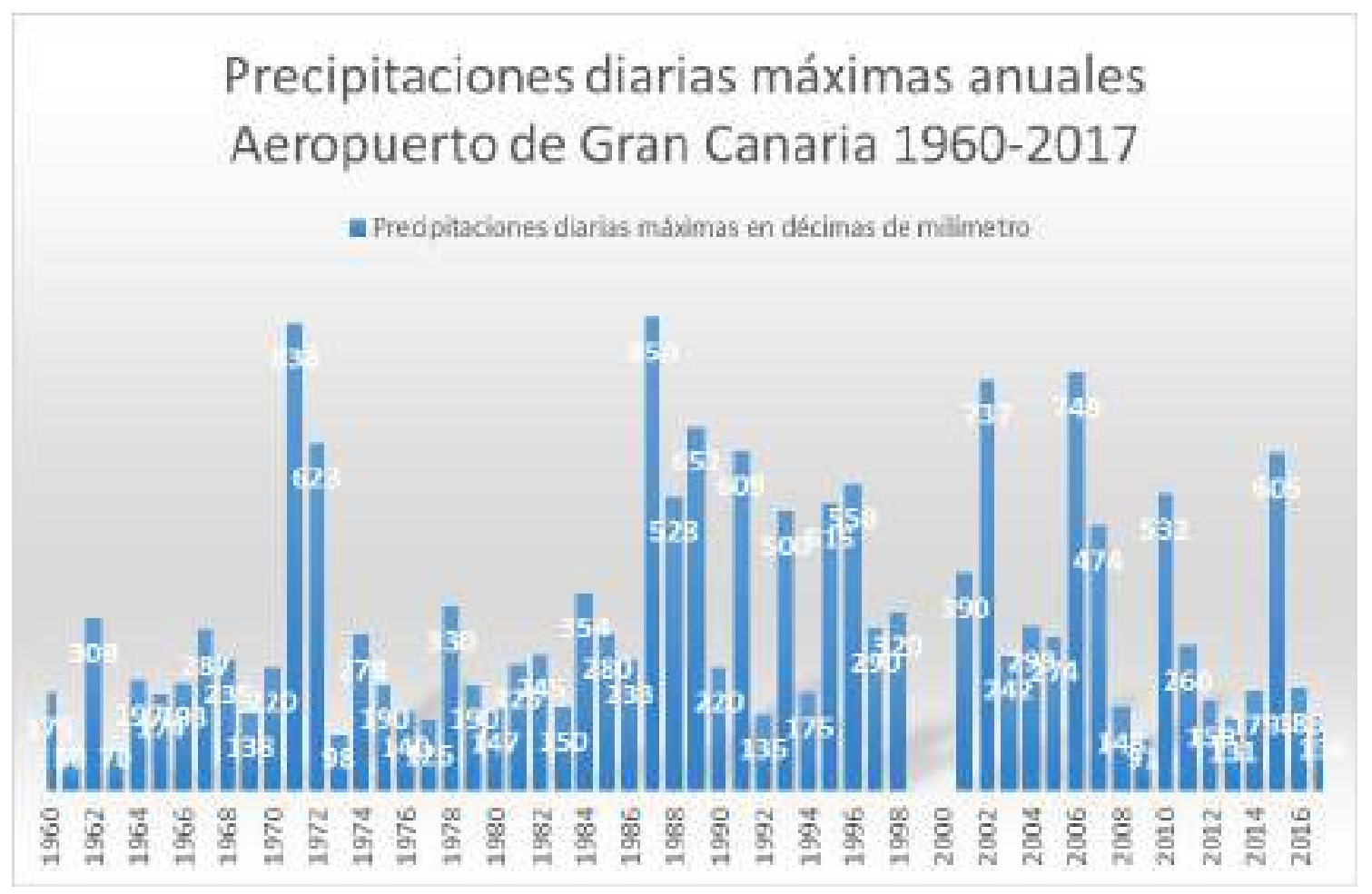

Figura 33: Precipitaciones diarias máximas anuales aeropuerto de Gran Canaria (1960-2017). (Fuente: AEMET)

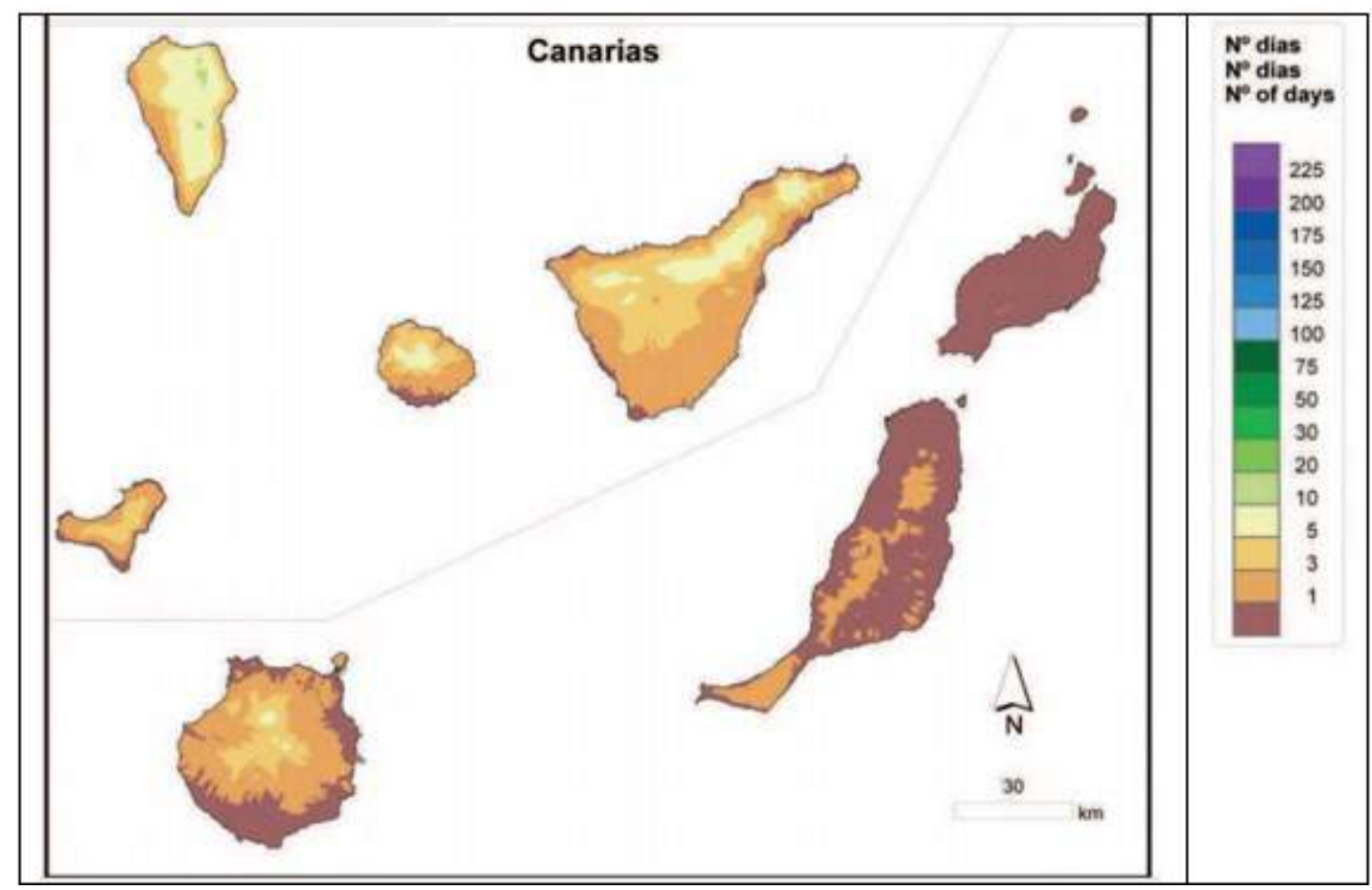

Figura 34: Número medio de días con precipitación superior o igual a $30 \mathrm{~mm}$ en el archipiélago de Canarias, (1971-2000). (Fuente: [AEMET, 2]) 


\begin{tabular}{|c|c|c|c|c|c|c|c|}
\hline \multirow{2}{*}{ Estación } & \multirow{2}{*}{$\begin{array}{c}\text { Dias } \\
\text { acumulaclon }\end{array}$} & \multicolumn{6}{|c|}{$\begin{array}{l}\text { Valor de retome estlmado de la preclplaclón mídma acumulada en los dilas Indicedos } \\
\text { pare un pertodo de: }\end{array}$} \\
\hline & & 2 afios & 5 attos & 10 afios & 25 afios & 50 afios & 100 ะโ์ \\
\hline \multirow{3}{*}{ Gran Canaria } & 1 & 27,4 & 45,6 & 57,6 & 72.7 & 64,0 & 95,2 \\
\hline & 2 & 35,7 & 59,3 & 75,0 & 94,7 & 109,4 & 123,9 \\
\hline & 5 & 40,9 & 67,5 & 85,1 & 107,3 & 123.8 & 140,2 \\
\hline
\end{tabular}

Tabla 7: Valores más altos de precipitación diaria (09-09 UTC) en el archipiélago de Canarias. (Fuente: [MESTRE y RODRIGUEZ 2015] )

Se observa que los años 50 fueron especialmente lluviosos y catastróficos, y que incluso en las zonas climáticamente secas se alcanzan acumulaciones elevadas, por encima de los $150 \mathrm{~mm}$ en un día.

Los estudios publicados sobre precipitaciones en Canarias señalan que la mayor intensidad horaria se da, sobre todo, en las vertientes orientales a altitudes medias.

Se tiene noticia de grandes desastres ocasionados por episodios de lluvias torrenciales en Canarias con muchas víctimas y graves daños sobre infraestructuras.

Entre los episodios históricos más catastróficos destacan el aluvión de 1645 que tuvo efectos devastadores con cientos de víctimas [ROMERO y YANES 1995] y el temporal de noviembre de 1826 en todo el archipiélago -sobre todo en Tenerife-, cuyas precipitaciones originaron la muerte de centenares de personas, estimadas sólo en el Valle de la Orotava, en más de 200 [QUIRANTES et al. 1993]. Este aluvión, con innumerables referencias históricas, ha sido con toda probabilidad el fenómeno meteorológico adverso de peores consecuencias para las islas. Pero no son los únicos, desde 1950 se pueden identificar más de cincuenta desastres asociados a precipitaciones torrenciales en todo el archipiélago.

En Gran Canaria podemos listar los siguientes registros diarios máximos:

\begin{tabular}{|l|l|c|c|}
\hline \multicolumn{1}{|r|}{ Id } & \multicolumn{1}{|c|}{ Nombre estación } & $\begin{array}{r}\text { Pcp } \\
\mathrm{mm}\end{array}$ & Fecha \\
\hline C652O & San Mateo-Los Llanos de Ana López & 278,2 & $4 / 12 / 1991$ \\
\hline C652O & San Mateo-Los Llanos de Ana López & 270,3 & $24 / 11 / 1989$ \\
\hline C656O & San Mateo- El Draguillo & 246,0 & $12 / 02 / 1971$ \\
\hline C635F & San Bartolomé de Tirajana-Casco & 242,5 & $6 / 12 / 1991$ \\
\hline C641I & Valsequillo-Cuevas Blancas & 235,7 & $6 / 12 / 1991$ \\
\hline C657K & Santa Brígida-Monte Coello & 231,0 & $28 / 01 / 2007$ \\
\hline C653O & San Mateo-Cueva Grande & 224,0 & $2 / 02 / 2010$ \\
\hline C658N & Las Palmas de G.C.-Jardín Canario II & 223,0 & $28 / 01 / 2007$ \\
\hline C658N & Las Palmas de G.C.-Jardín Canario II & 220,9 & $30 / 01 / 2011$ \\
\hline C658J & Las Palmas de G.C.-Jardín Canario I & 220,5 & $31 / 01 / 2011$ \\
\hline
\end{tabular}

Tabla 8: Top 10 de precipitación máxima diaria en Gran Canaria. (Fuente: AEMET)] 


\begin{tabular}{|c|c|c|c|}
\hline \multicolumn{4}{|c|}{$\begin{array}{l}\text { VALORES MÁs ALTOS DE LA PRECIPITACIÓN diaRIA (09-09 UTC) } \\
\text { MAIORES VALORES DA QUANTIDADE DE PRECIPITAÇO DIÁRIA (09-09 UTC) } \\
\text { HIGHEST VALUES FOR DAILY PRECIPITATION (09-09 UTC) }\end{array}$} \\
\hline \multirow{2}{*}{$\begin{array}{l}\text { Archipiélago } \\
\text { Arquipélago } \\
\text { Archipelago }\end{array}$} & \multirow{2}{*}{$\begin{array}{l}\text { Lugar } \\
\text { Local } \\
\text { Location }\end{array}$} & \multicolumn{2}{|c|}{$\begin{array}{l}\text { Precipitación máxima diaria }(1971-2000) \\
\text { Precipitaçảo máxima diária (1971-2000) } \\
\text { Maximum daily rainfall }(1971-2000)\end{array}$} \\
\hline & & $(\mathbf{m m})$ & Fecha/Data/Date \\
\hline \multirow{5}{*}{ CANARIAS } & San Andrés/El Hierro & 590,0 & $24 / 02 / 1988$ \\
\hline & Sauces-Espigón Atravesado/La Palma & 450,0 & $27 / 02 / 1988$ \\
\hline & Caldera de Taburiente-Taburiente/La Palma & 399,3 & $10 / 02 / 1978$ \\
\hline & Vilaflor/Tenerife & 358,9 & $11 / 04 / 1977$ \\
\hline & Mazo-Tigalate/La Palma & 350,0 & $17 / 12 / 1991$ \\
\hline
\end{tabular}

Tabla 9: Valores más altos de precipitación diaria (09-09 UTC) en el archipiélago de Canarias. (Fuente: [AEMET, 2])

A partir de los datos anteriores queda constatado que todos los eventos se han producido entre septiembre y abril, siendo especialmente numerosos de noviembre a febrero.

\subsubsection{Situaciones de precipitaciones extremas}

En este apartado se describirá uno de los episodios más singulares de precipitaciones intensas que afectó a la isla de Gran Canaria. Nos referimos a la situación del 6 de diciembre de 1991. En el siguiente mapa, presión al nivel del mar y temperatura en $850 \mathrm{hPa}$, se observa una profunda borrasca fría atlántica con $992 \mathrm{hPa}$ en su centro, induciendo viento del Suroeste sobre Gran Canaria.

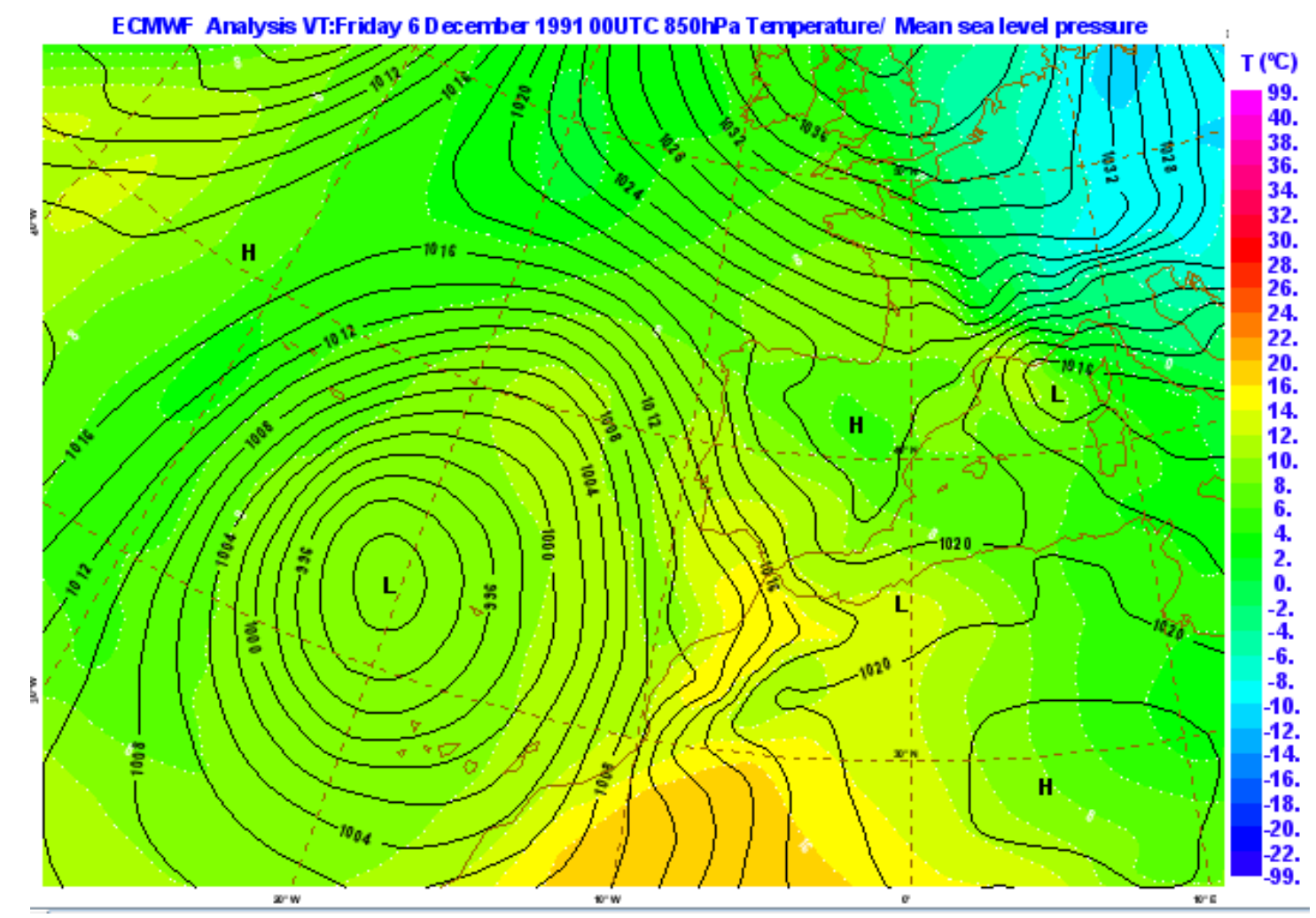

Figura 34: Análisis de superficie, 00 horas del 6 de diciembre de 1991. (Fuente: AEMET) 
En el mapa de altura del geopotencial de $500 \mathrm{hPa}$ y de temperatura al mismo nivel, se aprecia el núcleo frío centrado al oeste de Madeira, asociado a la baja en superficie, generando flujo del Suroeste sobre Gran Canaria a este nivel.

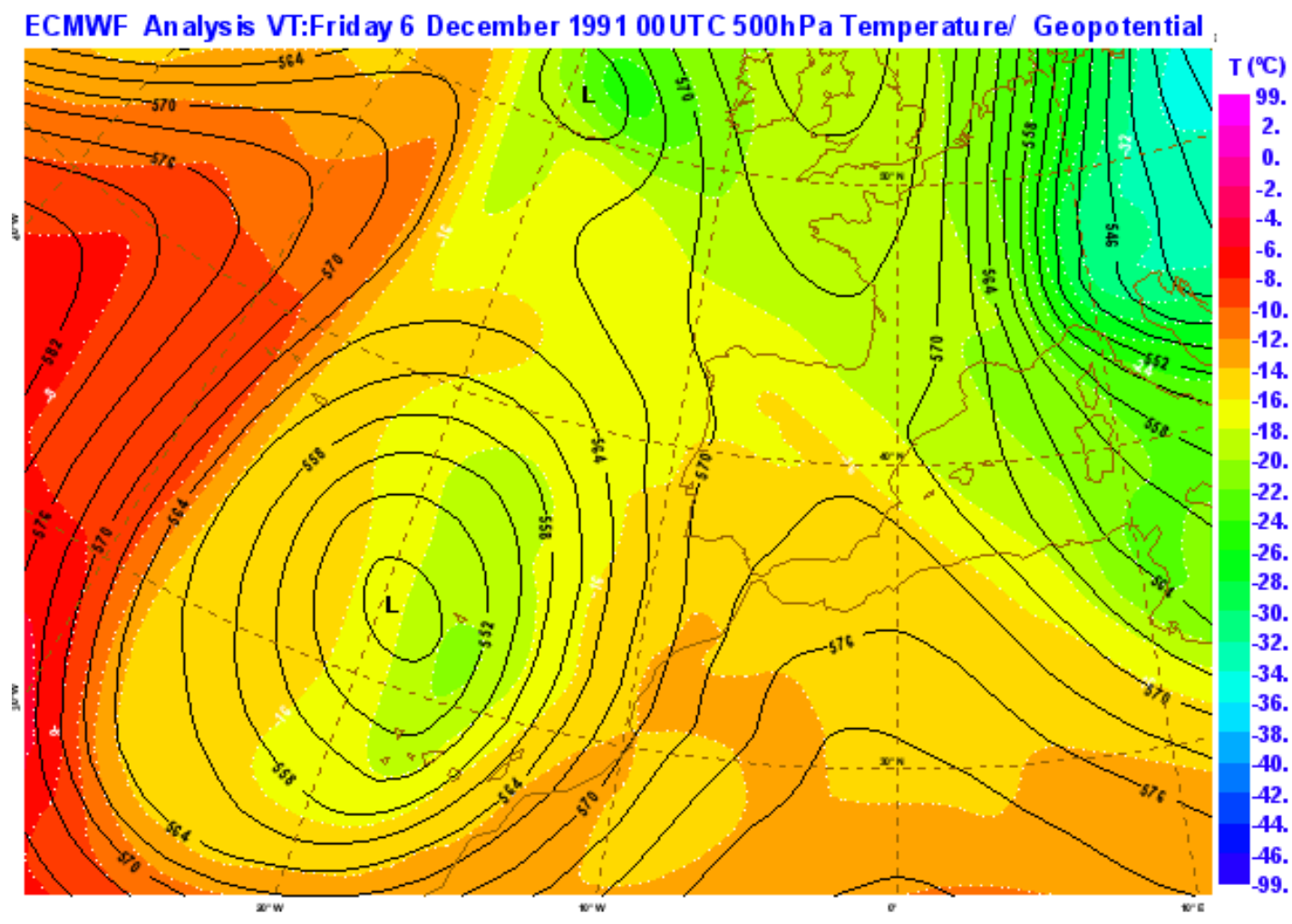

Figura 35: Análisis de 500 hPa, 00 horas del 6 de diciembre de 1991. (Fuente: AEMET)

A continuación se muestran los registros de precipitación acumuladas en 24 horas durante el día 6 de diciembre de 1991. Destacan los 242,5 mm acumulados en San Bartolomé de Tirajana. 


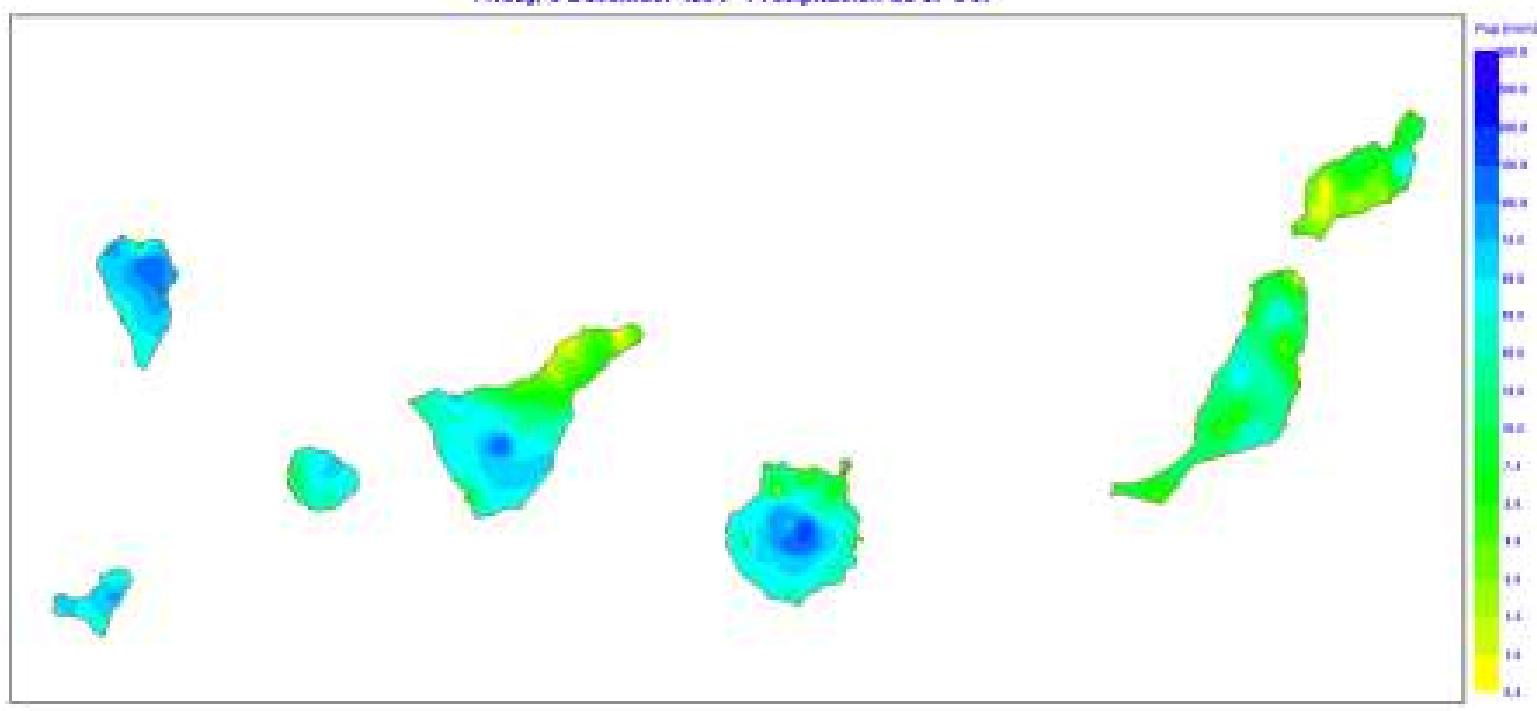

Figura 36: Precipitaciones acumuladas de 07 horas del día 6 de diciembre a 07 horas del 7 de diciembre de 1991. (Fuente: AEMET)

\section{FENÓMENO TEMPERATURAS EXTREMAS Y OLAS DE CALOR \\ 6.1 Descripción de las altas temperaturas y las olas de calor como fenómenos adversos}

En este apartado se toma como base el trabajo de César Rodríguez Ballesteros del Área de Climatología y Aplicaciones Operativas de AEMET [RODRIGUEZ 2017].

Se entiende por ola de calor un episodio de altas temperaturas, que se mantiene a lo largo de varios días, que afecta a una parte importante de nuestro territorio. Dentro de la diversidad de definiciones, en AEMET se utiliza la siguiente:

Se considera 'Ola de calor' un episodio de al menos tres días consecutivos, en que como mínimo el $10 \%$ de las estaciones consideradas registran máximas por encima del percentil del $\mathbf{9 5 \%}$ de su serie de temperaturas máximas diarias de los meses de julio y agosto del periodo 1971-2000.

Las estaciones que se seleccionan tienen que cumplir una serie de requisitos: funcionar en la actualidad, disponer de una serie suficientemente larga para poder calcular sus percentiles con precisión y distribuirse uniformemente sobre el territorio. Con estas premisas en Canarias AEMET tiene 6 estaciones (137 en toda España).

A continuación, se calcula para cada estación una 'temperatura umbral', que de acuerdo al criterio establecido, es el percentil del $95 \%$ de su serie de temperaturas máximas diarias de los meses de julio y agosto del periodo 1971-2000. Los mapas de las figuras 1 y 2 representan la distribución de temperatura resultante y la ubicación de las estaciones. 


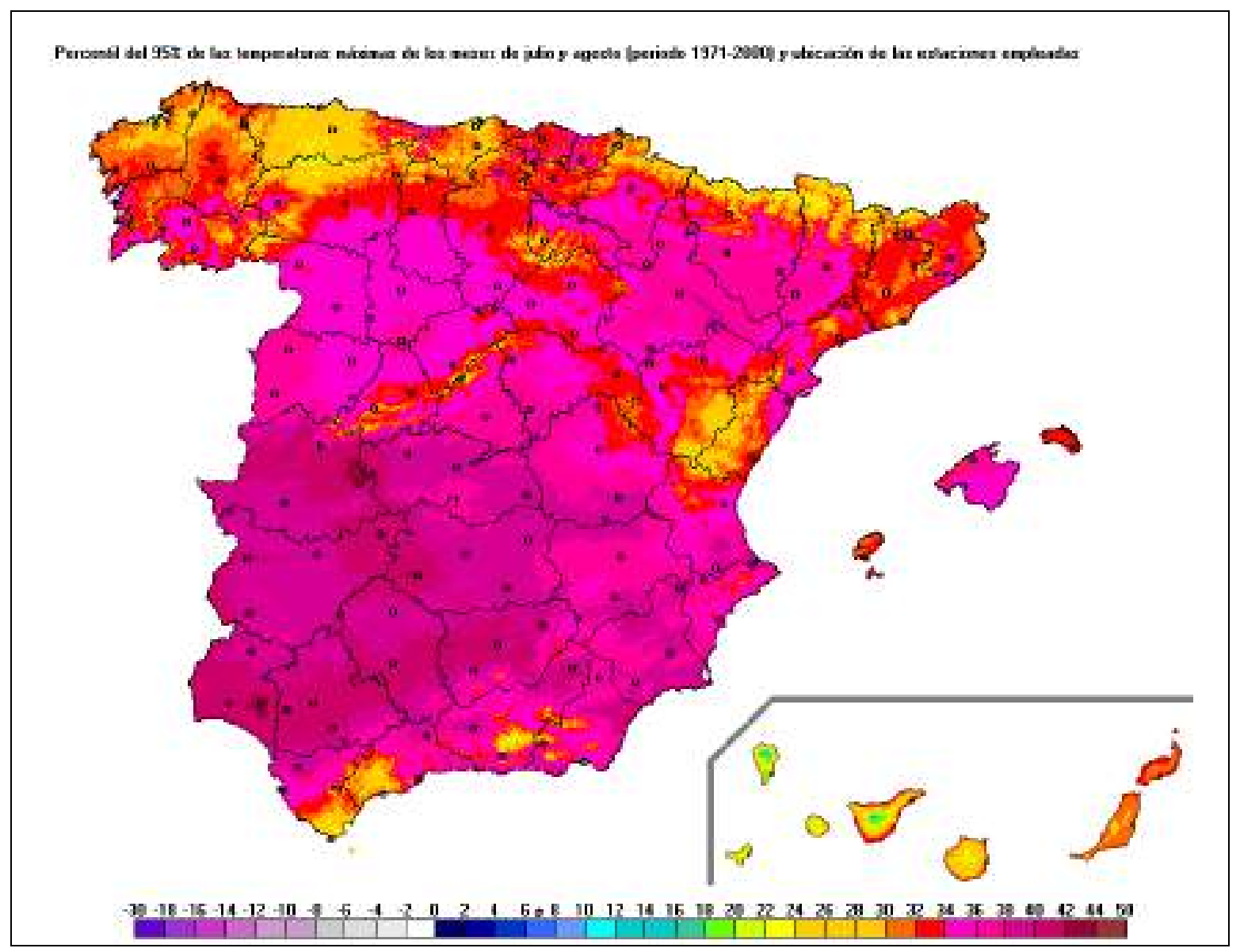

Figura 37: Percentil del 95\% de las temperaturas máximas de los meses de julio y agosto (periodo de 1971-2000) y ubicación de las estaciones empleadas. (Fuente: [RODRIGUEZ 2017]) 


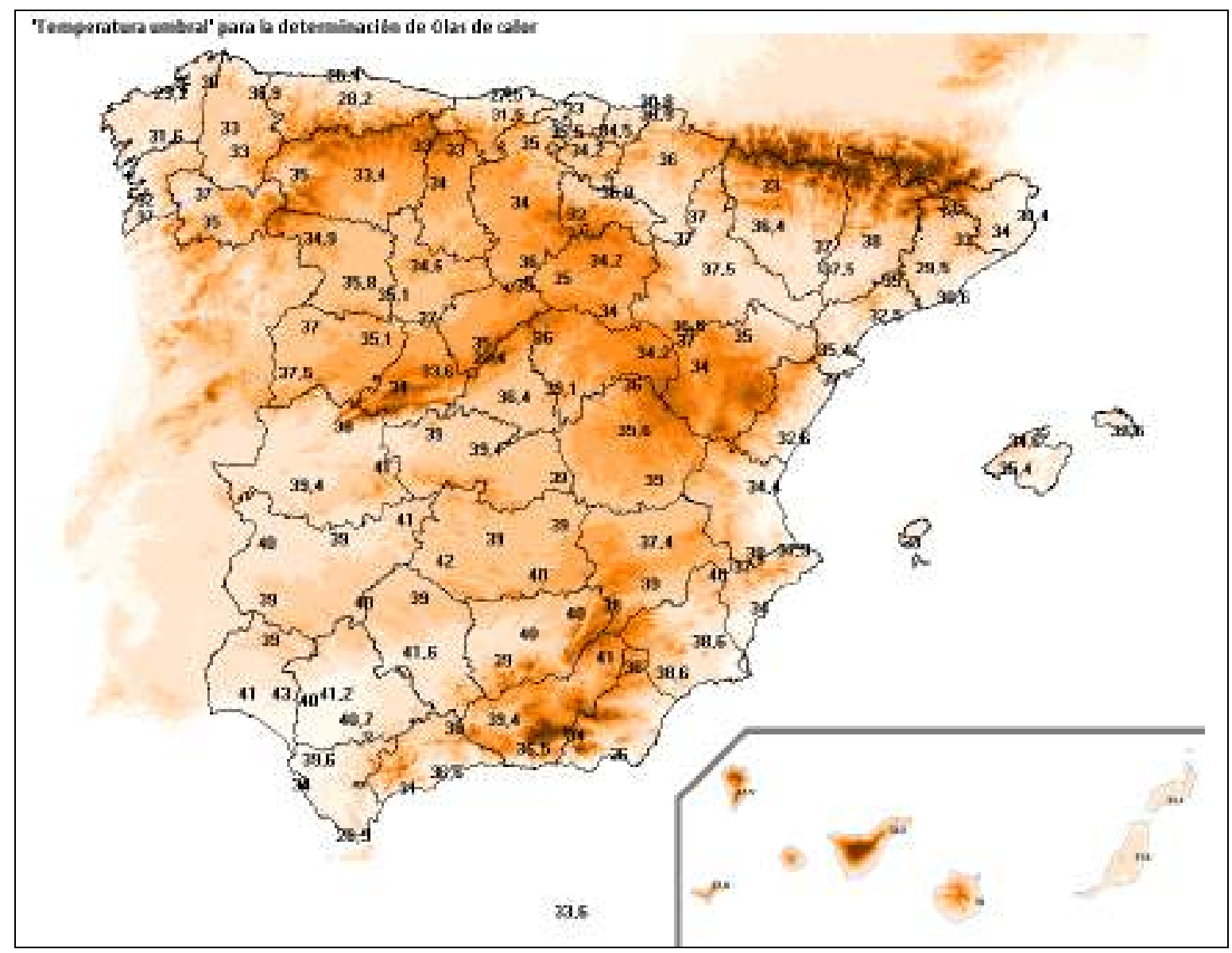

Figura 38: "Temperatura umbral" para la determinación de Olas de calor.

(Fuente: [RODRIGUEZ 2017])

A continuación se localizan los episodios, que según los criterios fijados, serán considerados 'Olas de calor', en tres etapas:

Primera etapa: Se obtienen para cada una de las estaciones seleccionadas, sus 'Episodios cálidos', entendiendo como tales, episodios de al menos tres días consecutivos con temperatura máxima que iguala o supera su 'temperatura umbral'. Dado que es bastante improbable que una 'Ola de calor' se presente fuera de los meses veraniegos, en este trabajo sólo se estudia el periodo comprendido entre el 1 de junio y el 30 de septiembre.

Segunda etapa: Se determinan los 'días cálidos', considerando como tales a aquellos en que al menos el $10 \%$ de las estaciones consideradas están dentro de uno de los 'Episodios cálidos' localizados en la primera etapa.

Tercera etapa: Finalmente se localizan las 'Olas de calor', que son todos aquellos episodios de tres o más 'días cálidos' consecutivos. Cuando dos 'Olas de calor' están separadas por tan sólo un día, se consideran una única ola. 
En el caso de los datos de Canarias se han procesado de manera independiente, pero con una variación respecto al criterio general, ya que al utilizarse solamente seis estaciones, bastaría con que uno de los observatorios registrase un 'Episodio cálido' para que se considerase 'Ola de calor' en el archipiélago; por ello, en Canarias, se exige que sean al menos dos las estaciones que registren un 'Episodio cálido' para que constituya una 'Ola de calor'.

Los tres factores que determinan la intensidad de una 'Ola de calor' son: las temperaturas alcanzadas durante la misma, su duración y el territorio afectado, siendo necesario cuantificar estos aspectos para cada una de las Olas, si se quiere valorarlas y compararlas.

Para estimar el territorio afectado durante una 'Ola de calor', se ha determinado el día que más provincias la registraron, asignando a la Ola dicho máximo. Se considera que un día determinado una provincia está viviendo una 'Ola de calor' cuando al menos uno de los Observatorios estudiados está dentro de un 'Episodio cálido', es decir, no es suficiente con que supere la 'temperatura umbral' de manera puntual.

Para determinar la magnitud de las temperaturas, en primer lugar se han determinado las estaciones con algún día de 'Episodio cálido' durante la 'Ola de calor', y se ha tomado la media de las temperaturas máximas de estas estaciones para el día más cálido como dato representativo; a esta temperatura se la ha denominado 'temperatura máxima de la ola'. También se ha calculado para cada estación la Anomalía máxima de las temperaturas registradas durante la Ola con respecto a su 'temperatura umbral', asignando como valor representativo para la Ola la media de dichas Anomalías; a este valor se le denomina 'anomalía de la ola'

Así pues, los cuatro valores elegidos para caracterizar una 'Ola de calor' son:

- Su duración.

- El número de provincias afectadas.

- La 'temperatura máxima de la ola'.

- La 'anomalía de la ola'. 


\subsection{Episodios de temperaturas altas y olas de calor, análisis histórico. Principales zonas afectadas e impactos habituales.}

Los resultados para Canarias se representan en el siguiente cuadro (1975-2017):

\begin{tabular}{|c|c|c|c|c|c|c|}
\hline \multicolumn{7}{|c|}{ ‘Olas de calor' en Canarias desde 1975} \\
\hline Año & Inicio & Fin & Duración & $\begin{array}{l}\text { Anomalía de } \\
\text { la ola }\end{array}$ & T. Máxima de la ola & \begin{tabular}{|l} 
Provincias \\
afectadas
\end{tabular} \\
\hline 2015 & $10 / 08 / 2015$ & $13 / 08 / 2015$ & 4 & 2,7 & 30,7 & 2 \\
\hline 2015 & $22 / 09 / 2015$ & $25 / 09 / 2015$ & 4 & 1,2 & 28,9 & 1 \\
\hline 2013 & $20 / 08 / 2013$ & $23 / 08 / 2013$ & 4 & 2,4 & 32,7 & 2 \\
\hline 2012 & $25 / 06 / 2012$ & $27 / 06 / 2012$ & 3 & 7,1 & 39,0 & 1 \\
\hline 2012 & $17 / 07 / 2012$ & $23 / 07 / 2012$ & 7 & 4,2 & 33,5 & 2 \\
\hline 2012 & 19/08/2012 & $22 / 08 / 2012$ & 4 & 2,9 & 31,9 & 2 \\
\hline 2012 & $20 / 09 / 2012$ & $26 / 09 / 2012$ & 7 & 1,7 & 29,4 & 1 \\
\hline 2011 & $20 / 06 / 2011$ & $23 / 06 / 2011$ & 4 & 5,0 & 37,4 & 1 \\
\hline 2010 & $27 / 08 / 2010$ & $31 / 08 / 2010$ & 5 & 3,9 & 33,5 & 2 \\
\hline 2009 & $24 / 07 / 2009$ & 01/08/2009 & 9 & 6,0 & 36,5 & 2 \\
\hline 2007 & $28 / 07 / 2007$ & $31 / 07 / 2007$ & 4 & 6,8 & 37,4 & 2 \\
\hline 2006 & 03/09/2006 & 07/09/2006 & 5 & 5,7 & 35,3 & 2 \\
\hline 2005 & $20 / 07 / 2005$ & $22 / 07 / 2005$ & 3 & 2,9 & 32,6 & 2 \\
\hline 2005 & $04 / 09 / 2005$ & 08/09/2005 & 5 & 5,4 & 34,8 & 2 \\
\hline 2004 & $23 / 07 / 2004$ & $29 / 07 / 2004$ & 7 & 6,9 & 36,2 & 2 \\
\hline 2004 & $04 / 08 / 2004$ & 06/08/2004 & 3 & 0,9 & 30,4 & 2 \\
\hline 2004 & $17 / 08 / 2004$ & $21 / 08 / 2004$ & 5 & 2,0 & 29,6 & 1 \\
\hline 2004 & $26 / 08 / 2004$ & $31 / 08 / 2004$ & 6 & 5,0 & 34,9 & 2 \\
\hline 2003 & $12 / 08 / 2003$ & $14 / 08 / 2003$ & 3 & 1,8 & 29,4 & 1 \\
\hline 2003 & $13 / 09 / 2003$ & $20 / 09 / 2003$ & 8 & 1,6 & 29,3 & 1 \\
\hline 2002 & $15 / 09 / 2002$ & $18 / 09 / 2002$ & 4 & 1,5 & 29,0 & 1 \\
\hline 1999 & 05/08/1999 & 07/08/1999 & 3 & 0,8 & 28,4 & 1 \\
\hline 1999 & $27 / 08 / 1999$ & 29/08/1999 & 3 & 3,8 & 33,1 & 2 \\
\hline 1998 & 05/08/1998 & 07/08/1998 & 3 & 3,2 & 34,9 & 2 \\
\hline 1990 & 05/08/1990 & $11 / 08 / 1990$ & 7 & 5,9 & 35,4 & 2 \\
\hline 1990 & $26 / 08 / 1990$ & 28/08/1990 & 3 & 4,8 & 35,9 & 1 \\
\hline 1987 & 07/09/1987 & $16 / 09 / 1987$ & 10 & 6,7 & 35,4 & 2 \\
\hline 1986 & 05/09/1986 & $07 / 09 / 1986$ & 3 & 4,9 & 34,4 & 2 \\
\hline 1985 & $03 / 09 / 1985$ & $05 / 09 / 1985$ & 3 & 3,7 & 35,1 & 1 \\
\hline 1984 & $17 / 07 / 1984$ & $19 / 07 / 1984$ & 3 & 3,2 & 35,3 & 2 \\
\hline 1983 & 05/09/1983 & 07/09/1983 & 3 & 6,1 & 36,1 & 2 \\
\hline 1983 & $25 / 09 / 1983$ & $27 / 09 / 1983$ & 3 & 4,9 & 35,0 & 2 \\
\hline 1982 & $24 / 07 / 1982$ & $27 / 07 / 1982$ & 4 & 5,8 & 36,7 & 2 \\
\hline 1980 & 06/08/1980 & 09/08/1980 & 4 & 4,3 & 34,7 & 2 \\
\hline 1978 & $11 / 09 / 1978$ & $13 / 09 / 1978$ & 3 & 5,6 & 33,7 & 2 \\
\hline 1976 & 05/08/1976 & $15 / 08 / 1976$ & 11 & 6,1 & 35,3 & 2 \\
\hline 1976 & $28 / 08 / 1976$ & $10 / 09 / 1976$ & 14 & 2,3 & 30,9 & 1 \\
\hline
\end{tabular}

Tabla 10: “Olas de calor en Canarias desde 1975. (Fuente: [RODRIGUEZ 2017]) 
Se muestran a continuación una serie de gráficos comparativos entre las diferentes 'Olas de calor':

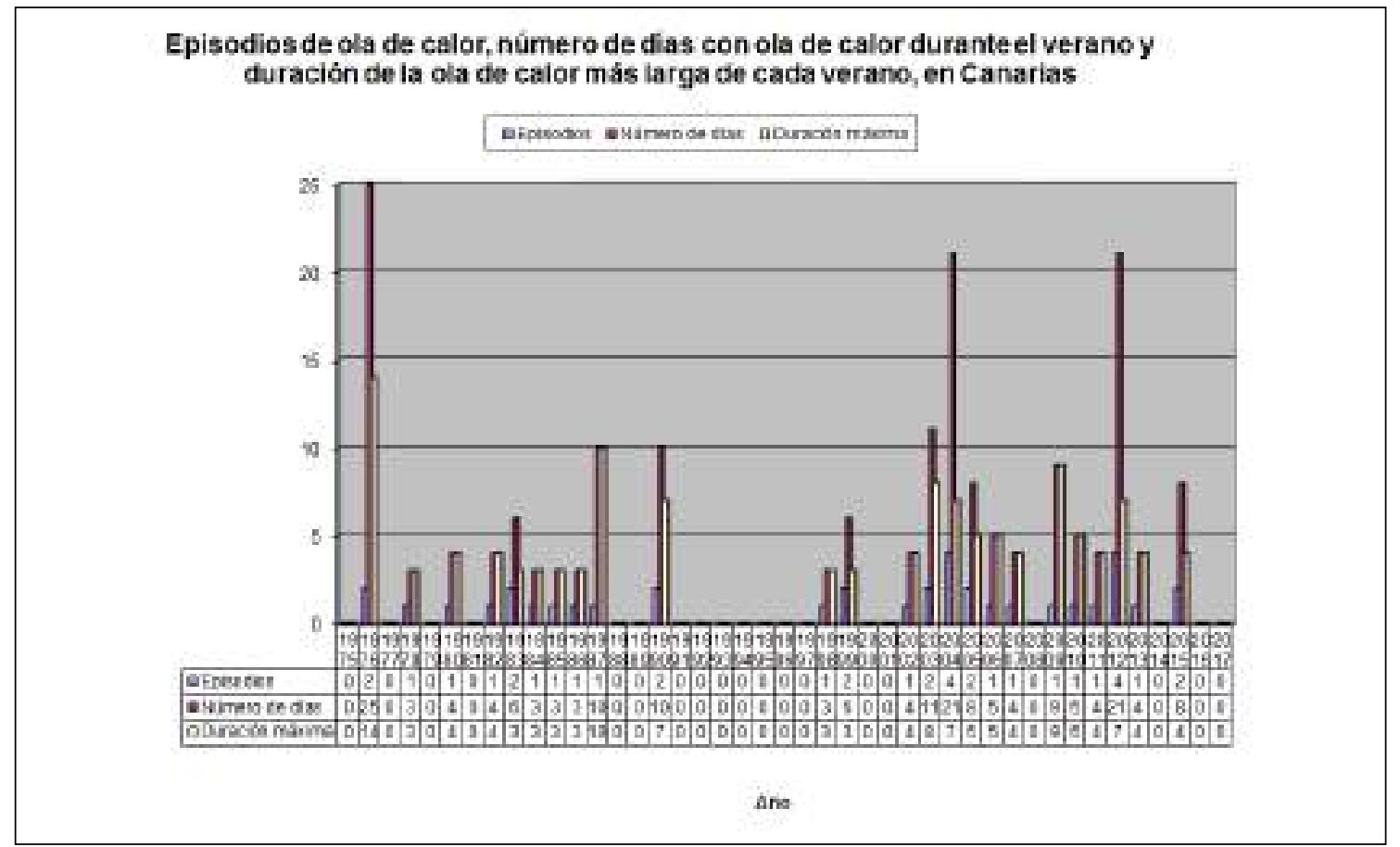

Figura 39: Episodios de "Olas de calor". (Fuente: [RODRIGUEZ 2017])

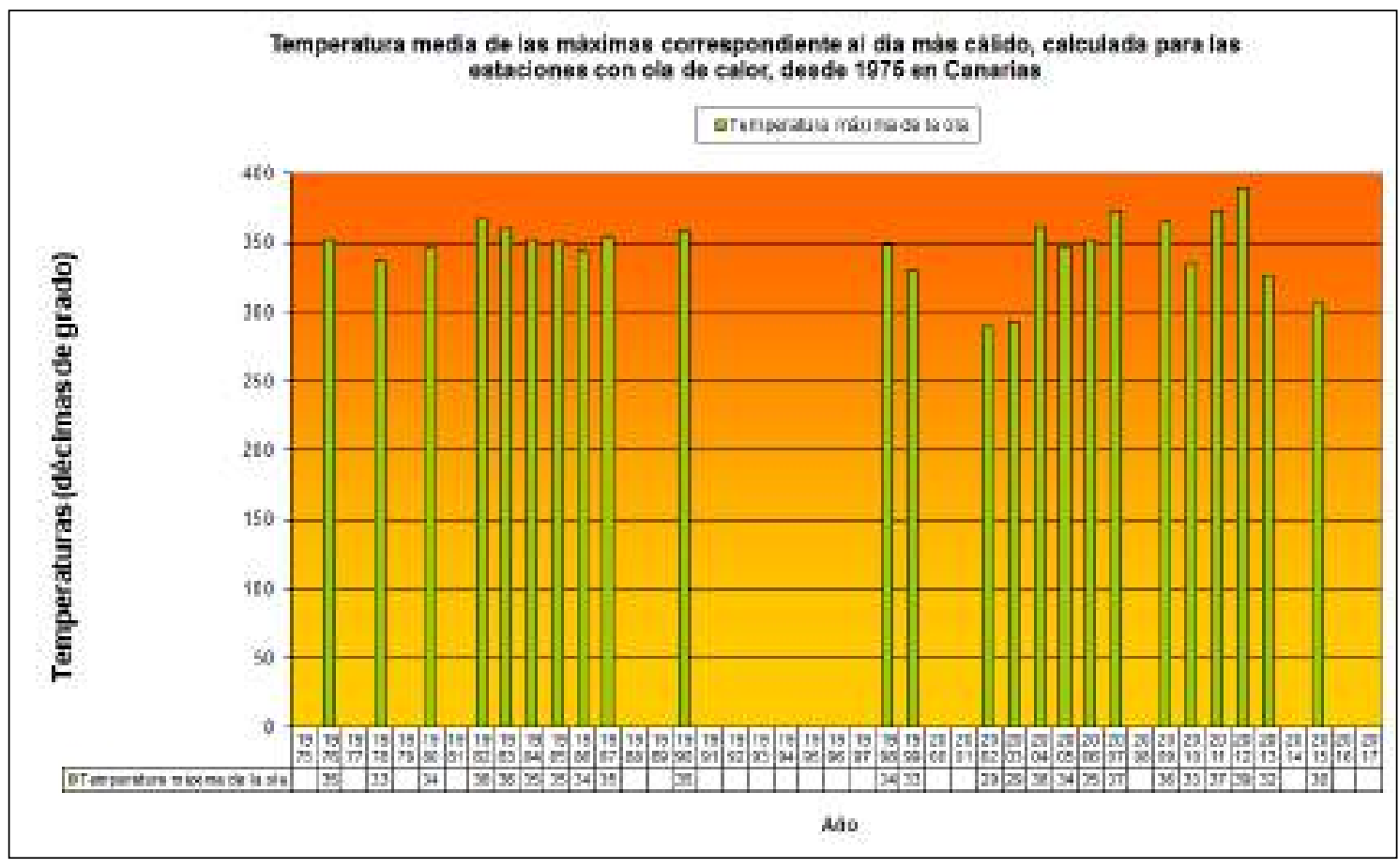

Figura 40: Temperatura máxima de las "Olas de calor". (Fuente: [RODRIGUEZ 2017]) 
Los gráficos de la figura 39 representan para cada año el número de episodios de 'Ola de calor', los días que totalizan, y la duración de la 'Ola de calor' más larga en Canarias. Destaca 1976, tanto por el número total de días con 'Ola de calor', 25, como por la Ola más larga, con 14 días de duración.

La figura 40 representa la 'temperatura máxima de la ola' más alta para cada verano, desde 1975. En Canarias, la 'temperatura máxima de la ola' más elevada, $39,0^{\circ} \mathrm{C}$, se alcanza el año 2012 , concretamente el 27 de junio; en segundo lugar se sitúan los $37,4{ }^{\circ} \mathrm{C}$ de los días 22 de junio de 2011 y 30 de julio de 2007.

Otra 'Ola de calor' muy intensa vivida en el archipiélago Canario, fue la acontecida entre los días 23 y 29 de julio de 2004, que abarcó a las dos provincias, dándose la circunstancia de que entre los días 25 y 28 afectó a las seis estaciones utilizadas en el estudio. El día más cálido resultó el 25 de julio, al que corresponde el mapa de la figura 41, con una 'temperatura máxima de la ola' de $36,2{ }^{\circ} \mathrm{C}$. La 'anomalía de la ola' es de $6,9{ }^{\circ} \mathrm{C}$, superada tan solo por los $7,1^{\circ} \mathrm{C}$ de la registrada entre el 25 y 27 de junio de 2012, si bien esta última afectó únicamente a la provincia de Las Palmas y duró tan solo tres días. Entre las temperaturas máximas alcanzadas estos días entre las estaciones de la red principal cabe mencionar los $42,9^{\circ} \mathrm{C}$ de Lanzarote 'Aeropuerto', los 40,0 ' $\mathrm{C}$ de La Gomera 'Aeropuerto', los $39,0^{\circ} \mathrm{C}$ de Santa Cruz de Tenerife, los $37,7^{\circ} \mathrm{C}$ de Gran Canaria 'Aeropuerto', todas ellas correspondientes al día 25 , los $42,6{ }^{\circ} \mathrm{C}$ de Tenerife 'Sur' el día 26, los $37,7^{\circ} \mathrm{C}$ del día 24 en Fuerteventura 'Aeropuerto', los $37,2{ }^{\circ} \mathrm{C}$ del día 26 en La Palma 'Aeropuerto' y los $31,2{ }^{\circ} \mathrm{C}$ también del día 26 en El Hierro 'Aeropuerto'. Izaña, a 2371 metros de altitud alcanzó los $25,9{ }^{\circ} \mathrm{C}$ el día 25 .

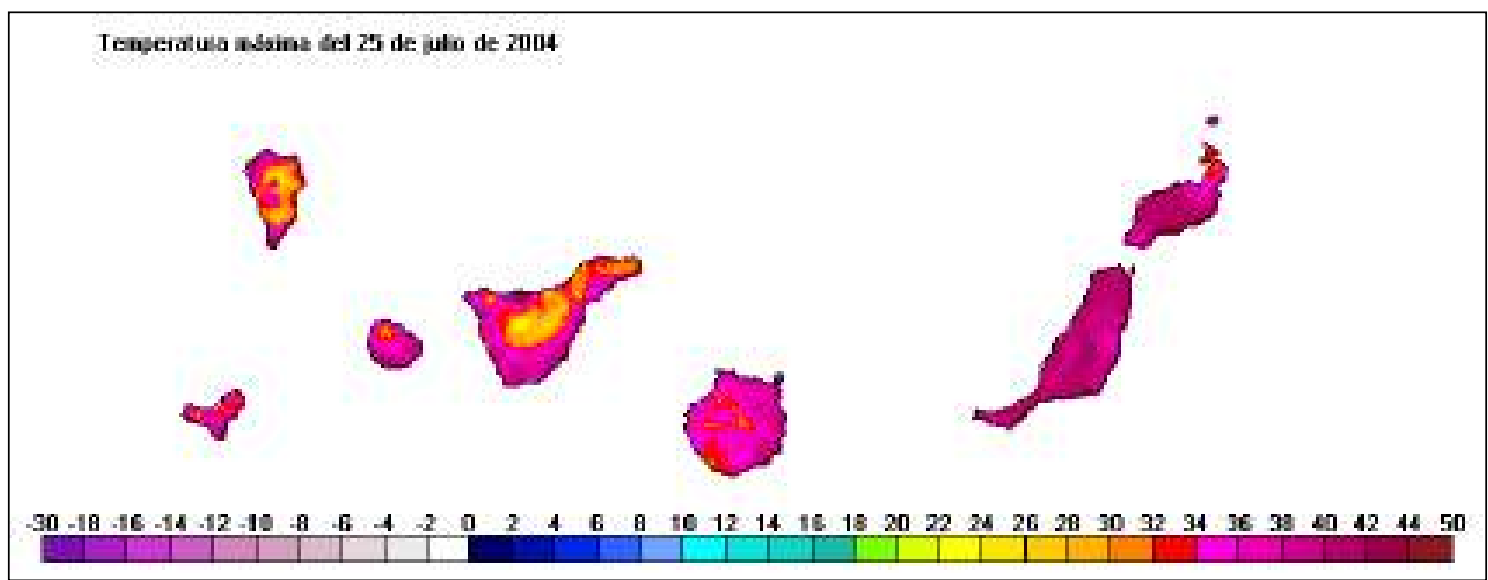

Figura 41: Temperatura máxima del 25 de julio de 2004. (Fuente: [RODRIGUEZ 2017])

\subsection{Patrones atmosféricos relacionados con episodios de temperaturas altas y olas de calor}

Las estructuras de la circulación atmosférica que dan lugar a olas de calor incluyen las situaciones de intrusiones saharianas que se describen en el próximo apartado. 


\section{FENÓMENO INTRUSIONES DE POLVO SAHARIANO}

En este apartado hay que destacar que AEMET tiene un papel fundamental a nivel mundial en las actividades relacionadas con el polvo atmosférico. De hecho, el Consejo Ejecutivo de la Organización Mundial de Meteorología designo al consorcio formado por AEMET y el Barcelona Supercomputing Center (BSC-CNS) para crear en Barcelona el primer Centro Meteorológico Regional Especializado, el cual está especializado en Pronósticos de Polvo y Arena. Para ello, AEMET dispone de dos modelos operativos de predicción de polvo:

\section{- $\quad$ BSC-DREAM8b v2.0}

- NMMB/BSC-Dust

Información adicional sobre estos modelos, así como pronósticos de polvo se pueden encontrar en www.dust.aemet.es

Además se realizan productos multimodelos basados en un sistema de predicción por ensemble que utiliza doce modelos (los dos modelos operativos de AEMET y diez que provenientes de distintos organismos como ECMWF,NCEP, NASA , etc..)

Información adicional sobre estos productos se pueden encontrar en www.sdswas.aemet.es

El centro (Barcelona Dust Forecast Center) comenzó sus operaciones en marzo de 2014, genera y distribuye predicciones operativas para el Norte de África, Oriente Medio y Europa.

Además, en Canarias AEMET cuenta con el Centro de Investigación Atmosférica de Izaña (CIAI) que está integrado en la Dirección de Planificación, Estrategia y Desarrollo Comercial de la propia Agencia.

El CIAI gestiona el Observatorio Atmosférico de Izaña (IZO), que es un observatorio de alta montaña en la isla de Tenerife, así como el Observatorio de Santa Cruz de Tenerife (SCO), a nivel del mar, y complementario del anterior, para la investigación de la calidad del aire urbana de fondo en la ciudad de Santa Cruz de Tenerife. La sede del CIAI se encuentra en Santa Cruz de Tenerife (capital de la isla).

El CIAI lleva a cabo la vigilancia e investigación de los componentes atmosféricos capaces de propiciar un cambio en el clima de la Tierra (gases de efecto invernadero y aerosoles) y un deterioro de la capa de ozono mundial, así como el de aquellos componentes que juegan un papel fundamental en la calidad del aire, tanto a escala local como global.

El CIAl es una Unidad Asociada Consejo Superior de Investigaciones Científicas (CSIC) a través del Instituto de Diagnóstico Ambiental y Estudios del Agua (IDAEA), bajo la 
denominación de "Grupo para el Estudio de la Contaminación Atmosférica". Su misión es desarrollar investigación sobre la calidad del aire, y específicamente sobre los aerosoles atmosféricos.

El CIAI contribuye al sistema de Vigilancia Atmosférica Global (VAG) de la Organización Mundial de la Meteorología (OMM) y a programas de otras redes asociadas a la VAG con el Observatorio Atmosférico de Izaña (IZO) y al Programa GURME con el Observatorio de Santa Cruz de Tenerife (SCO).

IZO también está integrado en el programa de la Red para la Detección del Cambio en la Composición Atmosférica (NDACC). NDACC está constituido por un conjunto de estaciones que utilizan exclusivamente instrumentos de teledetección, muy sofisticados y de muy alta calidad, para la observación y comprensión del estado físico y químico de la troposfera y la estratosfera. Las medidas están focalizadas sobre el ozono y aquellos otros componentes químicos y parámetros relacionados con él. NDACC es un componente clave de los esfuerzos internacionales en la investigación atmosférica y ha sido promovido por agencias científicas nacionales e internacionales incluyendo la Comisión Internacional para el Ozono, el Programa de Naciones Unidas para el Medio Ambiente (UNEP) y la Organización Meteorológica Mundial (OMM).

\subsection{Descripción de las intrusiones de polvo sahariano como fenómeno adverso.}

Se conoce como material particulado atmosférico (también conocido como aerosol atmosférico), a todas aquellas partículas sólidas y/o líquidas (excepto partículas de agua) que puedan estar presentes en la atmósfera, ya sean de origen natural o antropogénico.

Las intrusiones de masas de aire africano son las responsables de aumentar el nivel de material particulado mineral en zonas que pueden estar alejadas del continente fuente de este material.

El polvo mineral del desierto es el segundo más importante contribuyente al aerosol atmosférico global después del aerosol marino. [HUNEEUS et al. 2013]

Aunque existen otras zonas áridas del planeta que son fuentes de material particulado, son las africanas las que más material mineral aportan al total del material particulado existente en la atmósfera de nuestro planeta, con un rango de emisión entre 400 y 2200 Tg/año [GINOUX et al. 2001] [GINOUX et al. 2012] [GOUDIE y MIDDLETON, 2001].

El polvo tiene un importante impacto en el clima [FOLTZ y McPHADEN 2008] [PROSPERO y LAMB 2003] [TEGEN y TORRES 2005], calidad del aire [PROSPERO 1999] [PROSPERO et al. 2014] y la salud [DÍAZ et al. 2012] [KARANOSIOU et al. 2012] [PROSPERO y LAMB 2003]. La capa de aire sahariana (SAL: Saharan Air Layer) usualmente muy cargada con polvo mineral, alcanza regiones muy lejanas como el Caribe y América. 


\subsection{Particularidades locales}

En el caso de las islas Canarias es importante conocer los procesos que dan lugar transporte natural de material particulado desde zonas áridas de África, que habitualmente causan episodios de alta concentración de polvo en suspensión, (conocidos generalmente como calima), y que pueden presentar efectos en la salud de las personas, en la agricultura y en las condiciones de visibilidad. [ALONSO 2007].

Los episodios de intrusiones saharianas acaecidos en Canarias han sido documentados desde 1883, año del que data una muestra de "Iluvia de tierra en la noche de 22 de febrero de 1883 en Tenerife". Sin embargo Darwin en 1832, a su llegada al puerto de Santa Cruz de Tenerife, describe una situación de intensa calima; otra referencia ampliamente descrita es la de febrero de 1898 y la presencia de grandes cantidades de polvo en suspensión aparece reflejada también en multitud de textos antiguos. Este tipo de fenómenos atmosféricos son, por tanto, muy recurrentes en las islas (enero de 1983, febrero de 1994, marzo de1995, etc.), aunque los eventos de mayor grado sólo se producen de una a tres veces anualmente, constituyendo una amenaza más en el clima canario. [DORTA, 2007] .

En el cuadro siguiente se muestra algunas de las entradas masivas de polvo sahariano de mayor intensidad en los últimos años en Gran Canaria:

\begin{tabular}{|l|l|}
\hline \multicolumn{1}{|c|}{ Fecha } & \multicolumn{1}{c|}{ Cantidad máxima diaria $\left(\mathbf{g} / \mathbf{m}^{\mathbf{3}} \mathbf{~}\right.$} \\
\hline Febrero 1998 & 1312,8 \\
\hline Junio 1998 & 416,3 \\
\hline Octubre 1998 & 1143,4 \\
\hline Febrero 1999 & 1003,8 \\
\hline Diciembre 2001 & 510,5 \\
\hline Enero 2002 & 1862,0 \\
\hline Abril 2002 & 474,8 \\
\hline Octubre 2002 & 401,9 \\
\hline Marzo 2003 & $2020,4^{*}$ \\
\hline Febrero 2004 & $2295,5^{*}$ \\
\hline Agosto 2004 & $467,3^{*}$ \\
\hline
\end{tabular}

Tabla 11: Cuadro extraído y adaptado del artículo catálogo de riesgos climáticos y amenazas. (Fuente: [DORTA 2007])

Los datos son recogidos a 1930 m.s.n.m excepto * que son a 269 m.s.n.m.

Existen numerosos estudios focalizados en el transporte de polvo norteafricano a Canarias, que describen con detalle los escenarios atmosféricos propicios para las intrusiones.

En general todos estos estudios coinciden en que los escenarios meteorológicos que favorecen el transporte de polvo africano hacia Canarias están gobernados por un anticiclón del norte de África. Se verá con más detalle los escenarios posibles en el siguiente apartado. 
A continuación se analiza la frecuencia relativa de ocurrencia de episodios de reducción de visibilidad en Gran Canaria. Para ello se ha consultado la climatología del aeropuerto de Gran Canaria.

El periodo de registro comprende de 1998 a 2011. Para los litometeoros (litomet en las gráficas), los gráficos indican visibilidad menor o igual a 5000 metros por alguno de los siguientes fenómenos: Calima, polvo, arena, humo, remolinos de polvo o cenizas volcánicas.

Enero: Se realizaron 22801 observaciones entre las 00 y 23 UTC. La frecuencia relativa de visibilidad reducida por litometeoros fue de $1,2 \%$.

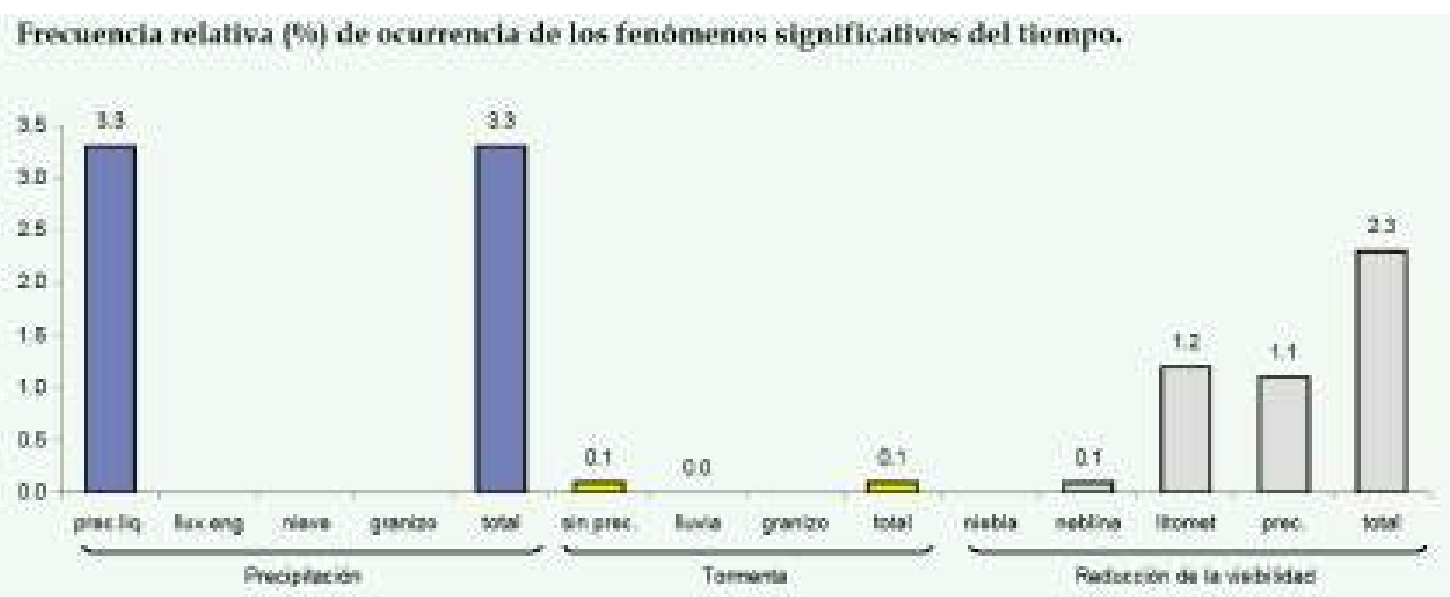

Figura 42: Frecuencia relativa (\%) de ocurrencia de los fenómenos significativos del tiempo. ENERO (Fuente: [AEMET, 2])

Febrero: Se realizaron 21001 observaciones entre las 00 y 23 UTC. La frecuencia relativa de visibilidad reducida por litometeoros fue de 2,8 \%.

Frecuencia relativa $(\%)$ de ocurrencia de los fenómenos significativos del tiempo.

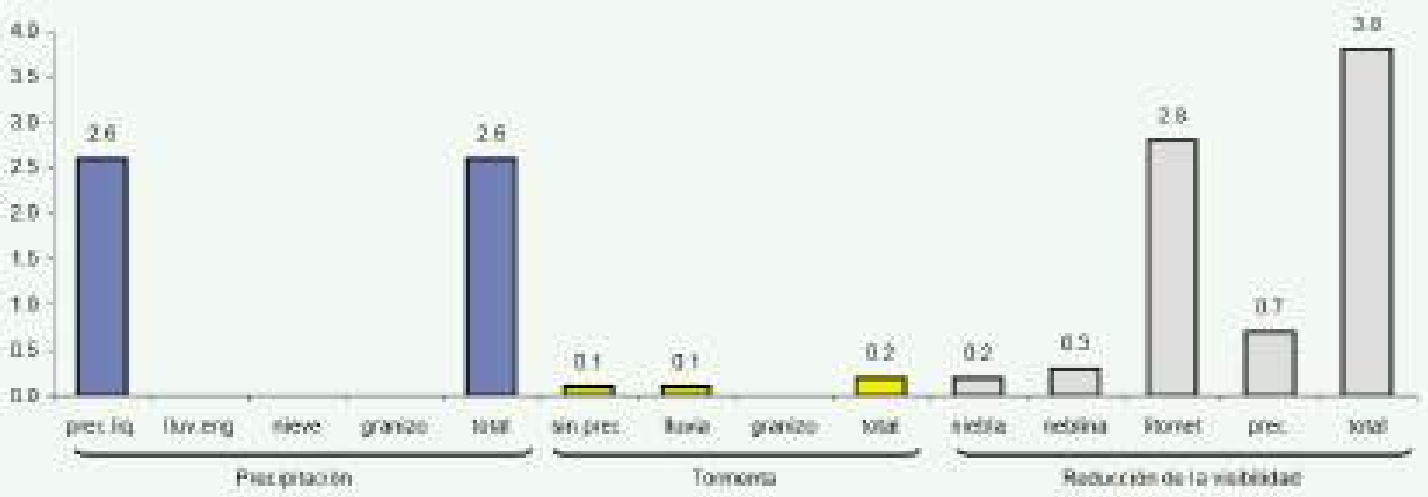

Figura 43: Frecuencia relativa (\%) de ocurrencia de los fenómenos significativos del tiempo. FEBRERO (Fuente: [AEMET, 2]) 
Marzo: Se realizaron 21984 observaciones entre las 00 y 23 UTC. La frecuencia relativa de visibilidad reducida por litometeoros fue de 2,2 \%.

Frecuencia relativa $(\%)$ de ocurrencia de los fenómenos significativos del tiempo.

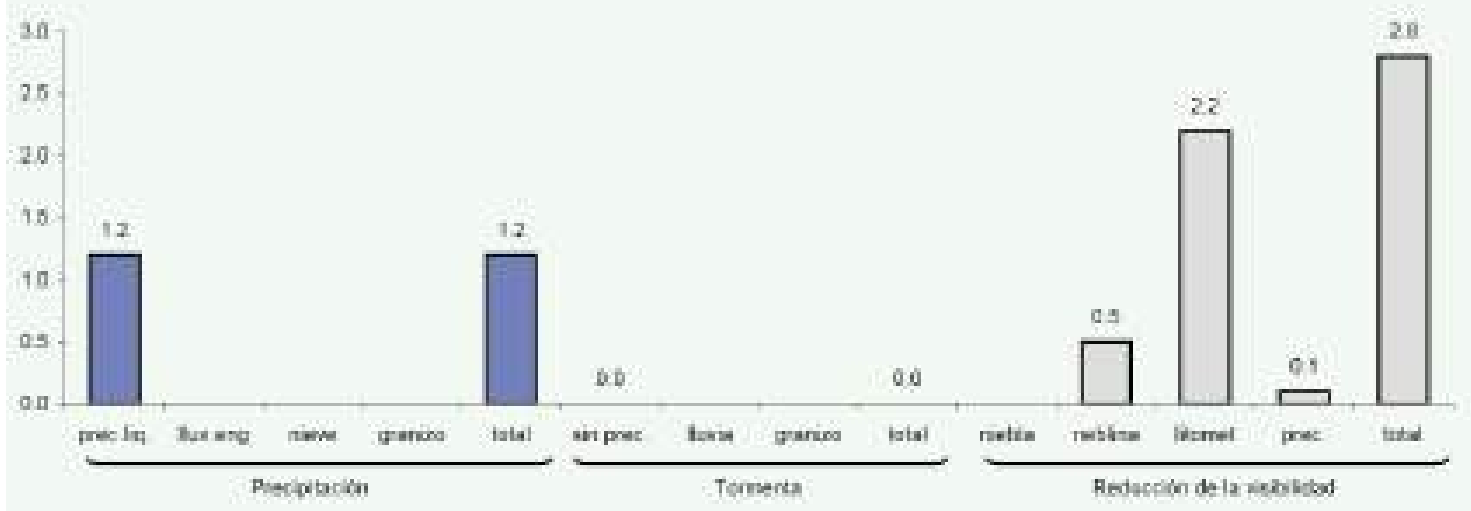

Figura 44: Frecuencia relativa (\%) de ocurrencia de los fenómenos significativos del tiempo. MARZO

(Fuente: [AEMET, 2])

Abril: Se realizaron 20489 observaciones entre las 00 y 23 UTC. La frecuencia relativa de visibilidad reducida por litometeoros fue de 0,6\%.

Frecuencia relativa $(\%)$ de ocurrencia de los fenómenos significativos del tiempo.

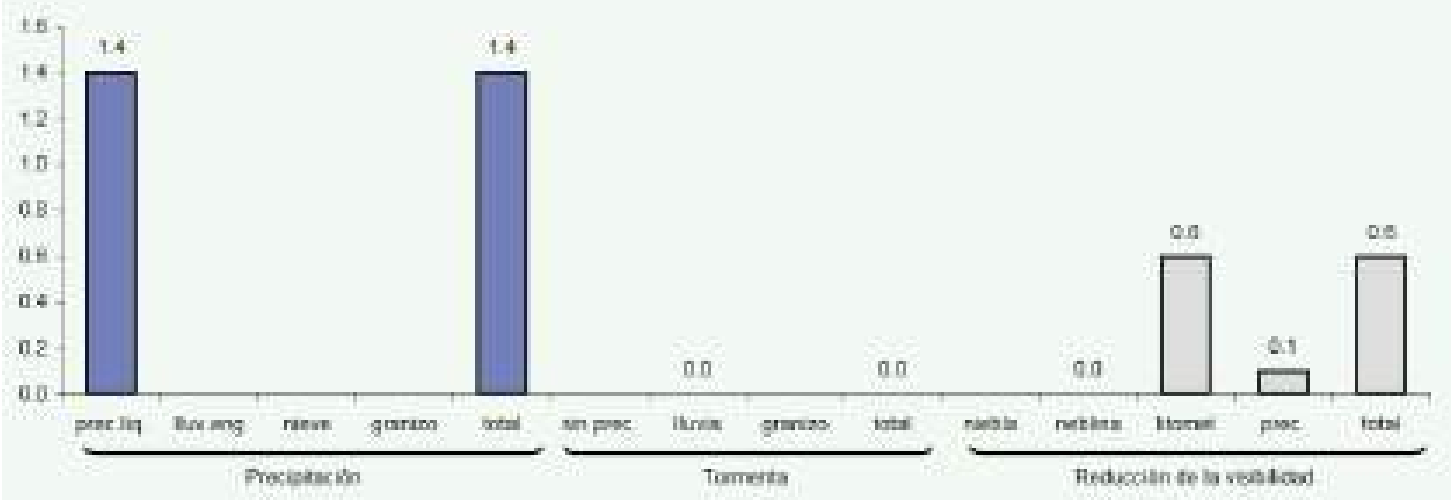

Figura 45: Frecuencia relativa (\%) de ocurrencia de los fenómenos significativos del tiempo. ABRIL (Fuente: [AEMET, 2])

Mayo y junio la frecuencia relativa de ocurrencia de reducción de visibilidad por litometeoros en el periodo 1998 a 2011 fue de $0 \%$. 
Julio: Se realizaron 20575 observaciones entre las 00 y 23 UTC. La frecuencia relativa de visibilidad reducida por litometeoros fue de 0,1\%.

\section{Frecuencia relativa (\%) de ocurrencia de los fenómenos significativos del tiempo.}

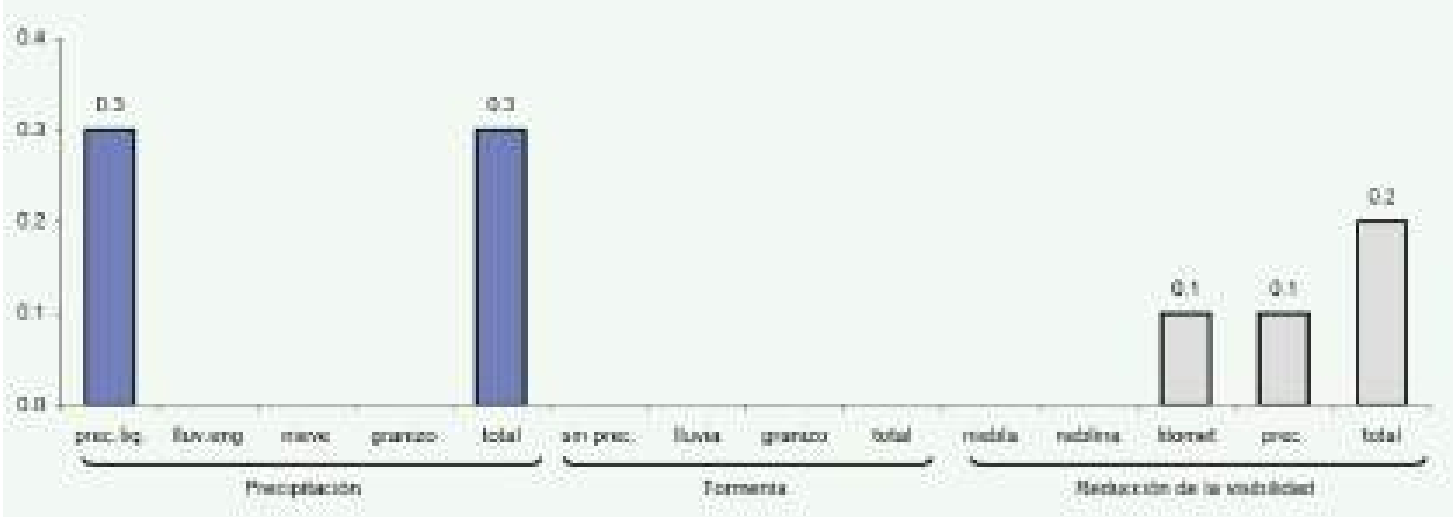

Figura 46: Frecuencia relativa (\%) de ocurrencia de los fenómenos significativos del tiempo. JULIO (Fuente: [AEMET, 2])

Agosto: Se realizaron 20665 observaciones entre las 00 y 23 UTC. La frecuencia relativa de visibilidad reducida por litometeoros fue de 0,3\%.

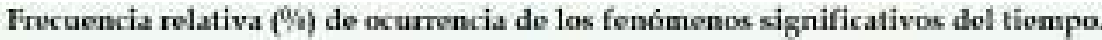

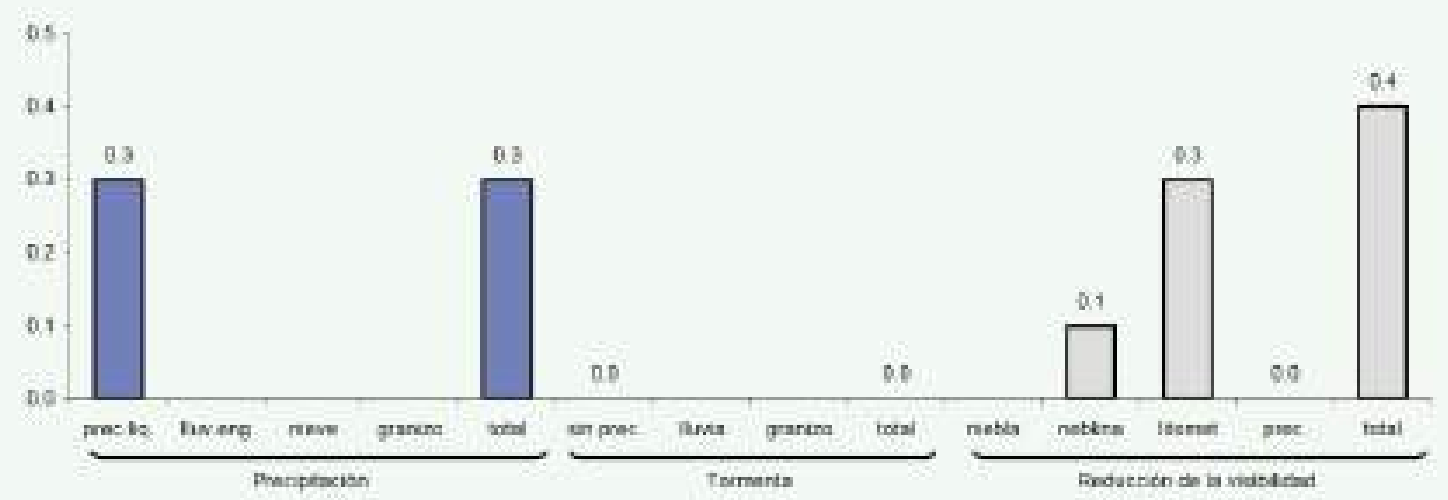

Figura 47: Frecuencia relativa (\%) de ocurrencia de los fenómenos significativos del tiempo. AGOSTO (Fuente: [AEMET, 2]) 
Septiembre: Se realizaron 20010 observaciones entre las 00 y 23 UTC. La frecuencia relativa de visibilidad reducida por litometeoros fue de $0,1 \%$.

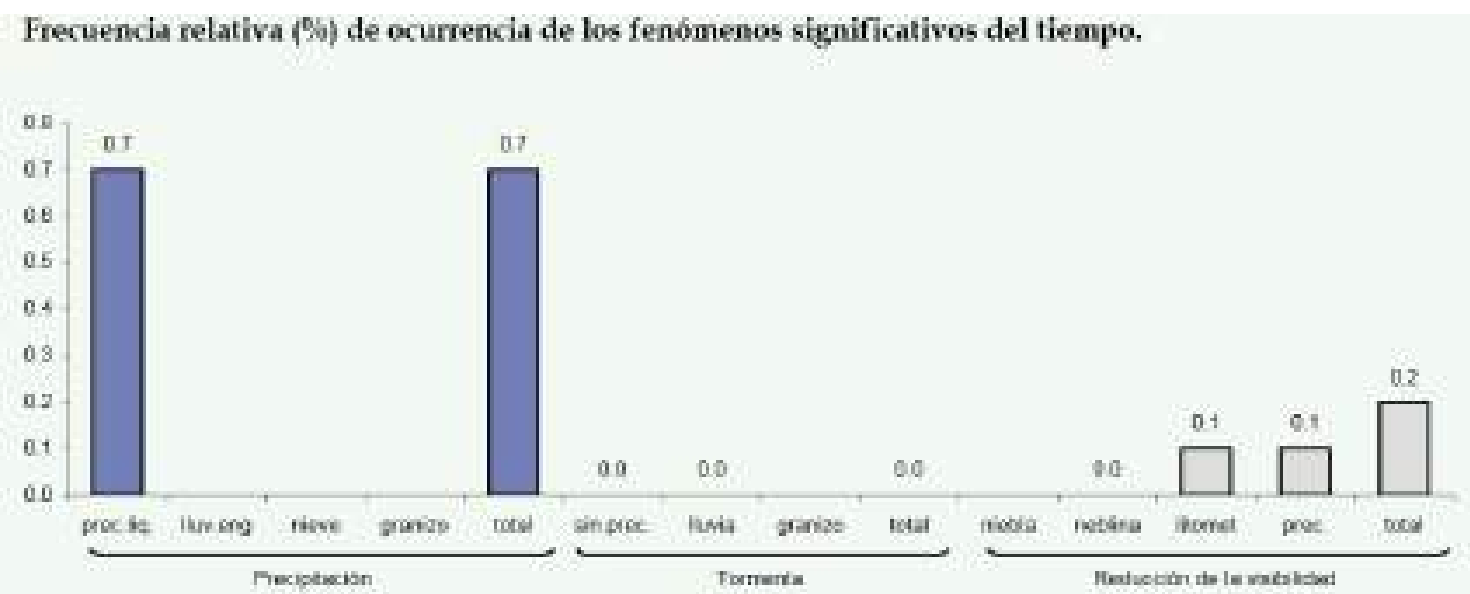

Figura 48: Frecuencia relativa (\%) de ocurrencia de los fenómenos significativos del tiempo. SEPTIEMBRE (Fuente: [AEMET, 2])

Octubre: Se realizaron 21619 observaciones entre las 00 y 23 UTC. La frecuencia relativa de visibilidad reducida por litometeoros fue de 0,6 \%.

Frecuencia relativa (\%) de ocurrencia de los fenómenos significativos del tiempo.

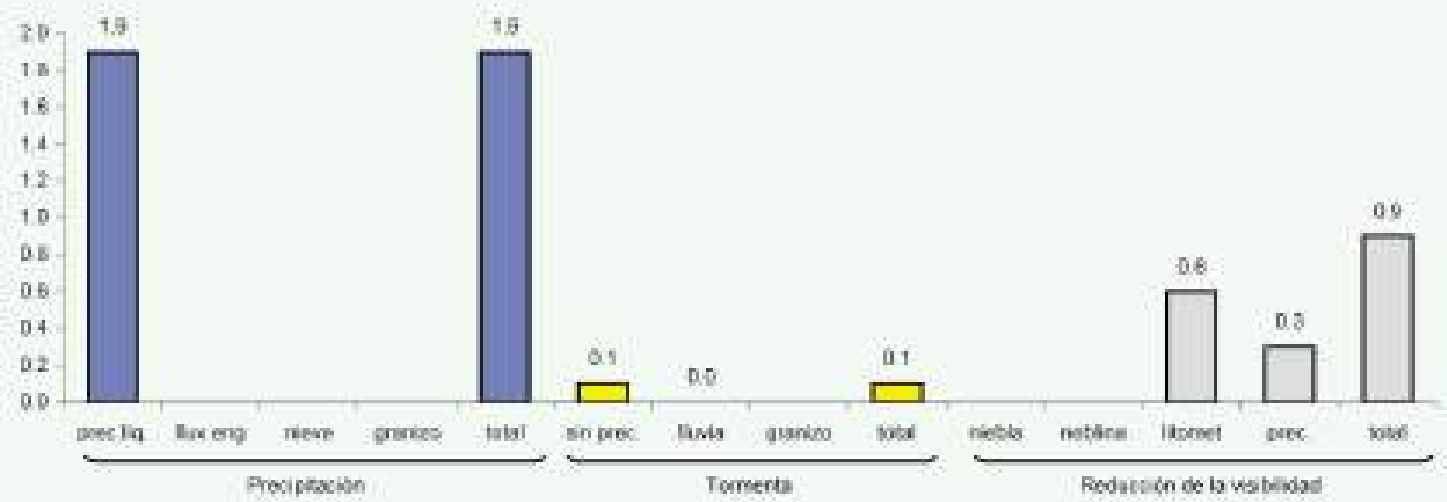

Figura 49: Frecuencia relativa (\%) de ocurrencia de los fenómenos significativos del tiempo. OCTUBRE (Fuente: [AEMET, 2]) 
Noviembre: Se realizaron 21401 observaciones entre las 00 y 23 UTC. La frecuencia relativa de visibilidad reducida por litometeoros fue de $0,7 \%$.

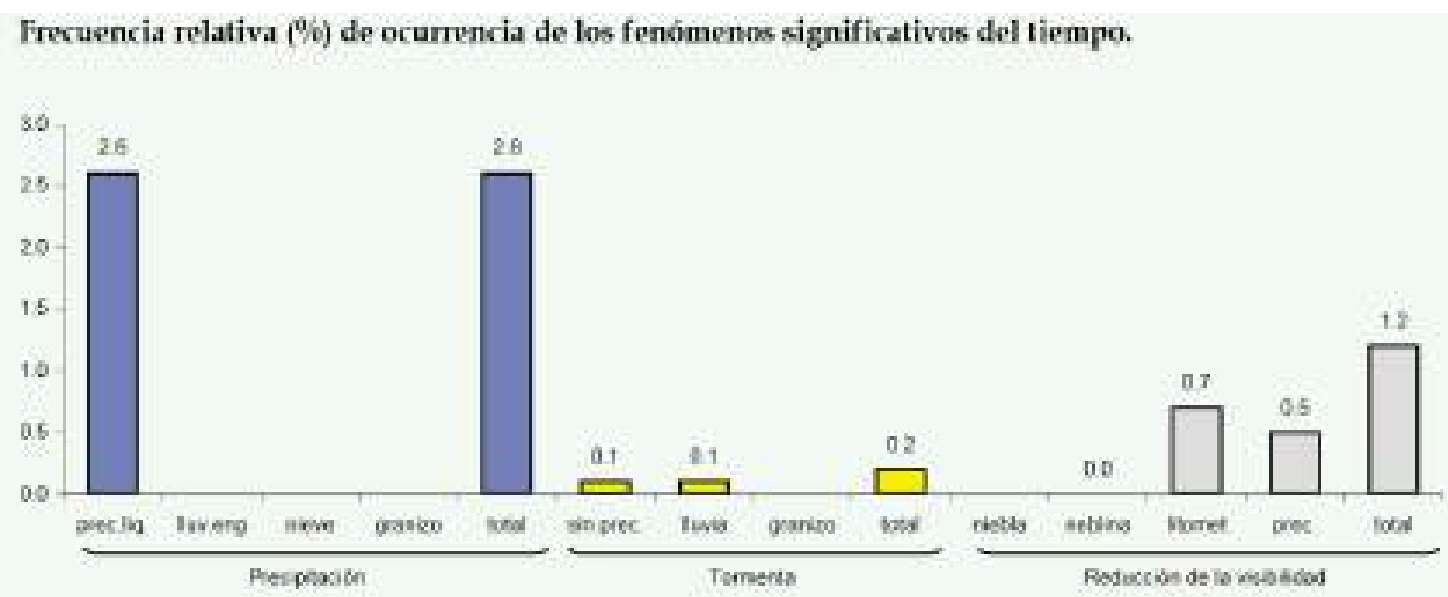

Figura 50: Frecuencia relativa (\%) de ocurrencia de los fenómenos significativos del tiempo. NOVIEMBRE (Fuente: [AEMET, 2])

Diciembre: Se realizaron 22214 observaciones entre las 00 y 23 UTC. La frecuencia relativa de visibilidad reducida por litometeoros fue de 0,4 \%.

Frecuencia relativa $(\%)$ de ocurrencia de los fenomenos significativos del tiempo.

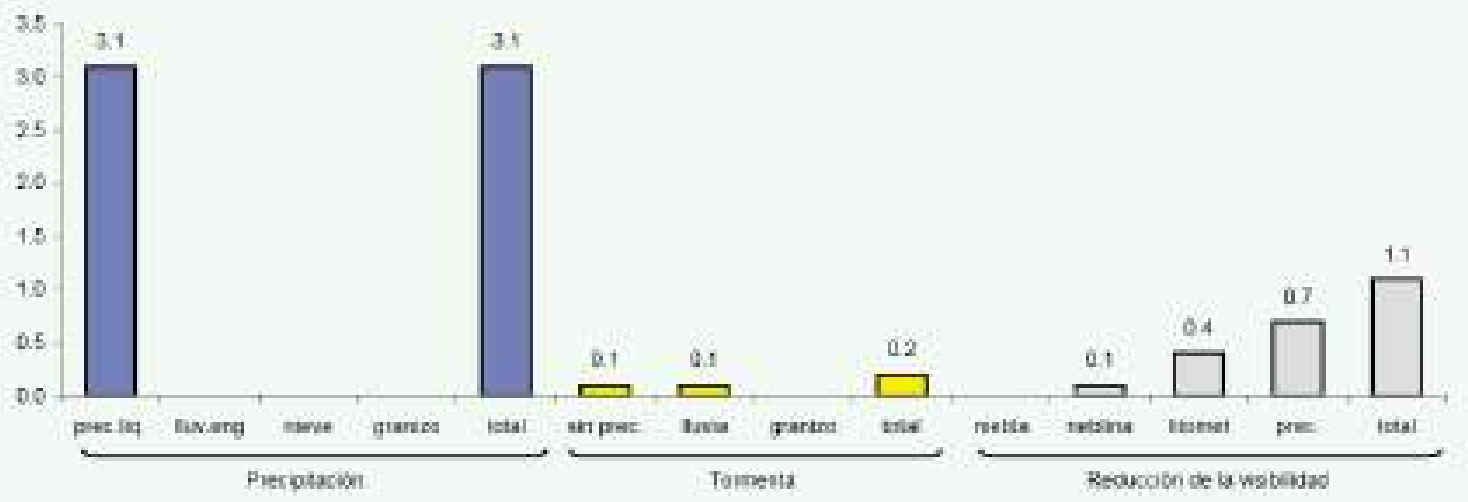

Figura 51: Frecuencia relativa (\%) de ocurrencia de los fenómenos significativos del tiempo. DICIEMBRE (Fuente: [AEMET, 2])

De los datos anteriores se concluye que los episodios de reducción de visibilidad debido a litometeoros son más frecuentes en la isla de Gran Canaria durante los meses de febrero y marzo. Por otro lado, los meses de menos ocurrencia de este fenómeno son mayo y junio. 
Hay que tener en cuenta que en numerosas ocasiones Canarias se puede ver afectada por la presencia de calima, sin que esta produzca una reducción de visibilidad significativa. Además la visibilidad tiene una limitación, y es que puede ser subjetiva ya que depende del observador.

Para no sólo basarse en el análisis clásico de identificación de situaciones de intrusiones de polvo ceñidas a reducción de visibilidad, se combinan los datos expuestos anteriormente con otros datos y estudios de interés que caracterizan a las intrusiones saharianas. Es interesante para este propósito analizar series temporales largas de AOD (espesor óptico de aerosoles). Para ello se toma como base dos publicaciones recientes [BARRETO et al. 2014] y [GARCÍA et al 2016]:

En el primero de estos estudios se reconstruye una serie temporal de 37 años de AOD monocromático a partir de medidas de irradiancia solar realizadas con el espectrómetro solar Mark-I situado en Izaña desde 1976. Esta serie se comparó con los datos obtenidos por la estación Cimel-AErosol RObotic NETwork (AERONET) y el Radiómetro de Filtro Preciso (PFR). El análisis preliminar de tendencia de AOD en el periodo de 29 años comprendidos entre 1984-2012 con Mark I no revelan tendencias significativas [BARRETO et al. 2014].

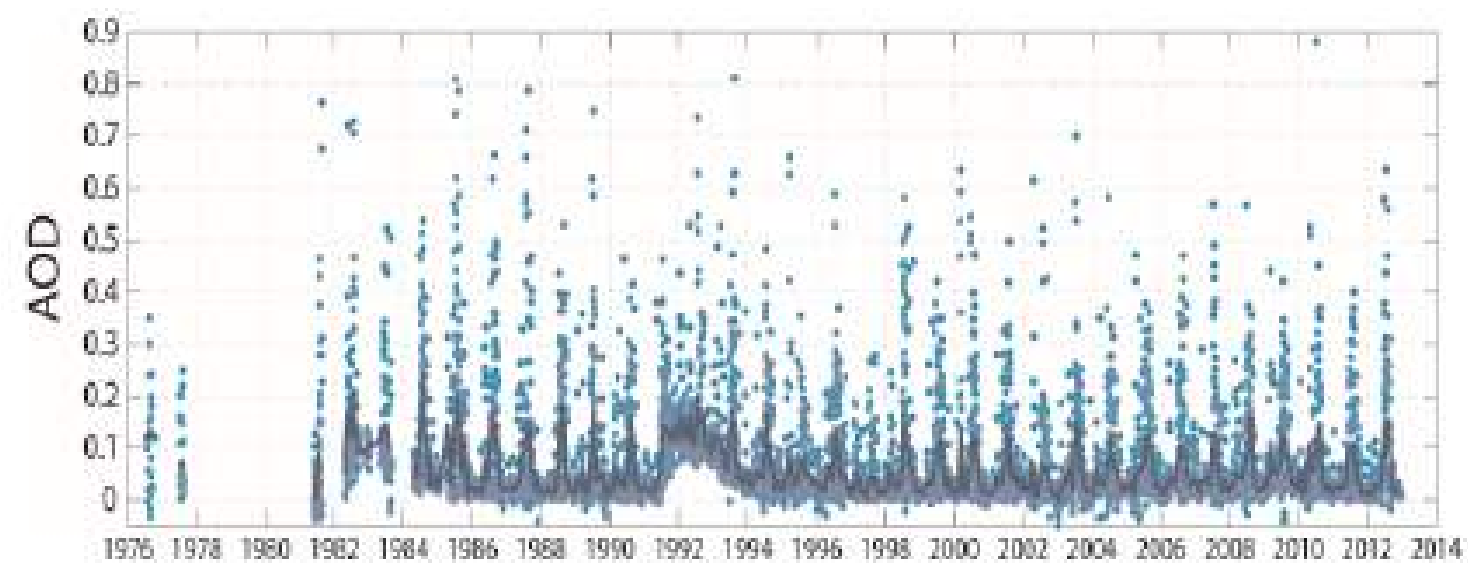

Figura 51: Media diaria de AOD en Izaña extraida del Mark-I. La media mensual se muestra con la línea violeta. (Fuente: [BARRETO et al.2014]) 


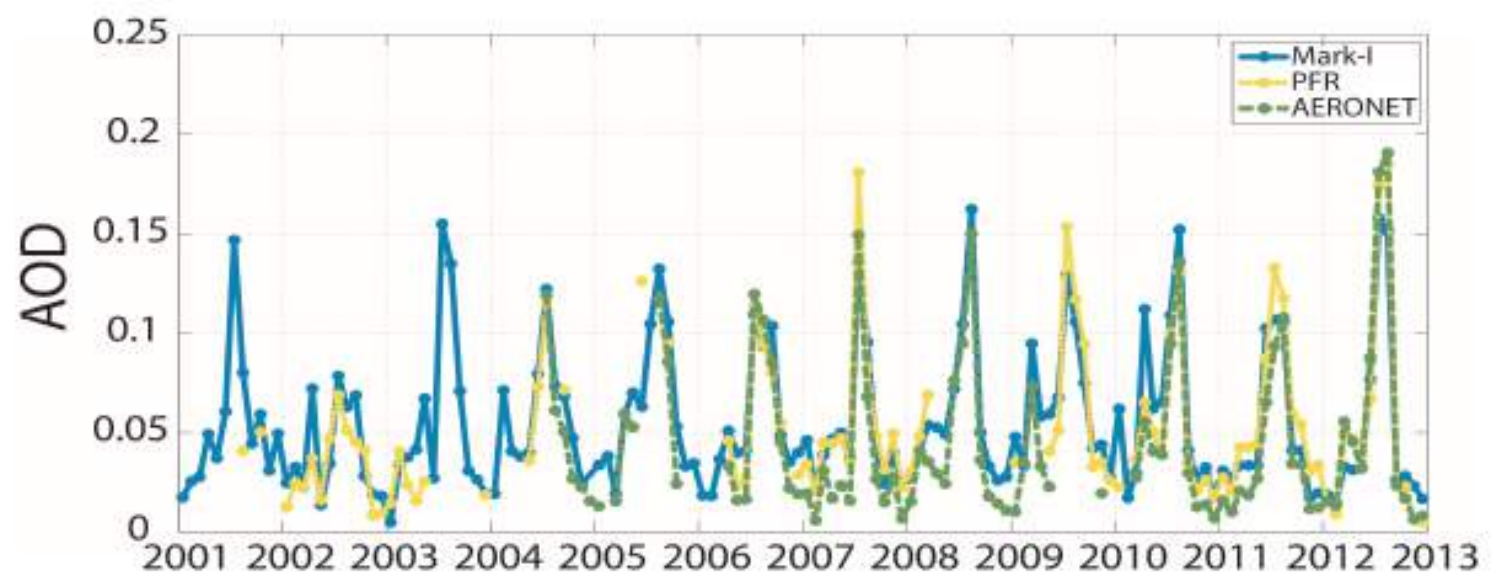

Figura 52: Homogenización de la media mensual del AOD para Mark-I (azul),PFR (amarillo) y AERONET(verde). (Fuente: [BARRETO et al.2014])

En el segundo estudio se reconstruye una serie de 73 años de AOD en $500 \mathrm{~nm}$ para el observatorio de Izaña. Se combinó AOD estimado mediante redes neuronales durante el periodo de 1941 a 2001, con medidas directas de AOD obtenidas con el PFR (Precision Filter Radiometer, PFR) entre 2003 y 2013.

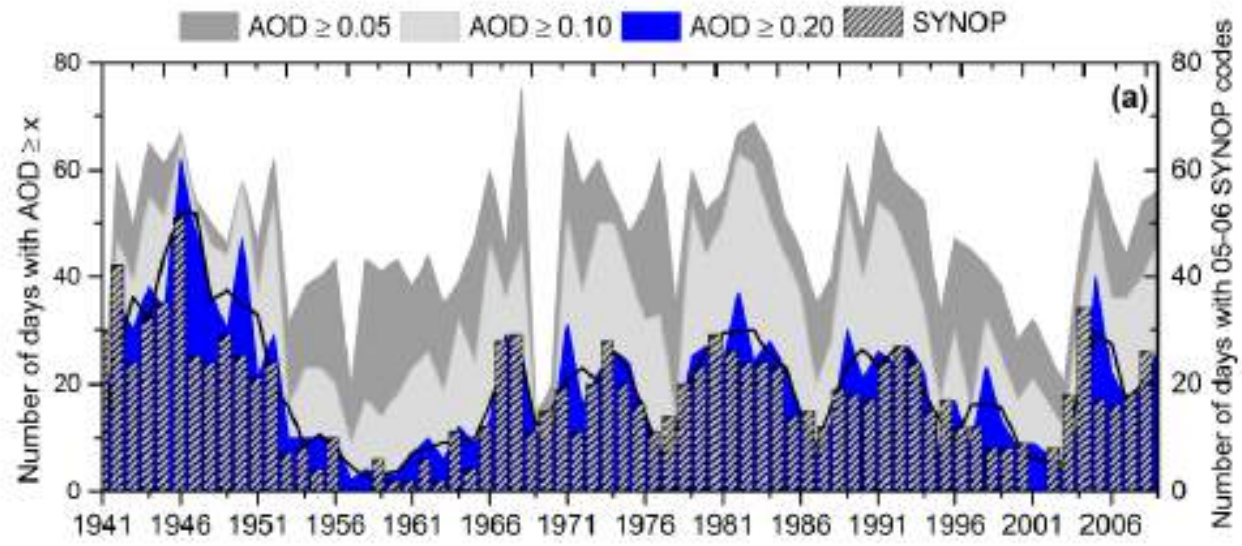

Figura 53: Número de días con AOD igual o superior a distintos umbrales. Número de días que se cifró calima. (Fuente: [García et al 2016])

La figura anterior muestra que existe una alta correlación entre valores AOD mayor o igual a 0,20 y los días en que se cifro calima por un observador (SYNOP). 


\subsection{Patrones atmosféricos relacionados con episodios de intrusiones de polvo sahariano}

Para la realización de este apartado se ha combinado la descripción detallada [VIANA el al. 2002], en la que se distinguen claramente tres épocas del año con estudios más recientes [RODRIGUEZ et al 2015] [CUEVAS et al 2017] para documentar la situación de verano:

\section{Verano (junio-septiembre):}

Durante los meses de verano las intrusiones africanas tienen lugar en niveles altos de la atmósfera. En la estación de verano la frecuencia máxima de ocurrencia de eventos de polvo ocurre en agosto (52\% de los días de agosto como media). [RODRIGUEZ et al 2015]

Este mes es de alto interés debido a que por un lado la Zona de Convergencia Inter Tropical está desplazada hacia el norte y consecuentemente la Capa de Aire Sahariana se exporta a latitudes más septentrionales (como evidencia de la mayor frecuencia del impacto del polvo en Izaña [TSAMALIS et al.2013] y el máximo de precipitación que tiene lugar en el norte de África tropical [NICHOLSON 2009]

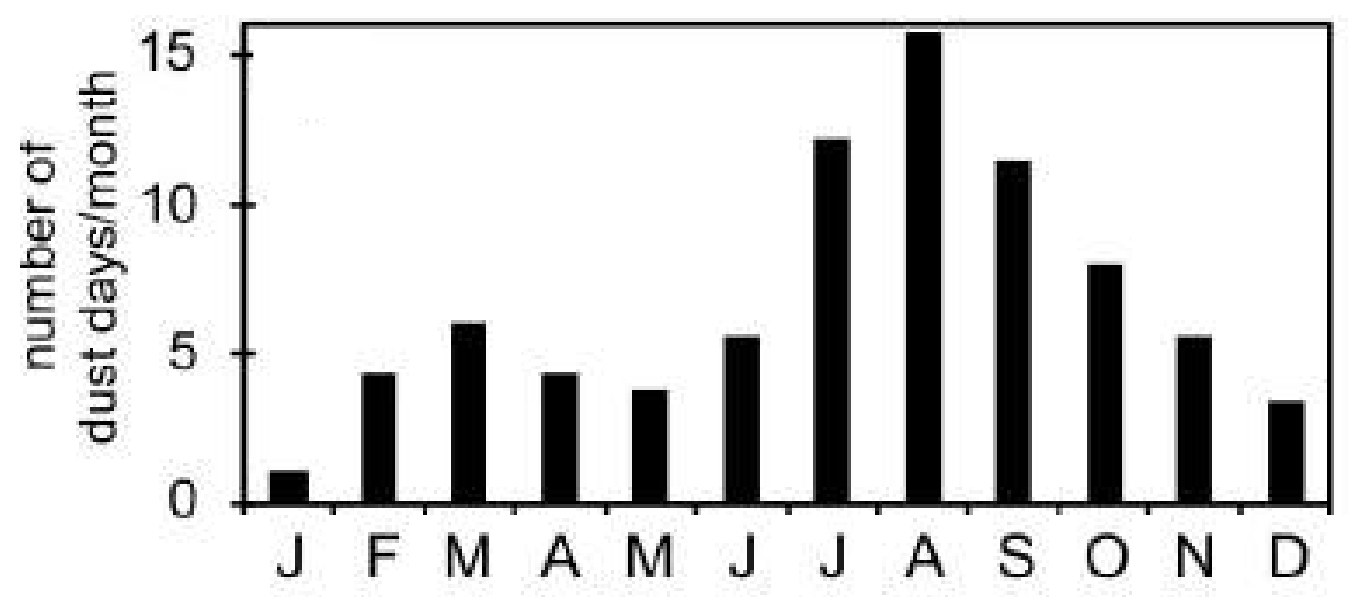

Figura 54: Frecuencia de eventos de polvo $\left(>10 \mu \mathrm{g} / \mathrm{m}^{3}\right)$ en Izaña en el periodo 1987-2014.

(Fuente [Rodriguez et al 2015])

En verano la situación típica del norte de África está influenciada por las altas presiones subtropicales y el monzón occidental africano [LAFORE et al. 2010]. Además la formación de una baja térmica en el Sáhara centro-occidental tiene también implicaciones con la movilización, transporte vertical y exportación del polvo en el Atlántico Norte en latitudes subtropicales [JONES et al 2003] [FLAMANT et al 2007], [KNIPPERTZ y TODD 2010] 
El dipolo situado en el norte de África permite encontrar un simple modelo conceptual para unir la variabilidad a largo plazo en la exportación de polvo en el Sáhara con la variabilidad a gran escala meteorológica en África noroccidental.

La medida de la variabilidad interanual de la intensidad del dipolo y por tanto su relación con el gradiente del geopotencial está relacionado con la intensidad del flujo geostrófico saliente del norte de África. [RODRIGUEZ et al 2015]

En la siguiente figura se observa una marcada variabilidad interanual en las concentraciones de polvo. Los años 1987,1997,2006 y 2007 de baja concentración media, con rango entre $17-30 \mu \mathrm{g} / \mathrm{m}^{3}$ y años con altas concentraciones medias 1988, 2008, 2010 y 2012, con rangos entre $100-140 \mu \mathrm{g} / \mathrm{m}^{3}$. [RODRIGUEZ et al 2015]
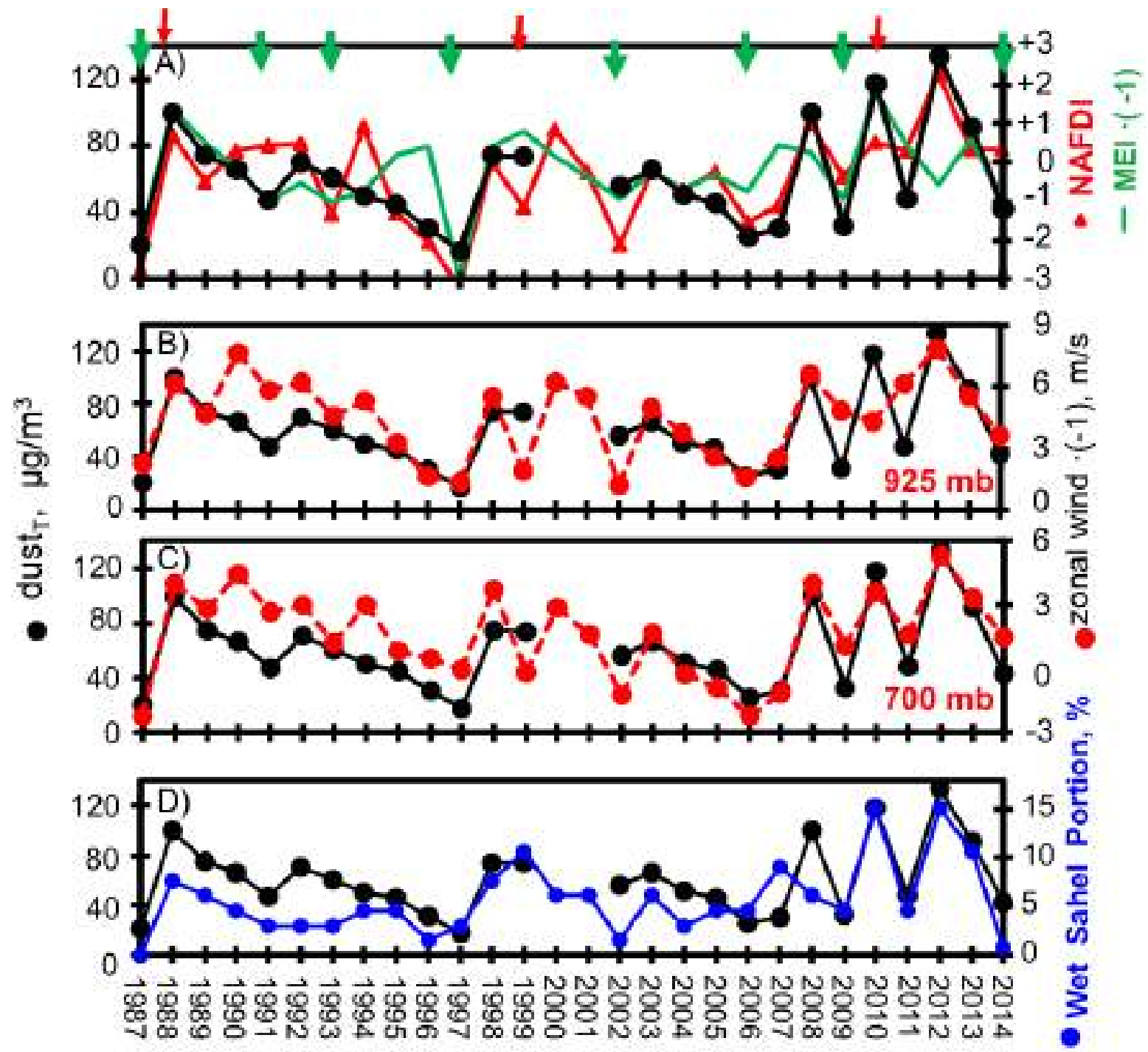

Figura 55: Evolución a largo plazo (1987-2014) del polvo y meteorología en verano.

(Fuente [RODRIGUEZ et al 2015]) 
Esta variabilidad especial de las condiciones meteorológicas sobre el norte de África está asociadas con el dipolo del norte de África:
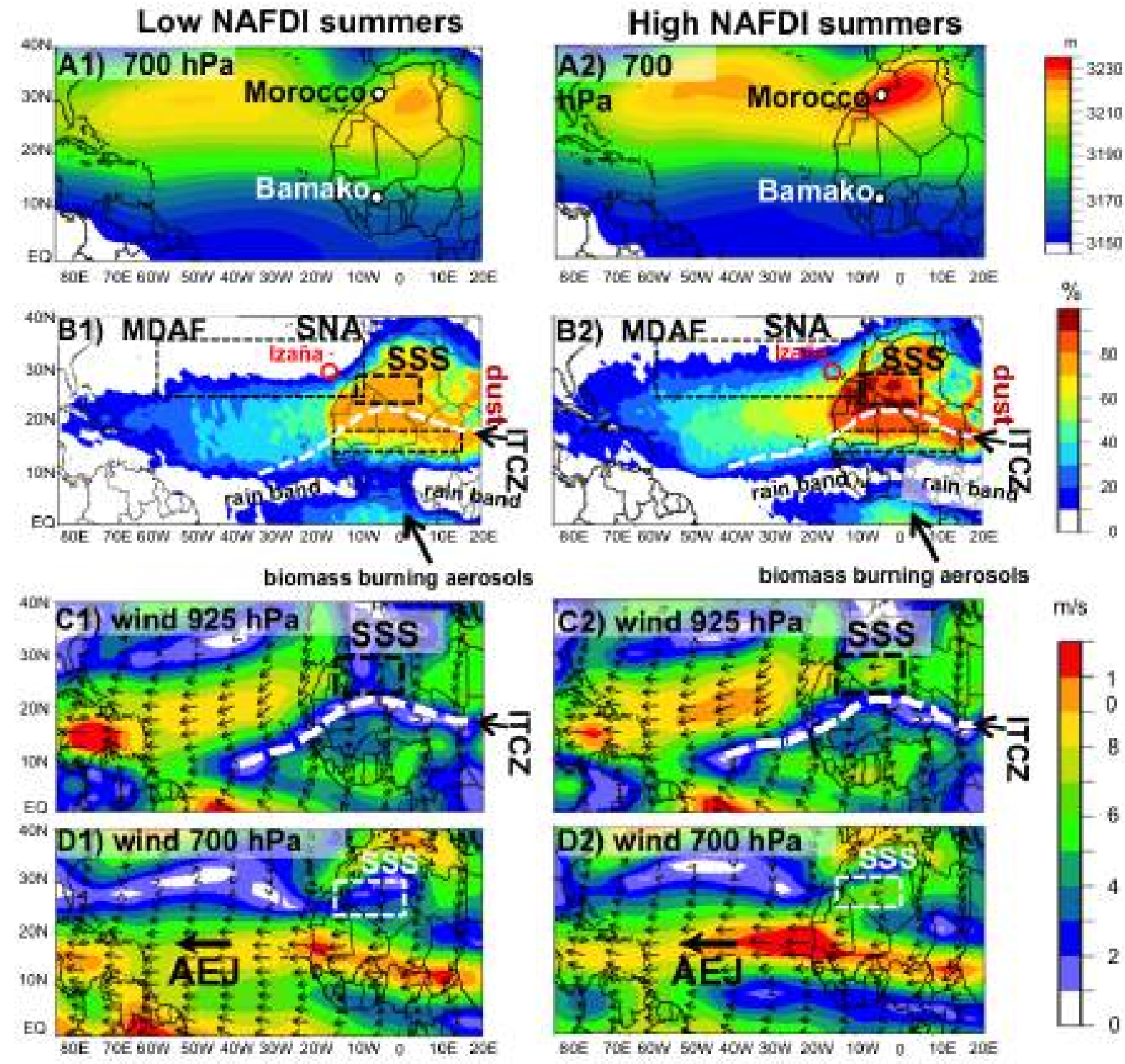

$\mathrm{m} / \mathrm{s}$
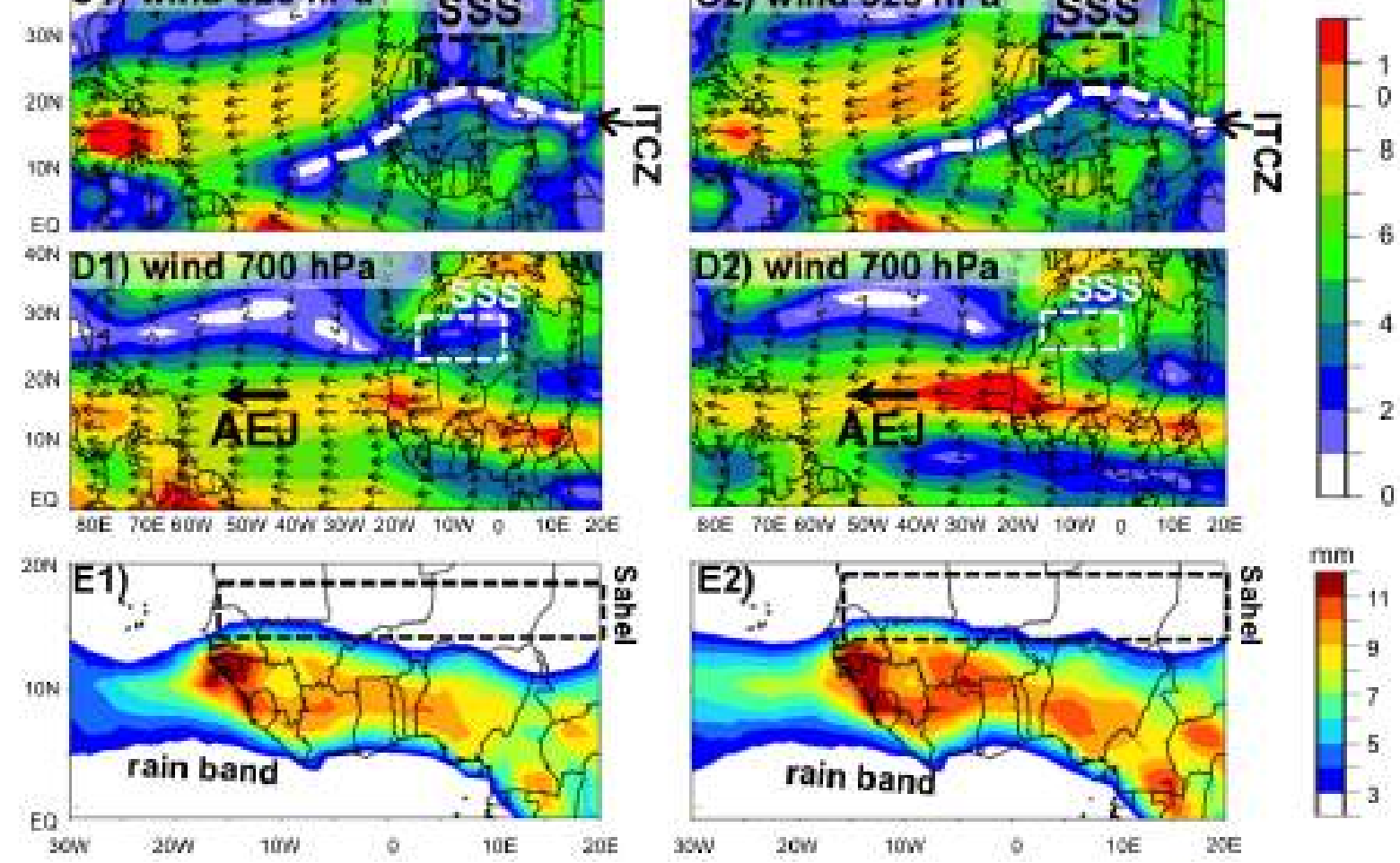

Figura 56: Dipolo del norte de África y distribución especial del polvo y promedios de campos meteorológicos con bajos y altos valores de intensidad de dipolo del norte de África (NAFDI).

(Fuente [RODRIGUEZ et al 2015]) 
Además en la referencia [CUEVAS et al 2017] se examina la interacción entre las ondas de Rossby de latitudes medias y la Intensidad del Dipolo del Norte de África. (NAFDI).

Este estudio pone de manifiesto, que se encontraron anomalías mensuales notables de cantidades generalizadas de AOD (espesor óptico de aerosol) para cada fase de NAFDI sobre el corredor sahariano de polvo, indicando que NAFDI presenta una variabilidad intraestacional y conduce el transporte de polvo sobre la cuenca mediterránea y el Atlántico Norte.

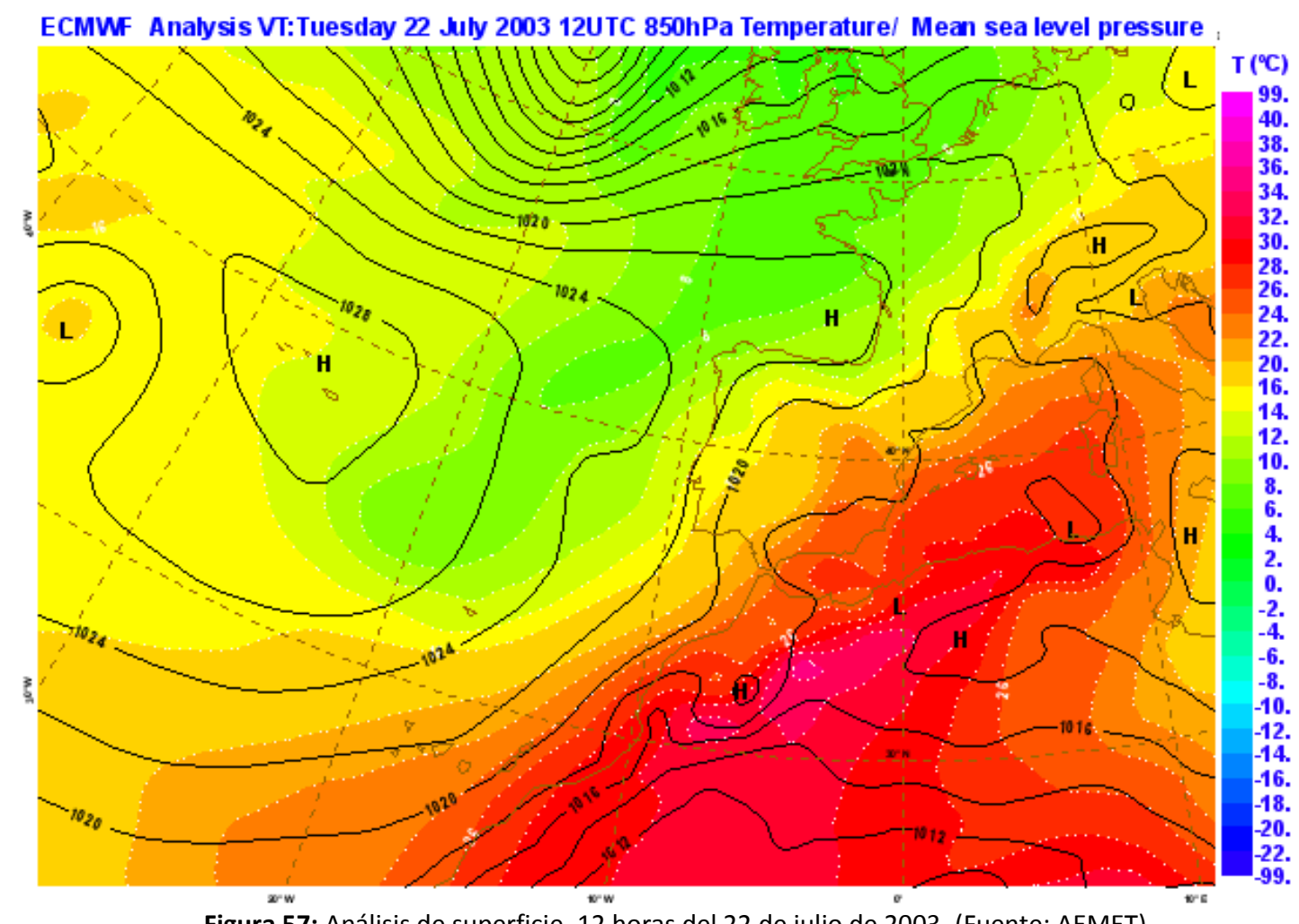

Figura 57: Análisis de superficie, 12 horas del 22 de julio de 2003. (Fuente: AEMET) 


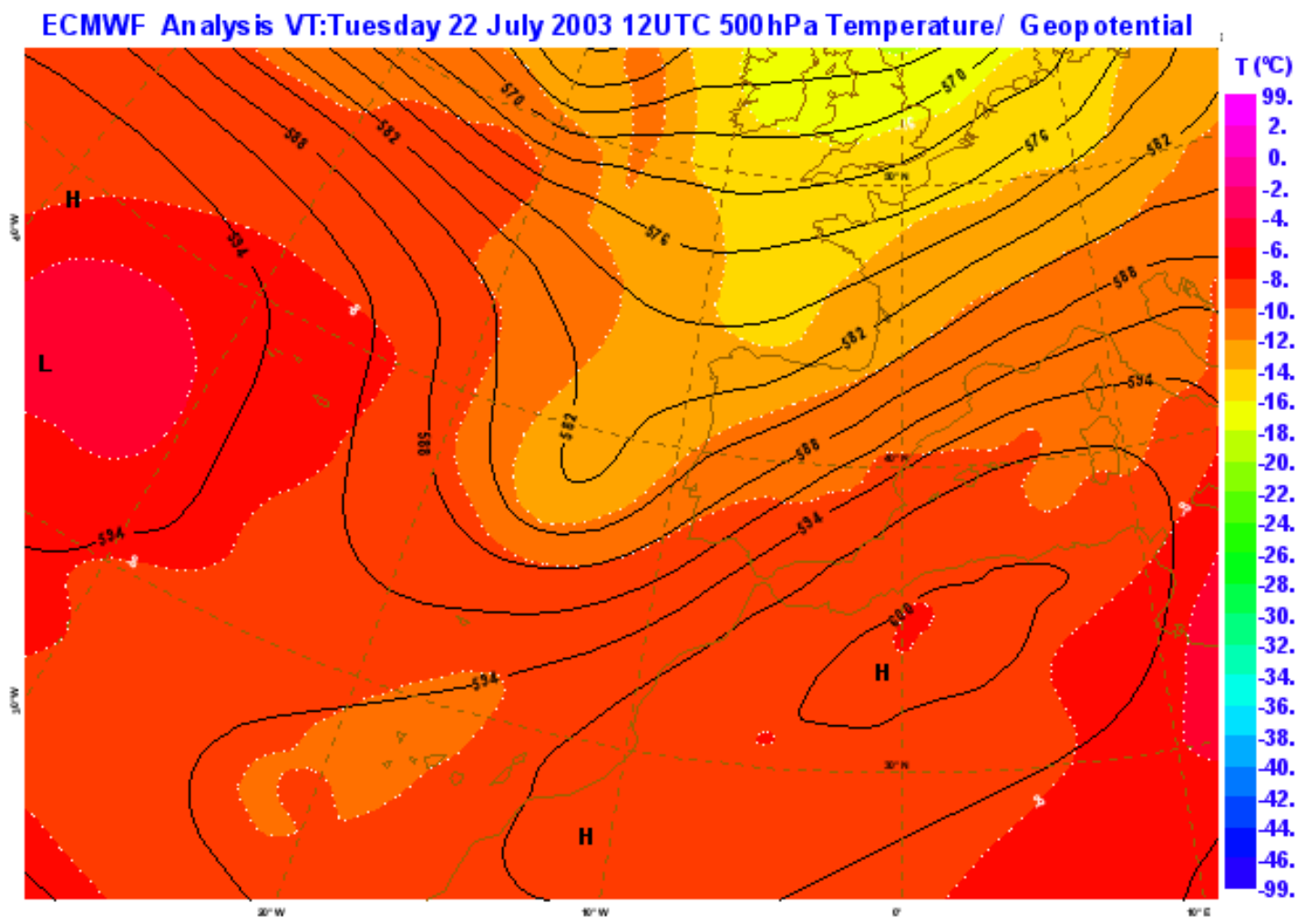

Figura 58: Análisis de $500 \mathrm{hPa}, 12$ horas del 22 de julio de 2003. (Fuente: AEMET)

\section{Otoño-invierno (octubre-noviembre):}

Durante estos meses la situación meteorológica en el norte de África sigue estando dominada por un anticiclón a nivel de superficie. Sin embargo no se observan procesos atmosféricos de importancia que lleven a una inyección de polvo desde la superficie de las zonas que potencialmente son fuente de material particulado mineral hacia la baja troposfera. Por lo tanto, los aportes directos de partículas desde África a Canarias sólo pueden darse por fenómenos de tormentas de polvo locales que tengan lugar cerca de las islas. Estas intrusiones son las de menor duración y habitualmente son muy intensas. Estas intrusiones suelen tener lugar en los niveles más bajos de la atmósfera, cercanos al suelo. Estos episodios también ocurren, en menor medida, en diciembre. 


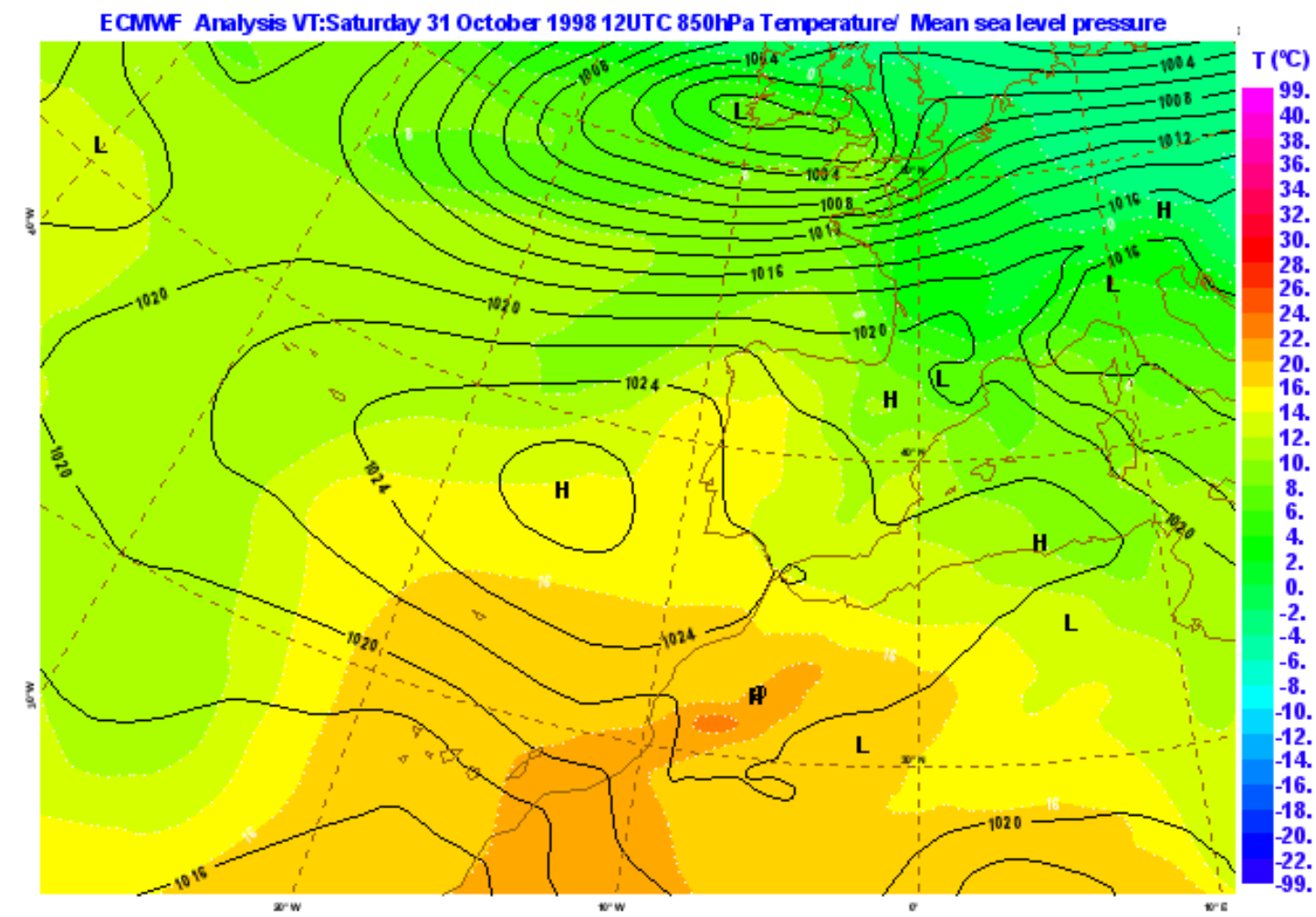

Figura 59: Análisis de superficie,12 horas del 31 de octubre de 1998. (Fuente: AEMET)

ECMWF Analysis VT:Saturday 31 October 1998 12UTC 500hPa Temperature/ Geopotential

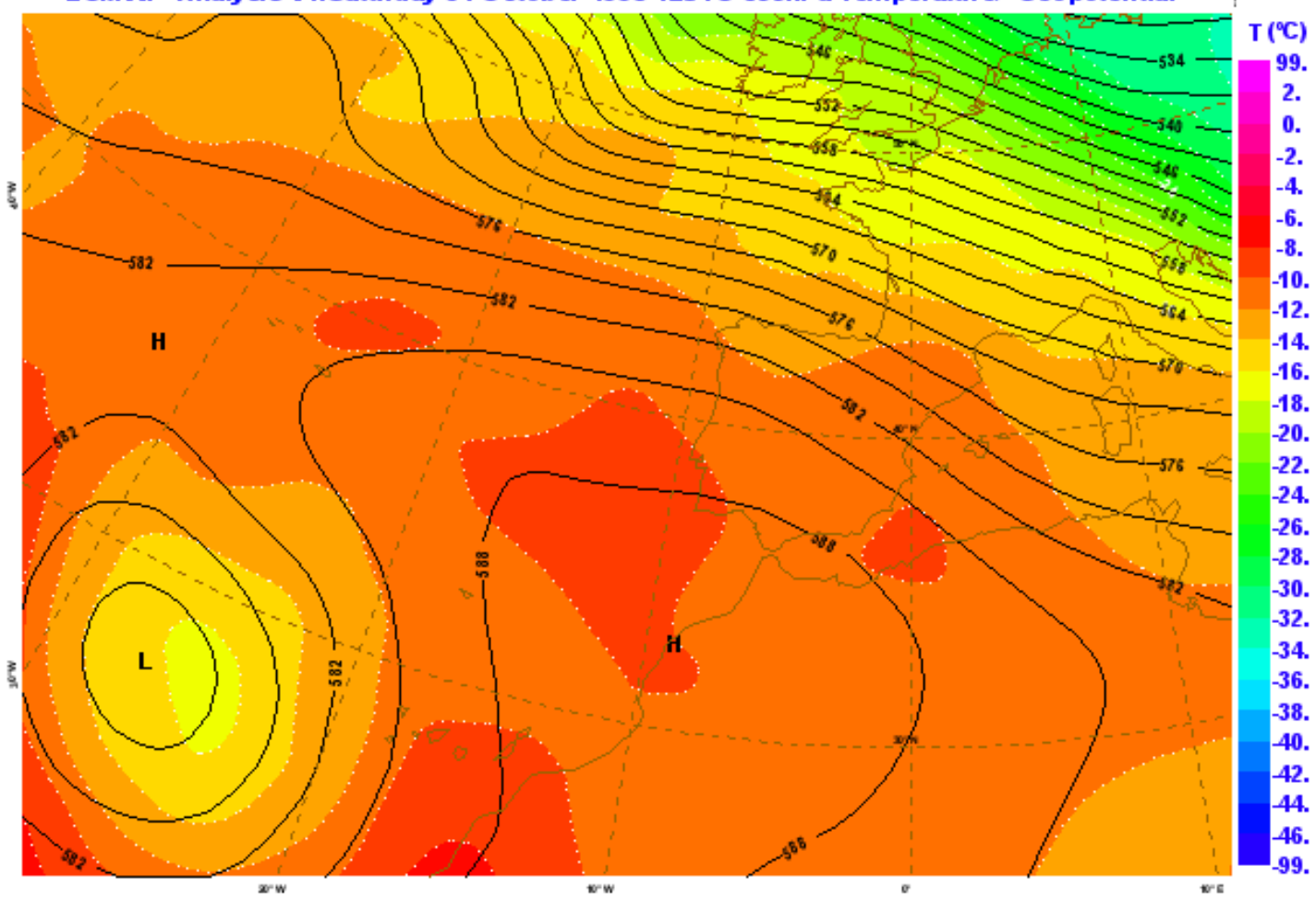

Figura 60: Análisis de 500 hPa, 12 horas del 31 de octubre de 1998. (Fuente: AEMET) 


\section{Invierno (febrero-marzo):}

Estas intrusiones, las más intensas del año, ocurren en la baja troposfera, a alturas por debajo de $2 \mathrm{~km}$ en algunos casos incluso en las zonas más bajas de la capa de mezcla. Tienen gran incidencia a nivel de superficie, y como hemos visto, esto repercute en episodios de visibilidad reducida.

El escenario meteorológico está dominado nuevamente por la presencia de un anticiclón sobre el norte de África, que puede situarse entre la costa atlántica del continente y próximo al mar Mediterráneo o la Ibérica.

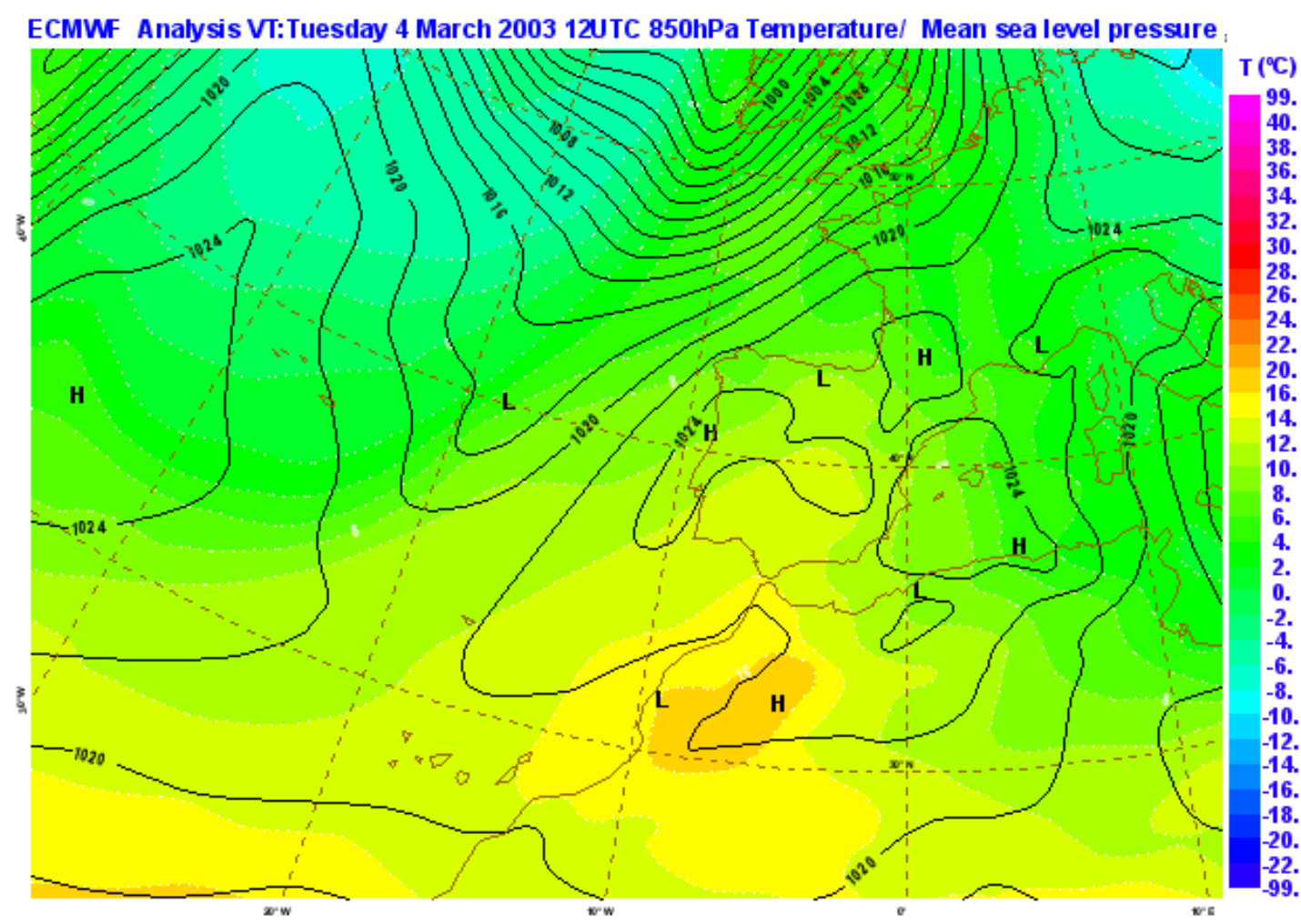

Figura 61: Análisis de superficie, 12 horas del 4 de marzo de 2003. (Fuente: AEMET) 
ECMWF Analys is VT:Tuesday 4 March 2003 12UTC 500hPa Temperature/ Geopotential

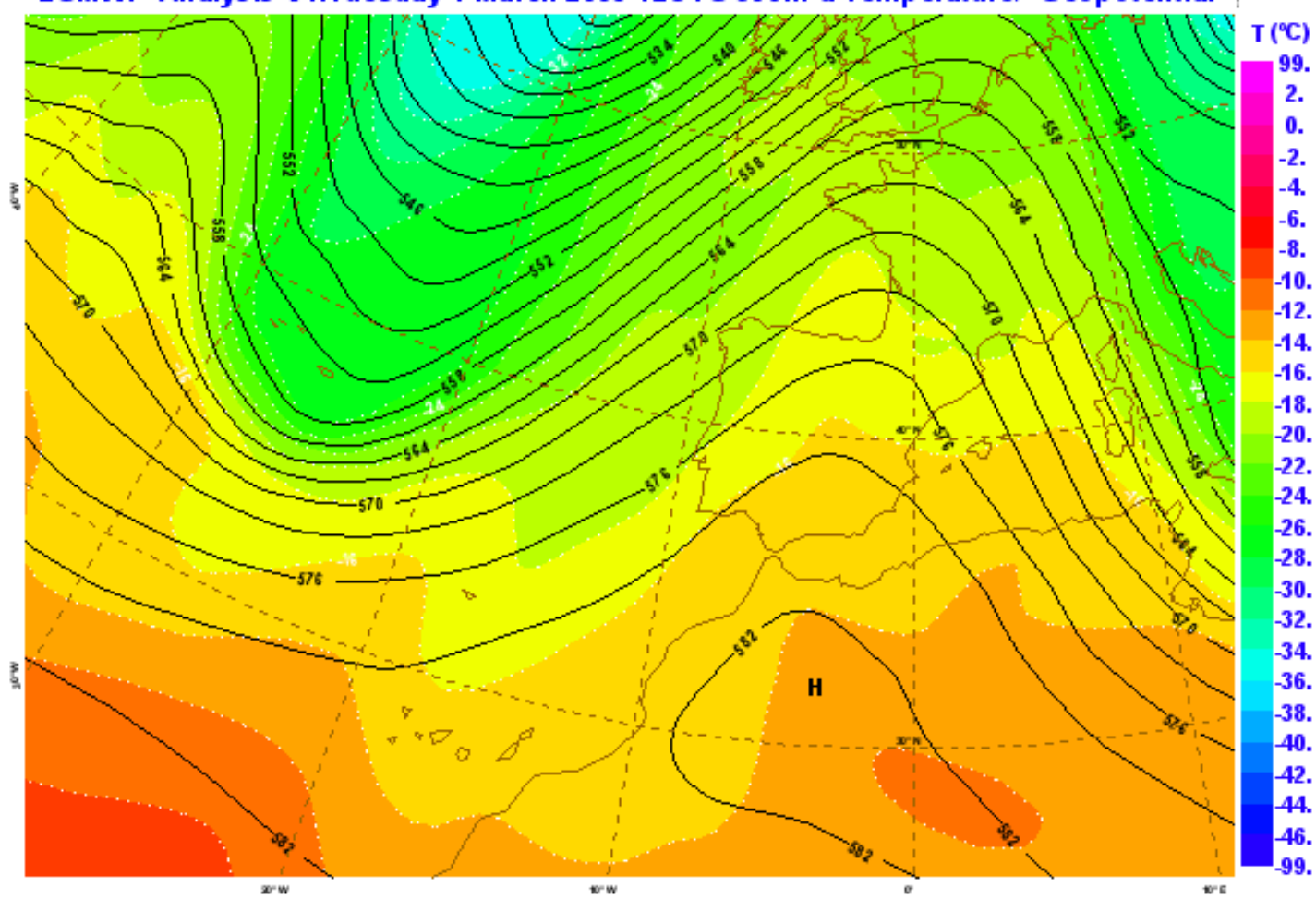

Figura 62: Análisis de $500 \mathrm{hPa}, 12$ horas del 4 de marzo de 2003. (Fuente: AEMET)

Aunque por lo general el polvo viaja en la troposfera libre cuando se transporta a grandes distancias, es de especial interés Canarias debido a la cercanía a la región fuente. Los episodios más destacados suceden cuando el polvo viaja confinado en la capa de mezcla marina.

Este tipo de episodios ocurren principalmente en invierno y llegan desde la baja troposfera del continente africano. En verano, cuando la inversión de alisios es más potente, las masas de aire procedentes de África afectan a la troposfera libre pero no a la capa de mezcla marítima donde predomina la situación más habitual en las islas, que es la de masas de aire procedentes del Atlántico Norte [TORRES et al. 2001]. 


\subsection{Episodios de intrusiones de polvo sahariano, análisis histórico. Principales zonas afectadas e impactos habituales.}

Este apartado hace referencia a la situación acaecida el 6 de enero de 2002. Este día el archipiélago canario y por ende Gran Canaria, estuvo afectado por una importante invasión de una masa africana que provocó una estampa difícil de olvidar.

Como consecuencia de este fenómeno, se redujo notablemente la visibilidad debido a la alta concentración de partículas en suspensión. Como caso particular comentar que el aeropuerto de Gran Canaria cifró en varios informes meteorológicos de observación aeronáutica, visibilidad horizontal de 50 metros e incluso en uno de ellos se cifró visibilidad de 0 metros.

A continuación se muestran varios METAR (METeorological Aerodrome Report) del aeropuerto de Gran Canaria del día en cuestión, extraídos de la base de datos de AEMET.

En el rectángulo rojo se resalta la visibilidad en metros observada en el momento de la emisión del informe.

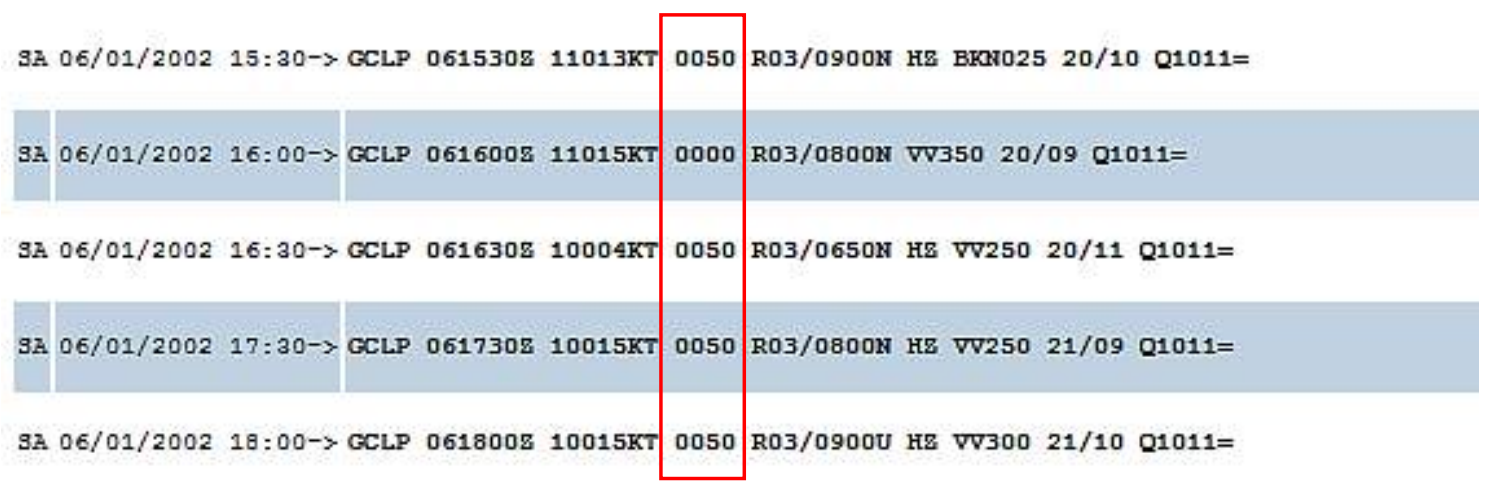

Figura 63: METARs del 6 de enero de 2002. (Fuente: AEMET)

En la figura siguiente se muestra el mapa de presión a nivel del mar y se observa la presencia de una baja de $1010 \mathrm{hPa}$ centrada al suroeste de las islas. Canarias quedaba afectada por tanto, por un flujo de Sureste en superficie. Además queda reflejado en el siguiente mapa, la presencia de un potente anticiclón de $1032 \mathrm{hPa}$ sobre el norte de África que se extiende hacia centro Europa.

Este tipo de situación en la cual se produce un cambio en la dirección de viento sobre el continente africano, ya que al sur del anticiclón sopla un viento de componente Este e incluso Nordeste y en las cercanías de la costa atlántica y en Canarias sopla viento del Sureste, han sido bautizadas entre predictores del Grupo de Predicción y Vigilancia de Las Palmas (AEMET Canarias) como "estructuras en abanico".

Debido al gradiente barométrico en niveles bajos y al giro del viento, este tipo de escenario es muy eficiente en cuanto al transporte de polvo hacia Canarias. 


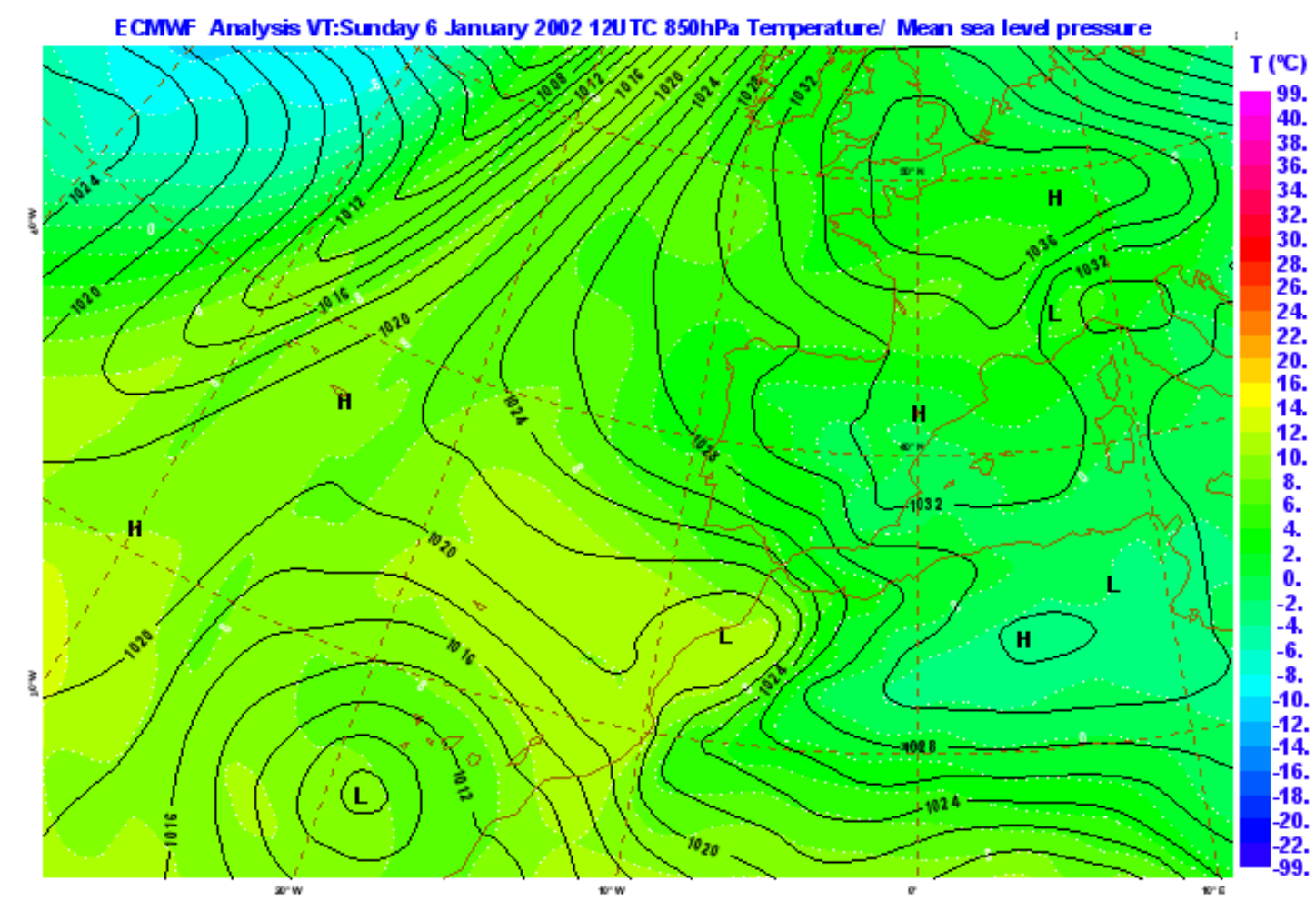

Figura 64: Análisis de superficie, 12 horas del 6 de enero de 2002. (Fuente: AEMET)

En $500 \mathrm{hPa}$ (siguiente figura), se refleja el núcleo frío de entre $-18 \mathrm{a}-22^{\circ} \mathrm{C}$ en niveles medios de la troposfera, asociado a la baja en altura que se situaba al suroeste de Gran Canaria.

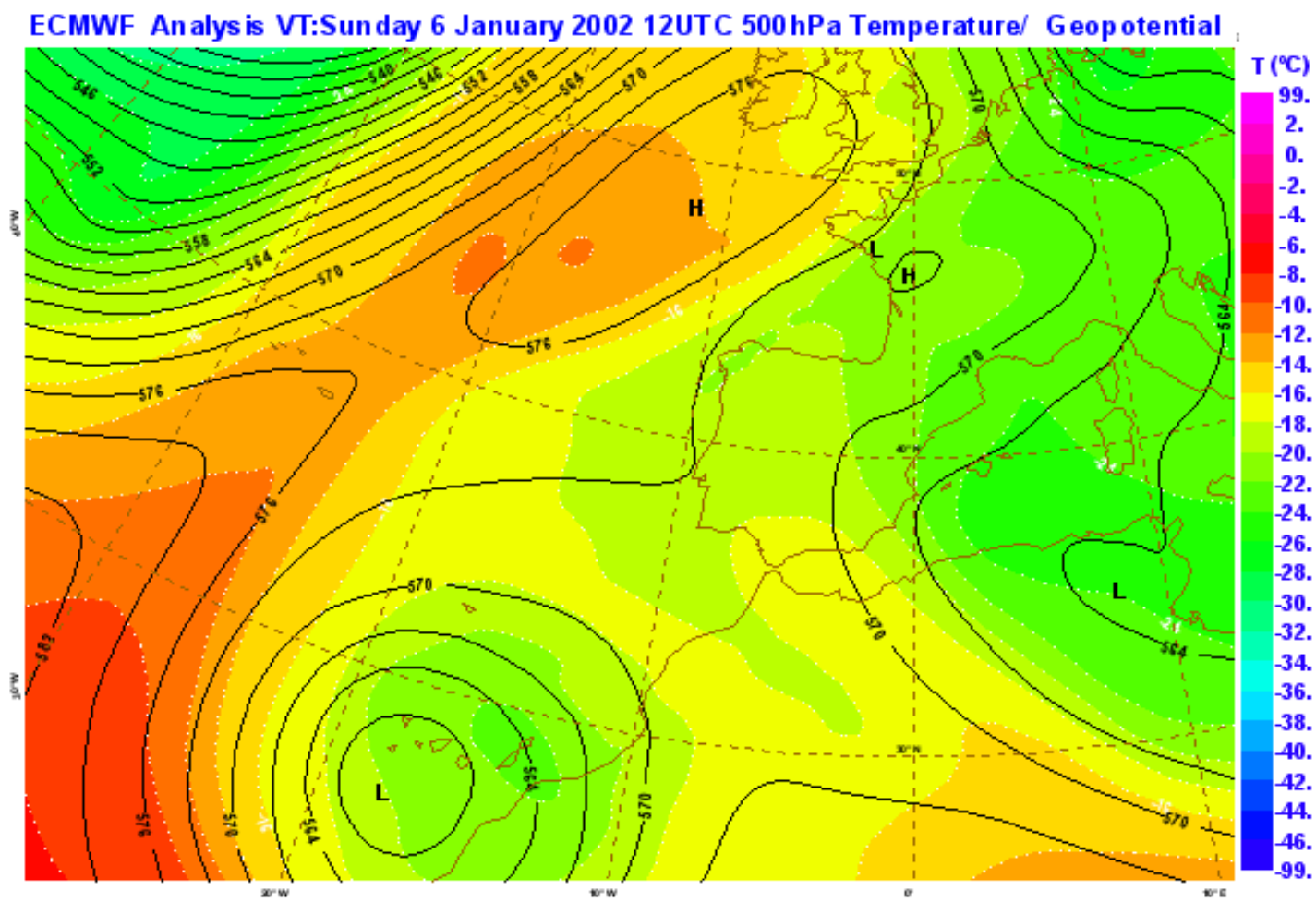

Figura 65: Análisis de $500 \mathrm{hPa}, 12$ horas del 6 de enero de 2002. (Fuente: AEMET) 


\section{FENÓMENO INCENDIOS FORESTALES}

\subsection{Descripción de las condiciones favorables a la ocurrencia de incendios forestales.}

Los incendios forestales pueden producirse por causas naturales (rayos asociados a tormentas secas) o por la acción del hombre (intencionados, negligencias, causas accidentales, etc.

Las condiciones meteorológicas juegan un papel muy importante inicialmente al favorecer la existencia de combustible seco que pueda favorecer la ignición (temperaturas elevadas, humedad relativa baja, vientos desecantes). Una vez desatado el incendio, el viento comienza a ser el elemento más importante (en el caso de que no se puedan producir precipitaciones) influyendo en la propagación y facilitando/obstaculizando las labores de extinción en función de sus cambios de intensidad y dirección.

\subsection{Particularidades locales}

En el caso de Gran Canaria y tomando como fuente los datos del Instituto Canario de Estadística (ISTAC) para el período 2000-2015, tenemos que por término medio se producen unos 50 incendios forestales al año, con una superficie forestal afectada media de 1268 hectáreas al año (que descontando el caso de 2007 sería de 106 hectáreas año).

El año que se produjeron más incendios forestales fue el 2006 con 69 casos y el en que se vio afectada más superficie forestal fue el 2007 con 18 701, 10 hectáreas (la isla de Gran Canaria tiene una superficie total de 156000 hectáreas).

Si se pone atención en las causas, en el período considerado solo hay un caso atribuido a la caída de rayos (en 2005) y dejando aparte los de causa desconocida (51,6\%), se tiene que debidos a negligencia y causas accidentales son el $25,8 \%$ e intencionados el $21,2 \%$.

Por la situación geográfica del archipiélago, lógicamente los flujos que generarán condiciones favorables para los incendios forestales serán los de componente este, cálidos y secos.

Según el ISTAC los dos mayores incendios que han afectado a Gran Canaria desde el año 2000 fueron el de 2007, que se produjo entre el 27 de julio y el 2 de agosto, con 18972 hectáreas afectadas y el de los días 20 a 23 de septiembre de 2017 con 2800 hectáreas.

\subsection{Episodios de condiciones favorables a los incendios forestales y patrón atmosférico típico.}

A título de ejemplo se puede ilustrar la situación meteorológica del incendio de 2007, que ha sido el mayor incendio forestal acaecido en la isla de Gran Canaria, desde que se tienen 
registros. Fue provocado por un trabajador forestal que ha sido recientemente juzgado y condenado. El foco inicial se localizó en el Parque Natural de Pilancones, en la zona de cumbre de la vertiente sur-suroeste.

Afectó a la tercera parte de la superficie forestal de la isla, dañando viviendas, fincas e incluso un parque temático ("Palmitos Park"). Ocasionó pérdidas materiales por valor de unos 90 millones de euros.

A nivel sinóptico existía una situación anticiclónica, entre 1012-1016 hPa sobre Canarias y un centro de bajas presiones de $1008 \mathrm{hPa}$ en el oeste del Sahara. Esta situación generaba un flujo de Nordeste a niveles bajos y de Este moderado a fuerte en medianías y cumbres.

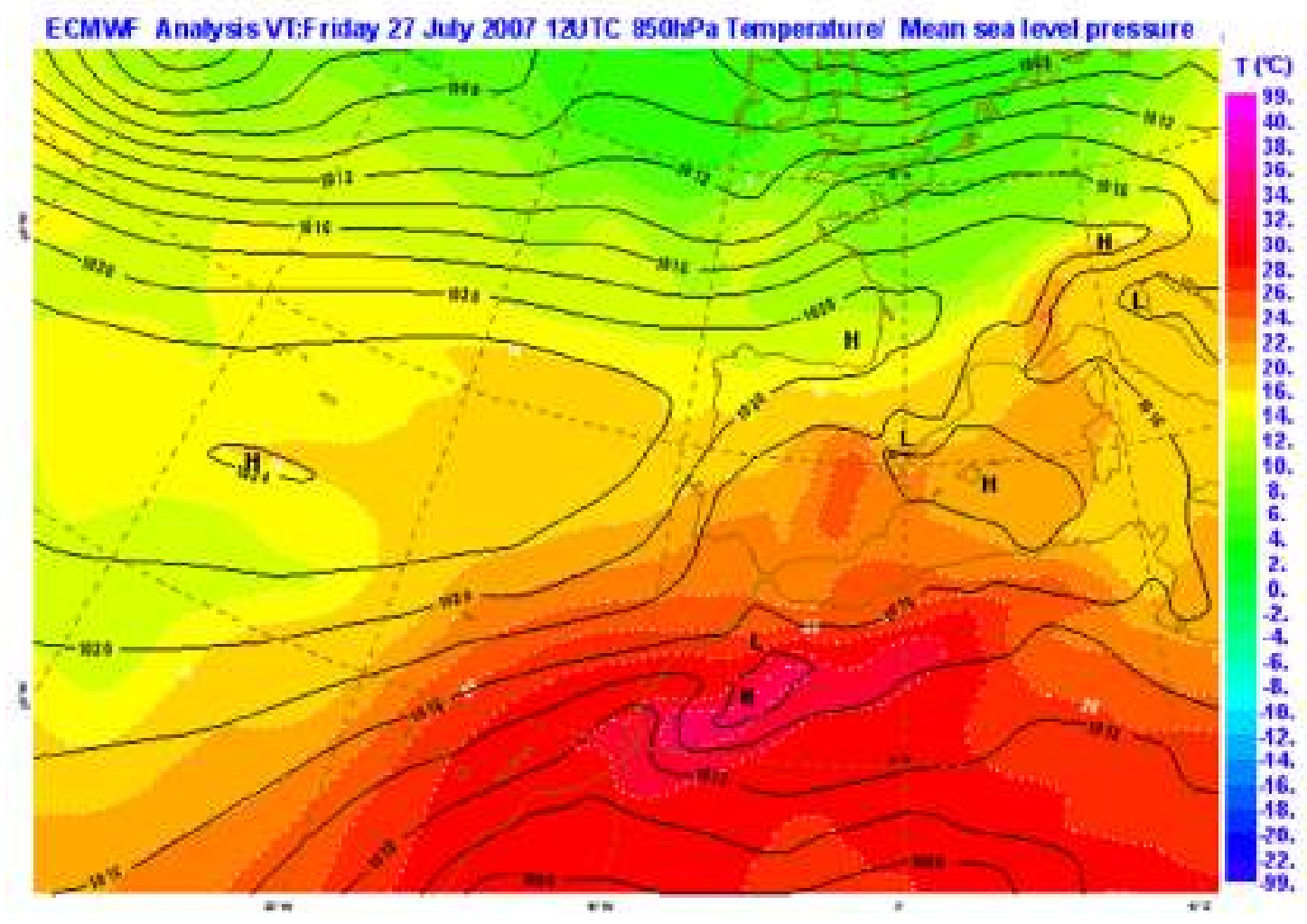

Figura 66: Análisis de superficie, 12 horas del 27 de julio de 2007. (Fuente: AEMET)

En $500 \mathrm{hPa}$ había una situación de total estabilidad con un máximo de geopotencial centrado sobre la vertical de Marruecos y temperaturas que en Canarias podrían estar en torno $\mathrm{a}-5{ }^{\circ} \mathrm{Co}-6{ }^{\circ} \mathrm{C}$. 


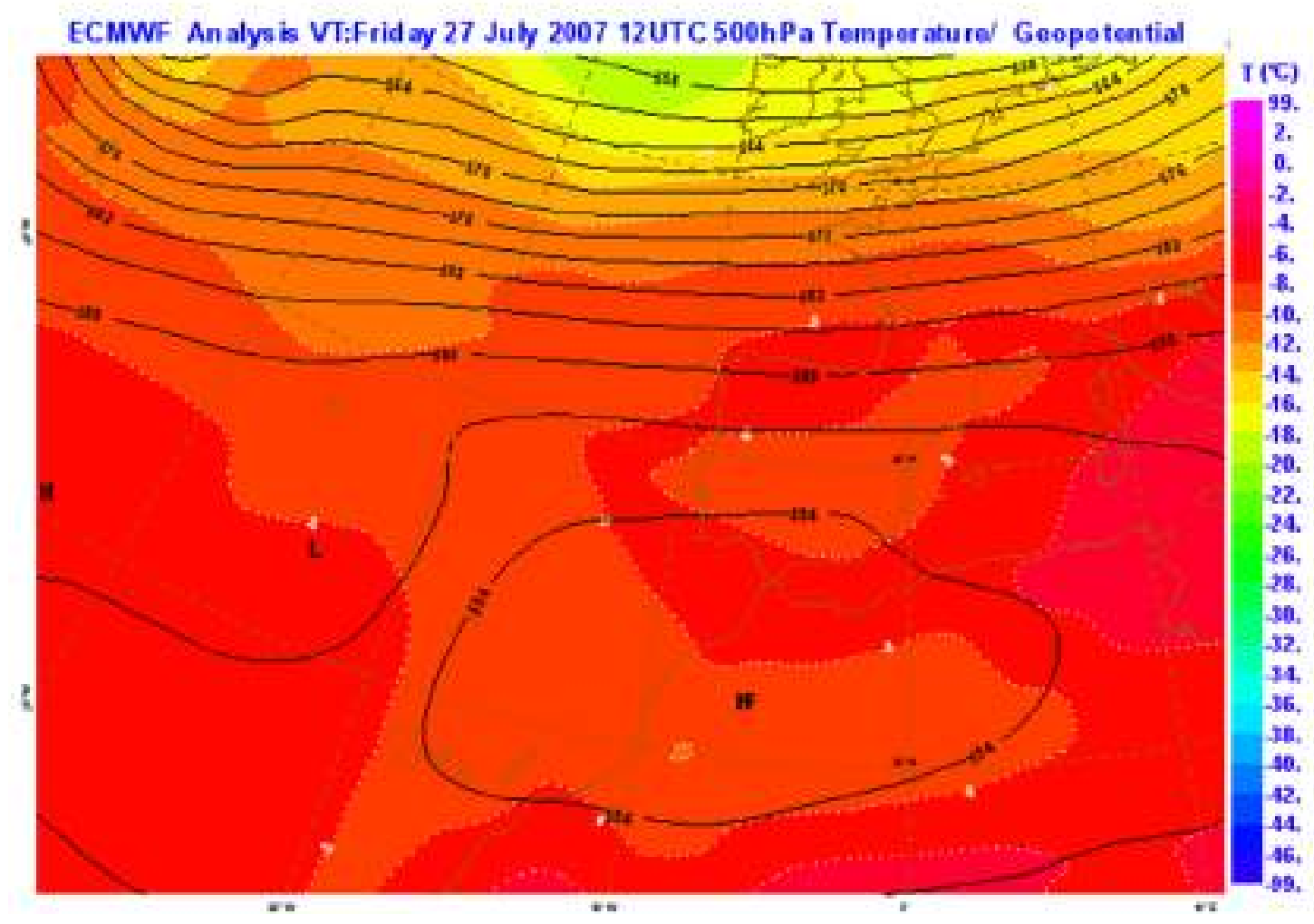

Figura 67: Análisis de 500 hPa, 12 horas del 27 de julio de 2007. (Fuente: AEMET)

Se emitieron avisos amarillos por temperaturas de $34{ }^{\circ} \mathrm{C}$ y $35{ }^{\circ} \mathrm{C}$ para cumbres de Gran Canaria, desde el día 27 de julio, extendiéndose hasta el día 31 de julio, en el que se elevó a nivel naranja. El día 31 de julio se emitió aviso amarillo por vientos de $70 \mathrm{~km} / \mathrm{h}$ para esa misma zona de cumbre.

Las temperaturas máximas registradas en las estaciones de las islas ese día ofrecían la siguiente distribución:

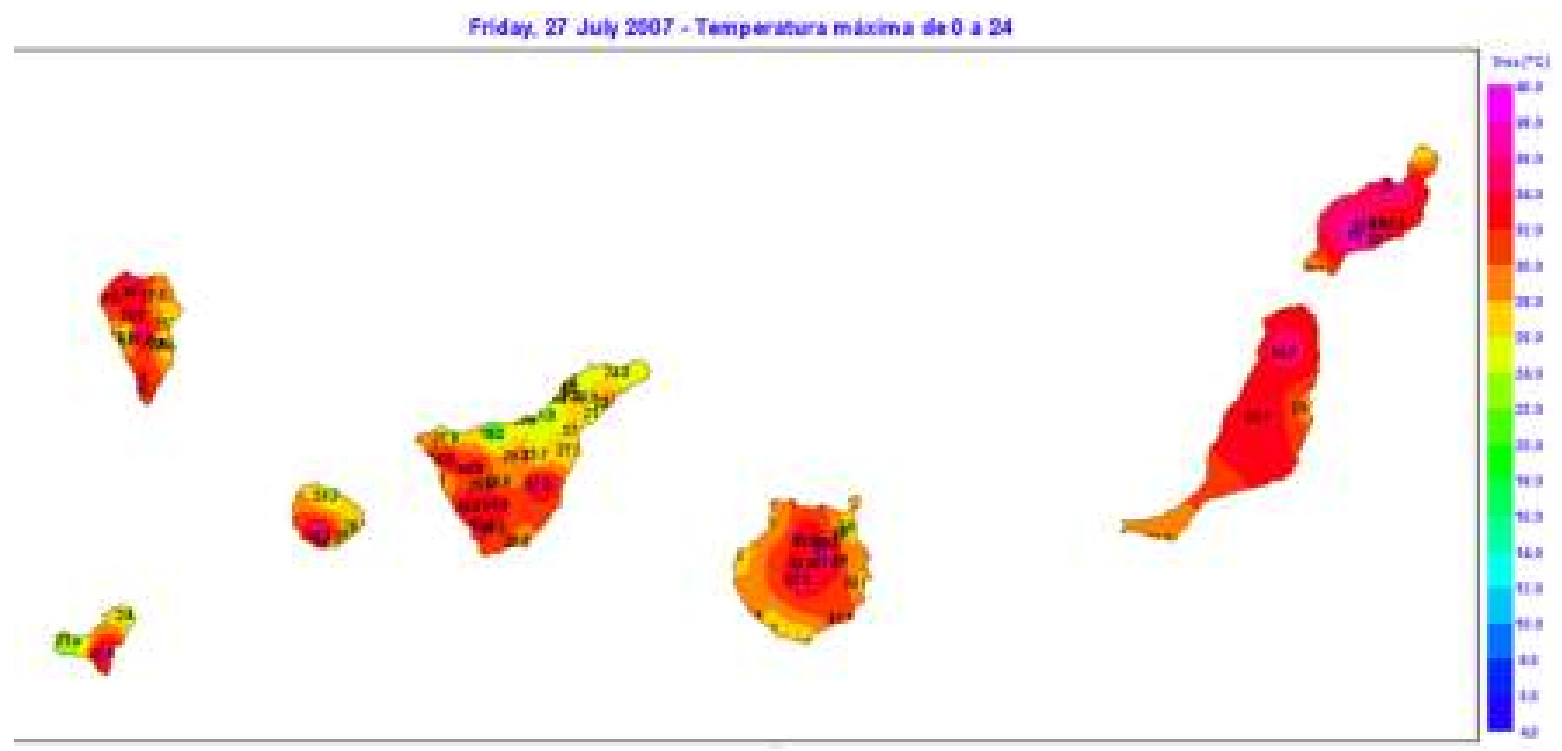

Figura 68: Temperaturas máximas observadas en 24 horas durante el 27 de julio de 2007. (Fuente: AEMET) 
Las temperaturas extremas diarias registradas en la estación meteorológica automática más cercana al foco inicial del incendio, durante los días de inicio y propagación del mismo fueron las siguientes:

San Bartolomé de Tirajana-Cuevas del Pinar. Altitud: 1217 metros

\begin{tabular}{|l|l|l|l|l|}
\hline Días & $\begin{array}{l}\text { Temperaturas } \\
\text { Máximas }\end{array}$ & $\begin{array}{l}\text { Hora } \\
\text { T.Máxima }\end{array}$ & $\begin{array}{l}\text { Temperaturas } \\
\text { Mínimas }\end{array}$ & $\begin{array}{l}\text { Hora T. } \\
\text { Minima }\end{array}$ \\
\hline $26 / 7 / 2007$ & 32,5 & $16: 14$ & 22,9 & $0: 51$ \\
\hline $27 / 7 / 2007$ & 35,5 & $15: 31$ & 26,7 & $6: 05$ \\
\hline $28 / 7 / 2007$ & 37,4 & $16: 22$ & 29,4 & $2: 11$ \\
\hline $29 / 7 / 2007$ & 38,0 & $16: 44$ & 29,5 & $6: 06$ \\
\hline
\end{tabular}

Tabla 12: Temperaturas extremas diarias en la estación más cercana al foco inicial del incendio. (Fuente: AEMET)

Aunque en el momento en el que aconteció el incendio, AEMET no disponía de estaciones meteorológicas con registro de humedad relativa en la cumbre de Gran Canaria, las estaciones costeras, como la del Aeropuerto o la de San Cristóbal en las Palmas de Gran Canaria, registraron valores de humedad relativa inferiores al $45 \%$, e incluso llegando a valores del $10 \%$, en el período comprendido entre los días 26 y 31 de julio.

Tampoco se disponía de registros de viento de estaciones situadas en la cumbre de Gran Canaria. En la estación meteorológica del Aeropuerto de Gran Canaria, las rachas máximas estuvieron comprendidas entre los 60 y los $70 \mathrm{~km} / \mathrm{h}$ y de componente norte, durante esos días.

Basados en todos los datos disponibles en la red de observación la distribución de las rachas máximas de viento fue la siguiente:

en todos los datos disponibles en la red de observación la distribución de las rachas máximas de viento fue la siguiente: 


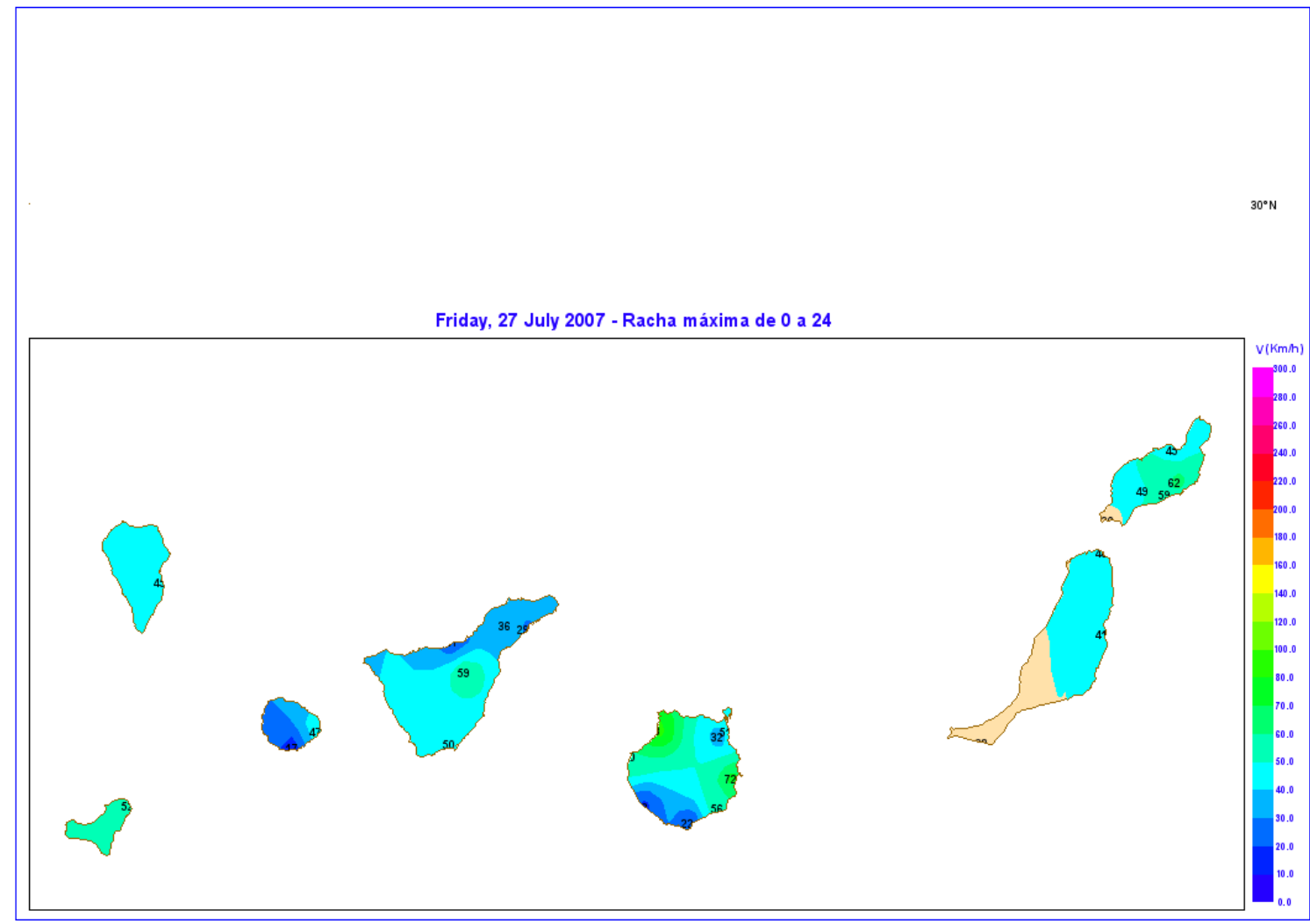

Figura 69: Rachas máximas observadas en 24 horas durante el 27 de julio de 2007. (Fuente: AEMET) 


\section{FENÓMENOS COSTEROS}

\subsection{Descripción de los fenómenos costeros como adversos}

El viento, al pasar sobre el mar, le transfiere parte de su energía, lo que provoca ondulaciones u olas en su superficie que se propagan en la misma dirección del viento, si su fuerza y dirección son constantes. La energía transportada por la ola es directamente proporcional al cuadrado de su altura, es decir, a la distancia vertical entre una cresta y un seno consecutivos. La altura de la ola aumenta con la velocidad del viento, el número de horas que sopla y la distancia recorrida en la zona generadora de las olas. Las olas que llegan a las costas de las islas Canarias son de dos tipos bien diferenciados, que dan lugar a sendos estados de la mar: mar de viento y mar de leva o fondo. En el mar de viento, el oleaje se encuentra bajo la acción del viento que lo genera; mientras que en el mar de fondo, las olas producidas en las zonas generadoras, al transmitirse, llegan a un lugar determinado en ausencia de viento.

\subsection{Particularidades locales de los fenómenos costeros}

Las costas Canarias tienen una longitud total de 1583 kilómetros. De manera general, en cada isla se distinguen la costa norte, formada por altos acantilados, y la costa sur, de carácter abierta y arenosa con una mayor cantidad de playas. Un rasgo característico de todo el archipiélago es la estrechez de la plataforma continental.

En general el litoral canario es el resultado de la combinación de procesos destructivos (erosión marina) y procesos constructivos (erupciones), de origen volcánico. Por tanto, y como resultados de estos factores, el litoral del archipiélago es abrupto y rocoso en general, aunque no obstante, existen excepciones Maspalomas (Gran Canaria), Famara (Lanzarote) y Jandía (Fuerteventura), que responden a un periodo volcánico más antiguo y menos dilatado en el tiempo, y a una plataforma bajo el agua más amplia, que favorece los procesos de acumulación.

Las islas se han formado en la parte oceánica de la placa africana, cerca del talud continental de la costa noroeste africana y están distribuidas transversalmente respecto a la corriente marina dominante, conocida como Corriente de Canarias, con canales de separación entre ellas relativamente cortos y, generalmente, de gran profundidad.

Por su naturaleza volcánica y juventud, la mayoría de las islas carecen de una plataforma insular extensa, siendo el conjunto Lanzarote - Fuerteventura y las islas de Gran Canaria y La Gomera las que presentan plataformas submareales más amplias, sin duda como consecuencia de su mayor edad. Por el contrario, las islas más jóvenes, como es el caso de La Palma y El Hierro prácticamente no poseen plataforma marina y en muchos sectores costeros es posible alcanzar los $200 \mathrm{~m}$ de profundidad a muy poca distancia de la costa 
(100-200 m). En general, las costas de las islas occidentales (La Palma, El Hierro y La Gomera), sobre todo las orientadas al norte y oeste, son muy acantiladas y carecen casi de playas, las cuales, cuando existen, se encuentran en la desembocadura de los barrancos principales y están formadas principalmente por cantos rodados ("callaos") de diverso calibre o por arenas negras volcánicas.

A pesar de la presencia de riesgos extremos, la mayoría de las poblaciones de las islas y las actividades económicas tienden a agruparse a lo largo de las costas, lo que amplifica la vulnerabilidad. Además, las costas han experimentado recientemente un aumento de la amenaza como resultado del rápido crecimiento de la población. Todos estos factores contribuyen a una mayor vulnerabilidad humana y riesgo costero. Hay que tener en cuenta los siguientes riesgos a la hora de la planificación del territorio en zonas costeras:

Aumento del nivel del mar, tormentas, la erosión costera, los tsunamis, deslizamientos de tierras, inundaciones y actividad sísmica / volcanes.

En verano, la zona de Canarias se ve afectada, bajo la acción de los alisios, por olas de viento del Noreste, por lo que principalmente las costas a barlovento de dichos vientos están sometidas a un oleaje casi persistente, que no suele alcanzar los $3 \mathrm{~m}$ de altura.

En aguas someras, de profundidad inferior a media longitud de onda, es decir, inferior a la mitad de la distancia entre dos crestas consecutivas, la acción del fondo afecta el avance de la ola, y si ésta incide formando un ángulo con la línea de la costa, se frenará primero la parte de ella que llega antes a aguas someras.

Por eso, los frentes de las olas o líneas de crestas, que son prácticamente rectilíneos en mar abierto, se curvan al llegar a aguas someras, es decir, se refractan y tienden a situarse paralelos a las costas de las diferentes islas del Archipiélago.

Cuando la relación de la profundidad y la altura de la ola es de aproximadamente 4/3, ésta rompe disipándose su energía, que se reparte desigualmente, debido a la refracción, a lo largo del frente de la ola. La energía se concentra especialmente en las partes de la ola que rompen en las puntas y cabos, sobre todo si junto a éstos los fondos son relativamente aplacerados.

En otoño, aunque el oleaje dominante es también del Noreste, el debilitamiento del anticiclón de las Azores hace que en la zona de Canarias su intensidad disminuya, produciéndose periodos de poco oleaje, frecuentemente interrumpidos por borrascas que, al atravesar el océano Atlántico Norte en su camino hacia Europa, suelen afectar a Canarias, especialmente en invierno. 
Cuando estas borrascas están muy distanciadas, el oleaje producido, a veces con altura superior a $10 \mathrm{~m}$, se propaga hacia el Sur, pudiendo alcanzar las islas Canarias como mar de fondo, después de recorrer hasta $3500 \mathrm{~km}$ en los que ha invertido de 2,5 a 3,5 días.

En general, procedente del primer cuadrante y, sobre todo, del cuarto, la mar de fondo llega a las costas canarias, donde se refracta, su longitud de onda se acorta y sus crestas, antes redondeadas y suaves, se agudizan, aumentando la altura de la ola que en ciertas partes de la costa, donde su energía se concentra, puede superar los 3,5 m. Otras veces, las borrascas pasan a menor latitud, originando fuertes vientos de componente Norte que afectan al Archipiélago y, en algunas ocasiones, producen olas del orden de $3 \mathrm{~m}$, sobre todo en las costas septentrionales de las Islas.

Cuando las borrascas están muy próximas a Canarias, pueden causar fuertes vientos y oleaje del Suroeste, originando temporales poco comunes, en las costas canarias sudoccidentales.

A medida que la primavera avanza, la situación anticiclónica en la zona de Canarias se refuerza, la influencia de las borrascas disminuye y el oleaje tiende a ser exclusivamente generado por los vientos alisios.

De forma general, en relación al oleaje, en todas las islas es resultado de la combinación del oleaje local, controlado por los alisios, y del generado por tormentas lejanas localizadas en el Atlántico norte y que pueden provocar situaciones conocidas como de "reboso" o "mar de fondo".

La situación normal es la de los alisios, que dejan un oleaje más tranquilo que los episodios tormentosos, en los que se han registrado olas de hasta $9 \mathrm{~m}$ de altura. La acción de los alisios junto con el efecto de barrera que ejerce el propio archipiélago al flujo de la Corriente de Canarias, crea condiciones para que a sotavento de las islas, especialmente en las de mayor relieve, se establezcan zonas de calma.

Estas zonas están menos batidas por el viento y en ellas las aguas se mezclan menos con las de la corriente general, dando lugar a zonas de aguas más cálidas y estables.

\section{Mareas}

La distribución de los continentes en la dirección Norte - Sur impide que la onda de marea se propague libremente de Este a Oeste, salvo en el océano Antártico, sin tierras en esa dirección. Por ello, la onda de marea se forma en dicho océano, desde donde, afectada por la configuración de las costas, por la profundidad y la topografía del fondo, penetra en el Atlántico y se desplaza hacia el Norte, alcanzando las islas Canarias y las costas atlánticas de altas latitudes. 
Así, por ejemplo, la onda de marea que produce pleamar a su paso por la latitud del cabo de Buena Esperanza, ocasiona unas 13,5 horas después la correspondiente pleamar en las islas Canarias, al propagarse hacia el Norte con una velocidad de $560 \mathrm{~km} / \mathrm{h}$.

En las islas Canarias, como en casi todas las costas atlánticas, las mareas son semidiurnas, es decir, que cada día lunar (24 horas y 50 minutos) se producen dos pleamares, o niveles máximos, y dos bajamares, o niveles mínimos, siendo aproximadamente iguales las amplitudes o distancias verticales entre pleamares y bajamares consecutivas.

Como es bien conocido, la amplitud de la marea varía a lo largo del año alcanzando valores máximos durante los equinoccios de primavera y otoño, en concreto en marzo y septiembre respectivamente, y que en las costas canarias son del orden de $3 \mathrm{~m}$.

Igualmente, la amplitud de la marea es mínima durante los solsticios: a principios de verano e invierno, alcanzando valores de hasta 0,7 m aproximadamente. Las horas y alturas teóricas de las pleamares y bajamares de todos los días del año, para diferentes puertos del Archipiélago Canario, vienen dadas en el Anuario de Mareas, publicado por el Instituto Hidrográfico de la Armada.

En las mareas influyen unos factores fijos, como la topografía del fondo y la configuración de la costa, y otros variables, como son ciertos fenómenos meteorológicos.

Así, por ejemplo, las playas con pendientes pronunciadas favorecen en general las mareas, mientras que los incrementos de presión favorecen las bajamares y perjudican las pleamares. Igualmente, el viento que sopla desde el mar con cierta intensidad y constancia, al acumular agua junto a la costa, incrementa la amplitud de la marea junto a ella, y la disminuye si sopla en sentido opuesto.

Por esa razón, tanto la batimetría como el viento, especialmente en verano, favorecen las mareas en las costas septentrionales de las islas.

Para analizar cómo afectan los fenómenos costeros a Gran Canaria, se ha hecho uso de los informes de boyas extraídos de la página web de Puertos del Estado [PUERTOS].

Los siguientes informes resumen el clima medio del oleaje para la boya de Las Palmas Este, perteneciente a la red costera. 


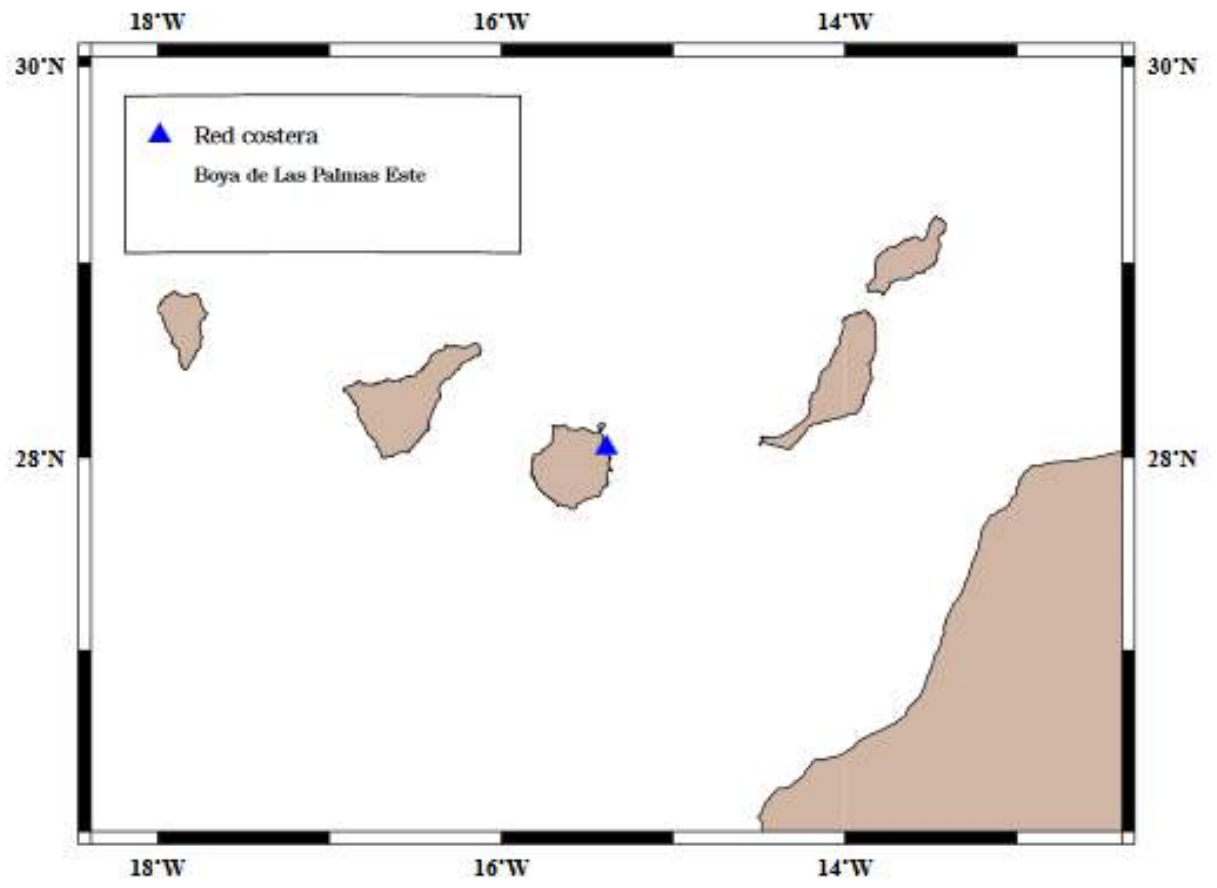

Figura 70: Red costera donde se muestra la localización de la boya Las Palmas Este. (Fuente: [PUERTOS])

En primer lugar se muestra las distribuciones de frecuencia para el periodo pico y la altura significativa a lo largo del año. La serie analizada comprende desde febrero de 1992 a agosto de 2017.

Se observa que en torno a un $42 \%$ el periodo pico registrado es de entre 6 a 8 segundos. Por otro lado la altura significativa es de entre 0,5 a 1,5 metros con una frecuencia superior al $60 \%$. 
Disfribución Conjunta de Periodo de Pico y Altura Significativa

Leigna : Boya de Las Palmas Este

Prziono : Anual

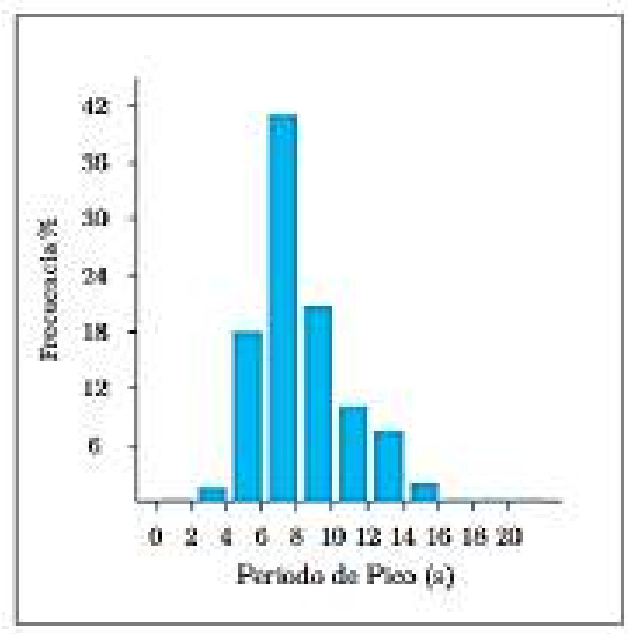

SeriE ANALIzada : Feh. $1992-$ Ago. 2017

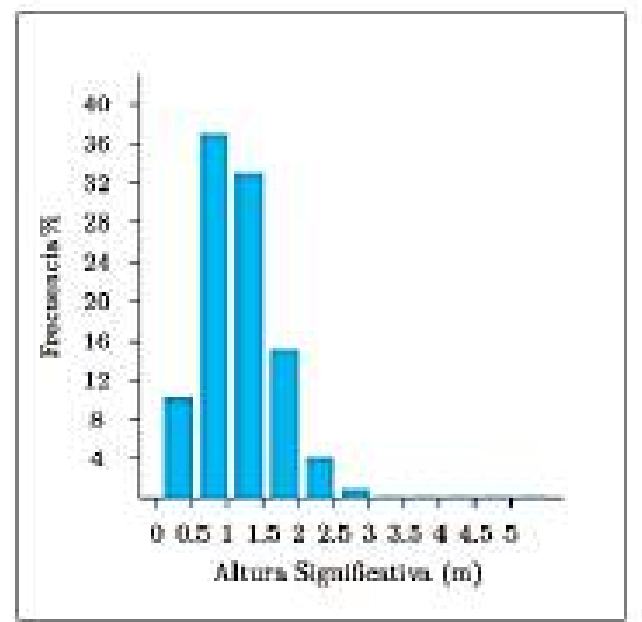

A continuación se muestra los gráficos por estaciones de periodo pico y altura de ola significativa para el análisis de la variabilidad estacional:

Distrabución Conjunta de PBriodo dB Pico Y Altura Sigaificativa

Lugak : Boya de Las Palmas Este

Prriono : Dic. - Feh.

Seriz Aramzada : Reb. 1992 - Ago. 2017
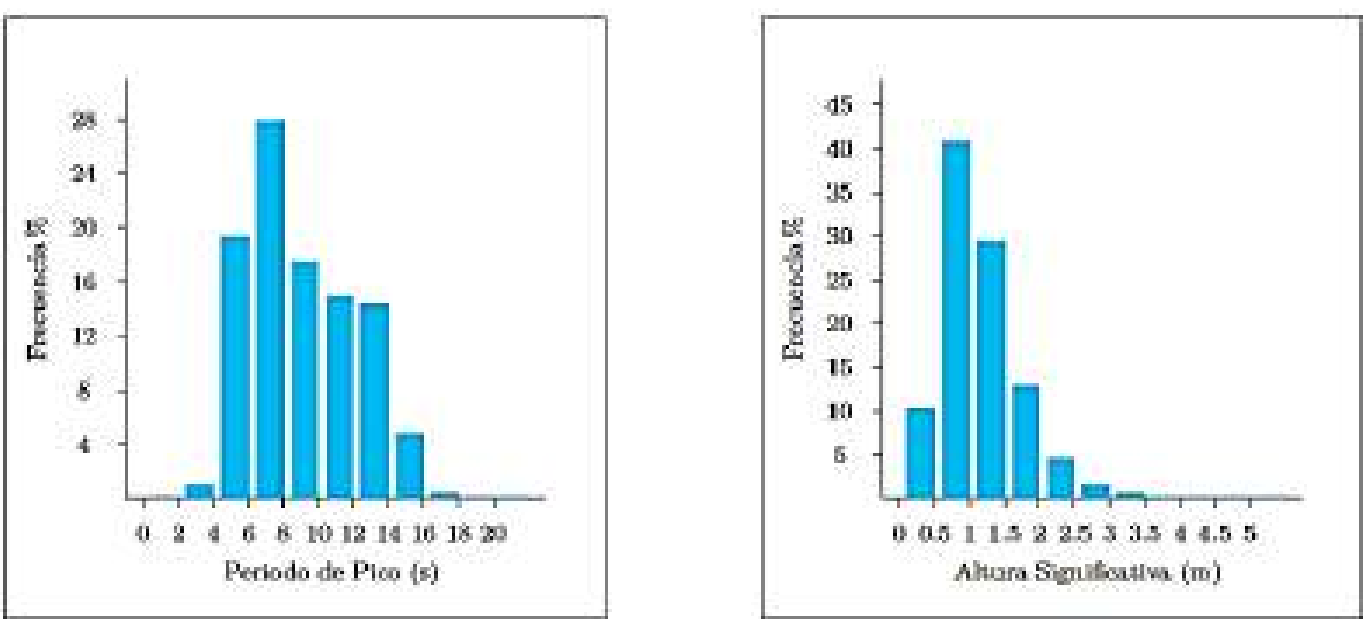
Distumución Conjunta de Pezuodo de Pico Y Altura Significativa

Lugart : Days de Las Palmas Exte

Peruodo : Mar. - May.

Sefue AnsLiznda : Feb. 1992 - Ago. 2017
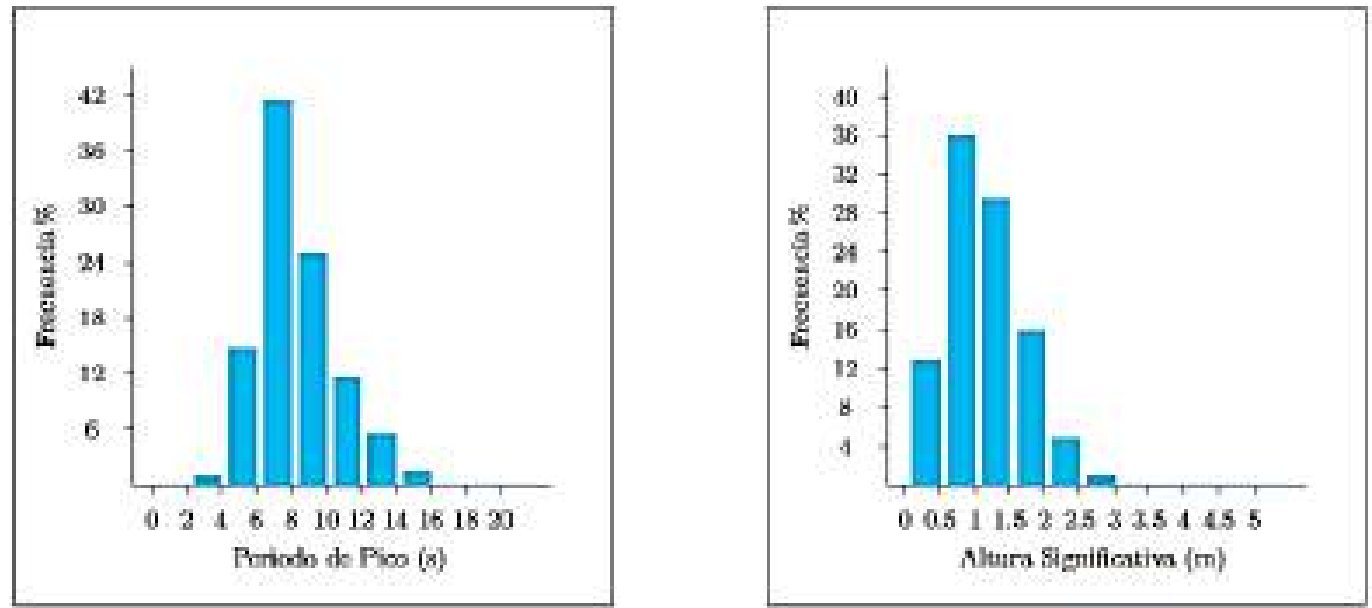

Distrabución Conjunta de PERIodo de Pico Y Altula Significativa

Lugar ; Boys de Las Palmas Este

Priodo : Jun. - Ago

Serar ANג1.rsd = Feb. 1992 - Ago. 2017
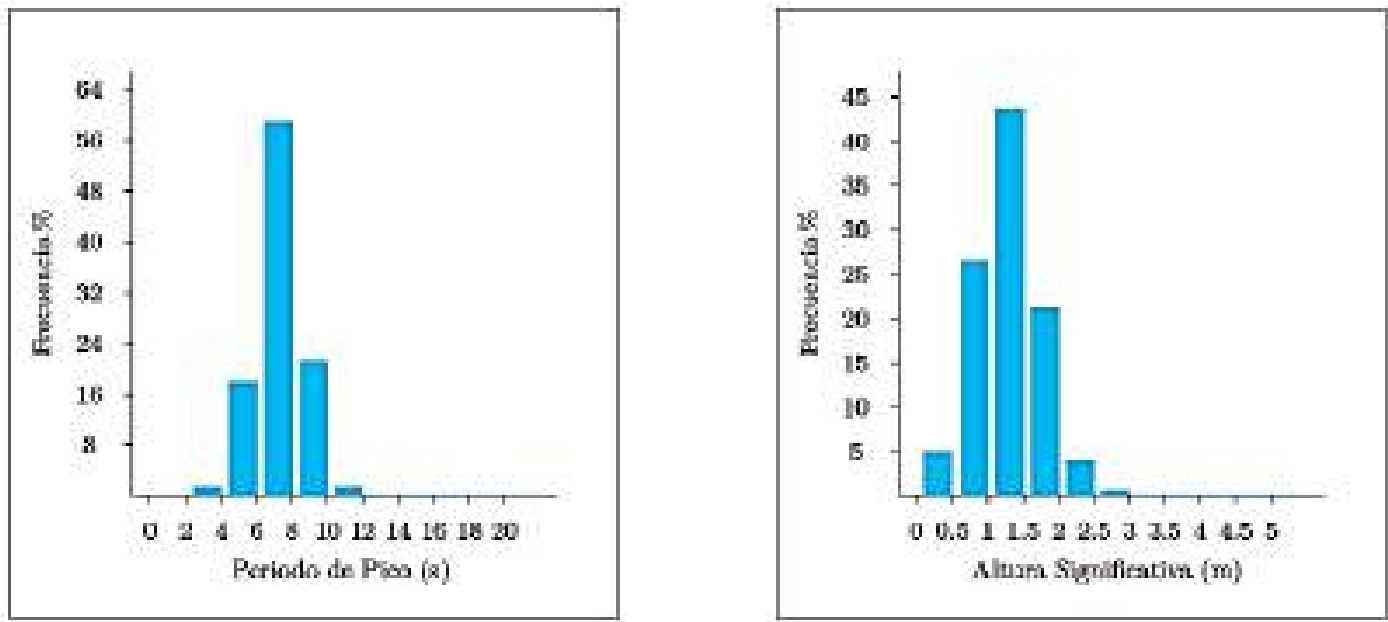
PERIODO : Sep - Now:

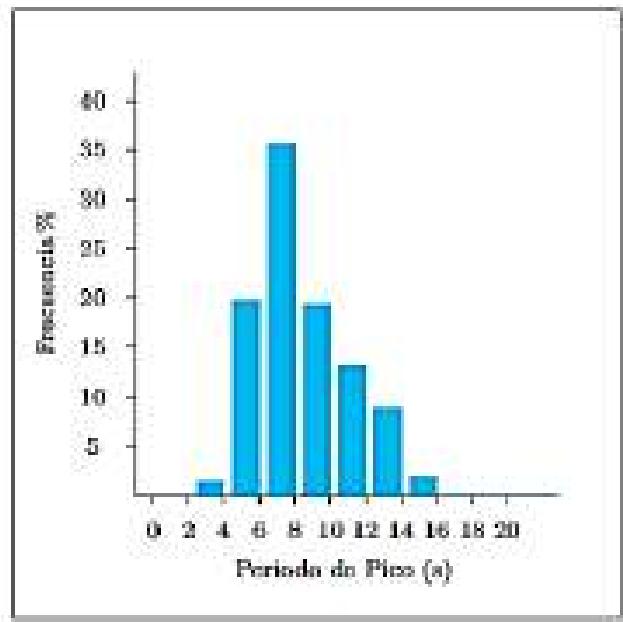

SERIE ANALIZADA ; Feb. 1002 - Ago, 2017

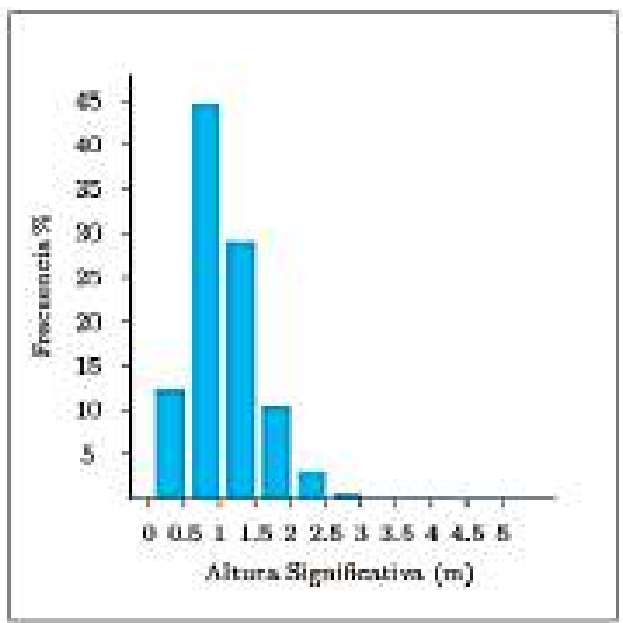

Figura 71: Periodo pico y altura significativa durante distintos periodos (Fuente: [PUERTOS])

Lo más significativo de estos gráficos es ver el aumento, por efecto de los alisios más intensos, de la altura de ola significativa durante los meses de verano, que con una frecuencia de $45 \%$ dominan las alturas de 1 a $1,5 \mathrm{~m}$.

Debido al predominio del régimen de alisios el oleaje proviene mayoritariamente del Nordeste:

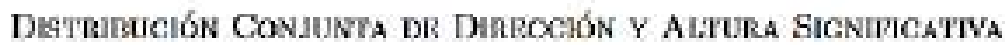

Lugar : Boya de Las Palmas Feste

Curtereo pB Drueczoness; Procedeacia

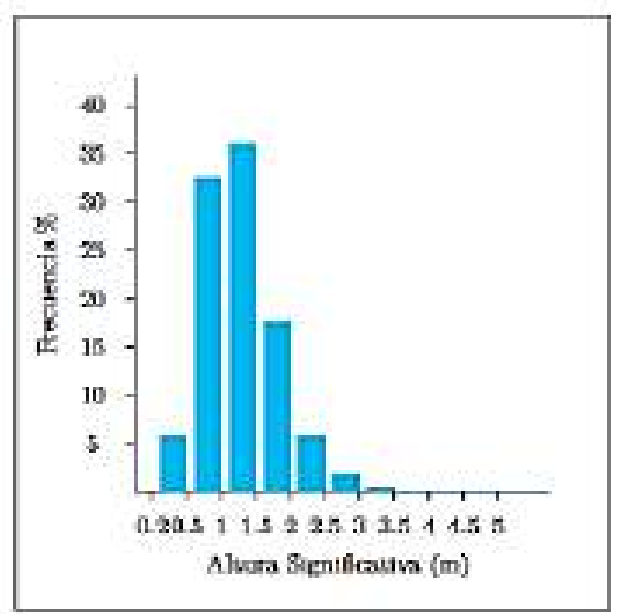

\section{PBRTODO : Annal}

Sezue Ascurand ; Ene, 2014 - Ago. 2017

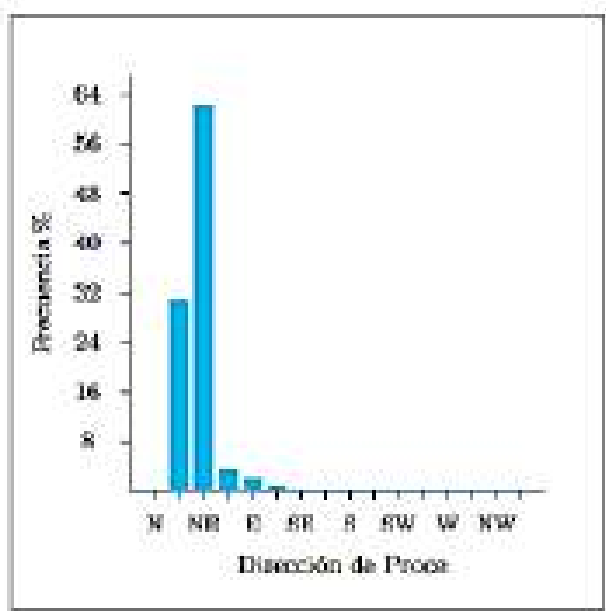

Figura 72: Dirección y altura significativa periodo anual (Fuente: [PUERTOS]) 
Este oleaje incide con el litoral de la fachada norte de Gran Canaria, provocando una altura de ola mayor en estas cosas, mientras que en la vertiente de sotavento, los litorales sur quedan resguardados al oleaje y vientos predominantes presentando zonas de calmas.

En el gráfico inferior se muestra la duración en días frente al porcentaje de superaciones de una altura de ola significativa de 1,5 metros. Se constata que la duración en días de episodios donde la altura de ola significativa sea superior a dicho umbral, con un porcentaje de $5 \%$ es de 6 días. Se ve que con la serie analizada (febrero de 1999 a agosto de 2017), existe una muy baja probabilidad de que la duración en días de superar la altura significativa de $1,5 \mathrm{~m}$ sea de 15 días.

PORCENTAJE DE SUPERACIONES

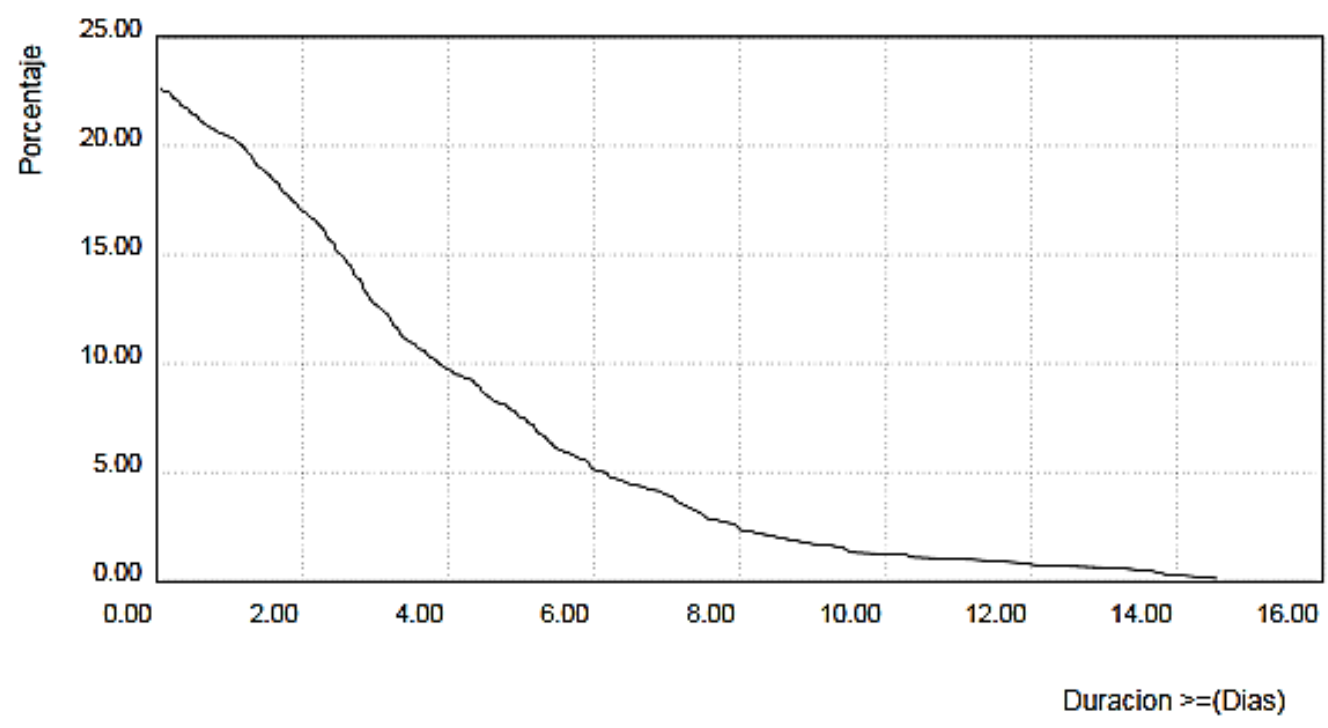

Figura 73: Porcentaje de superación del umbral de 1,5 m de altura de ola significativa durante $x$ días (Fuente: [PUERTOS])

A pesar de que la situación meteorológica predominante sea la de alisios, hay que tener en cuenta los fenómenos costeros asociados a otro tipo de situaciones que pueden tener efectos considerables en Gran Canaria.

Debido a que las infraestructuras portuarias están diseñadas para hacer frente al oleaje proveniente del Nordeste, las situaciones de Sur asociadas a borrascas, generan un gran impacto en las costas e infraestructuras costeras de la isla.

Dentro de estas situaciones de Sur hay que particularizar un tipo de escenario, que debido a ciertas características, la convierten en un fenómeno de interés particular. 
Estas situaciones son los episodios de mar de fondo que generan las borrascas invernales del hemisferio austral, y que al cabo de 4 o 5 días [PORTILLO et al 2007], puede afectar a las costas de Gran Canaria, donde se registra un aumento en los periodos de pico.

Hay que sumar a este fenómeno, que a finales de agosto principios de septiembre, la amplitud de marea es máxima y del orden de 3 metros.

Este tipo de oleaje de alto periodo se caracteriza por ser muy energético. Su peligrosidad se basa en que debido a que afecta principalmente al litoral sur de la isla, que permanece a resguardo del alisio intenso de verano, el mar de viento predominante no es significativo y por lo tanto puede coger a los bañistas desprevenidos. Hay que sumar que normalmente este tipo de oleaje de fondo no supera los umbrales de avisos establecidos en el Plan Meteoalerta y actualmente AEMET no dispone de avisos específicos para este tipo de fenómenos.

\subsection{Patrones atmosféricos relacionados con los fenómenos costeros}

\subsubsection{Situación de borrasca atlántica}

En la siguiente figura se describe el episodio ocurrido el pasado 28 de noviembre de 2014. En ella se muestra la presión a nivel del mar y la temperatura coloreada en $850 \mathrm{hPa}$. Se observa una borrasca situada al noroeste de la península ibérica de $992 \mathrm{hPa}$ y sobre Canarias un flujo intenso del noroeste que generó un oleaje sobre las costas Canarias de 5 a 7 metros.

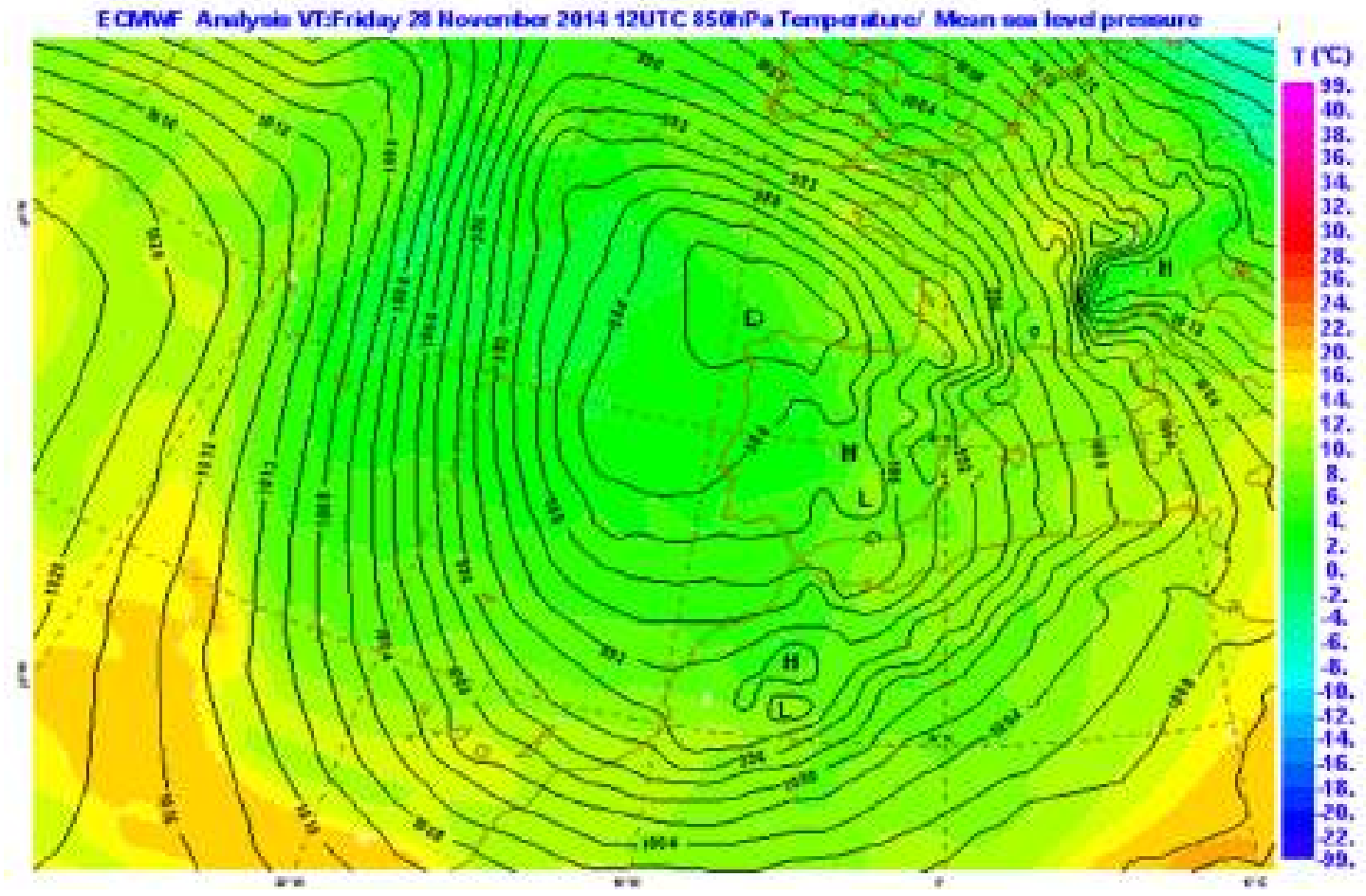

Figura 74: Análisis de superficie, 12 horas del 28 de noviembre de 2014. (Fuente: AEMET) 
En $500 \mathrm{hPa}$ el núcleo frío asociado a la baja en altura situada al noroeste de Portugal y como sobre Canarias soplaba un máximo de vientos del Noroeste en este nivel.

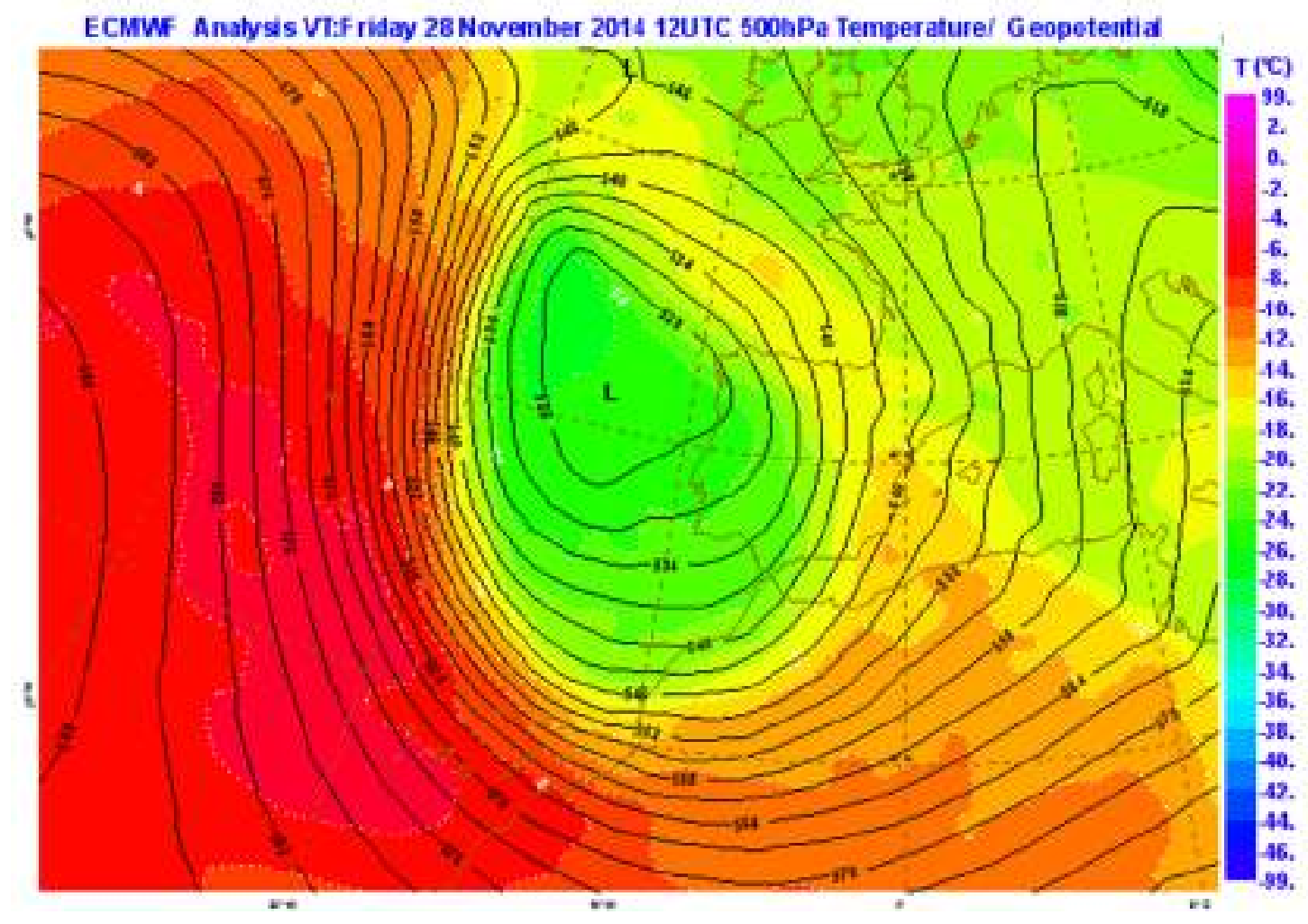

Figura 75: Análisis de 500 hPa, 12 horas del 28 de noviembre de 2014. (Fuente: AEMET)

Se muestra a continuación la serie temporal de la boya de Gran Canaria, consultada para la elaboración de este catálogo. Se ha hecho la consulta en la web de [PUERTOS]

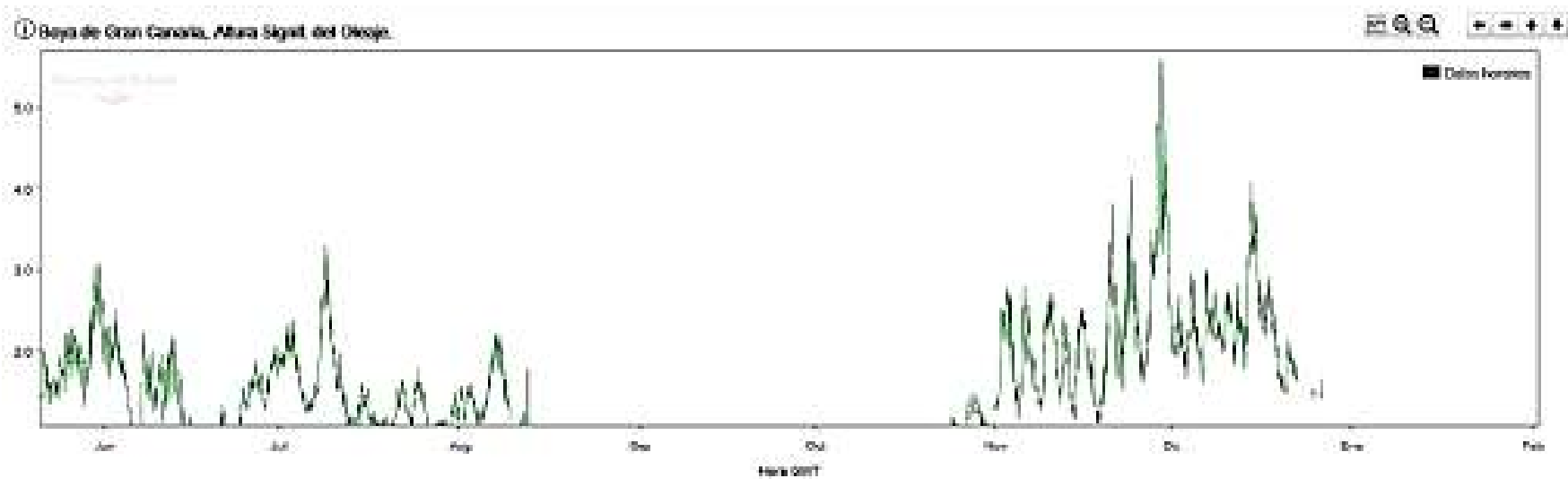

Figura 76: Serie temporal de altura de ola significativa de la boya de Gran Canaria (Fuente: [PUERTOS]) 
Para finales de noviembre de 2014, coincidiendo con la situación arriba analizada, vemos como la altura de ola significativa, supero los 5 metros.

En la siguiente figura se muestra para el mismo periodo y misma boya la altura máxima de oleaje. Destaca como para esta situación la altura de ola máxima registrada por la boya de Gran Canaria fue de 8 metros.

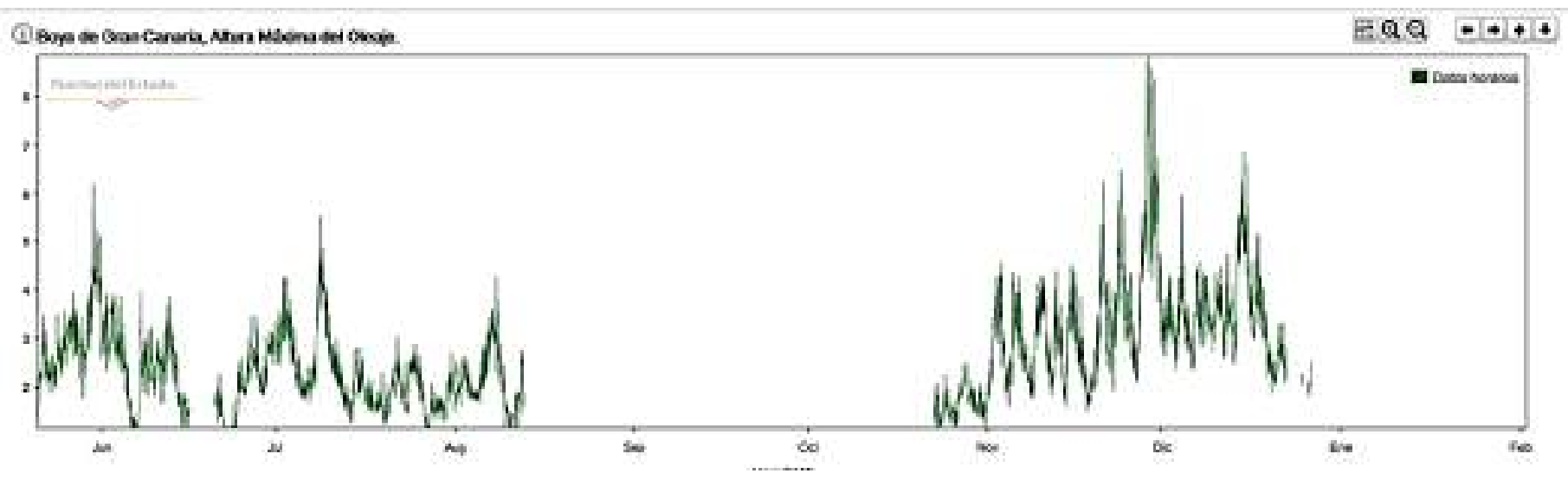

Figura 77: Serie temporal de altura máxima de oleaje de la boya de Gran Canaria (Fuente: [PUERTOS])

\subsubsection{Situación de alisios}

A continuación se analizará un episodio de fenómenos costeros adversos asociado a la situación típica de alisios. Este tipo de situaciones generan condiciones más locales de mal estado de la mar. En Gran Canaria debido a la incidencia del relieve sobre el flujo reinante, este oleaje se realza en los litorales sureste y noroeste de la isla.

Se describen a continuación las condiciones sinópticas que desencadenaron un evento de vientos de fuerza 7 y mar gruesa que afecto a las costas de Gran Canaria.

En superficie se ve reflejado la posición del anticiclón de 1026 hPa y centrado al suroeste de Azores. Por otro lado la baja térmica africana de $1006 \mathrm{hPa}$ situada al oeste de Canarias. Sobre el archipiélago soplaría un flujo intenso del Nordeste. 


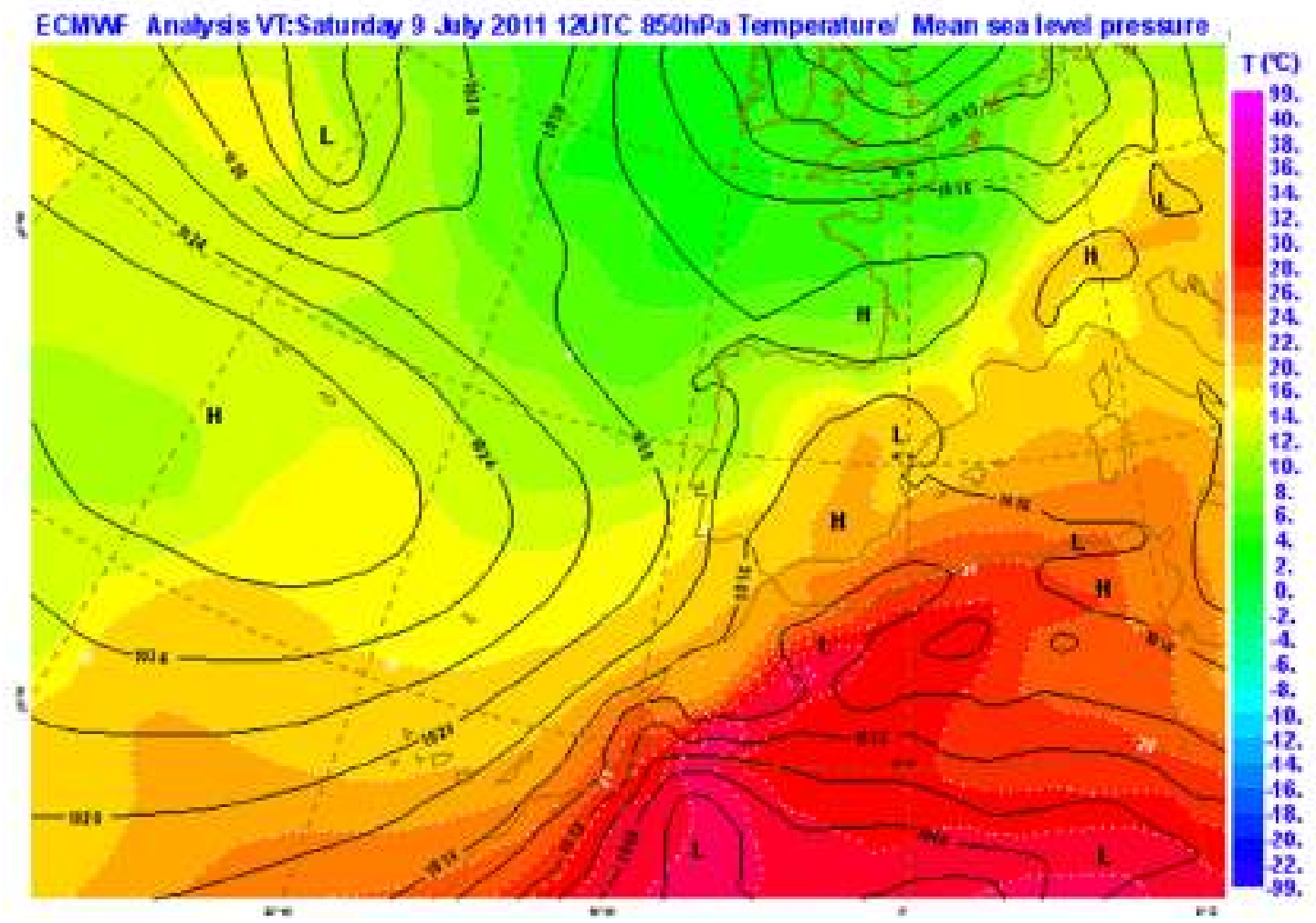

Figura 78: Análisis de superficie, 12 horas del 9 de julio de 2011. (Fuente: AEMET)

En la figura siguiente se ve como para esta situación la boya de Gran Canaria registró una altura de ola significativa de unos 3 metros.

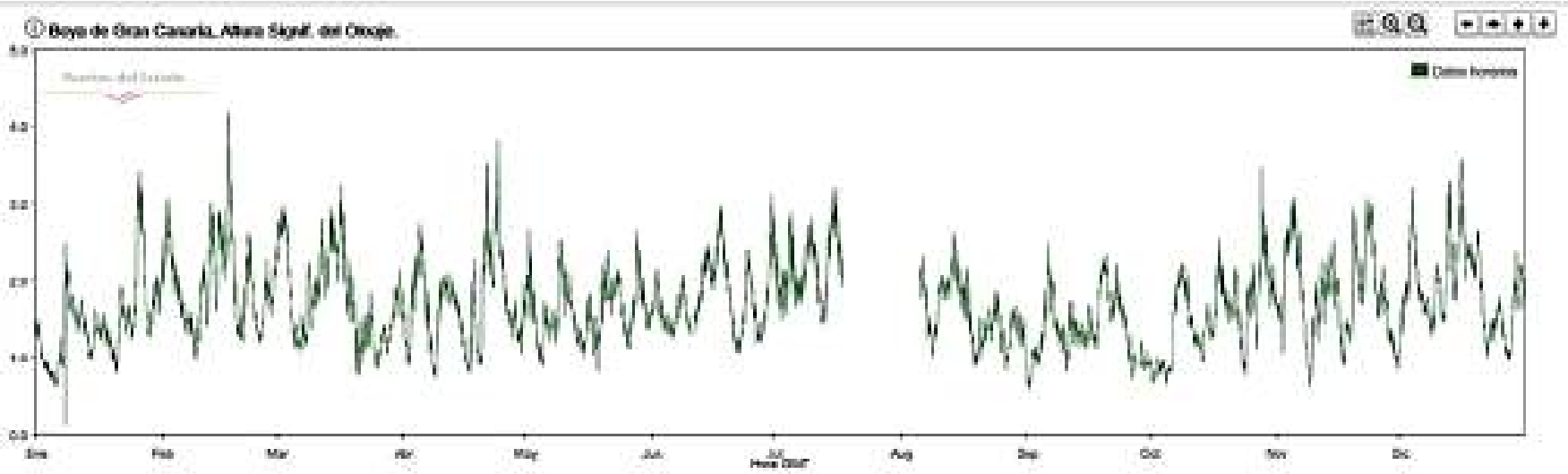

Figura 79: Serie temporal de altura de ola significativa de la boya de Gran Canaria (Fuente: [PUERTOS])

En cambio la altura máxima del oleaje estuvo en torno a los 5 o 6 metros. 


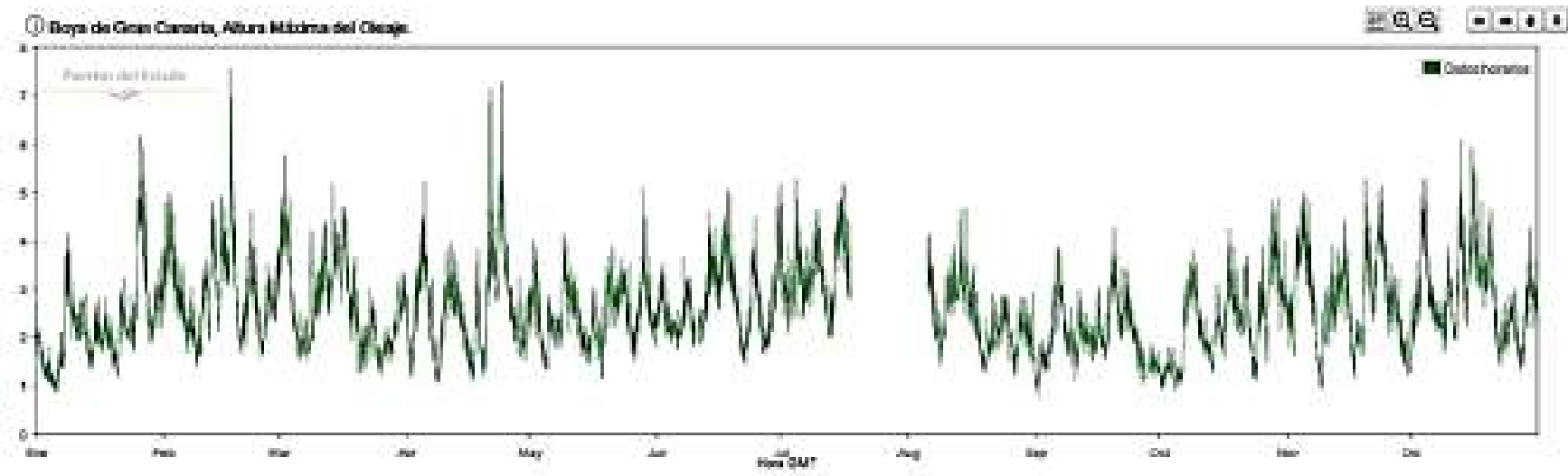

Figura 80: Serie temporal de altura máxima de oleaje de la boya de Gran Canaria (Fuente: [PUERTOS])

\subsubsection{Situación de mar de fondo del sur}

Se comentarán en este punto una situación de las denominadas "situaciones de mar de fondo del sur" introducidas en el apartado anterior.

Para ello se analizan los episodios sucedidos a finales de agosto de 2014 en los cuales fallecieron varios bañistas en las costas sur de Gran Canaria y se ocasionaron numerosos daños en varios paseos marítimos.

Como se expone en la siguiente figura, Canarias quedaba bajo la influencia de un anticiclón de 1020 hPa situado al oeste de Azores, con un flujo en este nivel del nordeste moderado.

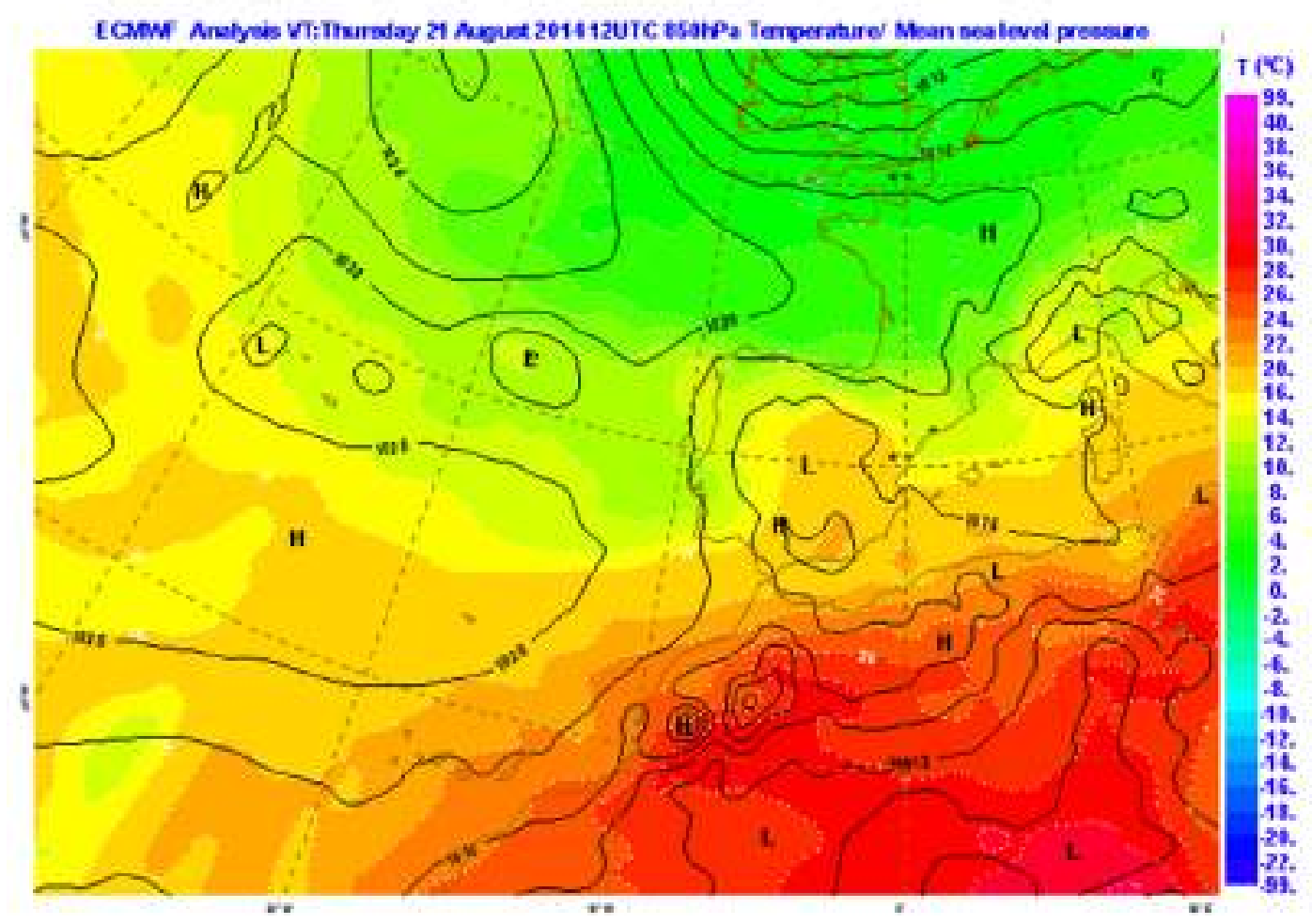

Figura 81: Análisis de superficie, 12 horas del 21 de agosto de 2014. (Fuente: AEMET) 
Sin embargo, durante los días 21 al 28 de agosto de 2014 las costas sur del archipiélago estuvieron afectadas por un mar de fondo del sur con periodos picos de hasta 25 segundos. Como se ha comentado anteriormente, este tipo de oleaje se genera en el invierno del hemisferio sur debido a borrascas.

En la figura inferior queda reflejado como a partir del día 21 de agosto, el periodo pico pasa de 10 segundos a 25 segundos coincidiendo con un cambio en la dirección de procedencia del oleaje, que pasa de $90^{\circ}$ (dirección este) a 225 (dirección suroeste).

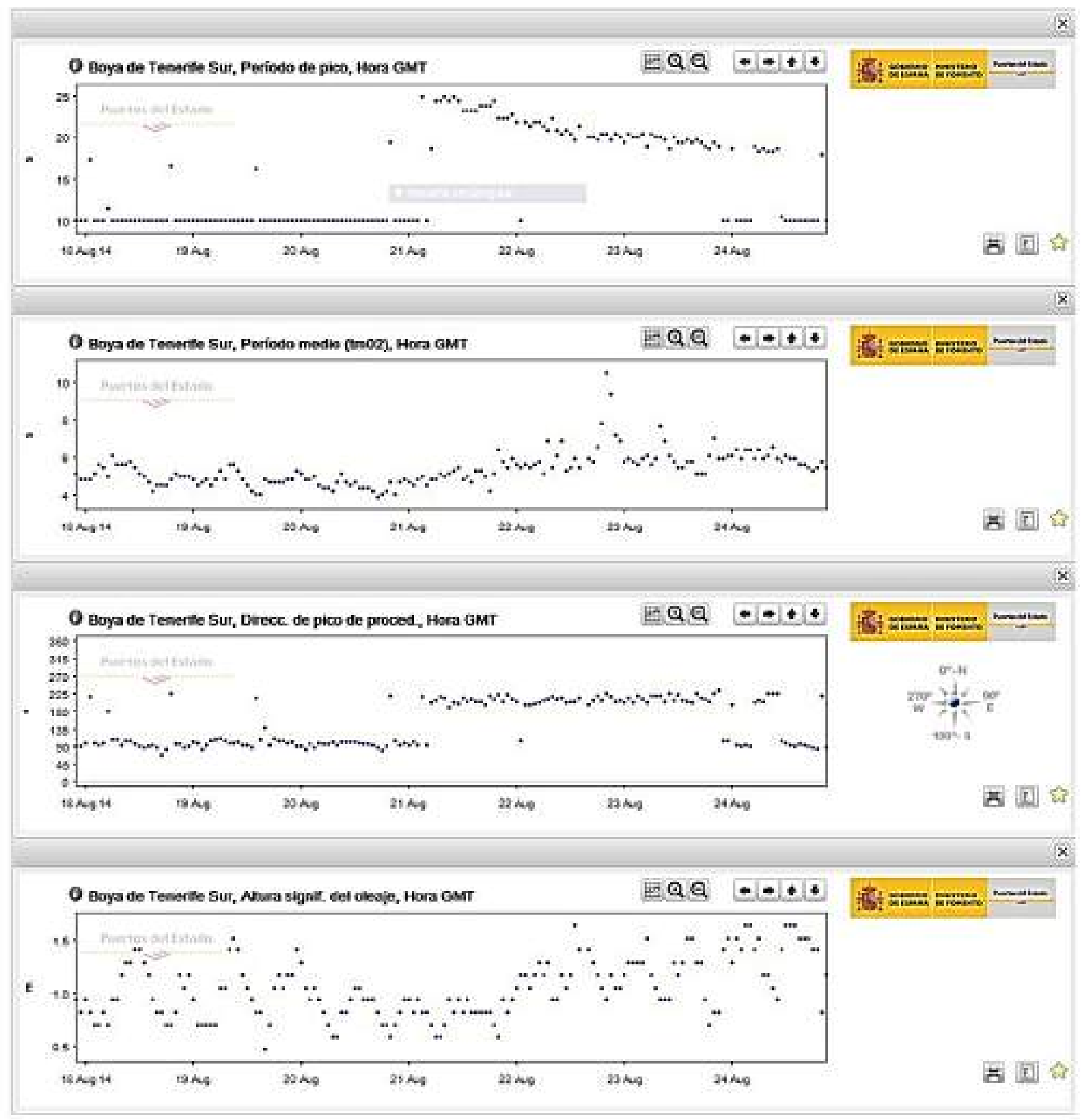

Figura 82: Serie temporal de distintos parámetros de la boya de Tenerife Sur (Fuente: [PUERTOS]) 
Es interesante ver en la figura anterior como la altura de ola significativa registrada fue del orden de 1,5 metros.

Hay que sumar al efecto de mar de fondo del sur con alto periodo, el efecto de las mareas vivas acaecidas durante el final de agosto de 2014. A continuación se muestran las pleamares y bajamares previstas para el episodio en cuestión. Queda reflejado como a partir del día 21 la amplitud de mareas fue en aumento, siendo máxima de hasta 2 metros (diferencia entre la pleamar y bajamar) a partir del día 24.

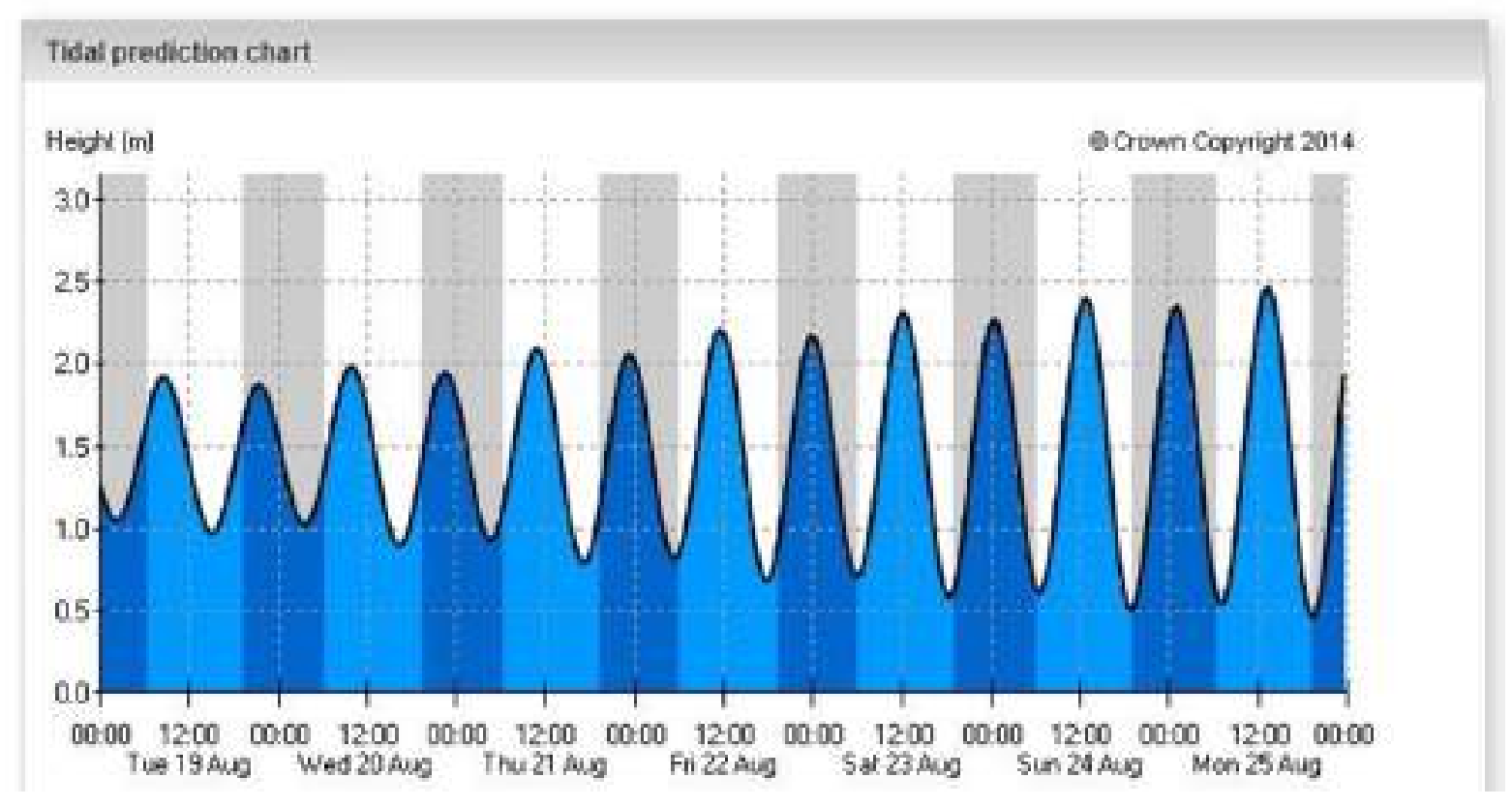

Figura 83: Serie temporal de mareas previstas para la semana del 19 al 25 de agosto.

\subsection{Episodios de fenómenos costeros, análisis histórico. Principales zonas afectadas e impactos habituales.}

En este apartado se hace referencia a la situación del ciclón extratropical "Xynthia", que afectó a Canarias finales de febrero de 2010. Para ello referimos al lector de esta guía a leer la descripción general de la situación hecha en el apartado de "vientos Fuertes".

Como queda expuesto en la siguiente figura, "Xynthia" generó en su paso por Canarias una altura de ola significativa de hasta 5 metros: 
Sin embargo la altura máxima registrada por la boya de Las Palmas-Confital fue de 8 metros:

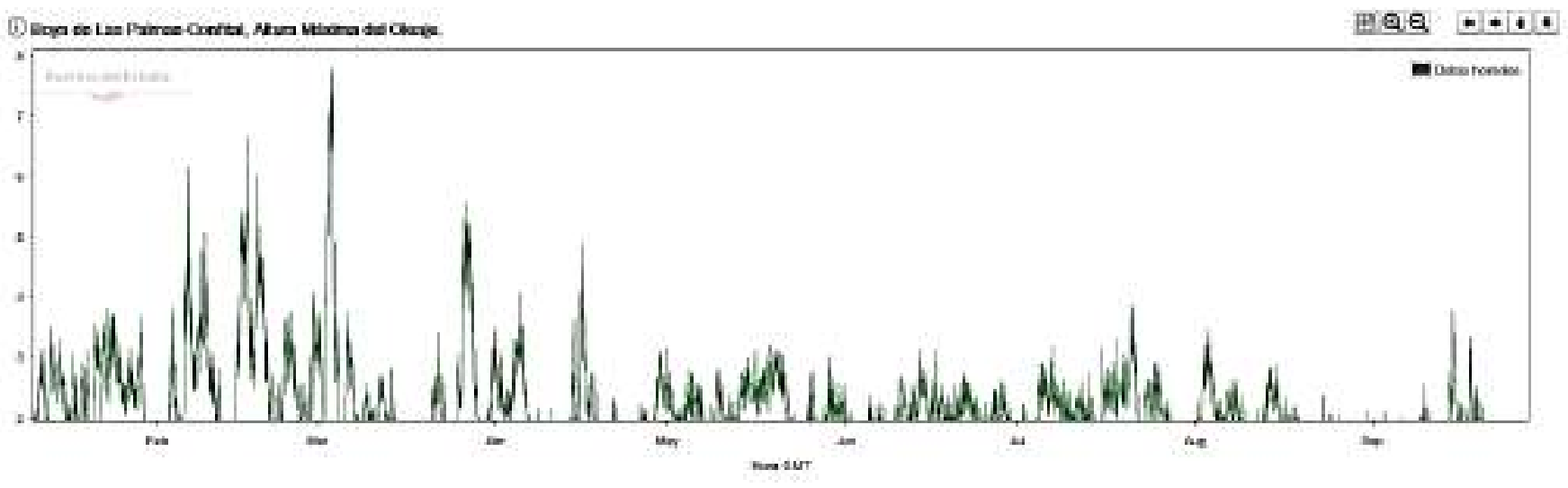

Figura 84: Serie temporal de altura máxima de oleaje de la boya Las Palmas-Confital (Fuente: [PUERTOS]) 
Bibliografía:

[AGUADO et al 2010] F. Aguado et al., (2010): Estudio de dos situaciones de precipitaciones intensas y vientos huracanados del invierno de 2010 en Canarias. Nota Técnica AEMET.

[ALONSO 2007] S.Alonso (2007): Caracterización de las intrusiones de polvo en Canarias. Tesis doctoral,Universidad de la Laguna.

[AYALA, 2002] Ayala, F. J. (2002): El sofisma de la imprevisibilidad de las inundaciones y la responsabilidad social de los expertos. Un análisis del caso español y sus alternativas. Boletín de la AGE, 33, p. 79-92.

[BARRETO et al 2014] A. Barreto, E. Cuevas, P. Pallé, P. M. Romero, C. Guirado, C. J. Wehrli, and F. Almansa (2014): Recovering long-term aerosol optical depth series (1976-2012) froman astronomical potassium-based resonance scattering spectrometer. Atmospheric Measurement techniques, 7, p. 4103-4116.

[CRIADO y DORTA 2003] Criado, C. y Dorta, P. (2003): An unusual blood rain over canary islands (Spain). The storm of January 1999. Journal of Arid Environments, 55, p. 765-783.

[CUEVAS et al 2017] E. Cuevas, A.J. Gómez-Peláez, S. Rodríguez, E. Terradellas, S. Basart,R.D. García, O.E. García, S. Alonso-Pérez (2017):The pulsating nature of large-scale Saharan dust transport as a result of interplays between mid-latitude Rossby waves and the North African Dipole Intensity. Atmospheric Environment, 167, p. 586-602.

[DÍAZ et al. 2012] Díaz, J., Tobías, A., and Linares, C. (2012): Saharan dust and association between particulate matter and case-specific mortality: a casecrossover analysis in Madrid (Spain), Environ. Health, 11, 1-6, doi:10.1186/1476-069X-11-11, 2012.

[DORTA 2007] P.Dorta (2007): Catálogo de riesgos climáticos en Canarias: Amenazas y vulnerabilidad. Geographicalia, 51 p. 133-160.

[FLAMANT et al 2007] Flamant, C., Chaboureau, J. P., Parker, D. J., Taylor, C. M., Cammas, J. P., Bock, O., Tim-ouk, F., and Pelon, J. (2007): Airborne observations of the impact of a convective system on the 10 planetary boundary layer thermodynamics and aerosol distribution in the inter-tropical dis- continuity region of the West African Monsoon, $\mathrm{Q}$. J. Roy. Meteor. Soc., 133, 1175-1189, doi:10.1002/qj.97, 2007.

[FOLTZ y McPHADEN 2008] Foltz, G.R., McPhaden, M.J. (2008): Impact of Saharan dust on tropical North Atlantic SST. J. Clim. 21, 5048e5060.

[FONT 1956] Font, I. (1956): El Tiempo Atmosferico en las Islas Canarias. Servicio Meteorologico Nacional, 96 pp.

[GALLEGO et al 2001] Gallego, D., R. García, E. Hernández, L. Gimeno, and P. Ribera (2001): An ENSO signal in the North Atlantic subtropical area. Geophys. Res. Lett., 28, 2939-2942.

[GARCíA et al. 2001] R. García Herrera, D. Gallego Puyol; E. Hernandez Martin, L.

Gimeno Presa, P. Ribera Rodriguez (2001): Influence of the North Atlantic oscillation on the Canary Islands precipitation. Journal of Climate,14 , 3889-3903. 
[GARCIA et al 2016] R. D. García, O. E. García, E. Cuevas, V. E. Cachorro, A. Barreto, C. Guirado-Fuentes, N. Kouremeti, J. J. Bustos, P. M. Romero-Campos, and A. M. de Frutos (2016): Aerosol optical depth retrievals at the Izaña Atmospheric

Observatory from 1941 to 2013 by using artificial neural networks. Atmospheric Measurement techniques, 9, p.53-62,

[GELADO et al 2003] Gelado et. al. (2003): Caracterización del aerosol saliariano en Gran Canaria. I Encuentro sobre Meteorología y Atmósfera de Canarias. Puerto de La Cruz (Tenerife), Ministerio de Medio Ambiente.

[GINOUX et al. 2001] Ginoux, P., M. Chin, I. Tegen, J. M. Prospero, B. Holben, O. Dubovik, and S.-J. Lin (2001): Sources and distributions of dust aerosols simulated with the GOCART model, J. Geophys. Res., 106(D17), 20255-20273.

[GINOUX et al. 2012] Ginoux, P., J. M. Prospero, T. E. Gill, N. C. Hsu, and M. Zhao (2012): Global-scale attribution of anthropogenic and natural dust sources and their emission rates based on MODIS Deep Blue aerosol products, Rev. Geophys., 50, RG3005, doi: 10.1029/2012RG000388.

[GOUDIE y MIDDLETON, 2001] Goudie, A.S., Middleton, N.J., (2001): Saharan dust storms: nature and consequences. Earth Sci. Rev. 56 (1), 179e204.

[HUNEEUS 2013] Huneeus, N., Boucher, O., and Chevallier, F. (2013) : Atmospheric inversion of SO2 and primary aerosol emissions for the year 2010, Atmos. Chem. Phys., 13, 6555-6573.

[JONES et al 2003] Jones, C., Mahowald, N., and Luo, C. (2003): The role of easterly waves on African desert dust transport, J. Climate, 16, 3617-3628, 2003.

[KARANOSIOU et al. 2012] Karanasiou, A., Moreno, N., Moreno, T., Viana, M., de Leeuw, F., Querol, X., (2012): Health effects from Sahara dust episodes in Europe: literature review and research gaps. Environ. Int. 47, 107e114.

[KNIPPERTZ y TODD 2010] Knippertz, P., and Todd, M. C.: The central west Saharan dust hot spot and its relation to African easterly waves and extratropical disturbances, J. Geophys. Res., 115, D12117, doi:10.1029/2009JD012819, 2010.

[LAFORE et al.2010] Lafore, J. P., Flamant, C., Giraud, V., Guichard, F., Knippertz, P.,Mahfouf, J. F., Mascart, P., and Williams, E. R.(2010): Introduction to the AMMA Special Issue on "Advances in understanding atmospheric processes over West Africa through the AMMA field campaign", Q. J. Roy. Meteorol. Soc., 136, 2-7.

[MARTín et al 2006] F. Martín, J. M. Sánchez-Laulhé, B. Orfila, I. San Ambrosio,J. J. Bustos, V. Quintero y C. Alejo (2006): Estudio de la tormenta tropical "Delta" y su transición extratropical: Efectos meteorológicos en Canarias (27-29 de noviembre de 2005). Nota Técnica AEMET.

[MESTRE y RODRIGUEZ 2015] A. Mestre Barceló, C. Rodriguez Ballesteros (2015): Periodos de retorno para la precipitación acumulada en varios días.Área de Climatología y Aplicaciones Operativas. AEMET 
[NICHOLSON 2009] Nicholson, S. E.: A revised picture of the structure of the "monsoon" and land ITCZ over West Africa, Clim. Dyn., 32, 1155-1171, doi:10.1007/s00382-008-0514-3.

[PORTILLO et al 2007] E. Portillo Hahnefeld, I. Peñate de la Rosa, J. Conde Criado (2007): Mar de fondo en las Islas Canarias procedentes del Atlántico Sur. La importancia de incorporar las condiciones de contorno del modelo WAM al Atlántico Sur. Nota Técnica AEMET.

[PROSPERO 1999] Prospero, J.M., (1999): Long-range transport of mineral dust in the global atmosphere: impact of African dust on the environment of the southeastern United States.PNAS 96 (7), 3396e3403. http://dx.doi.org/10.1073/pnas.96.7.3396.

[PROSPERO y LAMB 2003] Prospero, J.M., Lamb, P.J(2003): African droughts and dust transport to the Caribbean:climate change implications. Science 302, 1024e1027. http://dx.doi.org/10.1126/science.1089915.

[PROSPERO et al. 2014] Prospero, J.M., Collard, F.-X., Molinié, J., Jeannot, A., (2014): Characterizing the annual cycle of African dust transport to the Caribbean Basin and South America and its impact on the environment and air quality. Glob. Biogeochem. Cycles 29. http://dx.doi.org/10.1002/2013GB004802.

[QUIRANTES et al. 1993] Quirantes, F. et al. (1993): Los aluviones históricos en Canarias. Nuevos procesos territoriales. (XIII Congreso Nacional de Geografía), Sevilla. AGE y Universidad de Sevilla, p. 611-615.C.

[RODRIGUEZ et al 2015] S. Rodríguez, E. Cuevas, J. M. Prospero, A. Alastuey, X. Querol, J. López-Solano, M. I. García and S. Alonso-Pérez (2015): Modulation of Saharan dust export by the North African dipole. Atmospheric Chemistry and Physics, 15, 7471-7486.

[RODRIGUEZ 2017] Rodríguez Ballesteros (2017): Olas de calor en España desde 1975.Área de Climatología y Aplicaciones Operativas. AEMET

[ROMERO y YANES 1995] Romero, C. y Yanes, A. (1995): Aproximación a los riesgos naturales de las islas Canarias. VI Coloquio Ibérico de Geografía, Oporto, p. 1027-1032.

[TEGEN y TORRES 2005] Tegen, I., Torres, R., (2005): Global iron connections: desert dust, ocean biogeochemistry and climate. Science $308,67 \mathrm{e} 71$

[TORRES et al. 2001] Torres, C., Cuevas, E., Guerra, J.C., Carreño, V. (2001). Characterización de las Masas de Aire en la región Subtropical. In: Proceedings of the V Simposio Nacional de Predicción; available on CD under request, Instituto Nacional de Meteorología, Madrid, ISBN 84-8320-192-5.

[TSAMALIS et al.2013] Tsamalis, C., Chédin, A., Pelon, J., and Capelle, V. (2013): The seasonal vertical distribution of the Saharan Air Layer and its modulation by the wind, Atmos. Chem. Phys., 13, 11235-11257, doi:10.5194/acp-13-11235-2013.

[VIANA et al. 2002] Viana M.,Querol X., Alastuey A., Cuevas E. y Rodríguez S. (2002) Influence of African dust on the levels of atmospheric particulates in the Canary Islands air quality network. Atmospheric Environment 36, 5861-5875. 
Webs:

[AEMET,1]

http://www.aemet.es/es/conocermas/recursos en linea/publicaciones y estudios/public aciones/detalles/segundo Atlas climatologic

[AEMET, 2] http://hdl.handle.net/20.500.11765/3608

[GOBIERNO CANARIAS] www.gobiernodecanarias.org

[MAPAMA] http://www.mapama.gob.es/es/costas/temas/proteccionmediomarino/I Marco General Canarias tcm7-204329.pdf

[NRL] https://www.nrl.navy.mil/

[PUERTOS] www.puertos.es

Otras webs consultadas:

https://izana.aemet.es

https://dust.aemet.es

https://sds-was.aemet.es 